\title{
"A new old age? Exploring the values, attitudes and expectations of baby boomers and their implications for policy and practice in an ageing society"
}

\author{
Kathy Glasgow
}

\begin{abstract}
A thesis
submitted to the Victoria University of Wellington in fulfilment of the requirements for the degree of Doctor of Philosophy in Social Policy
\end{abstract}

Victoria University of Wellington

2013 


\section{Abstract \\ Title: A new old age? Exploring the values, attitudes and expectations of baby boomers and their implications for policy and practice in an ageing society.}

As a large age cohort, baby boomers needs, attitudes and behaviour can have a substantial impact on society. Despite international predictions that older boomers will behave in very different ways to current generations of older people little scholarly research has to date been done to explore 'kiwi boomers' attitudes to ageing or the underlying values that may predispose them to behave in a particular manner as older workers, consumers, voters and family members.

This study explores boomers views about their own ageing and considers how their expectations, attitudes and beliefs and underlying values may influence their behaviour as they age. Policy implications are then considered. Discourse analysis reveals prevailing paradigms and the degree of disparity or congruence with boomers' views is considered.

Eleven focus groups were held in urban and semi-rural settings around New Zealand with boomers born 1946 - 1965, to explore participants' views on ageing, their expected lifestyle in future years, what forms of assistance they expected to give or receive, and what attitudes and values they felt baby boomers typically had that may influence their behaviour in older age. Results are triangulated with existing data on boomers in New Zealand. Where possible comparisons are drawn with boomers in other countries and with older and younger generations in New Zealand.

Results indicate these boomers have a sense of common identity. Many articulated and appeared to have internalised common discourses about the boomer generation, although differences between older and younger, urban and provincial, socio-economic and ethnic groups were apparent. Most believed they would age differently to current generations of older people.

These boomers are interested in new forms of work, more flexible, creative lifestyles and more supportive living arrangements. They have a strong work ethic, but they value work/life balance, choice, freedom and autonomy in decision-making. They anticipate working longer, but on their own terms. They believe they should provide for their families, but the state has a responsibility to reduce inequities and support those in need. Like their parents they value self-reliance and independence, but also inter-dependence and intergenerational care responsibilities. There was a desire for more innovative intra-cohort care and support.

Despite areas of commonality, a key feature of the boomer cohort is their diversity and this presents a major challenge for policy and service development. Boomers accept their status as change agents. They anticipate drawing on previous experience to collectively influence policy. While it remains unclear on which issues they may converge, findings suggest the boomer cohort has the potential and inclination to advocate for social change. Processes of policy development will need to adapt to effectively work, with and not against this cohort. 


\section{Acknowledgements}

Grateful thanks to Judith Davey and Jenny Neale for their enduring patience, wisdom and support. As anyone who has completed a thesis will know, it's a long journey to the end, and there have been many twists and turns along the way. I couldn't have done it without you both.

This work would also not have been possible without the support of a Victoria University Vice Chancellor's Strategic Research Scholarship, for which I am eternally grateful. For this I also thank the New Zealand Institute for Research on Ageing (NZiRA), who called for research on this topic and provided me with valuable resources and work experience.

Appreciation and acknowledgement also to The Hope Foundation for their support in my earlier years of study, and to past and present staff and volunteers at the National Office of Age Concern New Zealand, from where I first set off on this journey.

To my wonderful friends, thank you from the tips of my toes for your ongoing support, encouragement and practical help. I feel truly blessed. I am especially grateful for the support and friendship of Nicki Wrighton, who was there for me throughout this journey, in both good times and bad. We miss you Nicki, but your contribution to our lives will forever continue.

Unending gratitude goes also to all my family who helped in so many, many ways. Special thanks to my father Neville - your faith in me helped me through. This is for you.

Last but definitely not least, to my children, Aeron and Kara, who have grown up with my study. You are a delight. Thanks for appreciating that work must be done. 


\section{Contents}

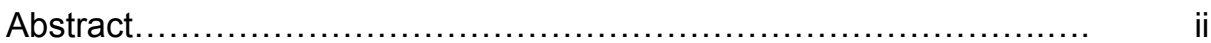

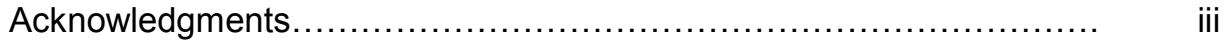

List of Figures and Tables............................................... vii

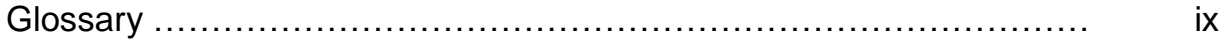

\section{Chapter 1: The Research Issue}

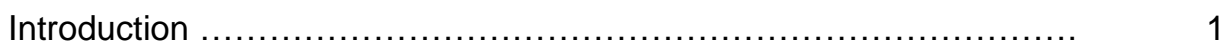

Overview of the Research ........................................ 2

Rationale for the Research ...................................... 4

Aims and Objectives of the Study ..................................... 8

Key Concepts ............................................................ 8

Outline of the Thesis Structure ...................................... 19

\section{Chapter 2: The Demographic, Social and Policy Context}

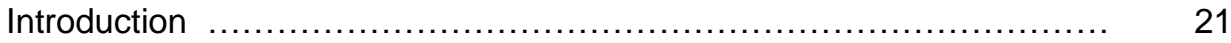

The Demographic Context.............................................. 21

The Baby Boom . ............................................. 21

Population Ageing ....................................... 25

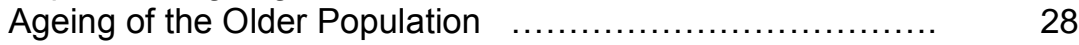

International Comparisons ................................... 30

Predicted Impact of Population Ageing ......................... 33

The Social and Cultural Context ....................................... 36

The Policy Context ....................................................... 44

The Welfare State in New Zealand ............................. 44

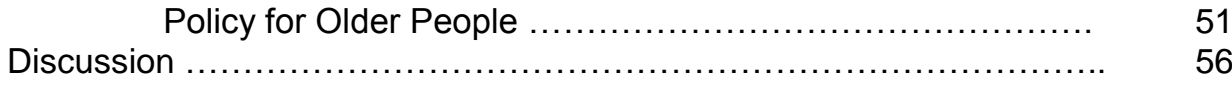

Chapter Conclusion ............................................... 58

\section{Chapter 3: Discourses on Boomers and Ageing}

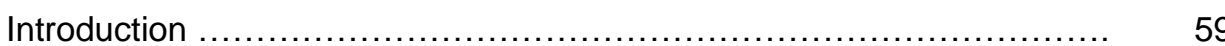

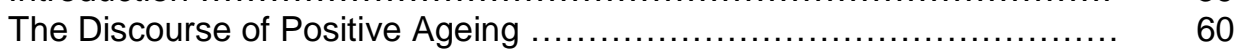

Positive Ageing Policy Development ......................... 60

Key Features of The Positive Ageing Strategy .................. 63

Critiques of the Positive Ageing Paradigm ....................... 65

Older Boomers as Consumer Citizens ........................... 69

Part One Discussion ............................................ 70

The Ageing Boomer Generation - Competing Discourses .................. 73

Ageing boomers - crisis or opportunity? ........................ 73

A Distinctive Generation? ........................................... 76

A Homogenous Group or Diverse Cohort? .......................... 79

Predictions - Selfish or Civic Minded? ............................ 81

Optimistic About Ageing or in Denial? .................................. 83

Part Two Discussion ....................................................... 85

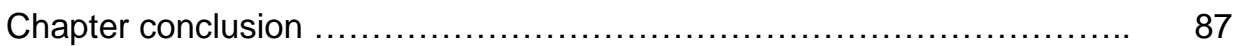


Chapter 4: Methodology

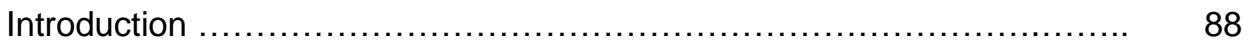

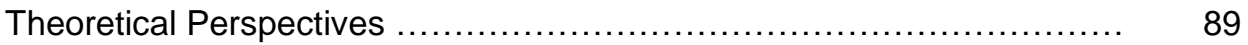

Social Constructionism ...................................... 91

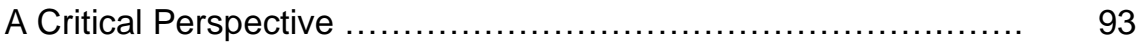

Critical Policy Analysis ............................................. 95

Critical Gerontology ............................................... 96

A Cohort Perspective on Ageing ................................ 98

Age Stratification and the Ageing and Society Paradigm ............ 98

The Life Course Perspective .......................................... 99

Methods ................................................................. 100

Focus Group Research ........................................ 100

Self Administered Questionnaire ................................. 103

Discourse Analysis ............................................... 104

Secondary Data Analysis ....................................... 106

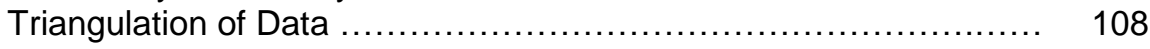

Research in Practice ................................................... 108

The Focus Groups .............................................. 108

Location of Groups ........................................... 109

Recruiting and Selecting the Sample ............................. 110

Research Ethics and Consent ................................. 112

Techniques of Data Collection .................................... 113

Moderating the Discussion ....................................... 115

Analysing the Data ............................................. 116

Strengths and Limitations of the Focus Groups .................... 118

Reflections on the Choice of Methods ..................................... 120

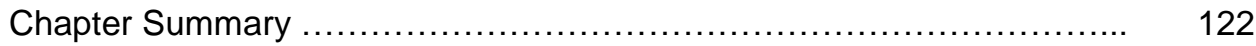

\section{Chapter 5: Findings Part One: "Talking 'bout my generation!"}

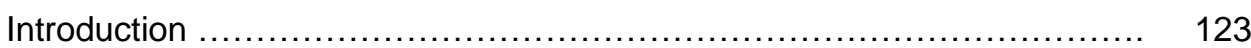

The Participants ................................................... 124

Views of Boomers in Mid Life ........................................... 126

Boomers' views on their generation .............................. 126

Characteristics of Boomers .................................... 135

Views on the Younger Generation ..................................... 139

Boomers looking after parents ................................... 141

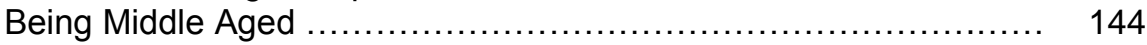

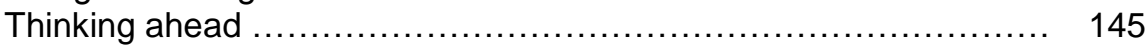

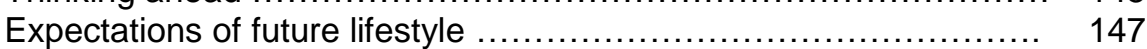

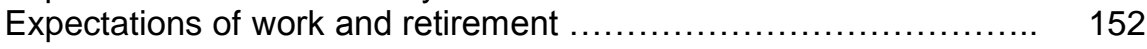

Attitudes to Planning for Late life ................................. 158

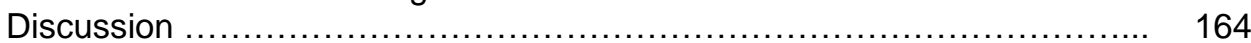

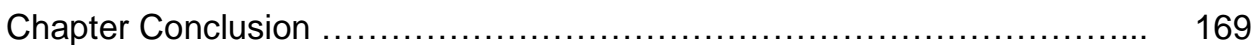


Chapter 6: Findings Part Two: "When I grow old..."

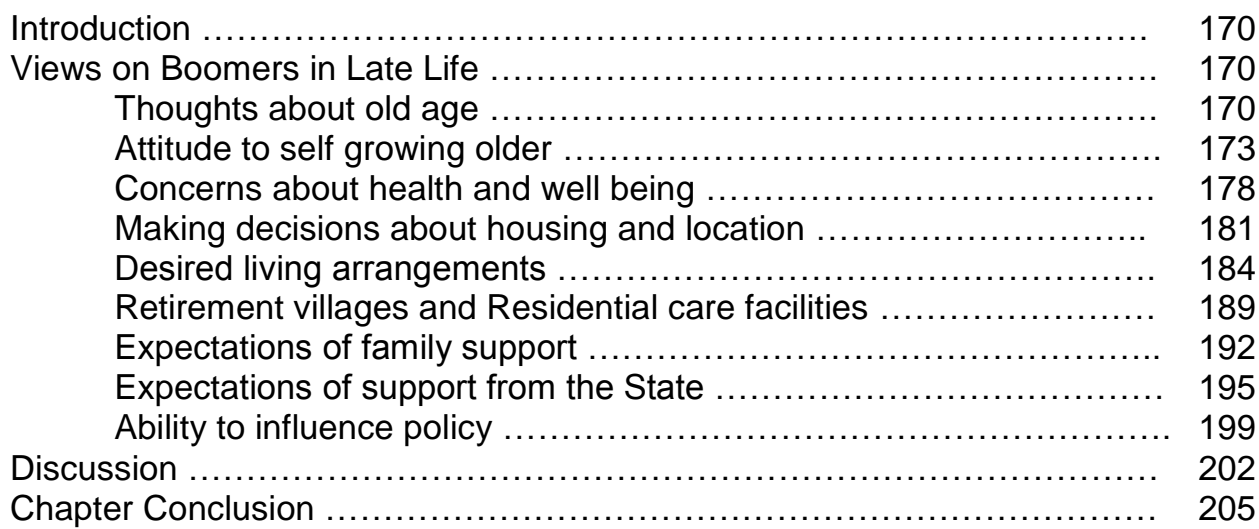

\section{Chapter 7: Boomer Beliefs and Values}

Introduction ........................................................ 206

Relationships between attitudes, beliefs, values and behaviour..... 207

Exploring Boomers Beliefs ............................................. 209

Participants' Beliefs about the Boomer Generation ................... 209

Beliefs about (Post)Modern Society ................................ 212

Beliefs about Boomers as Parents ............................... 212

Beliefs about Activism ......................................... 213

Beliefs about what it means to be old ..................................... 215

Beliefs about Older Bodies ........................................ 221

Beliefs about work, leisure and retirement ......................... 223

Beliefs about care and support ................................. 224

Beliefs about future financial circumstances ....................... 228

Exploring Boomers Values ................................................ 231

Common Values identified in the Focus Groups ..................... 231

Situating Boomers Values - World Values Surveys ................ 237

Discussion ............................................................... 239

Chapter Conclusion .................................................... 245

\section{Chapter 8: Policy Implications}

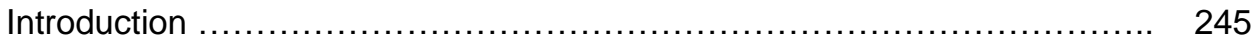

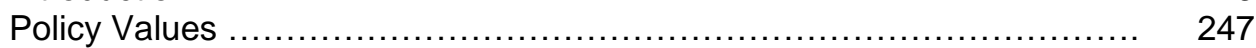

Boomers and policy - mismatch or congruence …........................... 249

Retirement Income Policy ........................................ 249

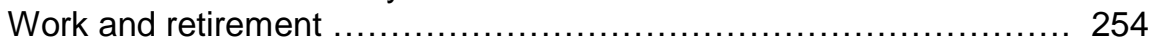

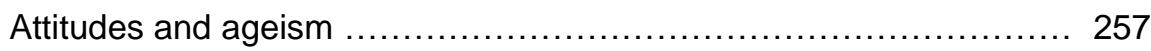

Meeting future care and support needs ................................. 263

Meeting expectations for housing and living arrangements .......... 266

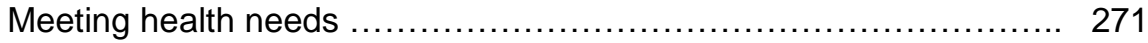

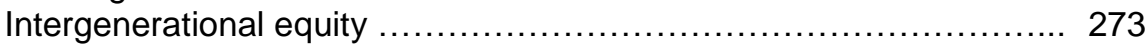

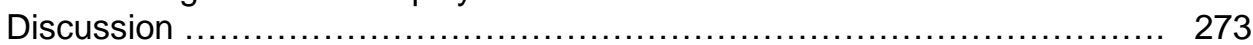

Chapter conclusion .................................................. 276 


\section{Chapter 9: Conclusion}

Key Findings ............................................................... 277

Evidence of a generational identity ................................... 277

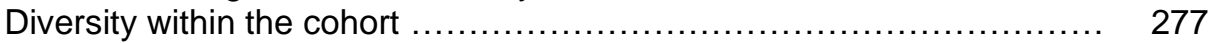

Belief in their collective power ..................................... 278

Shared values ....................................................... 278

Common expectations …........................................... 279

Continuities between the generations ................................ 280

Influence and Relevance of Values ...................................... 280

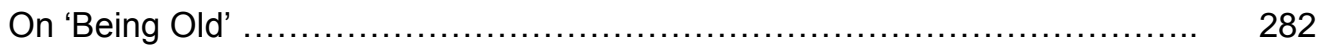

Boomers and Old Age Politics ............................................. 285

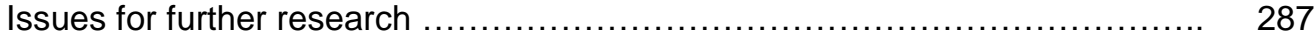

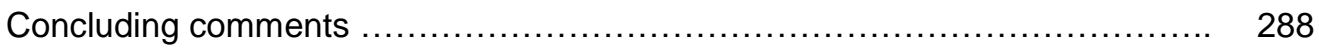

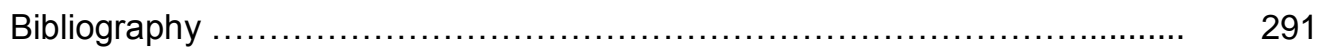

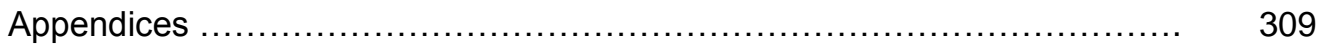




\section{List of Figures and Tables}

Figure One: Birth Numbers and Fertility Rates 1921-2010 22

Figure Two: Total fertility rate, Maori and total population, 1900-200 23

Figure Three: Projected older population by age band 28

Figure Four: Population Age Pyramids 1951, 2001, \& 2051

Figure Five: Projected Population Aged 65 Years and Over 30

Table 1: Strategies for an Ageing Society - Themes and Values 67

Table 2: Boomer Identity: Self-Identified Characteristics \& Beliefs 210

Table 3 Boomers' beliefs about old age $\quad 216$

Table 4 When is Old - Markers of Old Age $\quad 217$

\section{List of Acronyms}

AARP: American Association of Retired Persons

ACNZ: Age Concern New Zealand

APHRU: Alcohol and Public Health Research Unit

BOA: Business of Ageing

DHB: District Health Board

DSW: Department of Social Welfare

DOH: Department of Health

DOL: Department of Labour

EEO: Equal Employment Office

HOPS: Health of Older People Strategy

IGO: International Government Organisation

IMF: International Monetary Fund

$\mathrm{MOH}$ : Ministry of Health

MSD: Ministry for Social Development

NGO: Non-Government Organisation

NHS: national Health Service

NZS: New Zealand Superannuation

NZSF: New Zealand Superannuation Fund

NZSV: New Zealand Study of Values 1998

NZVS: New Zealand Values Study 2005

OECD: Organisation for Economic Cooperation and Development

OSC: Office for Senior Citizens

PMTPA: Prime Ministerial Taskforce on Positive Ageing

PAS: New Zealand Positive Ageing Strategy

SCU: Senior Citizens Unit

SHORE: Centre for Social and Health Outcomes Research and Evaluation

SPARC: Sport \& Recreation Commission

UN: United Nations

UNO: United Nations Organisation

WDC: Western Developed Countries

WHO: World Health Organisation

WTO: World Trade Organisation

WVS: World Values Study 


\section{Glossary of Key Terms}

Attitudes - a view or orientation towards persons, situations, institutions or social processes, subject to change and indicative of underlying values and beliefs.

Baby boom - a period of sustained 'high fertility' over a run of years, as measured by changes in the Total Fertility Rate. More specifically, this term is used here to refer to the post Second World War baby boom that occurred in a New Zealand and a number of countries (including Australia, Canada, the United States and, arguably, the United Kingdom), the period of which differs by country.

Baby Boomers (boomers) - those born during the post Second World War baby boom. For the purposes of this study, New Zealand baby boomers (or 'kiwi boomers') are defined using the Statistics New Zealand criteria of baby boomers as people living here who were born between 1946 and 1965, including those who have migrated here. This definition allowed comparability with official statistics, but it is acknowledged that there is debate as to the end, and to a lesser extent the beginning, of the baby boom in New Zealand.

In this study boomers born from 1946 to 1955 are defined as leading boomers and those born from 1956 to 1965 as trailing boomers.

Beliefs - constructs assumed as truth around which we organise our behaviour, acquired and developed over time.

Cohort - a collection of people with something in common, for example through being born in the same period (a birth cohort).

Generation - a group of individuals who were born and are living in the same period of time and who share certain traits, inclinations and aspects of identity as a result of a common cultural history.

Total Fertility Rate (TFR) - the TFR in any given year is a measure of the average number of children a woman could expect to have during her lifetime if she experienced the age-specific fertility rates for that year.

Values - strongly held, semi permanent and abstract ideas about what is desirable, proper, good or bad. 


\section{Chapter One: The Research Issue}

\section{Introduction}

Like many other countries, New Zealand experienced a boom in births in the years following World War II. About 1.125 million 'baby boomers ${ }^{, 1}$ were born in New Zealand over a twenty year period from 1946, almost doubling the total population (Statistics NZ, 1995).

As a significantly larger population group compared to previous cohorts, baby boomers' needs, attitudes and behaviour have had a substantial impact on society. Their activities and preferences as they have grown up have stimulated markets, and their interests and preferences have influenced social trends. At each stage of their life cycle their needs for housing, education, work and healthcare have drawn upon societal resources. Importantly their social and economic contributions as a large cohort have also been, and remain, significant.

In the context of an ageing population, it is the much anticipated needs and demands of this ageing cohort that has become the focus of public and policy concern. Growth in the number and proportion of older people $e^{2}$ in the New Zealand population is set to accelerate as increasing numbers of baby boomers turn sixty-five years of $\mathrm{age}^{3}$.

\footnotetext{
${ }^{1}$ Statistics NZ defines the baby boomers as those born in New Zealand between 1946 and 1965 (Statistics NZ, 1995); but compare Pool, Dharmalingam and Sceats (2007) who argue the boom was underway in New Zealand as early as 1943 and continued until 1973. Pool defines a baby boom as sustained high fertility for a run of years, as measured by a TFR at 3.0 or above per woman (Pool, 2007).

${ }^{2}$ The term 'older people' is acknowledged as being problematic, being by definition both comparative (older than whom?) and socially constructed (what is old?). 'Older people' is the favoured term currently used in New Zealand by service providers and policy makers, based on its acceptability compared to terms such as 'pensioners' and 'seniors'. It is a statistical category applied to people aged 65 years and over ( 65 being the current age at which New Zealanders qualify for government retirement income), and has that meaning when used in this thesis, unless otherwise defined.

${ }^{3}$ Using Statistics NZ's definition of baby boomers as those born 1946-1965, the oldest boomers began turning 65 in 2011 with the youngest turning 46 years of age.
} 
Boomers have been accused of bringing instability to social security and pension arrangements, with concerns expressed as to the consequences of such a large cohort entering retirement.

While we know that boomers will comprise the largest cohort of older New Zealanders in our history, we don't know how singularly they will behave, nor to what extent their behaviour in late life will differ from current generations of older people. Despite much policy and public debate about our ageing society, and significant research on baby boomers overseas, few New Zealand based academic studies have been completed. As a result little is known about 'kiwi boomers' attitudes to ageing or the underlying values that may predispose them to behave in a particular manner as older workers, consumers, voters and family members. This study seeks to address that gap.

In this chapter the research that is the focus of this thesis is outlined. The rationale and aims and objectives of the study are identified, and key concepts underlying the research are introduced. The chapter concludes with an outline of the structure of the thesis.

\section{Overview of the Research}

This study explores the attitudes and expectations of members of New Zealand's baby boom cohort as they consider their own ageing, and examines implications for social policy. The study describes boomers' view of themselves as members of an identified population group and explores the relationships between cohort identity, culture and policy.

Through focus group research, 'kiwi baby boomers' attitudes to and expectations of ageing were explored. Findings are triangulated with data from existing social surveys. Underlying beliefs and values of the boomer cohort are identified and influences shaping values are 
explored. The discussion compares and contrasts findings with international studies and with common representations of boomers in New Zealand and overseas.

The study then considers the degree to which boomer perspectives are represented in current policy on ageing. The study explores how prevailing theories and ideas about ageing and older people, including those held by boomers themselves, influence and are influenced by policy decision making. The approach recognises that socio-cultural context influences policy which in turn influences society (Hogwood and Gunn, 1984).

This New Zealand study takes place in the context of an ageing and increasingly globalised society, and in a nation where significant changes in social policy have taken place in recent decades. The political, social and historical context within which boomers are ageing, and within which social policy is developed, is discussed. Policies promoting attitudes to ageing and behaviour in older age are analysed to reveal current discourses on ageing and older people. Disparity and congruence between boomers' expectations and values and prevailing policy paradigms are considered.

Of interest is how boomers' attitudes and behaviour may shape the policy agenda and what role policy may play in shaping boomers' attitudes and behaviour as they age. Of relevance is the nature of the relationship between citizens and the state in setting policy agendas and how concerns of citizens are attended to. Of concern is the wellbeing of boomers and their families as they grow older. 


\section{Rationale for the Research}

There have been a number of calls for research on boomers' perspectives in New Zealand. A 2001 report on older people in New Zealand from the Ministry of Development (2001) noted the need to "consider the different life histories of future retirees" (p20) and identified the influence of baby boomers attitudes as an emerging issue (p90). In 2006 the then Retirement Commissioner, Diana Crossan, identified a need for more 'urgent research' on boomers' attitudes and values to ensure we do not 'plan blindly'. ${ }^{4}$ In the same year a report from the Office for Senior Citizens (OSC) on progress towards government's goals for 'positive ageing' also identified a need for more to be known "....about the attitudes of the baby boom generation and those of other age groups so that these can be taken into account in policy development" (Office for Senior Citizens, 2006, p19).

Knowledge of boomers' values will shed light on the acceptability of current policy approaches, especially the prevailing active, productive and positive ageing paradigm and the underlying social policy philosophy (Boston and Davey, 2006, p370). Failure to take baby boomers' perspectives into account may result in the development of unachievable policy goals or unintended outcomes.

While we know that boomers will comprise the largest cohort of older New Zealanders ever, there are many assumptions about the boomer cohort, how alike they are to each other and how different they are to current generations of older people. Some assumptions are coloured by stereotypes about old age and are generated by fears of intergenerational conflict. This study explores some of those beliefs and assumptions.

\footnotetext{
${ }^{4}$ Crossan as quoted in the Christchurch Press, 1 April 2006.
} 
Knowledge of boomers' attitudes and expectations may assist efforts to promote behavioural change to improve wellbeing in late life. Attitudes influence how individuals plan or prepare for late life (Keeling, Davey \& Glasgow, 2009). For example, those who view older age as a time for leisure and freedom from responsibilities may give less attention to the maintenance of workplace skills in late life. Attitudes also influence health behaviours, including the level of effort directed towards resisting the outward signs of ageing or to maintaining mid life patterns of physical activity. Findings may assist policy design and service planning and aid an understanding of people's motivations, including for involvement in the workforce or in unpaid work and voluntary activity.

Findings will also contribute to our knowledge of the constructed categories of age and generational identity. Estes, Biggs and Phillipson (2003) argue that ageing is problematised within policy in a particular way. Their concern is that the positions reinforce the legitimacy of a particular professionalised view and result in a restriction of ageing to a limited range of possibilities that are socially conforming. Boomers' response to these policy discourses is a central concern of this thesis. Findings will inform our understanding of the relationship between social and policy values and the influence of changing notions of what it means to be an older citizen in contemporary society.

The interrelated attributes of cohort size, cohesion and distinctiveness are central to any discussion about the impact the boomer cohort is likely to have. Summaries of boomers characteristics (Statistics NZ, 1995; Glasgow, 2005) show that the 'Kiwi' boomer cohort differs from earlier cohorts in a number of ways, with significant differences in family circumstances, patterns of work, level of education, degree of geographic mobility, and lifestyle behaviours, including the level and range of economic and recreational activity. 
While distinct from older generations in a variety of ways, this cohort is also diverse. Intra-cohort variation is apparent, with significant differences between early born or 'leading' boomers' (those born from 1946 to 1955) and later born or 'trailing' boomers (born from 1956 to 1965), by family structure, lifestyle and socio-economic status (Glasgow, 2005). Gender and ethnicity are additional variables within the cohort influencing life chances and experiences (Callister, 2006). These variables will be considered in later chapters.

Baby booms occurred in a number of other countries, including Australia, Canada, the United States and, arguably, the United Kingdom. Comparisons are made between New Zealand and these countries where possible, to aid understanding of the values and attitudes of the 'kiwi' boomer generation and how these reflect demographic, cultural and social characteristics.

While there has been little research on boomers in New Zealand (Buckland, 2009), a growing body of knowledge exists internationally (see for example Adler, 2006; Hamilton and Hamilton, 2006; Biggs et al, 2007; Karisto, 2007; Phillipson et al, 2008; Hudson, 2008). However findings from other countries are not necessarily relevant to the New Zealand context (Buckland, 2009). Gaps in knowledge are also apparent, as well as a tendency for policy to be based on assumptions about the boomer cohort. Quine and Carter (2006) for example, noted little data and much opinion about boomers in Australian policy documents. They concluded "...if policies are to be effective, empirical research obtaining information directly from baby boomers is required" (ibid, p7). British researchers have also called for further research, noting that:

"Much of the attention has focused on a relatively narrow band of issues... Little is known about the context within which these areas will operate, notably in areas such as changing social attitudes of boomers, social relationships, and expectations about future lifestyles" (Phillipson et al, 2008, Para. 8.6). 
Questions these researchers identified for further study include: does cohort size influence identity and has being a member of a (relatively) large cohort impacted on boomers' view of themselves; are they aware of the labels attached to their generation; and is there evidence of a collective identity with potential for community activism?

In the Unites States, Hudson (2008) has also raised a number of questions that are pertinent to this research, including:

- How singularly will the boomers behave in old age?

- How may the boomers impact on society, and how is society likely to respond?

- How good a fit there will be with the boomers' looming and various needs and preferences (housing, lifestyle, transport, environmental design)?

-Will older boomers work longer, or will they enjoy longer retirement, or both?

-Will older boomers be 'the most powerful lobby (group)'?

This study will assist in finding answers. These questions will be considered throughout this thesis and will be returned to for consideration in the final chapters. 


\section{Aims and Objectives of the Study}

This study examines the nature of baby boomer identity, explores boomers' expectations and considers how policy has both influenced and been influenced by the baby boom cohort. The research question asks what is the relationship between generational identity and policy?

The aim of the research is to compare the attitudes and values of a purposive sample of boomers with current policy on ageing. Objectives are to explore:

- the expectations a sample of New Zealand baby boomers have about their life in older age, including roles, purpose, identity, lifestyle, rights and obligations;

- the attitudes and underlying values that contribute to boomers' expectations of life in older age;

- how congruent boomers' values and expectations are with current policy paradigms;

- how policy may influence boomers' attitudes or behaviour as they age;

- how boomers' values and attitudes may inform and shape the policy agenda in an ageing society.

\section{Key Concepts}

\section{Attitudes, beliefs, and values}

An underlying premise of this research is that our expectations of life in older age and our behaviour in late life will be influenced by our attitudes and underlying beliefs and values. 
Attitudes (defined here as views or orientations towards persons, situations or processes) are indicative of underlying beliefs and values, and predispose us to respond in certain ways (Marshall, 1998; Rokeach, 1972). Attitudes are complex and dynamic attributes of personality that can be influenced by peer groups, desire to please, psychological stressors, and degree of insight or self-awareness. Attitudes are therefore subject to change, while values are more deeply and firmly held (Reich and Adcock, 1976).

Beliefs are considered here as constructs assumed as truth around which we organise our behaviour. Richardson (1996) notes that beliefs are commonly defined by social psychologists, anthropologists and philosophers as "psychologically held understandings, premises, or propositions about the world that are felt to be true" (p316). Rokeach (1972) defines beliefs as "any simple proposition, conscious or unconscious, inferred from what a person says or does, capable of being preceded by the phrase "I believe that"' ( $p 113)$. Beliefs tend to be self-perpetuated and those acquired early in life are more difficult to change (ibid). Beliefs about self or others can be positive or negative, limiting or empowering, and can impact on an individual's motivation, health and wellbeing. Beliefs affect our identity and act as signposts and boundaries as to how we respond to our world.

Values are abstract ideas about what is desirable, proper, good or bad. Rokeach (1972) suggests values are central beliefs about how we ought to behave, while Giddens (2009) describes values as ideas about what is good, right, fair or just. Values are held by individuals and shared within a culture. 
Cultural values are passed on to society members by informal and formal socialisation, through everyday exposures to customs, laws, norms, scripts, and organisational practices (Bourdieu, 1972; Schwartz, 1999). Cultural values are "the bases for the specific norms that tell people what is appropriate in various situations. The ways that societal institutions (for example the family, education, economic, political, religious systems) function, their goals and their modes of operation, express cultural value priorities" (Schwartz, 1999, p25).

Various theories exist as to how beliefs and values are acquired by individuals and transmitted in society. Theories of psychology focus on the influence of personality, individual predispositions, and the process of socialisation that occurs through the interaction of the child and adult with other members of society. Sociological theories explore how group membership affects attitudes and values, and the impact of factors such as social class and political ideology. Socio-economic circumstances also have an impact, through their effect on the environment of the individual.

Values are assumed to develop in childhood and young adulthood, firstly through identification with parents and later with peer groups. Through socialisation, the child and adult learn which attitudes and values are appropriate in a given environment (Reich and Adcock, 1976). Inglehart (1990) emphasises the conditions individuals grow up in, particularly during their early youth (up to around 15 years of age). Siemienska (2002) summarises a range of influences on values. Family and school and the broader environment in which an individual grows up play a role in socialisation. Parents seek to influence their children's attitudes and values, though they may seek to instil either change or continuity across the generations. Institutions or their agents can seek to influence societal values, such as through the schools, and tend to transmit the values held by elites in society. 
Various agents of socialisation can take on a new significance at various points in history and can shift significantly in times of rapid social change. Values and behaviours may also take on new meanings in various periods of life.

The study of values gained in popularity in the late 1970s (Chan et al, 2003), alongside growing interest in consumer behaviour. Measurement problems have been an ongoing issue. Values may be measured at the level of the individual as personal values, or at the level of the group as social or cultural values. Rokeach (1973) identifies 36 values (eighteen terminal or end state values such as freedom and equality, and eighteen instrumental or mode of conduct values, such as being independent and responsible), measured at the level of the individual but which he argues are widely held across human cultures. His list is not exhaustive and he allows for further identification of additional values by others (Reich and Adcock,1976).

Commonly, cultural values are identified through surveys of individuals. These are aggregated and averaged to produce common cultural values, which Schwartz (1999) defines as "conceptions of the desirable that guide the way social actors (e.g. organisational leaders, policymakers, individual persons) select actions, evaluate people and events, and explain their actions and evaluations" (Schwartz, 1999, p28). However Vauclair (2009) argues that cultural values measured by averaging the importance ratings of individuals, are measures of 'desired' rather than 'desirable' values. According to Vauclair, 'desired values' are those that individuals or social groups view as important, whereas 'desirable values' are those that reflect what individuals or groups perceive they 'ought' to value or strive for. Desirable values therefore take morality and cultural context into account. He argues desirable values may be identified by asking the individual whether they believe other people in their society would judge a certain value as right or good. 
It is possible however, that individuals may not be aware of what others deem as desirable, or they may infer from their own values thereby providing a 'false consensus' effect. Alternatively, asking individuals to what extent they think they are expected to follow or strive for a given value will reveal cultural values that are imposed and internalised. Importantly, while these methods are useful for studying the perceived values of a social group, they do not reveal whether the individual actually adheres to the value.

Not everyone will have equal opportunity to attain a desired or desirable value however, as in the case of wealth, success, power, or prestige. Values may also conflict with each other. For example the value of equality can conflict with the value of individualism, or a valuing of time with family may conflict with a value of work based achievement.

Cultural values may vary by class or ethnicity. New Zealand Maori are identified as more collective in orientation than non-Maori, with shared emphasis on obligations to the whanau (extended family) and iwi (tribe) (Durie, 1995). Cultural values may also vary by gender. Welland for example, argues that at the core of a 'traditional male identity' are values centred around protecting and providing; stoic strength in the face of adversity; and male responsibility for family wellbeing (Welland, 1999).

Categories of cultural values have been developed to assist understanding of cultural change and to allow cross cultural comparisons (see for example Hofstede, 2001; Schwartz,1999; Inglehart, 1990, 2008). 
Schwartz (1999) cautions that early theories of cultural values have tended to address limited aspects of culture rather than capturing a full range of potentially relevant value dimensions. He further argues that many instruments have not been validated for cross-cultural equivalence of meaning. When comparing national values, demographic and sub-cultural group differences between nations should be controlled for. The unique experiences demographic groups were exposed to by virtue of their location in society, need also to be considered.

Beliefs and values are evident in policy, influencing policy goals and the methods by which these goals are to be achieved. They underpin the ideas that are promulgated by experts, institutions and politicians to legitimate and stimulate policy decisions (Miskin, 2004). Beliefs influence policy values and provide a framework or policy paradigm that supports the evidential base that policy makers use to make policy choices. For example, policy relevant to baby boomers as they age is influenced by beliefs about population ageing and the baby boomer cohort, and also by value priorities concerning the role of the state, the responsibilities of citizens and the role of older people in society.

\section{Generational Cohort}

A generational cohort is a sociological concept referring to a group of people who grew up in the same time period and are thought to share aspects of identity as a result of a shared cultural history (Smith and Clurman, 2007). Generational cohort theory argues that individuals born at the same time will share certain traits and inclinations which persist over time (Vincent, 2005; Uhlenburg and Miner, 1996). 
The attitudes, beliefs and values of a generational cohort are influenced by important social changes and significant historical events, especially those that occurred in an individual's formative years (Edmunds and Turner, 2005; Mitchell, 1998; Strauss and Howe, 1991). Such events include wars, significant heroic figures (such as Martin Luther King), major shifts in resources (such as in economic recessions), or experiences that symbolise ideology (such as Woodstock).

Interest in generations developed in the early 1920s through the work of Karl Mannheim (1893-1947), who claimed that generational location is as influential as social class in shaping people's attitudes and beliefs. Mannheim identified that for a cohort (groups of people with something in common) to become a generation (groups of people born in the same year or series of years who share certain traits and inclinations) several factors are needed; both location in time (a birth cohort) and a distinct set of experiences, different from those of earlier or later birth cohorts (Mannheim, 1952/1997).

Howe and Strauss popularised the notion of generations with their theory of generational eras $(1991,1997)$. They theorised that members of a generation are shaped in lasting ways by the eras they encounter as children and young adults. Strauss and Howe's theory of history as a series of cyclical generational eras has been criticised as overly deterministic and culturally biased, but their ideas have nevertheless had a significant impact on generational discourses, especially within the marketing sector.

\section{Generational Identity}

Mannheim argued that not all generations see themselves as having a distinct character, but in times of rapid social change, a generation and sub-generations are more likely to develop a cohesive generational identity (Mannheim, 1952/1997). The quicker the social changes, the 
more likely young people will be different to older age groups, as they are forced to adapt to the new requirements of their rapidly changing situation (Mannheim, 1960). A generation's unique experiences and perspectives will also contribute to social change.

Gilleard and Higgs (2005) emphasise the influence of both structure and agency on generational identity. They note that a key task is to determine which elements spread more easily across other variables such as age, class, and gender. Turner (1998) notes that strained access to limited resources and the practice of social closure also influence generational identity, and shape collective activity.

Vincent (2005) warns against an overemphasis on structural influences that fail to take into account individualised experiences. Vincent considers how generational identities become more salient in some circumstances than in others. He argues that our understanding of generations can be enhanced if we avoid a strict chronological focus and instead consider the meaning that individuals themselves have about their own generation and their historical experiences. He further identifies that generational identity changes as members of the generation age and their experience of transitions in later life will be informed by multiple factors, not just events from their childhood and adolescence. Individuals must transform their identity as they move through life stages. Of interest to this study is the extent to which this is a collective transformation.

\section{Generational change}

Various theories exist as to how and why generational values change over time. Inglehart (2008) argues that a new generation's ideas begin to dominate society as they enter adulthood and take over from the older generation that is now passing on. In this way change is slow but systematic. 
Like Mannheim, Inglehart argued that intergenerational change will occur "whenever the formative experience of the younger birth cohorts are substantially different from those that shaped the older generations..." (Inglehart, 2008, p145). The greater the level of modernisation in society, the larger the differences between the generations.

Inglehart $(2000,2008)$ explored how changing societal conditions affect practices of socialisation and generational value priorities. He argues that in post-industrial societies a cultural shift from materialist to postmaterialist values has occurred, alongside increased levels of security associated with economic growth and the rise of the welfare state. A traditional emphasis on duty and charity, that had helped compensate for limited social mobility, was undermined by the rise of the Protestant ethic and increased legitimacy of economic accumulation. Conditions of peace and prosperity lead to a diminished need for rigid religious norms and absolute rules, and a growing generational concern for the meaning and purpose of life. Technological changes that have reduced the likelihood that people will die prematurely also impact. Inglehart notes that where survival is uncertain, insecurity leads to xenophobia, a desire for strong leaders, deference to authority, and a focus on physical and material growth. Having a basic sense of security has the opposite effect. He argues that post materialist values “...emerge as people come to place increasing emphasis on autonomy, selfexpression and the quality of life. This shift is linked with changing existential conditions - above all the change from growing up with the feeling that survival is precarious, to growing up with the feeling that survival can be taken for granted" (Inglehart, 2008, p131).

Inglehart links post-materialist values with a number of orientations, including an increased generational emphasis on freedom of expression and political participation, and a prioritising of goals of belonging, esteem and aesthetic and intellectual stimulation. As established authority is questioned, new social movements emerge with elite- 
challenging political action. Diversity is seen as stimulating not threatening, other groups are tolerated and individual self-expression can take priority over maximising economic growth.

Other scholars have explored the relationship between cultural trends, such as consumerism, materialism and individualism, and generational characteristics and values (for example Eckersley \& Dear, 2002; Myers, 2000, Putman 2000). Twenge et al (2010) identify a generational shift from intrinsic goals, such as meaning, community and affiliation, to extrinsic goals, such as materialism and status. This shift from intrinsic to extrinsic goals has been associated with waning generational interest in political affairs (Twenge, 2006) and increasing levels of narcissism (Twenge et al, 2008). Putman (2000) notes reducing involvement in community groups in modern societies. In New Zealand increasing narcissm (Wilson and Silbey, 2011) and decreasing intimacy in friendships (McPherson et al, 2006) have similarly been described.

Polish researcher Siemienska (2002) notes that the extent and direction of change in generational characteristics differs across countries. Factors identified as influential include: the influence of history and heritage on the meaning ascribed to certain values; the political system of the country; the degree of isolation (as a factor in xenophobia and acceptance of migrants); the system of grass roots organisations in a given country and the practicality of setting them up (for example women's organisations); and the level of control by authorities. The respondents' gender and levels of formal education were also relevant. 


\section{Globalisation}

Globalisation is considered here as a contextual factor influencing boomer generational identity and the nature of society in which boomers are growing older. Globalisation includes the global exchange of ideas and the impact of movements of people between countries. Globalisation also refers to the increasing interrelatedness of national economies, policies and cultures under the influence of new technologies. Giddens (2009) argues that society is changing under the influence of globalisation in profound ways. "Inevitably, our personal lives have been altered as globalizing forces enter into our local contexts, our homes and our communities through impersonal sources - such as the media, the Internet and popular culture - as well as through personal contact with individuals from other countries and cultures" (2009, p146). As a result, while there remain continuities between modern and past societies, institutions have altered and tradition and custom have become less effectual guides to behaviour. What earlier generations took for granted, now must be the subject of decision making in the context of additional choices and new knowledge.

Globalisation also influences policy. Deacon (2000) argues that globalisation has contributed to a crisis discourse amongst global actors about pensions and retirement ages. Walker (2005) also notes the impact of 'economic globalisation' ideology on welfare and old age policy, arguing that because older people are the main beneficiary of welfare, pensions and services for older people have become top priorities for cost reduction.

The influence of social conditions and ideology on generational and policy value priorities is explored further in following chapters. 


\section{Outline of the Thesis Structure}

Chapter One provides an overview of the research issue, an outline of key concepts and a summary of the aims of the study. In Chapter Two the demographic, social and policy context of boomers in New Zealand is outlined. Descriptions of the baby boom, population ageing and the social and policy environment provide a macro view of influences on the boomer cohort.

In Chapter Three prevailing discourses about baby boomers and old age are explored. In part one discourses on ageing are described through a critical review of positive ageing policy. This sets the scene for the review of the literature on the baby boom generation provided in part two. Boomers are considered as 'future generations of older people' and as 'consumer citizens'.

The methodology of the research is set out in Chapter Four, including theoretical perspectives that have informed the study and the methods used to collect and analyse data. Strengths and limitations of the research methods are discussed.

Chapters Five and Six present findings from the boomer focus groups. Themes are illustrated using quotes from participants and cross cutting issues are identified. Chapter Five focuses on boomers' views of their own generation and their attitudes in mid-life. Chapter Six explores boomers' thoughts about old age and their expectations of late life. Their expectations of support are also revealed. 
In Chapter Seven the underlying beliefs and values of New Zealand boomers are explored. The discussion compares and contrasts findings from the focus groups with other studies. This chapter explores how being a member of a (relatively) large cohort has impacted on boomers view of themselves and explores the following questions: have labels attached to their generation influenced their collective identity? Do they share common beliefs and values that make them a distinct group? How might their beliefs about the boomer generation influence their future behaviour?

In Chapter Eight the focus is on the degree of mismatch or congruency between boomers' views and current policy for older people. Boomers values and expectations are compared to current policy for older people and policy implications are discussed. Chapter Nine provides a summary of key themes in the thesis and concluding comments. 


\section{Chapter 2: The Demographic, Social and Policy Context}

\section{Introduction}

To understand boomer attitudes, values and likely behaviour in late life, it is important to consider the context in which they have grown up and in which they are growing older. This chapter explores the demographic, social and policy context of boomers in New Zealand. Descriptions of the baby boom and the nature of population ageing in New Zealand are provided, to contextualise policy responses. A historical overview of the social and policy environment then follows. This chapter provides a macro view of influences on the boomer cohort and provides an introduction to a more detailed exploration of the policy environment in Chapter Three.

\section{The Demographic Context}

\section{The baby boom}

Between 1946 and 1965, 77\% more babies were born in New Zealand than in the previous twenty years (Statistics NZ, 1995). New Zealand's fertility rate during the boom era was amongst the highest of all the Western Developed Countries ${ }^{5}$ and represented a major increase in family size (Pool, 2007). The birth rate rose rapidly from 2.1 births per woman in 1936 to a peak of 4.2 in 1961. New Zealand's peak total fertility rate of 4.2 compares to 3.9 in Canada, 3.8 in the United States, and 3.6 in Australia (N. Jackson, 2011a).

\footnotetext{
${ }^{5}$ Defined by Pool (2007) as all of Europe west of the Hajnal line (Gdansk to Trieste), including Iceland, the Mediterranean peninsula (including Greece), and the neo-Europes (Anglo-America and Quebec; Australasia) plus Japan.
} 
Total fertility rates in New Zealand levelled off around 1965, but the number of births remained high through to the early 1970s (see Figure 1), leading Pool (2007) to argue the baby boom in New Zealand lasted thirty not twenty years.

\section{Figure 1 - Birth Numbers and Fertility Rates 1921-2010}

Source: Statistics NZ, 2011.

http://www.stats.govt.nz/browse_for_stats/population/estimates_and_projections/dem ographic-trends-2011/births.aspx

\section{Live births and fertility rates}

\section{$1921-2010$}
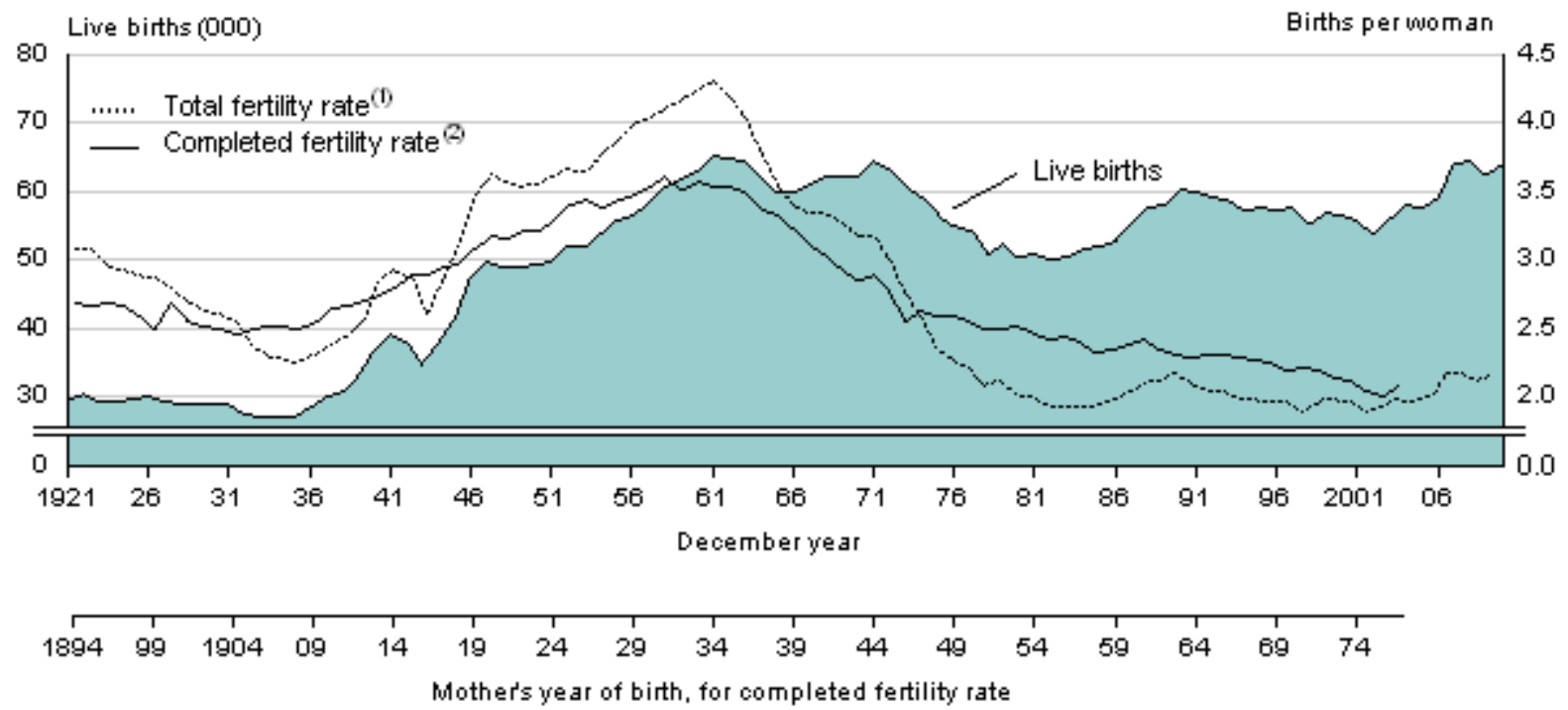

1. The average number of births a woman would have during her life if she experienced the age-specific fertility rates of that year. It excludes the effects of mortality.

2. The average number of children a woman born in a particular year has had during her life. The figures for $1962-77$ birth cohorts are estimates only.

Source: Statistics New Zealand

Strictly speaking the baby boom in New Zealand was a European phenomenon (Pool, Dharmalingam and Sceats, 2007). Patterns for indigenous Maori were very different (see Figure 2). Maori fertility rates were much higher, but with a smaller population these had little impact on overall figures. There was no rapid rise in Maori fertility rates, but in common with Pakeha, though to a much larger degree, rates fell dramatically in the 1970s. 
Figure 2 - Total fertility rate, Maori and total population, 1900-2000

Source: NZ Treasury, 2004. http://www.treasury.govt.nz/publications/researchpolicy/wp/2004/04-02/06.htm

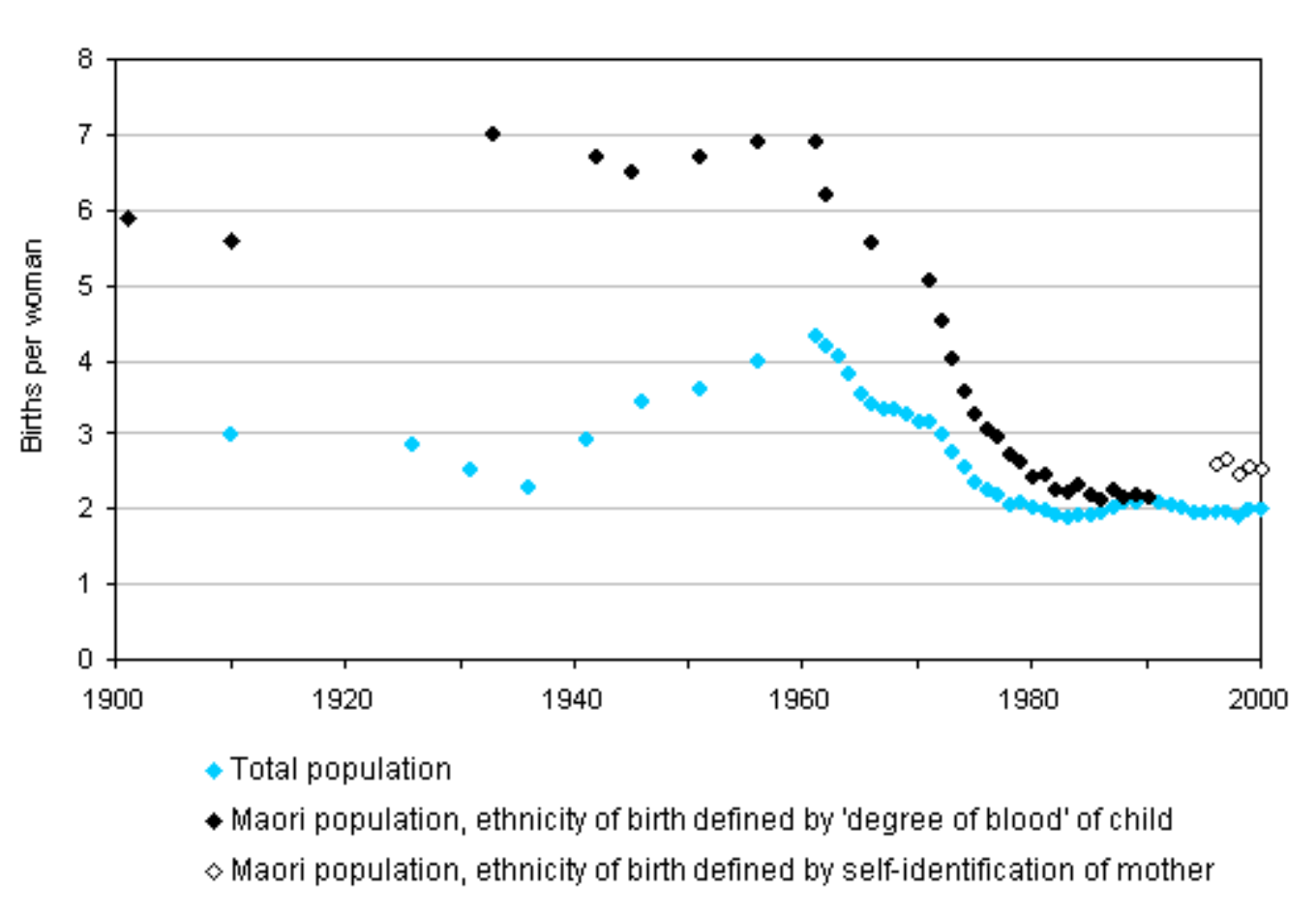

Both the size and shape of the boom are significant affecting the pace and degree of demographic change, and the window of opportunity available to respond to changing needs. The boom in New Zealand had two waves and troughs, with fluctuations in birth cohort size that has resulted in turbulent effects on policy and markets. Secondary effects are also evident as the boomers move through the life cycle, with a 'baby blip' in the early 1990s when the large sub-cohort of boomers born around 1960 had their children (Pool, Dharmalingam and Sceats, 2007). A further small blip is currently occurring, says Natalie Jackson (2011b), with the birth of baby boomers' grandchildren.

The characteristics of the baby boom varied between countries. Numerically, Canada experienced the largest baby boom in the world (Marshall, 2001) and a severe 'baby bust' that in the English speaking countries was surpassed only by New Zealand (Pool, 2007). 
In the United States the size of the boom was also large, with 76 million boomers born between 1945 and 1964 (Pew Research Centre, 2005). In the UK, the demographic peaks were less pronounced and less sustained than in America, Canada, Australia (Phillipson et al, 2008) and New Zealand. While the number of births in the UK boom years of 1947-1964 reached more than one million, even at its two peaks (wave one was immediately post-war, while wave two of birth rates peaked in the early 1960s) the increase in births "constituted only an additional 25 per cent of the average for the post war decades" (Falkingham 1987, p18), prompting Sandbrook (2005) to suggest there was no real baby boom in Britain.

Some countries, such as Finland had a short period of increased birth rates, with post war increases ending at the beginning of the 1950s (Karisto, 2005). Germany had no real boom with a moderate increase only in the early sixties (see Falkingham, 1987). Japan had a very brief baby boom after World War II, lasting only three years (Nitta, 2006).

Much has been made of a potential looming crisis as large numbers of boomers reach 'pension age'. The size of the baby boom cohort is seen as a problem, placing a burden on younger smaller cohorts who, it is argued, will have to fund the demands boomers make on the state. Phillipson et al (2008) note that the volume argument has been particularly strong in the United States and Canada, where the number of boomers is high. However they caution against an overly simple and reductionist view of the impact of the baby boom. Outcomes depend on the particular historical and economic set of experiences of each cohort, and the balance of advantages and disadvantages over preceding cohorts. Intra-cohort differences are also influential. 
Furthermore, numbers and rates are only part of the picture. The baby boom has been both a demographic and a social phenomenon. Phillipson et al note that "...the symbolism of the rise in the birth rate was at least as important as its demographic aspects. The (British) 'boom' may have been small but it was significant as compared with the decline in fertility characteristic of preceding decades - this created a sense of panic across many... countries" (Phillipson et al, 2008: paragraph 6.4). Yet when considered from a historical perspective, specifically the concerns about population decline prevalent in Europe and in New Zealand prior to World War II, there was potential to view the population boom much more positively.

Pool, Dharmalingam and Sceats (2007) identify the New Zealand baby boom era as a period of fundamental change in patterns of parenting and family residence and a pivotal era in terms of the values, norms and behaviours that drive family life. They note some demographic features of the baby boom were a return to patterns of the early pioneer years (early and universal marriage and high fertility rates especially at young ages, a pattern absent during the low fertility years from the 1880s through to World War II). However, they argue the dramatic changes that occurred after the boom era makes the boom family in some respects a deviant form, that is, the baby boom marked a temporary shift away from a longer term trend to low fertility.

\section{Population Ageing}

Like most developed countries, New Zealand's population is ageing. The median age of New Zealand's population has risen from 26 years in 1971 , to 36 years in 2005 , and is projected to be 45 years around 2045 (based on Statistics NZ series 5 projection which assumes medium fertility, medium mortality and medium migration projections) (Statistics NZ, 2006). 
Population ageing results from a shift from high mortality and fertility to low mortality and fertility. We are partly through the resulting transition in age structure, which began in the 1800s (Statistics NZ, 2006).

Changes so far have mainly affected the population under 65 years of age (Dunstan and Thomson, 2006). However as more members of the large boomer cohort turn 65 , rapid growth in the $65+$ population will occur, with corresponding shrinkage in the "working age" population.

Population ageing is often incorrectly attributed to the post-war 'baby boom', a view that has contributed to boomers being portrayed as a problem group (Phillipson et al, 2008), accused of bringing instability to future social security and pension arrangements. The baby boom actually delayed the general ageing of New Zealand's population (Statistics NZ, 2006; Dunstan and Thomson, 2006). A 'baby blip', or echo effect, that occurred around 1990 when children of boomers born around 1960 were being born, has had a similar, though smaller effect. There is also a second baby blip occurring now, as older boomers children are themselves starting to have babies (N. Jackson, 2011).

There are four dimensions of population ageing that need to be understood when looking at implications for New Zealand (N. Jackson, 2011). One is numerical ageing - that is the absolute increase in the number of older people, driven primarily by increased life expectancy and longevity. There has been a doubling of the number of people aged 65+ from 1970 though to 2005, when numbers reached half a million. By comparison, the population as a whole increased by 44 percent over the same period. Numerical ageing will increase as the boomers turn 65 from 2011, with the largest growth expected in the 2020s and 2030s. 
The second dimension is structural ageing - that is the increase in the proportion of older people, primarily caused by declining birth rates, and a drop in the proportion of younger people. By the late 2030s, the 65 and over age group will make up over one quarter of New Zealanders, compared with 12 percent in 2005 and 8 per cent in the 1969s (Statistics NZ, 2006). The third and fourth elements of population ageing are natural decline and absolute decline in population. A shift to a natural decline in our population will occur as a consequence of the higher proportion of older people, which eventually will lead to more deaths than births. Absolute decline occurs where there is insufficient replacement migration to offset the fewer births and increased deaths. Absolute decline is a particular issue for regions of New Zealand with a high influx of retirees, where growth will initially be stimulated, but it is growth that will be difficult to sustain.

Natalie Jackson (2011a) argues that in terms of effects, it is numerical ageing that drives up demand for services, health care and pensions, but it is structural ageing, and the relatively smaller proportions of young, that constrains capacity to cope in terms of tax take and labour supply. She argues:

“...the 'problem' is not the increased numbers of elderly (sic) - which is actually a wonderful problem to have. Rather it is the relatively diminished proportions of young. Indeed... the term population ageing has deflected our attention away from what may be its most profound element: the relative lack of young" (N. Jackson, 2011a, p4).

From 2011 to 2016 the total NZ population is predicted to grow overall by around $4.6 \%$, but it will be $19 \%$ at $65+$ years, and only $2.4 \%$ for all other age groups combined. Over the next 15 years (2011 to 2026), the projected growth is $13 \%$, but that conceals a $61 \%$ increase in the $65+$ year population, while all other age groups combined will grow by only $5.4 \%$ (N. Jackson, 2011a). These figures may be conservative, if life expectancy gains continue at their current rate. 


\section{Ageing of New Zealand's Older Population}

It is not only the total population that is ageing. The 65+ population is also, with significant growth in numbers of those in the oldest age groups. The first boomers will turn 85 years of age in 2031. By 2051 people aged $85+$ will account for 24 percent of those aged over sixty five, compared with 11 percent in 2005 (Statistics NZ, 2006).

People aged 80 and over will comprise 41 per cent of older people by 2051 (up from 27 per cent in 2011) (MSD, 2011). The Ministry of Social Development predicts that between 2026 and 2031 the number of people aged 80 and over will surpass the number aged $65-69$ for the first time, and will continue to increase ${ }^{6}$ (see Figure 3 ).

\section{Figure 3: Projected older population by age band}

Source: Ministry of Social Development, 2011.

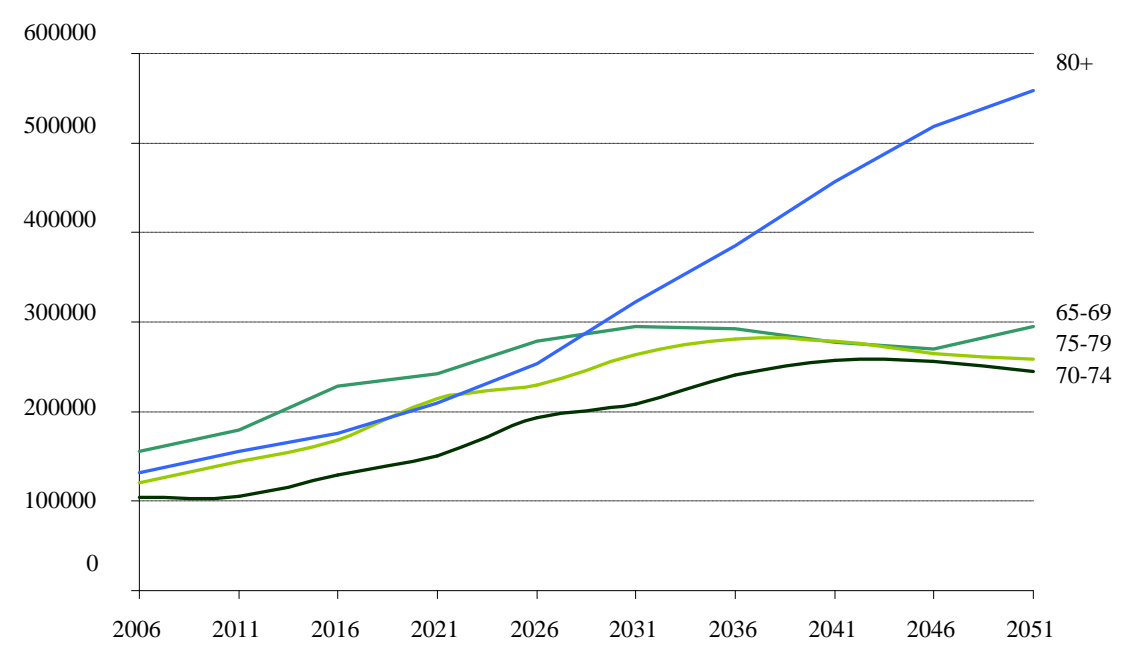

\footnotetext{
${ }^{6}$ Based on 2010 "medium" population projections provided to Treasury by Statistics New Zealand. These are broadly similar to the 2008-base projections contained in Treasury's 2009 Long-term Fiscal Statement, but have slightly higher projected numbers of people aged 75 and over, consistent with upward revisions in projected longevity.
} 
The impact of population ageing can be represented graphically by comparing population pyramids that show how the population age structure changes over time (Figure 4).

Figure 4: Population Age Pyramids 1951, 2001, \& 2051

1951

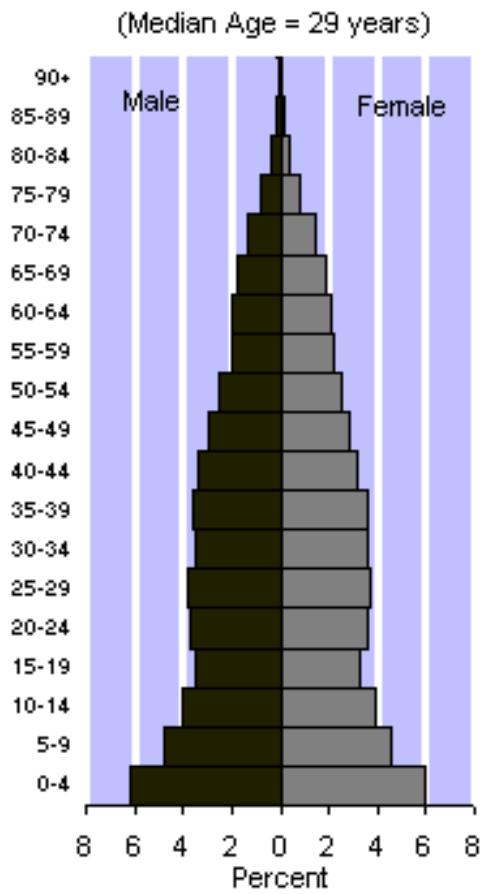

2001 (Base)

(Median Age $=35$ years)

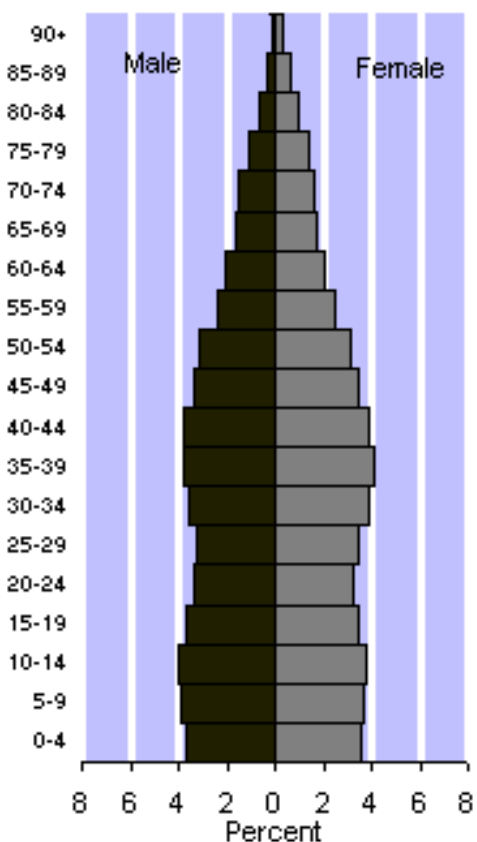

2051 (Series 4)

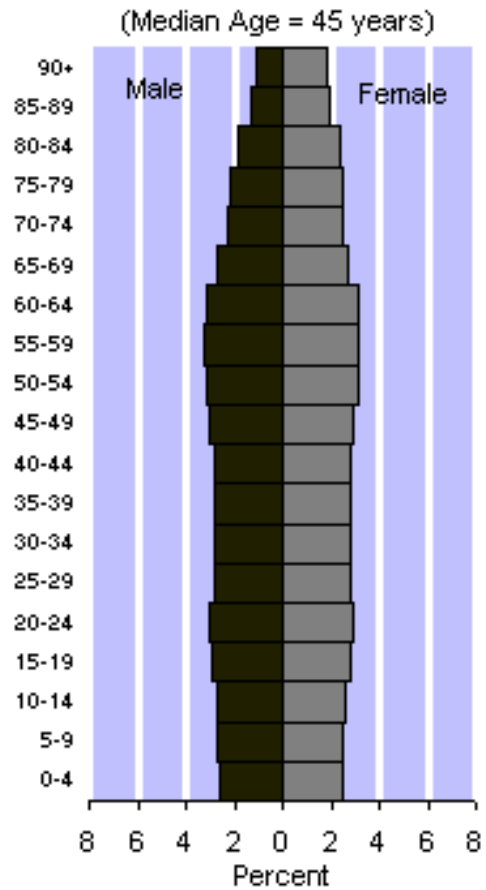

Source: Statistics NZ, Hot Off The Press National Population Projections 2001 (base) - 2051 Commentary, www.stats.govt.nz.

Note:

Series 4 population predictions assume (a) the total fertility rate will decrease to 1.85 births per woman by 2011 and then remain constant; (b) life expectancy at birth will increase six years during the projection period to 82.5 years for males and 86.5 years for females by 2051 , and (c) there will be a long-term annual net migration gain of 5000 people from 2007 onwards. 


\section{International Comparisons}

New Zealand will have the greatest numerical ageing of any OECD country and the highest annual increases in numbers aged 65+, due to the size and nature of the New Zealand baby boom (N. Jackson, 2011a). However the proportion of older people in New Zealand will remain significantly lower than many other OECD countries (Statistics NZ, 2006), including Japan, Italy and Sweden and to a lesser extent Canada. By 2030 the proportion of older people in New Zealand will be similar to Australia and the UK, but higher than the United States (Figure 5). This relates to ongoing high fertility (relatively) in New Zealand and the prolonged nature of the New Zealand baby boom (Pool, 2007).

Figure 5: Projected Population Aged 65 Years and Over

Projected Percentage of Population Aged 65 Years and Over 2009 and 2030

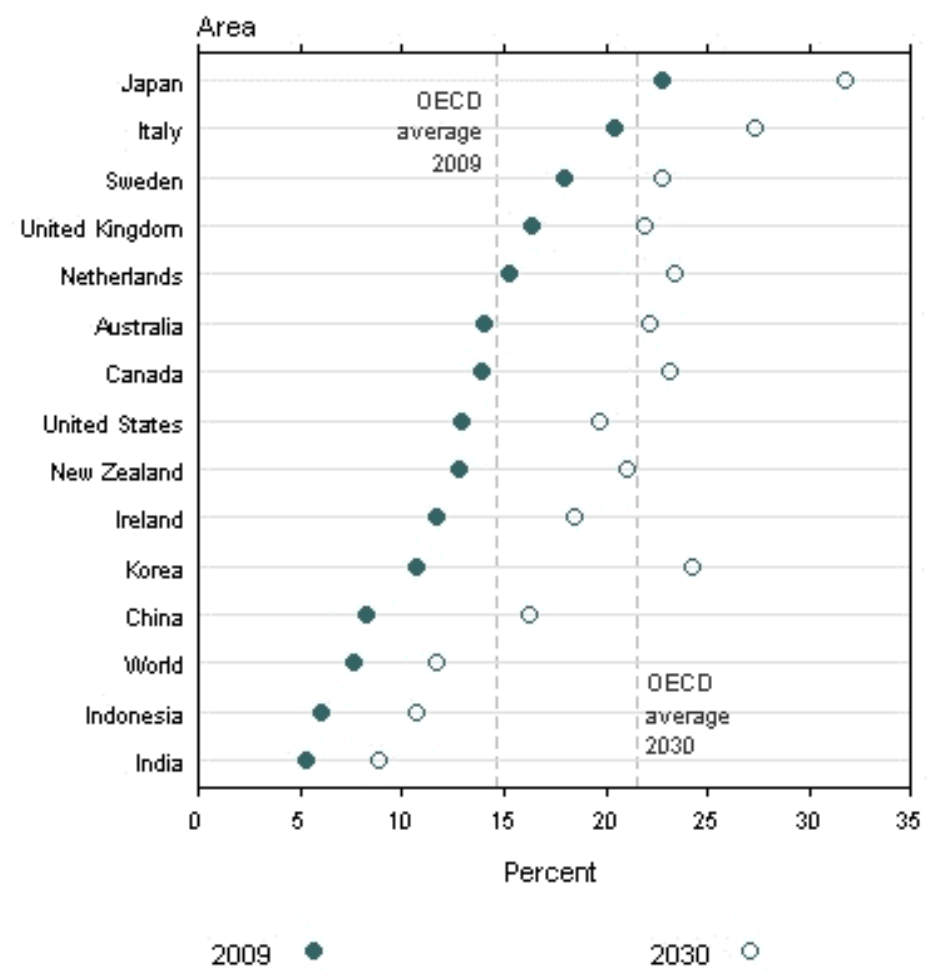

Source: OECD Factbook: 2009 Economy, Environmental and Social Statistics 
In most of Europe, where the boom was smaller and shorter, and where total fertility rates rose to little more than 3.0, the population is structurally older now (N. Jackson, 2011a). This provides New Zealand with greater opportunity to prepare for population ageing and to observe responses in other countries.

Importantly, in terms of age structure, there are fewer people in New Zealand aged 25 - 39 compared to other age groups (N. Jackson, 2011a). External migration is a factor. Young New Zealanders have tended to head overseas for their 'OE' (overseas experience). Now, particularly in the wake of rising student debt, there is the added lure of higher incomes and greater job opportunities. Some return, and others are replaced by new migrants, but many partner, have families and settle overseas. This pattern, combined with falling birth rates in each cohort is "driving up the median age faster than would otherwise be the case, given that New Zealand has the highest birth rate in the developed world" (ibid, p2). Jackson argues that this 'bite' out of the population will last at least fifteen years, with significant implications for New Zealand's capacity to respond to population ageing and the predicted exit of boomers from the workforce. Much will depend on how young people can be retained in New Zealand, or be encouraged to return home from travels.

New Zealand also has a very mobile population and a high level of internal migration, which has an impact on population ageing and age structures in the regions (Statistics NZ, 2006a). Younger cohorts tend to move to the cities and older cohorts to smaller urban and semi-urban areas that are popular as retirement locations, creating diversity in age structures. These changes are occurring at different times, with some regions already having a very high proportion of older people. 
Another key affecting population ageing in New Zealand is the significant difference in age structure between Maori and non-Maori New Zealanders (N. Jackson, 2011a\&b). In 2006, Maori made up 14\% of the total population, but a larger proportion of younger age groups. The median age of the European-origin population in 2006 was 38 years, compared to 23 for Maori; that is, 50 per cent of the Maori population was aged less than 23 years. Maori aged 0-14 years account for 21 per cent of all 0-14 year olds, and 18 per cent of all 1524 year olds. Natalie Jackson notes that "....young Maori will play a significant role in New Zealand's future labour force, and attention to their specific educational, training, and social needs must be a paramount consideration" (2011, p18). The Pacific population is also youthful, with those aged 0-14 comprising approximately 11 per cent of all 0-14 year olds. The Asian-origin population has a bulge in the 20-29 year age group, but many are students who may only be here temporarily (N. Jackson, 2011a\&b).

The European ethnic group will contribute most to the numerical increase in the 65+ age group between 2001 and 2021 (from 270,000 to 690,000 ), but the fastest growing is the Asian ethnic group, increasing by fivefold between 2001 and 2021 (from 11,000 to 56,000). The Maori population aged $65+$ is projected to number 56,000 by 2021 , compared with 20,000 in 2001, while the older Pacific population is projected to increase from 9,000 to 26,000. However, Maori and Pacific and Asian populations will continue to have younger age structures than European (Statistics NZ, 2006a). 


\section{Predicted impact of population ageing}

A common representation of the impact of population ageing is the 'dependency' ratio, that is the number of old and young, the two groups assumed to be 'dependent' on others for income and care, compared to the number of people of 'working age', usually assumed to be those aged $15-64$. The $65+$ dependency ratio (number of people aged $65+$ per 100 people aged 15-64) in New Zealand is predicted to increase from 15 per 100 in 1951 to reach 45 per 100 in 2051 (based on medium mortality projections). This means that for every person aged 65+, there is projected to be 2.2 people in the 'working-age' group in 2051 (compared with 5.5 people in 2004). However, the growing 65+ dependency ratio is partly offset by a decrease in the 0-14 dependency ratio (the number of people aged 0-14 per 100 people aged 15-64). This has decreased from 57 per 100 in 1961, to 33 per 100 in 2004, and is projected to decrease further to 28 per 100 in 2018 before remaining relatively constant. Nevertheless, the total dependency ratio (the number of people aged 0-14 and those aged 65+ per 100 people aged 15-64) is projected to rise from 51 per 100 in 2004 to 73 per 100 in 2051 (Statistics NZ a \& b).

Dependency ratios are now almost routinely critiqued. For example, the projected total dependency ratio for 2051 is similar to that experienced in the 1950s and 1960s when the baby boomers were young, a fact noted by some who comment that the country has successfully managed to cope with this degree of dependency in the past (St John, 1999). The total dependency ratio peaked at 71 per 100 in 1960. However dependencies in a young population can not be assumed to be the same as those that occur in a society where the old outnumber the young. 
To know what the effect of ratios will be, more needs to be known about the characteristics of the three age groups. The complex interdependencies between the three age groups need consideration, including social and financial exchanges between generations within families. The assumed dependency of the 65+ age group also ignores the economic contributions made by older people as consumers and tax payers, investors and shareholders, volunteers, family members and, in growing numbers, in the paid workforce. Age dependency ratios do not take account of changing patterns of workforce participation or other changes that may influence degrees of dependency, including the possible effects of new technologies, and change in levels of disability.

Research on boomers' expected activities in older age can provide useful information for those analysing age based dependencies. A 2011 report by the Ministry of Social Development has predicted that future generations of older New Zealanders will make a significant contribution to the economy (MSD, 2011). Their modelling forecasts:

- A doubling of the labour force aged 65 and over, from 3-4 per cent in 2011 to $7-10$ per cent by 2051 ;

- A possible tenfold increase in their earnings from employment, from just over $\$ 1$ billion to about $\$ 10$ billion ${ }^{7}$;

- Increased total contributions from tax paid on earnings from employment, from about $\$ 200$ million to about $\$ 1.8$ billion;

- A rise in the total value of unpaid and voluntary work by older people, from an estimated $\$ 5-6$ billion to more than $\$ 22$ billion;

- Contributions from consumer spending by older people of over $\$ 45$ billion (up from about $\$ 11$ billion).

Predictions about the effect of population ageing need to take these factors into account.

\footnotetext{
7 Values are expressed in real 2006 dollars, adjusted for the expected real growth in the value of wages between 2011 and 2051.
} 
Demographic variables such as gender are also important to consider. For example, living arrangements vary by gender, with a higher proportion of older women living alone (Davey, 2006c). Those living alone tend to have more difficulty maintaining their independence and need more support (Dwyer et al, 2000). Single older women have been more likely to be renters with a lower standard of living, as a result of lower lifetime earnings and more adverse economic effects of divorce compared to men (Else and St John, 1998). However, the gender imbalance at older ages is expected to decrease, especially at the oldest ages, as the gap in life expectancy between male and female narrows (Statistics NZ, 2006a). That may mean more older women with partners in future years and more older men living alone. Increasing numbers of older men and women who are not partnered is a further trend to consider (Statistics NZ, 2006a).

The older population is also predicted to become more ethnically diverse. This will likely result in more diverse care and support needs in the future, with rates of chronic disease, patterns of care and family networks varying by ethnic group. Complicating issues of intergenerational dependency, many Asian and Pacific families will have older relatives overseas. In addition, many Maori, Pacific and to a lesser extent Asian children, will have parents and grandparents of European ethnicity. For example, in 2002-04, 49 percent of Maori births had a non-Maori parent, and 41 percent of Pacific births had a nonPacific parent (Statistics NZ, 2006a). The above examples show the interaction of demographic and social variables and the complexity of predicting future outcomes. 


\section{The Social and Cultural Context}

The expectations of boomers for late life and how they may prepare for older age will be influenced by experiences throughout their lives. Wellbeing in late life is also influenced by socioeconomic circumstances through the life course. It is important therefore to consider the sociocultural context of the boomer cohort's lives.

The first baby boomers were born into a New Zealand very different to today. In the 1940s and 50s, New Zealand's culture was still significantly aligned with that of Britain, with the majority of the nonMaori population having migrated from the United Kingdom. Cultural bonds between the countries were strong, as evident when one in four New Zealanders turned out to see Queen Elizabeth during her 1953 tour of the country (www.teara.govt.nz). Alliances were economic as well as social; more than half our exports (primarily agricultural) went to the UK market and nearly half of our imports came from there (www.nzhistory.net.nz).

In the 1950s, the Cold War and concerns about communism were influencing politics and industrial relations and New Zealanders were fighting in the war in Korea (Trotter, 2007). Radio ruled the decade until television began broadcasting in 1960. Urbanisation and housing development were creating sprawling new suburbs, and 'milk bars' and rock and roll were influencing urban teen culture (Yska, 1993). The changes brought new social issues, such as those described in the 1954 Mazengarb report on 'juvenile delinquency'. This report created a moral panic, laying the blame for teen misbehaviour on "...the absence from home of working mothers (though levels at that time were low), the easy availability of contraceptives, and on young women who enticed men into having sex" (www.nzhistory.net.nz). 
Rapid changes in domestic technology were occurring, though innovations took some time to reach into New Zealand households. The following excerpt describes life in the 1950s and reveals the extent of change over the lives of boomers.

"In the mid 1950s there was just one (landline) phone for every five people, with many rural households on party lines they shared with others. International toll calls had to be booked in advance through a toll operator. By 1959 only $54 \%$ of dwellings had a refrigerator and just $57 \%$ had a washing machine. Almost $14 \%$ of homes did not have piped water and nearly $19 \%$ did not have a flush toilet. Flying was a novelty and trips to Britain were mostly by ship. Flights to London via Sydney took three to five days. Pubs shut at $6 \mathrm{pm}$ and the 'six oclock swill' before closing was an established drinking behaviour." (http://www.nzhistory.net.nz/culture/the-1950s/overview)

New Zealand was in the early stages of a 'golden age of welfare' when the first boomers were born. The period from 1945-1973 is considered a time of security and prosperity, with economic stability and low unemployment (Rudd, 1997). The first Labour Government had introduced a range of benefits and begun an era of family friendly policies that extended the housing, health and education systems (see next section for an analysis of policy shifts). It was however, a conservative National party that dominated economic and social policy through most of the baby boom era (Trotter, 2007), in Government from 1949 through to 1957 and again from 1960 to 1972.

In the early boom era, most young people typically lived with their parents until they got married and set up home in the suburbs. Home ownership levels were high and very early marriage, rapid childbearing and larger family size became the norm (being a new trend for nonMaori but a continuation for Maori families) (Pool et al, 2007). The neolocal, nuclear family unit became the dominant family structure (earlier for non-Maori but by 1960 for Maori as well), shaping the experiences of baby boomers. 
Marriage was almost universal and a prevailing 'cult of domesticity' encouraged most women to stay at home to look after the children (Pool et al, 2007). Divorce levels were low during the boom era (increasing from the end of the 1960s), but this does not mean that boomers' parents (and early boomer couples) remained together. A quarter of women from cohorts married before 1970 had separated by their twentieth wedding anniversary. Those who had married younger, and who were pregnant at the time or very soon after, were at most risk of divorce (ibid). This leads Pool et al to argue that "the upsurge of divorces over the last two and a half decades of the twentieth century was determined in part by patterns of family building that typified the golden era of family life, the Baby Boom" (Pool et al, 2007, p188).

Social changes during the boom era were significant (King, 2003, Trotter, 2007). Women's participation in the workforce, which had declined in the early part of the boom, grew as increasingly younger wives and older married women took on part time work (Statistics NZ, 1995; Pool et al, 2007). Levels of tertiary education increased for both men and women, the middle class expanded with the rise of administrative and managerial roles, and living standards improved for most.

The situation for Maori was also changing (King, 2003). Most Maori had lived in remote rural communities until after the Second World War, when the rural to urban migration commenced. Life expectancy for Maori in the mid 1950s was around fifteen years below non-Maori. Life expectancy at birth for non-Māori was 69 years for men and 74 for women, while for Māori the figures were 54 and 58 (www.nzhistory.net.nz). Growing awareness of economic disparities and ongoing loss of land led to a Maori resurgence and increasing assertiveness which, alongside the protest movements of the $1960 \mathrm{~s}$ and 70s, "pushed race relations and the place of the Treaty of Waitangi into the forefront of national life" (www.teara.govt.nz). In response, in 1975 the Waitangi Tribunal was set up to address land grievances. 
Over the 1960s and 1970s a questioning of institutions and increasing protests, combined with a renaissance of art, music and literature, and Maoritanga $^{8}$ (King, 2003), contributed to New Zealand "carving out its own identity separate from the British mother country" (Waldegrave and Koopman-Boyden, 2010, p2). Television and increased international travel contributed to social change, increasing New Zealanders' exposure to other cultures. The media brought international news to New Zealand, with coverage of the Moon landings, the assassinations of Martin Luther King and the Kennedys, and the Vietnam War, influencing attitudes and values of young boomers (Trotter, 2007).

Also influential was the women's movement which was active in New Zealand in the 1970s, with protests, conventions and street marches seeking support for legislative change. Key issues included the right of women to control their own fertility, equality in the workplace, violence against women and children, and sharing of domestic work and child rearing (Trotter, 2007; Waldegrave and Koopman-Boyden, 2010).

Mutchler and Burr (2008) identify key socio-historical events such as those described above as "markers of a cultural reshaping of group and self-identity, opportunities, and expectations" (in Hudson, 2008, Vol 1, p25). They argue that the events of the 1960s and 1970s in America had special significance for leading edge boomers approaching adulthood there. They speculate that as a result boomers "bring with them unique views of the meaning and significance of race, gender and ethnicity" (ibid, p25). Similarly in New Zealand, Waldegrave and Koopman-Boyden (2010) identify Maoritanga and the womens' movement as "two movements (which) have changed many of the stereotypical assumptions about participation, socialisation and human rights in civil society" (p2).

\footnotetext{
${ }^{8}$ Maoritanga may be loosely defined as the traditions, ideals and culture of Maori people and Maori nationalism (Merriam-webster.com).
} 
Migration in the 1960s and 70s also had an impact, exposing the predominantly European New Zealand population to a wider range of cultural values and related race relations issues. For example, migrants from the Pacific Islands, who increased in number from the 1960s, became the targets of policy when economic conditions tightened in the mid-1970s (Trotter, 2007). A series of 'dawn raids' by police that took place on the homes of alleged 'overstayers', led to concerns about human rights violations and a questioning of the powers and actions of police and politicians. The unfairness of actions that split up families in targeted racial groups received media and university student attention, and increased public debate of racism in New Zealand. Increasing protest led to the policy being overturned, but this period in New Zealand's history still resonates within Pacific families today (www.nzhistory.net.nz).

By the late 1960s and early 1970s, as many boomers were approaching their teens, a shift to cohabitation as the first form of union was taking place, as contraception, sterilisation, and to a lesser degree abortion replaced marriage as a strategy for managing the risks of conception (Pool, et al 2007). Early boomers contributed to this trend and trailing boomers embraced it. From the mid seventies, more young adults lived with non-related others in a flatting situation. Increasing numbers of boomers studying at university influenced this trend. Prior to this, young people had mostly stayed at home, boarded or lived in hostels till they married and teenage pregnancy had resulted in marriage or adoption. Rates of adoption had increased from around 250 babies a year before the boom, to an average of 2400 per year from 1944 to 1980 (Belich, 2001). By the early 1970s, a values shift had occurred towards women keeping their babies, though not necessarily marrying in haste (Pool, et al 2007). 
Leading baby boomers entered the job market in times of high employment and a prosperous economy, but trailing boomers had a different experience. The New Zealand economy faltered following the oil shock of 1973 and the impact on exports of Britain joining the European Economic Community. The economic situation contributed to a change in government from Labour to National in 1975 and a change in policy approach (Trotter, 2007). To try and keep the country prosperous, Prime Minister Robert Muldoon maintained a high degree of economic control and regulation over the next decade and commenced a programme of 'think big' projects. But the fall of oil prices made these projects increasingly controversial and uneconomic, and inflation and unemployment increased (Belich, 2001; King, 2003). By the time boomers born in the 1960s entered the job market, unemployment was rising.

In the mid 1980s, a programme of economic liberalisation began which had a profound impact on the country. In 1984 following a snap election called by Muldoon, Labour regained power under the leadership of David Lange. His Finance Minister Roger Douglas removed controls over the economy, privatising state enterprises and questioning aspects of the welfare state (Boston, 1999; Trotter, 2007). For many these policies (outlined in more detail in the next section) were considered an assault on New Zealand's egalitarian traditions (www.teara.govt.nz).

Other Labour policies still reflected their core character, as evident in anti-nuclear policy. This won much support domestically and within the Pacific, though it caused a significant fracture in New Zealand's policy relationship with the United States (Trotter, 2007). Labour also passed the Homosexual Law Reform Act in 1986, after public campaigns for reform in the mid eighties. That campaign had caused lengthy and at times bitter debate about human rights, amidst fears about the demise of the family and the spread of AIDS (www.nzhistory.net.nz). 
Unemployment peaked at $11 \%$ in 1992 when boomers, then aged 27 to 46, made up the bulk of the labour force (Statistics NZ, 1995). A significant number of boomers in manual jobs, especially Maori and Pacific workers, were made redundant as economic and technological changes affected the sector (Belich, 2001; King, 2003). Significant restructuring of the public service in the 1980s also affected boomers employed in that sector. Major changes to social welfare in the 1990s under the influence of the National governments of 1990-1999 deepened hardship for those out of work (Boston et al, 1999). In response to changing economic conditions a significant group of kiwi boomers moved overseas, with many 'crossing the Tasman' to Australia. In 1991, 11\% of boomers born in New Zealand were living in Australia (Statistics NZ, 1995) with boomers making up almost half of the total New Zealand born population living there.

For women, increasing career opportunities were developing (Statistics NZ, 2001), exemplified when In 1997 National's Jenny Shipley became New Zealand's first female Prime Minister, following her successful challenge for the leadership. Shipley had caused controversy in the early 90 s as Minister of Social Welfare with a policy of cutbacks to benefits. She was also a supporter of controversial reform of the public health system including the unpopular (and short lived) concept of user charges in public hospitals. Then in 1999, a change of government resulted in a coalition government between Labour and the Alliance led by Helen Clark, who became New Zealand's first 'elected' female Prime Minister. This began a period when key constitutional positions were held by women, including the Prime Minister, the Governor General, the Attorney General and the Chief Justice. This cemented a New Zealand reputation as a trail blazer in women's rights since 1893, when New Zealand had become the first self-governing country to grant women the right to vote in parliamentary elections (www.mwa.govt.nz; www.teara.govt.nz ). 
Labour remained in power from 1999 to 2008, with support from minor parties in varying coalition agreements, including with the Greens, who grew into a viable political party over this period. This decade saw strong economic growth, improved welfare assistance for low income families and a revitalising of the public sector (see next section for more detail of policy changes).

By 2011, kiwi baby boomers were aged 46-65 and had reached what have traditionally been peak income years. A significant proportion of mid-life boomers work long hours (more than 50 hours a week), but an increased number are working part time (especially men) (Davey, 2003; Statistics NZ, 2006b). Some part time workers are undertaking a midlife career or lifestyle change, or are engaging in further education, while others are reducing hours in preparation for gradual retirement (Davey, 2002; Keeling, Davey and Glasgow, 2009). The oldest boomers reached 65 years of age in 2011, becoming eligible for the age pension (New Zealand Superannuation). Preparing financially for late life has become an increasing focus for a some mid-life boomers (Keeling, Davey and Glasgow, 2009), with older cohorts more likely to be saving sufficient to maintain living standards post retirement (Scobie et al, 2004). Some boomers may struggle to do so, including those who affected by the economic recession of 1987-1992, those with extended periods of unemployment or limited employment, and those in low status occupations with reduced level and security of income.

Family circumstances of the boomer cohort in mid-life are diverse. As the cohort has aged, more boomers have divorced and more have remarried (Statistics NZ, 2006b). Some remained childless, others are 'second time around' parents, more are becoming grandparents and some are in empty nest years (albeit with periods where children bounce back home) (ibid). An increasing proportion of the cohort has experienced a significant health event and more boomers have died. By 2016, the size of the boomer cohort is predicted to decline, when total deaths exceed the number of immigrant additions (MSD, 2011). 


\section{The Policy Context}

Significant change in social policy has occurred over the course of New Zealand boomers' lifetimes, from the 'golden age of welfare' of their childhood to a residualist welfare state at the close of the twentieth century. A brief history of the welfare state is described below, followed by a summary of changing policy for older people. This section highlights how the level of obligation and nature of policy support for older people has varied, reflecting dominant ideology and beliefs about the role of older people in society.

\section{The Welfare State in New Zealand}

The 1938 Social Security Act enacted by the first Labour Government, established the New Zealand welfare state. The aim, according to then Prime Minister Michael Joseph Savage, was to provide for persons unable to support themselves due to age, illness, unemployment, widowhood 'or other misfortune' (Gustafson, 1986, p223), to safeguard them from poverty and neglect, and to free dependent persons from being 'an economic burden to relatives and friends' (p226). This Labour government introduced a range of benefits, including a universal old age pension; they extended the health and education systems; and addressed sub standard housing through regulation, low interest loans and low cost State housing. Labour had entered office following the severe economic depression of the 1930s. This context, combined with the pressures of the Second World War, meant they were able to increase control over the economy without much opposition (Rudd, 1997). The Reserve Bank was nationalised and compulsory arbitration and compulsory unionism were restored and a progressive income tax regime was developed. Labour's measures aimed at full employment and were intended to reduce New Zealand's vulnerability to international economic conditions (ibid). 
British economist John Maynard Keynes' ideas provided a justification for widening the boundaries of the state in post war capitalist society. The Keynesian paradigm supported more active government management of the economy to control the unstable effects of the market. According to Rudd (1997), while these measures reduced personal autonomy, they fostered a sense of social solidarity.

Not all benefited equally from the welfare state. All benefits except the aged pension and (from 1946) the family benefit were means tested and recipients had to meet criteria to ensure they were of 'moral character and sober habits' and therefore 'deserving'. The family benefit could be stopped if it was not being used for children; the unemployment benefit was conditional to seeking work and not available to those without work due to 'misconduct', and the invalids benefit was not provided if the incapacity was self induced (O'Brien and Wilkes, 1993). A 'family wage' concept meant higher wages for men than women, whether or not they had dependants (Hyman, 1997). Wages for workers outside the union or in a workplace not covered by awards were not protected and support for women outside of marriage, and adults not in paid work, was conditional (Rudd, 1997).

Workers' wages and employer profitability rose and living standards improved for most over the next three decades to the early 1970s, with economic stability and minimal industrial unrest. Unemployment remained less than $1 \%$ and economic growth averaged $4.5 \%$ per annum (Rudd, 1997). However, the real value of benefit levels declined over the years. A Royal Commission of Inquiry on Social Security was set up in 1969 and following their report in 1972 benefit levels were increased (Stephens, 1999). 
The Commission recommended that the welfare state should ensure all citizens were "able to feel a sense of participation in and belonging to the community" (Royal Commission on Social Security, 1972, p65). They identified the community as responsible for ensuring dependent people have a 'standard of living consistent with human dignity and approaching that enjoyed by the majority irrespective of the cause of dependency" (ibid, p65). The Commission recommended the morals clause be removed and a 'domestic services benefit' be set up for sole parents, women alone and women caring for those who were sick.

By 1973 the international recession was having an impact on the country. Rising debt and growing unemployment meant increased pressure on the government budget. Support for the welfare state started to reduce amidst growing neo-liberal ideology that was gaining popularity internationally, with the neo-liberal Thatcher government from 1979 in the United Kingdom and the Reagan administration from 1980 in the Unites States (Boston,1999; Rudd, 2001)

Significant changes to social assistance began from 1984 as the new Labour government began implementing a range of reforms. Boston, Dalziel and St John (1999) outline the factors leading to change: "In part this has been the result of fiscal pressures, prompted in turn by lower economic growth and higher unemployment, an ageing population, increased demand for health and education services, and changing family structures. In part too, it has stemmed from public concerns over welfare abuse and fraud, and opposition to rising tax rates. But this waning support has also reflected a significant shift in the intellectual climate, most notably the growing ascendancy of market liberalism and neo-conservatism." (p3) 
Policy analysts within the Treasury, along with the New Zealand Business Roundtable, a neo-liberal association of businessmen, applied pressure on government through the 1980s. The welfare state was criticised as failing to overcome disadvantage encouraging dependency, and creating perverse incentives that undermined economic growth. The view was that many who received assistance could and should expect to pay for themselves. They argued for a more targeted social policy regime, with cuts in expenditure and means testing in many areas, including health. Advice from Treasury was that benefit levels were high by international standards (a view since refuted - see Stephens, 1999, p 247). It was argued that the margin between benefits and wages was too small causing little incentive to find work.

Market liberals questioned extensive state intervention in the economy and argued the state was inefficient and authoritarian, reducing entrepreneurial initiative and productivity. Instead the market was to be given free reign and individuals more choice to enable the economy to prosper (Rudd, 1997). The market had become the key to a productive society and individualism was promoted (O'Brien and Wilkes, 1993).

Changes introduced as a result by the fourth Labour Government (1984-90) included the cutting of taxes, the sale of government assets, the introduction of private sector management styles into the public sector, the deregulation of the finance sector and freeing up of interest rates (Boston et al, 1999). Other changes included the introduction of increased targeting of assistance to low income families (through family support), means testing of some student allowances and notably, a tax surcharge on superannuation in 1985 (see next section for a discussion of changes to superannuation). The freeing of interest rates made housing loans more available but more expensive, although targeted assistance to help low-income earners to buy was made available (Else and St John, 1998). But as a consequence of rapid restructuring, unemployment increased. 
Changes brought in by the fourth Labour Government were minor however, compared to the radical restructuring of the welfare state that followed after the centre-right National Government won office in 1990. Key principles underlying National's approach were 'fairness', 'selfreliance', 'efficiency' and greater 'personal choice' (Bolger, 1990). 'Fairness' was defined as ensuring those in 'genuine need' had access to assistance; 'self reliance' meant increasing the ability for individuals to take care of themselves, 'efficiency' meant achieving the best value for tax dollars spent and 'greater personal choice' meant encouraging alternative providers of services through private provision (Boston et al, 1999, p13). Significant increases in targeting and large benefit cuts followed, along with major changes in the way social assistance was provided. The aim of reform was to reduce 'dependency' on the state and decrease public expenditure. The residualist model of welfare was supported by neoliberals, who argued for a 'minimal safety net' approach. They claimed that overly-generous welfare states threatened individual freedom or liberty, by placing too little emphasis on rewarding individual effort, while making universal benefits accessible to the 'undeserved' (Boston et al, 1999, p24).

Resulting changes included restructuring of the health care system with separation of funding, purchasing and provision, the introduction of an accommodation supplement and a shift to market rates for public housing; more targeted student allowances, cuts in subsidies and the introduction of a student loans scheme. Abatement rates for many forms of social assistance were increased (see Boston et al, 1999) and a 'Code of Social Responsibility' was proposed in 1997 (eventually dropped), to outline the new nature of a contract between welfare recipients and the State (see Davey, 2000). Despite growing public protest and political opposition, and the modification or nonimplementation of a number of key proposals, significant change in social policy continued throughout the next decade. 
The impact of the social policy reforms of the 1990s has been enduring and significant politically, economically and socially. Politically the unpopularity of many measures "contributed to loss of confidence in the political system" (Boston et al, 1999, p16) and to change in the electoral system (with the introduction of proportional representation in 1993). Economically, some argue benefit cuts exacerbated the recession while others claim longer term benefits to the labour market and the budget deficits (James, 1997). Socially, the changes "accentuated income inequalities, intensified the incidence and severity of poverty and contributed to a greater sense of social exclusion and alienation" (Boston, 1999, p16). Despite the intent of the reforms, the number of welfare recipients increased through the 1990s. Though subsequent governments modified some of the policies introduced in the 1990s, the welfare state at the end of the decade was very different to what it was prior to reform. Incremental changes since have increased the complexity of assistance and significant targeting remains.

In 1999 a Labour government was returned to power. This was a 'Third Way' government, influenced by social democratic ideas but accepting of the market as the best way to allocate resources. The Third Way aim was to balance the worst excesses of the market through the expansion of civil society and more community-based governance. Social citizenship was emphasised, with promotion of rights but also responsibilities (Hughes and Fergusson, 2000). Responsible state intervention and good management was to ensure effective welfare with reduced costs. Under this fifth Labour Government a 'Social Development' approach to social policy was introduced, that aimed to prevent social exclusion and promote participation (MSD, 2001b). The approach emphasised both 'fairness' and economic efficiency:

"Policies that reduce the extent of social exclusion are desirable as they improve the fairness or distribution of well-being across the population ...There are also important efficiency reasons ...For example, if reducing poverty will improve health outcomes - this may increase the productive potential of the economy through 
increasing participation in work, and also reduce expenditure on healthcare. Similarly a focus on improving educational outcomes for those most at risk of failure will also have important economic benefits... and lower levels of benefit receipt" (MSD, 2001b, p4).

Major economic and social policy changes were made under Labour over the next nine years, including significant policy development for older people (outlined in the next section). 'Working for Families' policies were introduced to provide new assistance to low and middle income families with adults in the workforce, and interest in student loans was reduced. The public sector was strengthened and a 'whole of government' approach was promoted with enhanced partnership with the non-government sector in a number of areas. Tax for high income earners was raised and the minimum wage was increased. The health system was restructured and population-based bulk funding for primary care was introduced. The level of the pension, now called New Zealand Superannuation (NZS), was linked to wages, and the rate for married couples was increased.

In 2008, a mood for change resulted in a National-led coalition voted back into parliament under John Key. In the 2011 election they secured a second term in office. Welfare reform currently underway aims to reduce costs and increase 'fairness'. This government's broad goals include providing 'better and smarter' public services. Government expenditure and debt are targeted for reduction and change aims to improve 'productivity, efficiency and innovation' (www.national.org.nz). 


\section{Policy for older people}

Levine and Roberts (in Koopman-Boyden, 1993, p.230) state that "from the beginnings of welfare provision, successive (New Zealand) governments have recognised an obligation towards the country's older inhabitants". Early measures, such as the 1885 Hospitals and Charitable Institutions Act, linked old age to illness and care of older people with medical and institutional care. Koopman-Boyden (1993) argues that the introduction of the Old Age Pension in 1898 furthered this association and contributed to the idea that the old are unproductive.

The early introduction of an old age pension in New Zealand was a consequence of the aged being seen by the colonial administration as a problem group, but also a deserving poor within settler society (McLennan, 2010). Only the poorest of the poor received this pension. It was only available to the 'right kind of person', resident, of good character, aged 65 and over and with no income or assets (Else and St John, 1998; Hawke, 2005). Maori and Chinese were excluded Chinese had no residency rights and Maori were seen to have their own extended family supports to call on (McLennan et al, 2010). McLennan argues that a significant reason for New Zealand's early introduction of an old age pension was because family support networks for many settlers had been left behind when they emigrated. Official statistics produced for the Colonial Office in Britain reveal that;

"by the late nineteenth century, there were many indigent old men and women who did not have any kin network to support them and who were living in absolute penury, with many depending on the fickle support of local parishes, and with significant numbers ending up in local goals and lunatic asylums - this causing the colonial administration to incur unacceptable costs" (McLennan et al, 2010, p135). 
The 1938 Social Security Act introduced a two tier system to pensions, with the means tested old age benefit for those who qualified from age 60 , and a taxable universal payment to those 65 years and over. This was partially funded from a social security tax of $5 \%$ of earnings, later absorbed into general income taxation revenue (Hawke, 2005). As the country prospered after 1945, some larger employers set up employee pension schemes or endowment life insurance policies, and a Government Superannuation Fund was set up for government employees.

Only a small percentage of the population was covered by these schemes. With the age benefit set at about $68 \%$ of the average wages and rising costs eroding its value over time, increasingly pensioners felt they were not sharing equally in the prosperity of the country.

Superannuation increasingly became a political issue and in 1972 the Royal Commission on Social Security recommended higher pension levels.

The next major social policy change for older people came in 1975 when Labour introduced a state-run employment- based contributory savings scheme, designed to supplement the pension and provide older people with non-means tested income support. The scheme was controversial, with concerns that women's lower earnings put them at a disadvantage and concerns over state control of the capital (St John, 1999). The scheme was 'politically unstable' and superannuation became an election issue as each party "tried to outbid one another as to what they could offer" the significant minority of older voters (Rudd, 1997, p245). National won the election and introduced their 'National Superannuation' scheme in 1977, only nine months after the previous scheme had been introduced. 
National Superannuation was a universal taxable pension available to all residents at age sixty. The scheme was an expensive one, resulting in an increase in costs of over $80 \%$ in the next five years (Rudd, 1997). A series of adjustments reduced its value over the next decade, including the introduction in 1985 by Labour of a controversial surcharge on superannuitants' 'other income' (St John, 1999). The introduction of the surcharge, was a fundamental shift away from universality to an (effectively) income-tested payment (Hawke, 2005). The intention of the surcharge was to reduce cost, though St John notes that when taxes were flattened in 1986 and again in 1988, "in effect it restored some tax progressivity for those over 60 with significant other income" (St John, 1999, p283).

The surcharge was viewed as a broken political promise by Labour and caused much bitterness amongst superannuitants. They formed the New Zealand Superannuitants Federation (later Grey Power Incorporated) and campaigned against the surcharge over the next decade. Labour reduced the surcharge rate in 1986 then increased it slightly in 1988. They reviewed options for the state pension, but decided to retain the pay-as-you-go system. However notice was given that the age of eligibility would gradually rise to age to 65 . Tax subsidies on private retirement savings were also removed, leading to the closure of many superannuation schemes and making New Zealand the only OECD country to not have a savings tax (Hawke, 2005). Labour's changes at this time reflected their neoliberal driven "concerns about efficiency... (and)... a belief in the ability of market signals to guide investment" (St John, 1997, p284).

National, back in power from 1990, pledged to repeal the surcharge but then abandoned the idea, instead announcing in the 1991 Budget their plan to turn the pension into a welfare benefit. This was to be a tightly targeted, subsistence level safety net for the poor (St John, 1992). This proposal reflected their focus on self reliance. 
Significant lobbying by 'outraged superannuitants' saw the legislation repealed the following year and a return to National Superannuation, but with the surcharge increased, the income threshold lowered, and the age of entitlement to rise sooner and faster, from age 60 to 65 years between 1992 and 2001 (compared to 2001 to 2026 as proposed by Labour). The overall effect was a real decline in the value of the pension and a loss of security, with no certainty as to the future level of payment relative to wages or income thresholds. St John (1997) argues that this episode contributed to the dissatisfaction that ultimately led to reform of the electoral system and the introduction of proportional representation. The surcharge was eventually abolished in 1998 after much political debate and significant lobbying.

A referendum on a retirement savings scheme was held in 1997. The proposed scheme was intended to save the state money by partially privatising the state pension and it was argued the scheme would encourage individual responsibility and give more freedom from state interference. However most people would not have been better off until around 2039 and the proposal failed, with $91.8 \%$ of voters saying 'no' in the referendum. Rudd (1997) attributes the fact that radical changes to superannuation failed to eventuate to the political clout of the 'elderly electorate' and lobbying by Grey Power.

In 2001 the fifth Labour government established the New Zealand Superannuation Fund (NZSF), designed to partially pay for future costs of the old age pension, now called New Zealand Superannuation, which are anticipated to rise with population ageing. Contributions to the New Zealand Superannuation Fund were later suspended by the National government (elected in 2008) as the economic downturn deepened, but these are expected to recommence in 2016. 
The New Zealand Positive Ageing Strategy (PAS), launched in the same year, included a goal for 'secure and adequate income for older people' and a requirement for government departments to report on actions taken to progress goals (see Chapter Three for analysis of this strategy).

Labour also established the 2006 'KiwiSaver' retirement savings scheme. KiwiSaver is a work based scheme, with voluntary employee contributions matched by employer contributions and a one-off government contribution in the first year, plus tax credits to boost savings. The scheme aims to increase the rate of personal saving for retirement and has broad political support, although changes have been made since its introduction, including in 2008 when the National government reduced the minimum level of contribution and removed fee subsidies. 


\section{Discussion}

Though boomers were born into a 'golden age of welfare' that lasted till the mid 1970s, not all have shared equally in the benefits of a welfare state. As McLennan (2010) notes "even middle class boomers have faced difficult times. In their forties or fifties, they faced redundancies as industry was restructured and downsized. Their children are confronted with greatly increased education costs and a much more competitive job market" (p163-164). These factors suggest a diversity of circumstances from which boomers will be preparing for late life.

Boomers have experienced rapid social and technological change over their lifetime, with new opportunities for travel and communication, for education and (especially for women) employment. A wider range of lifestyles and identities have become available, offering greater choice and increased diversity, with resulting impact on boomers attitudes and beliefs and expectations. Just how growing up in a rapidly changing society has influenced boomers is a theme returned to in later chapters.

Expectations of the role of the state and the responsibilities of citizens have also shifted, alongside concerns about costs of welfare in the context of change in dependency ratios. Neoliberalist ideology has transformed previously Keynesian notions of collective responsibility. Neoliberalists advocated for change, arguing the welfare state emphasised the rights of citizens at the expense of their responsibilities. Higgins (1999) disputes this claim, noting that the 1938 Social Security Act was intended to balance a prior focus on individual responsibility with a commitment from the state, creating a social contract that involved 'deferred obligation'. Under this contract those receiving support from the welfare state are recognised as 'prior' or 'future' taxpayers who will pay the state and community back at some point, while those paying taxes can be confident that they in turn will receive support when they are no longer able to work. 
Brook Cowen (in Miller, 1997, p341) maintains that neoliberalism has affected 'the fabric of political and policy debate in New Zealand' influencing (boomers) ideas about what policy should look like and what the role of government, and citizens, should be. Rudd (2001) argues these ideas have permeated the attitudes of New Zealanders, influencing their expectations of the welfare state. Whereas once the welfare state was seen as desirable, it is now considered in terms of 'affordability' (2001, p425). Rudd claims that those who benefited from the reforms (notably middle income earners) see their ability to provide for themselves as the result of their individual responsibility and hard work, and feel little obligation to help those less well off than themselves, who are made to feel it is their own fault "...or at least it is up to them as individuals to redress the problems" (ibid, 2001, p425). It is unclear to what extent this view is shared within the boomer cohort.

Also influential are the major shifts in old age policy during boomers' working life. The history of instability in superannuation policy is likely to have influenced New Zealand boomers' expectations of state support. The message to older citizens from both Labour and National from 1984 and on through the 1990s, through a series of formal reviews, was that “...citizens should provide for their own retirement rather than expect automatic provision by the state. Frequent changes to eligibility criteria were combined with gloomy predictions about a future New Zealand burdened with an ageing population" (Rudd, 1997, p253). Concerns about demographic change prompted the development of positive ageing policy promoting citizen contribution and a shared responsibility for income security in old age, to enable 'less demand on social services' (Dalziel, 2001, p11). As will be outlined in the next chapter, policy aims to influence the 'problematic' boomer cohort and it is the underlying discourses of current policy on ageing to which we next turn our attention. 


\section{Chapter Conclusion}

Context and influencing factors through the boomers' life course has been discussed in this chapter. Demographic change and the social and economic and policy context will combine as influences on the boomer cohort's experiences and on their beliefs, attitudes and expectations. Rapid societal change has resulted in differing experiences for older and younger members of the boomer cohort. The earliest boomers were born into a prosperous post war economy, and a welfare state that privileged the family. These leading boomers grew up in the 1950s and 1960s, a time of urbanisation and Maori migration; of rapid growth in secondary and tertiary education; full employment and a developing New Zealand identity distinct from it's British colonial roots. Trailing younger boomers grew up in a very different New Zealand society in the 1970s and early 1980s; a time of increasing economic insecurity, market liberalisation, high unemployment and declining relative prosperity. All boomers have been influenced by the changing economic and technological conditions; increasing ethnic and social diversity and a renaissance of art and Maoritanga; a questioning of social institutions and major shifts in gender based roles; and the neoliberal turn in social policy.

The changes outlined above have occurred at the same time as New Zealand society is ageing. Population ageing has contributed to boomers being identified as a 'problem group' and a target group for policy. In the next chapter prevailing discourses about what it means to be a baby boomer growing older in an ageing society are considered. 


\section{Chapter Three: Discourses on Boomers and Ageing}

\section{Introduction}

An underlying assumption of the current study is that commonly held beliefs about ageing and older people, and about what it means to be a baby boomer in an ageing society, are inevitably linked. In this chapter, ideas about boomers and ageing in New Zealand are explored. Current policy discourses on ageing are described through a critical review of positive ageing policy. This sets the scene for a literature review of representations of the baby boom generation.

In part one of Chapter Three, the positive ageing discourse is explored. The development of the New Zealand Positive Ageing Strategy is described and comparisons are made with strategies developed in Australia and the United Kingdom to illustrate global influences on policy. Critiques of positive ageing are outlined and influences on key policy paradigms are discussed.

In part two, common discourses on baby boomers are considered. There is now a growing body of social science literature on the baby boomers internationally and a larger body of popular works. A brief overview of major themes in the international literature is provided, with New Zealand examples given where available. This overview is illustrative of the range of perspectives, but is limited by a lack of local data on boomers in New Zealand. The literature is more extensive in the United States, which as a consequence has tended to be applied to other countries (Phillipson et al, 2008). A smaller but growing number of more recent studies in the United Kingdom, Europe and Australia has added to the body of knowledge. 


\section{The Discourse of Positive Ageing}

\section{Positive Ageing Policy Development}

Current policy for older people in New Zealand promotes old age as a 'positive' and 'productive' life stage. The policy approach is set out in the New Zealand Positive Ageing Strategy (PAS) (Dalziel, 2001). The principles, goals and recommended key actions outlined in the Strategy are intended to act as a framework for government policies and programmes. PAS states that:

"it is important that government policies across a range of areas including employment, health, housing, and income support - allow and encourage older people, and future generations of older people, to experience ageing as a positive and productive phenomenon." (Dalziel, 2001, p11)

A key precursor to current policy was the setting up in 1996, of a Prime Ministerial Taskforce on Positive Ageing (PMTPA), by the National government of the day. Their brief was to consider "the likely future impact, based on current projections, of a decreasing ratio of people in our national labour force relative to an increasing number of older 'retired" people; and the actions and responses which can be made by Government, communities and individuals - and which are achievable" (emphasis in original, PMTPA, 1997a). The brief reveals a concern with the impact of population ageing on New Zealand society, a focus on age dependencies, and a desire to promote mutual responsibility. The taskforce took a life course approach to ageing. Older age was presented as part of a continuum rather than a distinct life stage, with ageing 'beginning at birth'. Three core values were identified: 'respect, responsibility, opportunity'. 'Responsibility' involved "playing our part and being accountable for our actions (and) developing our own independence as a basis for inter-dependent relationships within families, communities and society" (PMTPA, 1997b, p8). 
Following extensive public consultation, the taskforce published Facing the Future: A Strategic Plan (PMTPA,1997b) which outlined recommended actions for government and other sectors. The taskforce placed emphasis on challenging stereotypes; early treatment of reversible health conditions; improving the experience of growing older, and removing "the arbitrary barriers that society has put up between older and younger New Zealanders" (PMTPA 1997b p4). The report promoted a positive view of older people and the benefits of intergenerational activity. Recommended actions were broad ranging but lacked funding and the Report slipped quietly out of view soon after publication (Opie, 1999). The work of the Taskforce nevertheless marked a new policy focus on positive ageing and a life course approach.

The National Government's vision for older people at this time was outlined in their 1996 policy document From Welfare to Well-being. 'Well being', implied capability, self-reliance, coping families, and individuals making a positive contribution to their communities. Their vision for older people was: "that older people are encouraged and supported to remain self reliant, and that they continue to participate and contribute to the wellbeing of themselves, their families, and the wider New Zealand community" (DSW, 1996, p7). From Welfare to Well-being signalled National's welfare reforms, aiming to reduce dependency on the State, promote productivity, and shift responsibilities back to families and individuals (Davey, 2000). National's vision for older people reflected these goals. Briefing Papers prepared by the Senior Citizens Unit (SCU) in 1996 for the Minister for Senior Citizens outlined the benefits of promoting older persons' continued productivity. Demands on costly health services would be reduced by encouraging older people to remain fit and healthy for as long as possible through educational, recreational and leisure programmes, while continued participation in the paid workforce would "...not only maintain the self esteem of the individuals involved, but will also help to reduce financial dependence on the State and contribute to economic growth" (SCU, 1996, p1). 
The health of older people was a key focus of advocacy by community agencies at this time. In 1997 the Older People's Health Forum, comprising a wide range of organisations including Age Concern New Zealand, called for more support from government for older people, and better coordination and co-operation between primary and secondary health providers and community agencies (ACNZ, 1997). They sought a range of complementary strategies to promote the health of older adults and support for older people to remain in their own homes at long as possible (later to be referred to as 'ageing in place'). Health promotion advocates also focused on older people. The Alcohol and Public Health Research Unit (APHRU) called for more attention on health promotion, funding for cross-sector forums and training for health providers to counter ageist perspectives (APHRU, 1999).

International policy goals were also influential. The World Bank's 1994 report Averting the Old Age Crisis influenced policy agendas. Walker (2005) argues that the World Bank's impact is 'difficult to over-estimate' (p818). Along with the IMF and the WTO, the World Bank "amplified global fears concerning population ageing" (ibid, p818) and pushed for multi-pillar pension schemes with the state reduced to a minimal role. Similarly, in Maintaining Prosperity in an Ageing Society (OECD, 1998) the OECD delivered strong messages to member countries to discourage early retirement and increase the capacity of older people to remain economically productive. OECD used a 'demographic time bomb' discourse (Huber and Skidmore, 2003) to argue that governments could best prepare by aiming for surpluses and lowering debt. This was followed in 2000 by Reforms for an Ageing Society (OECD, 2000), which outlined policy responses and a series of working papers promoting 'productive' ageing (Davey and Glasgow, 2006). 
Other international influences included the World Health Organisation's promotion of active and healthy ageing as policy goals $(1999,2001)$ and the United Nations International Year of Older People (IYOP) in 1999. As the year approached, the New Zealand government announced a number of projects to commemorate IYOP. These included research on factors to enhance the independence of older people (Dwyer et al, 2000), which informed early development of positive ageing policy, and public health funding for a resource to prevent late life depression (ACNZ, 1999). The theme for IYOP ("Towards a society for all ages") was promoted by the Ministry of Social Policy's Senior Citizens Unit (later called the Office for Senior Citizens). This theme reappeared in the Positive Ageing Strategy, identified as a strategy to promote a 'society for all ages'.

A change of government at the end of 1999 saw Labour take over the development of policy for older people. Labour's 'social development' approach to social policy aimed to prevent social exclusion and promote participation (MSD, 2001b) and in 2001 they released the New Zealand Positive Ageing Strategy (Dalziel, 2001). The strategy “...seeks to address the risk of social exclusion among older people by identifying gaps in government policy that might contribute to this risk" (ibid, p9).

\section{Key Features of the Positive Ageing Strategy}

The New Zealand Positive Ageing Strategy (PAS) promotes "positive attitudes to ageing and expectations of continuing productivity (that will) challenge the notion of older age as a time of retirement and withdrawal from society" (p9). PAS emphasises the value and contribution of older people in society and "their capacity for productive work of all kinds" (Dalziel, 2001, p3). PAS argues "it is in everyone's interest that older people are encouraged and supported to remain self reliant" (ibid, p10). PAS aims to improve opportunities for people to participate so they can "contribute many more years to society" and as a result there will be "less demand on social services" (Dalziel, 2001, p11). 
An underlying objective of PAS is to influence the attitudes and behaviour of "future generations" (boomers and beyond) as they age, so they can "experience ageing as a positive and productive phenomenon" (Dalziel, p11). The Strategy looks to the future, anticipating that up-coming generations of older people (the baby boomers and successive cohorts) will be healthier, more skilled and educated, and more active in the workforce than previous generations. PAS argues that increased productivity will help to ensure the needs of current and future generations can be met. PAS encourages all New Zealanders to play their part in developing a 'society for all ages'; through ongoing participation. It promotes 'active' and 'productive' and 'healthy' ageing, encouraging individuals to maintain healthy lifestyles and "workers of all ages" to “...maintain and increase their skills and productivity as they grow older" (Dalziel, 2001, p10).

PAS argues against the disengagement theory of ageing (Cumming and Henry, 1961) and promotes a positive and preventive stance (Boston and Davey, 2006). No precise definition of positive ageing is provided in the Strategy, but it identifies an underpinning premise:

“...that the years of 'older age' should be both viewed and experienced positively. The focus is therefore not only on the experience of older individuals, but also on younger generations' attitudes, expectations, and actions regarding ageing and older people" (Dalziel, 2001, p9).

Determinants of positive ageing have been described by various authors, although a variety of overlapping and related terms are used, including successful ageing, productive ageing, and active ageing (see for example Baltes and Baltes, 1990; Bass et al, 1993; \& Bevan and Jeeawody, 1998). PAS describes 'positive ageing' as a multidimensional concept that includes factors relating to health, financial security, independence, selffulfilment, attitudes, personal safety and security, and the physical environment. 
PAS has been implemented through Positive Ageing Action Plans that list government agency work items to positive ageing goals. The Action Plan for 2008 to 2010 (the last published) indicates that forty one central government agencies and thirty six local government agencies report actions under goals of PAS (OSC, 2008).

PAS remains the overarching framework under the current National Government, in its second term at the time of writing. Notably, the 2012 Briefing to the Incoming Minister prepared by the Office for Senior Citizens and Ministry of Social Development advises that "an opportunity exists to review the current strategy on ageing and to align it more with active ageing, with its focus on maintaining the good health and participation of older New Zealanders" (OSC, 2012a, p3).

The Positive Ageing policy approach is not without its critics. In the next section the policy approach is critiqued. Comparisons are made with strategies for older people in Australia and the United Kingdom and prevailing policy paradigms are outlined.

\section{Critiques of the Positive Ageing Paradigm}

The strategy supports and promotes a positive / active / productive ageing 'policy paradigm' that reflects and reveals dominant discourses on ageing and social policy (Opie, 1999; Davey, 2002; Glasgow, 2005). This discourse aligns with the policy paradigm promoted by international organisations such as the OECD and the World Bank, who encourage member countries to increase the capacity of older people to remain economically productive. 
Deacon (2000) argues that globalisation has contributed to a discourse among global actors about pensions and retirement ages. Walker (2005) points out that it is not globalisation per se that is a threat to policy for older people. Rather "it is the nature of the economic globalisation that determines its impact" (Walker, 2005, p817). These authors argue present era is dominated by neo-liberalism which favours free markets, a liberalisation of trade and reduced welfare. Inequality is seen as inevitable and competition requires minimal taxes, flexibility of job markets and minimal welfare costs. As older people are the main beneficiary of welfare, pensions, health care and long term care have become top priorities for cost reduction.

The dominance of global policy ideas is apparent when comparing strategies on ageing in three OECD countries (Davey and Glasgow, 2006). A comparative analysis of New Zealand's PAS with those of Australia (the National Strategy for an Ageing Australia, Andrews, 2002) and the United Kingdom Opportunity Age - Meeting the challenges of ageing in the 21st Century, HM Government, 2005) shows a striking similarity of policy themes (see Table 3) (ibid). All three strategies adopt a positive ageing paradigm.

Opie (1999) has described positive ageing as a discourse "intended to reposition the largely unproductive aged body produced by capitalism in the earlier part of this century" (p83). She argues that technological advances and workforce role specialisation have provided greater opportunities to make use of older workers (see also Phillipson, 1998). There are benefits to the state from policies that look to older people as a 'resource'. But there is no recognition of the increased possibility of frailty or of declining strength and capacity in later years.

"What is absent is any reference to the unpredictability, contradictoriness and inconclusiveness of the ageing process... Dependency is written as a moral issue, as something that with sufficient forethought and planning can be held in control by the individual ageing subject" (Opie, 1999, p83). 
Table 1. Strategies for an Ageing Society - Underlying Themes and Values

Source: Davey and Glasgow, 2006.

\begin{tabular}{|c|c|c|c|}
\hline Themes & $\begin{array}{l}\text { New Zealand Positive Ageing } \\
\text { Strategy }\end{array}$ & $\begin{array}{l}\text { National Strategy for } \\
\text { an Ageing Australia }\end{array}$ & Opportunity Age (UK) \\
\hline $\begin{array}{l}\text { Fostering a } \\
\text { positive view of } \\
\text { ageing }\end{array}$ & $\begin{array}{l}\text { Positive attitudes to ageing and } \\
\text { expectations of continuing } \\
\text { productivity challenge the notion } \\
\text { of older age as a time of } \\
\text { retirement and withdrawal from } \\
\text { society. The focus is on lifetime } \\
\text { experiences contributing to well- } \\
\text { being in older age, and older age } \\
\text { as a time for ongoing } \\
\text { participation in society. (p.9) }\end{array}$ & $\begin{array}{l}\text { Together we can ensure } \\
\text { that the ageing of our } \\
\text { population is a positive } \\
\text { experience. (p.v). }\end{array}$ & $\begin{array}{l}\text { Ageing something to celebrate not } \\
\text { fear. } \\
\text { We must explode the myth that } \\
\text { ageing is a barrier to positive } \\
\text { contribution to the economy and } \\
\text { society, through work and through } \\
\text { active engagement in the community. } \\
\text { (p.v). }\end{array}$ \\
\hline $\begin{array}{l}\text { Promoting } \\
\text { attitudes which } \\
\text { respect and value } \\
\text { older people }\end{array}$ & $\begin{array}{l}\text { Older people are important } \\
\text { members of society and have } \\
\text { the right to be afforded dignity in } \\
\text { their senior years (p. 9). Goal } 8 \text { - } \\
\text { People of all ages have positive } \\
\text { attitudes to ageing and older } \\
\text { people }\end{array}$ & $\begin{array}{l}\text { Positive and informed } \\
\text { attitudes to and by older } \\
\text { Australians are } \\
\text { fundamental to an } \\
\text { ageing nation. }\end{array}$ & $\begin{array}{l}\text { Altering attitudes to later life is crucial } \\
\text { and root out discrimination in all its } \\
\text { forms. (p.32) }\end{array}$ \\
\hline $\begin{array}{l}\text { Recognising and } \\
\text { supporting older } \\
\text { people's } \\
\text { participation and } \\
\text { contribution }\end{array}$ & $\begin{array}{l}\text { Opportunities for older people to } \\
\text { participate in and contribute to } \\
\text { family, whanau and community. } \\
\text { (p.16) }\end{array}$ & $\begin{array}{l}\text { Policies that support } \\
\text { continued economic and } \\
\text { social contributions by } \\
\text { older people will be } \\
\text { essential }\end{array}$ & $\begin{array}{l}\text { We must explode the myth that } \\
\text { ageing is a barrier to positive } \\
\text { contribution to the economy and } \\
\text { society, through work and through } \\
\text { active engagement in the community. } \\
\text { (p.v) }\end{array}$ \\
\hline $\begin{array}{l}\text { Valuing self- } \\
\text { reliance, } \\
\text { independence, } \\
\text { individual } \\
\text { responsibility }\end{array}$ & $\begin{array}{l}\text { It is in everyone's interest that } \\
\text { older people are encouraged } \\
\text { and supported to remain self } \\
\text { reliant and that they continue to } \\
\text { participate and contribute to the } \\
\text { well-being of themselves, their } \\
\text { families and the wider NZ } \\
\text { community. } \\
\text { Principle - to enable older people } \\
\text { to take responsibility for their } \\
\text { personal growth and } \\
\text { development through changing } \\
\text { circumstances. (p17) }\end{array}$ & $\begin{array}{l}\text { Public programs should } \\
\text { supplement rather than } \\
\text { supplant the role of } \\
\text { individuals, their families } \\
\text { and communities (p2) } \\
\text { (Issues include) the } \\
\text { importance of healthy } \\
\text { ageing to enable a } \\
\text { greater number of older } \\
\text { people to remain healthy } \\
\text { and independent. (p.1) }\end{array}$ & $\begin{array}{l}\text { The primary responsibility for } \\
\text { keeping active and participating in } \\
\text { society lies with older people } \\
\text { themselves. (p.30). } \\
\text { We must balance the rights older } \\
\text { people can expect - security, an } \\
\text { adequate income and decent } \\
\text { housing - with a continuing and } \\
\text { growing contribution from then as } \\
\text { citizens and as elders of society (p.2) }\end{array}$ \\
\hline
\end{tabular}


The discourse of positive ageing has been accused of promoting a resistance to and denial of old age (Higgs, 1997). Others have criticised the underlying concepts. 'Active ageing' is criticised for promoting a 'busy ethic' (Katz, 1999); 'productive ageing' for its emphasis on paid work that minimises other contributions to society (Morrow-Howell et al, 2001); and 'healthy ageing' for perpetuating a biomedical view of old age (Estes et al, 2003). The concepts of self-reliance and independence within PAS are critiqued as Euro-centric, with little consideration of how these fit with concepts such as filial piety (Davey and Glasgow, 2006) and interdependence (Glasgow, 2005).

The discourse also presents as unproblematic the right of the state to intrude in the lives of individuals, with its goal setting approach and promotion of particular behaviours and attitudes. The approach has been accused of conferring a moral responsibility onto individuals (albeit a responsibility shared by the state) for the well-being of society and current and future generations (Opie, 1999; Glasgow, 2005). Boston and Davey (2006) further argue that PAS represents "the emergence of a new social contract between the generations, based on self reliance, mutual obligation, social responsibility and 'active' citizenship" (p371). 


\section{Older People as Consumer Citizens}

The publication in 2011 of the Ministry of Social Development report 'The Business of Ageing' (BOA) (MSD, 2011) marked a new emphasis in policy for older people in New Zealand, identifying ageing boomers as 'mature consumers'. The report takes a cohort approach, with boomers described as better educated, in better health, with different expectations than their parents and with more money to spend. BOA quantifies the contribution baby boomers will make as future older New Zealander's, through employment earnings, taxes and spending.

The stated intent of the BOA report is to provide "information on the potential economic contributions of older New Zealanders, to balance concerns about the economic costs of an ageing population" and "encourage discussion amongst business groups, employers, NGOs, individuals and government agencies" (p. 3). Players must 'work together' to implement Government's key priorities for older people which are "to encourage employment of mature workers" and "to change attitudes about ageing" (MSD, 2011, p.2). Reflecting a focus on 'choice', the authors of BOA acknowledge that not all baby boomers will want to remain in paid work, so "flexibility and changing attitudes will be key to harnessing the potential of those who do" (MSD, 2011, p2).

BOA reflects a discourse of 'consumer citizenship' (Baumann, 1998; Higgs, 1997; Jones et al, 2008), under which the state's role is to enable the citizen to achieve, while the citizen has a responsibility and duty to successfully do so. An underlying ideology is that a failure to be an "agentic consumer" means to be seen as a failure in society (Baumann, 1998). Jones e al argue that consumerism and the consequent view of citizen responsibilities has influenced successive governments (in the United Kingdom) to reduce their commitment to funding later life. 
"Rather than retirement being a government responsibility, it is now seen as belonging to the arena of the active citizen consumer and lifestyle manager" (Jones et al, 2008, p75).

Jones et al (2008) outline how 'citizen consumership' has been promoted globally alongside a narrowing of the client population seen as eligible for care or deserving of welfare. Previous notions of 'solidarity and universality' have been affected by increased emphasis on 'individual agency and responsibility' (2008, p116). According to Jones et al, the language of consumption and the market used in policies, reflects the "material conditions of expanding global commodity capitalism and its associated consumer culture" (2008, p114). Policies talk of clients, consumers and customers rather than patients, residents and citizens. An emphasis on choice and competition in welfare provision within the consumer citizenship discourse also draws on global neoliberal ideology that has emphasised a crisis in welfare and a questioning of the role of the state.

\section{Part One Discussion}

PAS has now been in place for more than ten years. A Progress Report in 2006 (OSC, 2006) concluded that PAS "has had considerable success in promoting the interests of older people" but they note a need to consider the characteristics of the next cohort of older New Zealanders. The authors updated emerging issues (first outlined in the baseline Positive Ageing Status Report of 2001), and included the following statements:

- "Experiences in mid-life (the 40-60 years age group) are an important influence in later life. The financial situation of the large baby boom cohort... requires monitoring and research, especially with respect to their labour-force participation levels, their intentions and choices regarding retirement, and their savings and accumulation patterns" (MSD, 2001a, p5). 
- "The baby boom generation will bring its own acquired attitudes, expectations and aspirations to later life... More needs to be known about the attitudes of the baby boom generation and those of other age groups so that these can be taken into account in policy development" (p19).

There is little direct reference to the baby boom cohort in PAS, other than as a 'future generation' of older people, however a key message for boomers within PAS is to take responsibility for preparing for their own productive ageing. The publication of the Ministry of Social Development report 'The Business of Ageing' (BOA) (MSD, 2011) strengthens the focus on the baby boomers, and highlights their impact on society as mature consumer citizens.

The analysis of policies reveals a dominant paradigm of ageing, with increased policy emphasis on older citizens' responsibilities, and the influence of International Global Organisations (IGOs) on national policy goals and values. The ideological hegemony of economic liberalisation promoted by IGOs has been criticised by commentators on older age policy such as Walker (2005). He does acknowledges as positive the human rights perspective of United Nations Organisations such as the World Health Organisation (WHO), and their "attempt to create a broad perspective on ageing" (p831) with 'Active Ageing: A Policy Framework' (WHO, 2002). He also supports regional approaches to policy development that recognise the interdependence of countries. For example, regional policy discussions had produced the 1999 Macao Plan of Action and the 2002 Madrid International Plan of Action of Ageing (MIPAA) (United Nations, 2002). Walker notes that such plans are and raise the profile of ageing and are important 'points of reference' which grass roots organisations can use to apply pressure on governments. He argues that governments do pay attention to these international plans, as evidenced by progress made implementing their recommendations. 
A quote in the introduction to the New Zealand BOA Report, reflects the tendency for policy makers to seek international endorsement for domestic policies (Miskin, 2004), and illustrates the ongoing influence of global ideas. The quote from the Director of the World Health Organisation's (WHO) Department of Ageing and Life Course, calls for "Governments around the world to invent a new future to tackle the needs and possibilities of population ageing" (emphasis added) (MSD, 2011, p.iii). Use of the quote confirms continued concerns about the effects of population ageing and a desire to harness the potential resources posed by a large proportion of older boomers. That potential depends however on how boomers will behave in late life, how they respond to policy messages, and how congruent their attitudes and values are with policy goals. 


\section{The Ageing Boomer Generation - Competing Discourses}

In Part One, key policy discourses on ageing were discussed. Baby boomers were identified as a future generation of older people whose behaviour and attitudes in late life will determine how well New Zealand can become a 'society for all ages'. Policy targets their positive and productive ageing.

In Part Two, ideas about the characteristics and behaviour of the boomer cohort are explored. Portrayals in the literature on boomers are considered, with common and competing discourses identified. As the intention is to explore representations of boomers, no attempt is made here to identify the validity or reliability of the various studies, nor are the effects of differing study types or participant characteristics explored. The following section builds on the work of Phillipson et al (2008) who analysed a range of social science articles, media publications and social and cultural histories relating to (older) boomers in a number of countries. Additional material, including from New Zealand studies has been added in the analysis below. The chapter concludes with a summary of portrayals and identifies some key areas requiring further research.

\section{Ageing boomers - crisis or opportunity}

Several competing representations of the boomer generation have been apparent in the international literature, reflecting and contributing to beliefs about boomers and the impact they will have as a large cohort growing older (Biggs, Phillipson, Leach and Money, 2006; Phillipson et al, 2008).

In the first representation, the ageing of the boomers is seen as a crisis or catastrophe for which governments and society are woefully unprepared (Dychtwald, 1999; OECD, 1996). There is a focus on the "difficulties the boomer generation is likely to bring to the economy and the health care 
system" (Phillipson et al, 2008: paragraph 4.8), with a more recent moral dimension added to the economic debate of the 1980s (ibid: paragraph 4.9). Underlying assumptions are that boomers' later years will be spent in a leisure filled, unproductive retirement, with the boomer generation portrayed as users of scarce resources and creators of conflict with other generations (Phillipson et al, 2008; Goldsmith, 2008). Financial, social and moral crises will result unless boomers are encouraged to change their behaviour, work longer, save harder, stay healthy, and contribute to and participate in society (Dalziel, 2001).

Resulting anxieties about the boomer generation focus on affordability of their consumer lifestyles and their potential to mobilise as a social and political force (Estes et al, 2003; Martin, 2005). Negative beliefs about boomers are associated with this view, with boomers presented as a selfish and greedy generation, who have benefited from educational and welfare systems, spent up large, contributed to rising debt, environmental woes and social and moral decline (Phillipson et al, 2008).

In the second scenario, the large and well educated boomer cohort is presented as a 'resource' (MSD, 2011) and their ageing as an opportunity for transformation of outdated assumptions about late life (Freedman, 2002). Related beliefs are more positive and include that boomers are pioneers of new lifestyles, who are challenging traditional life course boundaries (Phillipson, 1998) and who represent new thinking about 'age as opportunity' (Biggs and Powell, 2001). As an educated and altruistic cohort (Achenbaum, 2005) and as experienced activists who have campaigned for change (Steinhorn, 2006) they will fight for a more tolerant and responsible society. As a distinctive and financially comfortable group of consumers (Metz and Underwood, 2005), too large and too affluent a group to be ignored (Thornhill, 2005), they will bring a more positive view of older people as financially independent elders (Evandrou and Falkingham, 2006). 
These common portrayals of boomers have been challenged. Goldsmith (2008) has little time for the 'catastrophians' who he says promote a pessimistic scenario of generational conflict and economic and social decay. These views he says are based on assumptions of lengthy periods of unproductive retirement. Instead, improved health, work environments that encourage late life work, and (American) boomers own desire to keep working create the potential for a more prosperous future.

Assumptions about boomers' affluence and spending power have been critiqued (Butrica and Uccello, 2004; Hughes and Rand, 2004; Quine, Bernard and Kendig, 2006). In the United States, studies indicate that while some boomers are doing well, others are struggling financially (Adler, 2006). Although American boomers have achieved a higher standard of living than their parents, there has been greater inequality in earnings (Hughes and Rand, 2004). Hamilton (2006) argues that the supposed wealth of Australian boomers is reserved for a small portion the majority will instead struggle to fund their own retirement. In New Zealand, intra-cohort diversity in economic circumstances is also a feature of boomers as they approach older age (Pool and Hillcoat-Nalletamby et al 1999; Callister, 2006).

A portrayal of boomers as a 'lucky generation' that has benefited from post World War prosperity and welfare has also been critiqued. In New Zealand, Thomson (1991) argues that it is boomers' parents who are the lucky generation, receiving more from the state than they contributed over their lifetime. Boomers, he predicts, might just 'break even'. In Australia, Hamilton (2006) argues that although Australian boomers are commonly envied for their experience of free education and luck with booming house prices, they were not so lucky economically in their adult years, nor are they confidant about retirement. 


\section{A distinctive Generation?}

Boomers are often portrayed as a distinctive generation, different from their parents. International predictions are that boomers will behave in very different ways to current generations of older people (Huber and Skidmore, 2003; Harkin and Huber 2004; HSBC, 2005; Quine and Carter, 2006; Quine, Bernard, and Kendig 2006).

Australian researchers note differences in financial attitudes between the generations (Quine, Bernard and Kendig, 2006). The Australian Office for Senior Citizens (OSI, 1997) has argued that those in their formative years (older childhood and early adulthood) in the 1920s, 30s and 40s, experienced the hard and frightening years of the Great Depression and the Second World War. Consequently their perception of life was coloured by a deep need to 'save for a rainy day'. They survived by playing it safe. In contrast those growing up fifteen years later "...grew up with frugality followed by economic prosperity and the rebuilding programme that followed the Second World War. They spend, but they also harbour a great need to save." (p12) Those born later still, are better educated and 'born consumers', with a more relaxed attitude to debt and the use of credit cards.

Zeitz (2005) claims there is more continuity than differences between boomers and preceding generations. Nevertheless she identifies a defining characteristic of boomers as their lifelong quest for fulfilment and satisfaction, which has 'inevitably fallen short'. Zeitz (2005) describes boomers as the most intensely studied, the most widely celebrated and the most roundly condemned of all American generations. 
Gabrinski (1988) argues boomers have been portrayed as a cultural and spiritual focal point for society (see also Strauss and Howe, 1991; Howe and Strauss, 1997), with more temporary labels than any other generation - just add the word "generation" to "Pepsi", "rock" "Woodstock", "sixties", "Vietnam" "love", and many other terms. Gabrinski calls American boomers 'the most watched generation ever', who have grown up not just with TV but on TV (Grabrinski, 1998). One consequence, according to Gabrinski, is that boomers see themselves as the embodiment of moral wisdom.

Boomers are also said to be more liberal in their outlook than other generations (Huber and Skidmore, 2003; Harkin and Huber 2004) and more demanding of the state. Boomers in British focus groups, for example, strongly defended the principles of welfare and free healthcare and wanted certainty concerning existing social entitlements (Harkin and Huber 2004). These boomers were also described as cynical. There was a feeling of having been let down by institutions they once could trust and participants felt disillusioned.

Commonly boomers are characterised as individualistic. British boomers are described as more individualistic in their approach to decision making than previous generations (Huber and Skidmore, 2003). American boomers are said to operate more on individual, parallel pathways than from a collective stance (Grabinski, 1998).

New Zealand boomers are described as 'fiercely independent in their individuality' (Buckland, 2009). Martin (2005) identifies individualism and liberalism as two distinctive generational characteristics shaping New Zealand boomers responses:

"Their individualism rests on a number of bases; their orientation away from formal authority; being more anti-establishment, more nonconformist, less deferential, less trusting of those in authority, more hostile to organised religion. The liberalism of this cohort is centred on personal lifestyle choices and the extent to which these should remain 
personal. It is a progressive liberalism that has been shaped by social movements such as anti-racism, 'women's liberation', and the green movement." (Martin, 2005, p176)

Boomers have different expectations about work and retirement compared to previous generations (Phillipson and Smith, 2005). As 'pioneers of mass consumption' (Evandrou, 1997; Harkin and Huber, 2004; Phillipson et al, 2008) boomers are viewed as having a new consumer based identity that is separate from work (Gilleard and Higgs, 2005; Huber and Skidmore, 2003; Metz and Underwood, 2005). British boomers for example, are seen as 'savvy consumers' who are 'more non-conformist', valuing choice, freedom and autonomy. 'Freedom' is a common value associated with the boomers, who are said to expect freedom of choice to work and retire, and freedom of lifestyle (Harkin and Huber 2004).

Harkin and Huber (2004) suggest that younger boomers more widely reflect the attitudes generally associated with the boomer generation. Younger boomers in British focus groups displayed a stronger desire to be different; and were interested in new forms of work and more flexible and creative, individualised ways of living. These boomers expect to grow old in a different way to their parents. They were determined not to be forced to retire, but were also suspicious of government plans that may coerce them to work. They did not want to be dictated to and had a strong belief in doing things for themselves.

The New Zealand boomer cohort differs from their parents' in a number of ways with significant differences in family circumstances (Pool et al, 2007) and in patterns of work, level of education, degree of geographic mobility, and lifestyle behaviours including the level and range of economic and recreational activity (Statistics NZ, 1995; Glasgow, 2005). But significant intra-cohort variation is also apparent, between leading and trailing boomers, male and female boomers and between ethnic sub-groups. 


\section{A homogenous group or a diverse cohort}

While common representations portray boomers as a homogenous group, academic studies have emphasised intra-cohort diversity. The boomer cohort is commonly divided into sub-groups by age, as 'early' or 'late' boomers or 'leading edge' or 'trailing edge', or 'first wave' and 'second wave' boomers, in acknowledgment of the differing age position these sub-cohorts have in relation to historical events.

In New Zealand, leading and trailing boomers have had quite different socio-historical experiences. Leading boomers had similar patterns to their parents in terms of marriage and family formation. They benefited more from family friendly social and educational policies in the post war years and received greater assistance from government housing policies than trailing boomers (Statistics NZ, 1995; Glasgow, 2005).

In Australia, attitudes to the state vary between socio-economic boomer sub-cohorts. Lower socio-economic boomers were more likely to hold the government responsible for ensuring adequate income and were less likely to have planned for their older age (Quine, Bernard and Kendig, 2006). Boomers in Australia have become subject to new expectations for self provision without having had the years to take opportunities to do so. They feel hard done by as compulsory superannuation was introduced late in their working lives.

There is also intra-cohort variation between high and low income groups in the way boomers picture retirement, the timing of it, and how they intend to fund it. Hamilton and Hamilton (2006) argue the depiction of Australian boomers as never wanting to retire is simplistic and based on the expectations of wealthier boomers. Quine, Bernard and Kendig (2006) found significant socio-economic differences in Australian boomers' plans to scale down work prior to retirement. 
Lower income boomers in Australia are more disadvantaged, compared to other generations and other boomers. They commonly feel they have to work and have few funds. They would like to have choices, would retire early if they could and are worried about funding their retirement. Higher income boomers see retirement as a change of career, an opportunity to shift down a gear and explore interests and hobbies. They are more concerned about loss of status than financial security. (Hamilton and Hamilton, 2006.)

Lower socio-economic boomers were less likely to have planned for their older age and were more likely to hold the government responsible for ensuring adequate income. They were more likely to report working full time, though not by choice, and were less likely to report enjoying work. Those in lower income groups had more difficulty remaining in work and anticipated more difficulty funding their own retirement. (Quine and Bernard 2006.)

American boomers have been divided into five distinct groups according to differences in attitudes toward continued work and concerns about their future (Roper 2004). In an online survey for the American Association of Retired Persons (AARP) boomers were asked about their current satisfaction with their lives, their near-term goals, their anticipated problems and barriers to achieving their goals, and their outlook on planning for the future. Based on results, they divided boomers into: The Strugglers (15\%); The Anxious (23\%); The Enthusiasts (13\%); The SelfReliants (30\%) and Today's Traditionalists (25\%). Differences in life circumstances and attitudes between younger and older boomers, and between different racial and ethnic groups have also been identified (Keegan and Gross, 2004; Hudson, 2008). 


\section{Predictions - Selfish or Civic Minded}

Gabrinski (1998) argues that boomers were indulged by parents and communities who had great expectations for them. They became selfabsorbed and self-indulgent adults, with a 'pick and choose' idealism, and an apparent lack of interest in building community life. Gabrinski notes however, that in midlife boomers appear to be growing up, with a new sense of responsibility, greater self-denial and a new seriousness (Grabinski, 1998, pp.77-78).

Despite claims of increasing narcicissm and individualism, international studies reveal a persisting and common sense of duty towards family, and an acceptance of responsibility by those in the boomer age group for younger family members (Ogg and Renault, 2006; HSBC, 2007). There is variation between countries as to the degree of responsibility the boomer age group places on the government, family, employer and self for financial security in old age, but all were considered important. In the mature economies, the younger pre-retirement age groups believed that government should provide the majority of financial support for them in old age, but most did not believe their government would do so. The majority of participants did not support increased taxes or lower pensions as a means of financing and supporting the ageing population, but did support compulsory savings and were willing to work longer (HSBC, 2008).

In the United States almost one fifth of participants in AARP's study expect to provide financially for ageing parents $(18 \%)$ or children $(17 \%)$ during retirement, but they reject the idea of having to themselves rely on family for financial support (only $10 \%$ thought they ought to). However they do expect family to provide emotional support ( $70 \%$ believe they should) (AARP, 2004). 
Harkin and Huber (2004) predict that boomers in Britain may reassess the kind of care they expect from their family and may prefer or even demand care from public, private or not for profit sector services. They found British boomers strongly defend the principles of welfare and free healthcare and want certainty concerning existing social entitlements. There was a feeling of having been let down by institutions they once could trust and their study participants felt disillusioned and cynical.

There is debate as to the likelihood that boomers will form a self-interested voting bloc and whether age can be a catalyst for political movement (see Phillipson, 1982 on the possibility of achieving unity amongst older people and Martin, 2005 for a discussion of pre-requisites for a boomer based social movement). Boomers are characterised as experienced activists (Estes et al, 2003), but Phillipson et al (2008) emphasise that politics will be affected by cultural and social differences within the cohort. New Zealand boomers are said to be self determined with a youthful hedonism, but balanced by a sense of responsibility (Buckland, 2009). In a study comparing kiwi boomers with those in the United States, Buckland concludes that New Zealand boomers are less likely to break the rules, but are more likely to assume that rules don't apply to them.

International research reveals changing expectations and visions of later life in a range of countries (Phillipson and Smith, 2005; HSBC, 2005, $2006,2007 a \& b, 2008)$. Increasingly later life is seen as a time of opportunity and activity, and traditional definitions of old age as a time for rest and relaxation are considered outdated (HSBC, 2007a). A mandatory retirement age is commonly rejected and people want periods of work, education and leisure in their retirement (HSBC, 2005).

Huber and Skidmore (2003) argue that British boomers' distinct history and diverse characteristics will bring change to existing cycles of learning, caring, work and leisure in older age and they speculate on possible implications for family and intergenerational relationships. 
American boomers continue to view older age as an opportunity for leisure, hobbies and time with family, but most expect to work in retirement (around 80\%) (AARP, 2004). More expect to work for needed income while fewer now plan to work for enjoyment. Around half expect to devote more time to community service and volunteering.

Hamilton and Hamilton (2006) argue that Australian boomers are at the heart of a transition in expectations and understandings of retirement and norms as to fair and acceptable methods of funding. The boundaries of retirement are now blurred. It is no longer a distinct phase and many boomers favour ongoing work.

New Zealand boomers also want a different and later retirement experience than their parents (Buckland, 2009). Part time work is increasingly being used as a transition to retirement and factors influencing retirement decisions are changing (Davey, 2008; Keeling, Davey \& Glasgow, 2009; Waldegrave and Koopman-Boyden, 2010). There is increasing workforce participation at older ages compared to equivalent ages for earlier cohorts, but also considerable intra-cohort diversity (Callister, 2006).

\section{Optimistic about Ageing or in Denial?}

Harkin and Huber (2004) found that while British boomers were positive about early old age, they were anxious about becoming 'old old'. They were fearful of physical and mental degeneration and of becoming too frail to do what they want or to live independently. These boomers were reluctant to engage with being older, finding it difficult to imagine themselves as very old. Harkin and Huber conclude that boomers appear idealistic when considering their own ageing. 
In HSBC's international research, attitudes to ageing vary considerably by country, however surveys reveal a positive view of later years is common to many. The HSBC research reveals a shift in modern retirement lifestyles and patterns within and across the participating countries (New Zealand is not a participant). HSBC's study is too general to allow detailed age group comparisons, but some broad age differences were noted, for example people aged in their sixties in mature economies felt they had more control and a higher quality of life than those in their forties and fifties (HSBC 2007).

Gilleard and Higgs (2005) identify a youth culture established in the postwar period as being influential on British boomers' attitudes, creating a dilemma for them in later life, with an aversion to growing old that has resulted in denial or active resistance of ageing. In Australia, Hamilton (2006) is concerned that some boomers are in denial, with unrealistic expectations about their opportunity to find work or self employment. Only $12 \%$ think they will be fully reliant on the age pension, lower than Treasury projections. Two studies by the American Association for Retired Persons (AARP, 1998; 2004) reveal that while American boomers remain optimistic about their prospects for retirement, their expectations have become more conservative over time. Fewer now view retirement as a time to indulge themselves (48\% in 2004 , compared to $55 \%$ in 1998 ) or equate retirement with having enough money and financial security $(31 \%$ compared to $41 \%$ in 1998).

In New Zealand, boomers are optimistic about their future years (Buckland, 2009). Most participants in Buckland's study (79\%) disagreed that their best years were behind them and did not see themselves as facing limits due to age (70\%). A majority (73\%) agreed with the statement that they had no intention of having a quiet retirement and $89 \%$ agreed that there is no reason for them to feel any less vital or energetic as they get older. Most (92\%) agreed with the statement that "life is a set of endless opportunities no matter what your age". 


\section{Part Two Discussion}

Key ideas about boomers were identified by Phillipson et al (2008) in a review of literature published between 2002 and 2006 and the New Zealand examples described in this chapter support their findings.

First, boomers are viewed from a demographic perspective, as a large cohort that has transformed family structures and contributed to population ageing (see NZ Treasury, 2004, Pool et al, 2007 and MSD, 2001 (a) for key examples in New Zealand). Second, interest has centred on boomers as consumers, emphasising their distinctive post war experiences (see Gilleard and Higgs, 2005; Edmunds and Turner, 2002, and in New Zealand MSD, 2011). As consumers boomers are contributing to social change, transforming cultural fashions and mores, lifestyles and the nature of the modern life course. Thirdly, a 'politicisation' argument has emphasised boomers as a cohort with the numbers to potentially be a powerful lobby group. From this perspective boomers tend to be portrayed as more radical and challenging in their attitudes than preceding generations (see Huber and Skidmore, 2003; and for discussion of this issue in New Zealand, see Martin, 2005; and Buckland, 2009).

Phillipson et al (2008) identify gaps in the international scholarly literature, including systematic studies of social and family relationships affecting boomers (but see Pool et al, 2007 for a New Zealand exception), and studies of boomers' lifestyle expectations. Also identified is a need to explore inter-country differences. Comparisons between countries can be problematic due to differing definitions, variety in demographic peaks and troughs within each boom, and differences in socio-economic and policy environments. Further research is needed exploring the context within which boomers are making decisions about their future lifestyles, and the factors influencing disparities and differences between the generations, and between subgroups of boomers. 
Public debate is 'often hostile' to the boomer generation who have been described as selfish and self-indulgent. Phillipson et al (2008) caution against reductionism and over generalisation and suggest that continuities across generations and diversity of responses within the boomer cohort require additional attention. They call for 'vigilance' to avoid perpetuating excessive generalisations about the boomer generation.

Huber and Skidmore (2003) conclude that boomers in old age will likely fall into one of three groups:

- A selfish generation - a generation of individualists, pioneers of the consumer society, uniting around their own fulfilment and their wealth, with little regard for the less well-off or future generations.

- As civic defenders - a generation of liberal activists against the erosion of the public realm, creating the conditions for radical and progressive politics.

- As invisible elders - a fragmented generation, failing to coalesce, with little or no influence, splintering into sub groups absorbed into other currents of social change.

In New Zealand, Martin (2005) supports the above categorisation, but also predicts that consumerism will form the basis of boomers political activity and expectations of the state. He concludes that their understanding of the good life will be framed in consumerist terms, with expectations of choice, customisation and quality. 


\section{Chapter Conclusion}

In this chapter ideas about current and future generations of older people have been described. The positive ageing approach identifies older people as a potential resource and their behaviour as a legitimate target for policy. Boomers are considered as 'future generations of older people' and as 'consumer citizens'. Policy treats boomers as a problem group, one "to be managed by strategies including extending working life, voluntary work, or performing additional caring roles within the family" (Phillipson et al, 2008, para 1.2).

Policy on ageing reflects underlying discourses on the role of older people in society and shifts in political ideology, with increasing emphasis on the social responsibilities of citizens, epitomised in National's 'From Welfare to Wellbeing' slogan (Davey, 2000) and Labour's 'social development' approach to welfare (Glasgow, 2005). As a future generation of older people, boomers are encouraged to accept responsibility for their own active and productive old age, in order to reduce demands on the state and on younger generations.

There remains a tendency to stereotype boomers as a homogenous group who are better educated, in better health, with different expectations than their parents and with more money to spend. Boomers are commonly defined as a distinct generation about whom predictions can be made about their future behaviour. To better understand how alike or diverse boomers are, and how boomers differ from previous generations, more cross-generational and cohort specific data is needed. Otherwise predictions may be based on false assumptions, not only about boomers but also about current generations of older people.

In the following chapter, theoretical influences on discourses are considered, as our attention turns to the methodology guiding this study. 


\section{Chapter 4: Methodology}

\section{Introduction}

In Chapter One the rationale for the research and the specific aims and objectives of the study were outlined. Chapter Two outlined the context and Chapter Three explored policy and literature to identify discourses on boomers. We turn now to a description of the theoretical framework of the research and the way in which the study has been conducted. In this chapter there is a description of the theoretical perspectives that have informed the study and the underlying key concepts. The methods used to collect and analyse data are described and the strengths and limitations of the research methods are discussed.

The design of any study needs to keep the aims and objectives of the research in mind. The underlying purpose of this research is to inform policy to assist in meeting the needs of boomers and their families as they grow older. To achieve this, the study examines the nature of baby boomer identity and the context within which it has developed; explores boomers' expectations; and considers how policy can both influence, and be influenced by, the baby boomer cohort. The research explores prevailing discourses about the ageing baby boomer cohort, including those expressed within policy and by boomers themselves and considers the relationship between discourse and cohort values and expectations. The study has multiple layers, with analysis of policy and cohort identity and consideration of past, present and future contexts. From the broadest perspective, the research considers meaning making and social change in contemporary society and explores the multi-directional relationship between policy, culture and identity. 


\section{Theoretical Perspectives}

Given the multi-layered nature of the study as outlined above, a pluralist approach to methodology has been taken. This pluralist approach is one influenced by post-structuralism and postmodernism, world views and bodies of theory that emphasise the inevitable plurality and instability of meaning in contemporary society.

Post-structuralism emphasises that social structures and cultural codes are diverse and fragmentary (Scott, 2006). Post-structuralism is an approach to social science that developed in a number of intellectual fields, and is particularly evident in the works of Jaques Derrida, Jaques Lacan and Michel Foucault. These writers assert that "there is no reality independent of the textual and cultural constructions through which we come to know it" (Scott, 2006, p203). The task of the researcher is to deconstruct texts and modes of discourse "in order to uncover the contradictions and absences that structure them as cultural products" (ibid p203). Post-structuralists reject the idea that absolute truths about the world can be discovered and argue instead that multiple interpretations of reality are inevitable (Giddens, 2009, p1128). This approach acknowledges that meanings, for example of ageing, will inevitably differ, across time, by status and according to situation. Meanings between generations and between citizens and the state will also vary.

Post-structuralism is often equated with postmodernism, the cultural manifestation of the period of social and economic change that followed the Second World War. Postmodernism is regarded as a consequence of late capitalism and the transition from Fordism to post-Fordism, characterised by the extension of industrialisation to all sectors of society through the infusion of new technologies, and the growing importance of intellectual workers such as scientists and technicians. Post-modern society is highly pluralistic and diverse and, Giddens argues, is no longer governed by progress (Giddens, 2009). 
Crotty (1998) describes modernism (a world view characterised by scientific rationalism) and postmodernism as on a continuum, rather than as being distinct from each other. The direction of change he argues is from clarity to ambiguity and from certainty to the tentative, the provisional, and the contingent. Crotty (1998) argues that a key difference between postmodernism and modernism is that postmodernist perspectives do not uphold any vision of salvation. Postmodernists reject the idea of 'Grand Narratives' (Macey, 2000, p309) and the idea of single explanations or philosophies (Giddens, 2009). French philosopher and theorist Michel Foucault, for example, holds this position. He questioned the credibility of rationality and progress and the idea of an autonomous subject able to free themselves from the domination of others. Foucault was influenced by the philosopher Nietzche, who viewed society as proceeding from one form of domination to another (Scott, 2007). For Foucault changing techniques of power operate through discipline, surveillance and discourse. Discourses and power strategies are enmeshed as power/knowledge complexes that are connected to wider social and political practices (Scott, 2006).

Not all theorists agree. Social and political theorist Jurgen Habermas was critical of the extreme relativism of postmodernism and the poststructuralist view that there is no universal knowledge, truth or moral standards. Habermas also criticised post-structuralist theorists for failing to recognise the emancipatory potential of the Enlightenment tradition, which Habermas said should be not abandoned but rediscovered (Crotty, 1998).

My own theoretical position falls between those of Habermas and Foucault. Like Habermas, I retain an optimistic desire for emancipation through discovery. But I reject Habermas's underlying universalism and do not assume a single pathway to redemption, nor a single desired final outcome. Like Foucault I view knowledge and power as inextricably linked, but I reject his discursive reductionism, where discourse is posited as a causal force upon everything else. This makes my approach pluralistic and thoroughly post-modern. 
Boomers are ageing within, and contribute to this post-modern society and as such this context requires acknowledgment and consideration. As a researcher, and a baby boomer myself, my own standpoint also influences the way this research has been designed and undertaken. Qualitative research methods that encourage reflection by the researcher on the politics of their work are especially appropriate (Lindlof and Taylor, 2002). The approach taken acknowledges that post-modern research has a focus on local manifestations rather than broad generalisations and, because meanings are unstable in a rapidly changing society, requires the situating of social problems in their historical and social context. With this in mind, the theoretical perspectives and methods of the research are now considered.

\section{Social Constructionism}

The research approach is positioned within a constructionist epistemology. Constructionists view social reality as the creation of the interaction of individuals and groups (Giddens 2009, p1132). The task of social research is to explore the processes by which members of society come to know and simultaneously create what is 'real' to them.

My approach emphasises the social dimension of constructionism - that is with a focus on the collective (rather than individual) generation of meaning (Crotty, 1998). This perspective acknowledges that meanings differ between cultures and also between groups of people within a given culture. It also acknowledges that common-sense beliefs and interpretations are influenced by broader social forces, such as capitalism, patriarchy and globalisation.

This study considers ageing and old age as constructions, and explores the nature of that constructed meaning within policy and as articulated by boomers themselves. The focus is on how these constructions influence expectations, behavioural norms and experiences in late life. 
While placing emphasis on the constructed and shared meanings of ageing, my perspective is one of critical realism. My approach is critical, as emphasis is placed on the way that "...particular sets of meanings, because they have come into being in and out of the give-and-take of social existence, exist to serve hegemonic interests" (Crotty, 1998, p59) (see below for a discussion of this critical perspective). My approach is realist as ageing is acknowledged as a biological as well as a social and cultural phenomenon. As argued by Crotty, it is no contradiction to say that something is constructed and also real (1998, p63). The nature of a construction may change but the phenomenon being constructed is real nonetheless.

Critical realism "holds that an objective external world of causal mechanisms can be grasped conceptually through scientific investigation, but that models produced by science can never be seen as direct reflections of that reality" (Scott, 2006, p198). Reality is viewed as a "complexly stratified, open system which, while real - that is it exists independent of our knowledge of it - can only be known to us through the ever-distorting lenses of culture, history and practice" (Carolan, 2005, p10).

Critical realists view social structures as key causal mechanisms, but the causal potential of nature is not written out entirely (Carolan, 2005). Causal tendencies are considered multidirectional and emphasis is placed on open systems of reciprocally interactive entities. Biological reductionism is rejected, but ecological and biophysical phenomena are considered as part of our social world.

This approach allows for the acknowledgment of the biological reality of human ageing while recognising that the meanings are themselves socially constructed. As argued by Turner (1992) "it is possible to integrate the view that the body exists independently of the forms of discourse which represent it, while accepting the idea that the body is socially constructed by discursive practices" (1992, p49). Turner views the ageing 
body from this perspective - as simultaneously both discursive and animated, both socially constructed and objective. This is not a position shared by Foucault, whose analysis of the human body as the product of discourse has been criticised for failing to consider the biological body (Turner, 2003). While the material nature of the body was not ignored by Foucault, he does not consider the body itself as a causal force to regimes of power/knowledge.

Turner recognises that age is socially constructed as a status position and is interested in the ageing body as a representation of power. He notes, for example, that the way in which ageing human bodies are represented has changed, with a new emphasis on activity, fitness and preventative medical care. He argues that the ageing of populations has brought chronicity to the forefront of medical problems, giving a special urgency to fitness (1992, p165). In this way Turner's work provides a useful perspective for considering the relationship between policy and ageing boomers' identity.

\section{A Critical Perspective}

The research takes a critical perspective, one that is informed by critical theory. Critical theory here refers to a range of theories that take a critical view of society and seek to explain the knowledge production therein (Macey, 2000). The approach draws upon the work of the Frankfurt School and the writings of Adorno and Horkheimer and, more recently, Habermas (Jamieson et al, 1997). Habermas (1973) viewed critical theorists as guided by an interest in the future and the realisation of a rational society. The starting-points of critical theory are Marx's theory of ideology as illusion and Freud's concept of individual delusion (Macey, 2000). 
The critical approach is emancipatory and aims to critique what is normally taken for granted and to dispel the illusions of ideology, in order to explain why social agents "accept or consent to systems of collective representation that do not serve their objective interests but legitimate the existing power structure..." (Macey, 2000, p75). As Macey argues, critical theory seeks to give agents a self-critical awareness and to supply the knowledge to demonstrate that a transition to a 'freer and more fulfilling' society is objectively or theoretically possible, and that it ought to be transformed. "It does not, however, predict the inevitability of that transformation (but) merely points to what ought to be done rather than to what will happen ( $\mathrm{p75}$, emphasis in original).

A key feature of critical perspectives is a commitment to reveal and critique dominant power relations. Critical inquiry by researchers aims to keep the spotlight on power relationships within society and is "at all times alive to the contribution that false consciousness makes to oppression and manipulation" (Crotty, 1998, p157). In my research, power relations are considered through analysis of prevailing policy paradigms and discourses concerning the ageing baby boomer cohort.

An additional focus of critical perspectives is to identify and support ways to bring about change in the cause of social justice (Crotty, 1998). A key goal of this research is to inform policy to assist in meeting the needs of boomers and their families as they grow older. An underlying assumption is that greater understanding of the perspectives, expectations and patterns of behaviour of the ageing boomer cohort will enhance effective policy in an ageing society.

In applying a critical perspective to this research a number of underlying assumptions are present. As outlined by Kincheloe and McLaren (1994) these are:

- that all thought is mediated by power relations that are social in nature and are historically constituted;

- that facts can not be isolated from the domain of values or ideology; 
- that relationships are mediated by the social relations of capitalist production and consumption;

- that language is central to both conscious and unconscious awareness;

- that certain groups are privileged over others and that oppression is most forceful when social status is accepted as natural, necessary or inevitable;

- that oppression has many interconnected forms;

- and that research practices are themselves, often unwittingly, implicated in the reproduction of systems of oppression.

Critical inquirers recognise that culture is not a realm apart from everyday society but mirrors its contradictions and oppressions. Critical inquirers seek to detect these and call them into question (Crotty, 1998).

\section{Critical Policy Analysis}

A critical approach to social policy requires analysis of influences on policy processes, and consideration of how the policy agenda shifts in response to dominant ideology and societal changes. Analysis needs to take into account the historical, ideological and institutional context as well as the role of 'experts', professionals, policy agents, and those with control over knowledge production. Applying a critical gaze (Achenbaum, 1997) to policies can enable those that reinforce inequities, under the influence of prevailing ideology or unquestioned assumptions, to be called into question.

Grace (1990) advocates for a policy scholarship approach that goes beyond a simple emphasis on the logistics of policy implementation. What is needed is consideration of the underlying values of policy, the role of interest groups, and the political, ideological, social and economic context in which policy is developed. This approach recognises that policy advice 
is not value free. The policy analyst (and researcher) needs to be aware of their own underlying "political and ideological biases and the preconceptions, assumptions and sheer wishful thinking which will influence (their) view of the ways things are and might be" (Hogwood and Gunn, 1984, p63).

The approach taken in my research incorporates a critical perspective by examining the wider political, economic, and ideological context within which policy for boomers, as future generations of older people, is situated. A critical approach recognises that social policy involves "evaluative judgments about the nature of the economic and social system and about what is needed for well-being" (Cheyne et al (2008, p6).

Cheyne et al (2008) argue the underlying premises of policy need to be clearly articulated and that policy advisors need to be interested in both the 'how' and 'why' of policy. "Quality policy advice involves a transparent process of articulating and assessing the values informing policy advice in order to see which particular interests are enhanced by specific policy directives and to identify how the policy alternatives impact on different groups" (p137).

\section{Critical Gerontology}

The critical perspective of critical gerontology provides a theoretical framework for understanding ageing (Estes et al, 2003; Jamieson et al, 1997). Estes et al (2003) assert that critical gerontology "goes beyond appearances to ask questions about the motivating forces underpinning the functions of what it is to age well" $(2003, p 78)$.

The political economy perspective is a key strand within the critical tradition and remains influential in gerontology today. Within gerontology this approach seeks to understand the "conditions and experience of ageing" (Estes et al 2003, p20). Those working from a political economy 
perspective have explored how the organisation of work and state structures influences social needs and life chances, thereby shaping inequalities of subgroups in society. Early approaches used a social problems perspective with a focus on policy and welfare needs. In the $80 \mathrm{~s}$ gerontologists drew on Townsend's (1981) theory of 'structured dependency' to explore such constraints. Conflict theorists within gerontology emphasised social inequalities relating to the capitalist organisation of society (Phillipson, 1982), status politics in a consumer society (Turner, 1998) and the impact of demographic change.

Humanistic gerontologists critiqued existing theories of ageing and developed theories that reveal the subjective and interpretive dimensions of ageing, with an increased emphasis on meaning and experience. Their moral economy perspective seeks to explore an "absence of meaning affecting older people, and the sense of doubt and uncertainty that is thought to permeate and influence day-to-day lives and social relations" (Estes et al, 2003).

In the mid to late 1990s the rise of identity politics and the theorisation of social movements has also been influential in gerontology, with increased understanding of cultural domination (rather than exploitation of classes) through patterns of representation, interpretation and communication. Antonio Gramsci's contributions, including his concept of ideological hegemony (1971), were also influential in theory development, allowing a greater understanding of the role of beliefs and ideas and the manner in which discourses of political and economic regimes reflect and perpetuate power relations (Estes et al, 2003). More recent debates within critical gerontology incorporate and consider the effects of globalisation including the influence of trans-national organisations, changing global ecology, global technologies, global migration, and global workforce issues (Phillipson, 2006; Harper, 2006). 


\section{A Cohort Perspective on Ageing}

This research considers boomers' generational identity and approach to their own ageing. It uses a cohort perspective of ageing which recognises that members of an age group and life stage are located within a historical context and are enmeshed within an institutionalised social structure (Uhlenberg and Miner, 1996). Cohort succession and social change are dynamic processes that challenge and alter the structures that shape how individuals age. The unique history of a birth cohort and the institutionalised structure of the life course will both shape the behaviour of the cohort and will in turn be altered by the behaviour of the cohort. However continuities across generations and diversity within the cohort need also to be taken into account.

\section{Age Stratification and the Ageing and Society Paradigm}

An early macro-level approach that remains of significance to the present study is the 'ageing and society paradigm' developed by Matilda Riley (Riley et al, 1999). Building upon her earlier work of 'age stratification' the focus of the theory is on the influence of social structures, including policy institutions, on the process and experience of ageing, and on age based stratification in society.

"Its central theme is that, against the backdrop of history, changes in people's lives influence, and are influenced by changes in social structures and institutions. These reciprocal changes are linked to the meanings of age, which vary over time." (Riley et al, 1999, p327.)

Age stratification theory has been criticised for exaggerating the role of status, for lack of attention to power struggles and conflict, and for ignoring intra cohort differences (Estes et al, $2003 \mathrm{p} 16$ ). Nevertheless the theory is useful for its focus on age based cohorts and social and historical factors influencing the ageing experience. An important concept within age stratification theory is that of structural lag or the tendency of structures to 
not keep pace with other changes within society. Structural lag can occur when social structures do not adapt to new cohorts with different characteristics from the one before (Riley and Riley, 1994). Hence policy for older people may become out dated when patterns of behaviour change and policy remains based on old assumptions.

\section{The Life Course Perspective}

Also relevant for a focus on cohort-historical factors is the life course perspective (Elder 1974; Neugarten and Hagestad 1976) that emphasises the ongoing influence of historical, social, economic and environmental factors that occurred at earlier ages in the individual's or cohort's life. Life course theory "bridges macro-micro levels of analysis by considering the relationships between social structure, social processes and social psychological states" (Estes et al, 2003, p16-17). This theory has been criticised for equating social forces with social change, and for its unproblematic approach to choice as a determinant, in addition to ignoring intra-cohort differences (ibid, 2003). However life course theory allows policymakers to consider how individuals are linked over their lives to others, are nested in families and are affected by institutions that bring both opportunities and constraints (Bengston et al, 2008). The approach also assists an understanding of cumulative advantage or disadvantage across the life course. 


\section{Methods}

A multi method approach has been taken, employing qualitative research methods and primary and secondary data analysis.

\section{Focus Group Research}

Primary qualitative research with a purposeful sample of boomers was completed using focus group methods to explore what kinds of expectations boomers have about their life in older age, including roles, identity, lifestyle, rights and obligations. Eleven focus groups were held in urban and semi-rural settings around New Zealand.

This method was chosen to facilitate exploration of a range of views and the underlying reasons. A key advantage of this face-to-face approach is the ability to collect rich and detailed data, with opportunity for immediate validation and probing. While this method of study is not suitable for quantifying the degree to which views are held within a population, focus groups are useful for identifying major themes. (Denscombe, 2002.)

Thus focus group research is a useful method for exploring the social construction of norms, values, roles and identity, and how that may translate into behaviour. Their ability to provide explorative data on a chosen topic, especially where there is a desire to explore group rather than individual views is key. Focus groups allow participants to interact, build on each other's comments and reveal collective opinions.

Focus groups can provide an indication of the nature and strength of views held by a given group. Focus groups also allow exploration of underlying thought processes and factors contributing to attitudes, to reveal 'why' such views may have developed (Morgan, 1988). Individual behaviour of participants is subject to group influence - a strength where group identity 
is the focus of research. The group may start with relative uncertainty as to the degree they share common views on the discussion topic. As more members of the group share their experiences and perspectives, they typically find some common areas in which they both agree or disagree, and often the sources for their various levels of agreement or disagreement (Morgan, 2008).

A further advantage of focus group research is that a greater number of participants can be interviewed in a shorter timeframe compared to individual interviews. The amount of data generated may be less (about $70 \%$ of the amount of ideas generated by equivalent individual interviews) but this can be an advantage in terms of time spent on analysis (Morgan, 1988).

The researcher needs to aim to keep a discussion going until areas of agreement or disagreement are revealed, or consensus is reached. Differences in perspectives may be revealed when participants ask for more information and the asking and answering of questions can reveal insight into thought processes. In analysis of resulting data the researcher pays attention to what members find interesting (a lengthy discussion on a topic), what they find important and areas of controversy. Topics where participants find there is significant agreement may not be much discussed or one person's summary may be a sufficient representation of others' views. Alternatively there may be topics where there is acceptance of individual views rather than consensus. (Morgan, 1988.)

With self contained focus groups, that is where the results stand alone without being one stage of a larger study, the results are useful for reporting on their own without the need to collect further data, or can be triangulated with results from different forms of data in the same field. Results stand alone as evidence of these participants' choices and opinions, even though different results may be obtained through additional data collection. 
In focus group research a relatively low level of moderator involvement is maintained to allow knowledge to come from participants' perspectives (Morgan, 1988) and to avoid researcher-based expectations gained from earlier sessions to influence the direction of discussion in later sessions. Moderation is required to ensure the desired set of topics is covered, to facilitate group dynamics, cut off unproductive discussion and to probe topics where more information is wanted, or to compare thinking of new participants with findings from previous groups. The facilitator needs to take care to direct the discussion without putting words into participants' mouths and must walk a fine line between understanding empathy and disciplined detachment (Morgan, 1988).

A focus group typically has seven to ten participants who are chosen because they have characteristics in common that relate to the topic of study. The researcher creates an environment for discussion allowing for multiple points of view without the need for consensus. Discussion is planned beforehand to obtain information on points of interest. The group is repeated several times with different people to identify patterns and trends in the discussion. This form of interviewing uses open ended questions and is non directive, allowing the participant to voice opinions, comments and explanations to share their experiences and attitudes (Kreuger, 1994).

Participants in focus groups may be strangers or acquaintances. Participants who have minimal contact with each other can assist disclosure. Where groups include friends, co-workers or family members, this can present difficulties. Familiarity with the moderator can also be problematic, particularly if there is a hierarchical relationship (such as between a manager and employee). Familiarity is primarily an issue of analysis, where it can be hard to determine whether comments were influenced by the topic or by past, present or future interaction with other members. (Kreuger, 1994.) 
As the research progressed the strengths and limitations of the method were revealed. These and other aspects of 'research in reality' are described later in this chapter.

Analysis of focus groups is inductive, deriving understanding from the discussion as opposed to confirming a theory. Thematic analysis was used to explore transcripts of resulting discussion, and to identify areas of common agreement or disagreement. Aspects of discourse analysis (outlined below) were drawn upon to assist the identification of underlying attitudes, beliefs and values.

\section{Self Administered Questionnaire}

A self administered questionnaire was used to collect demographic data from participants including level of education, income and retirement planning, areas not amenable to group discussion. The questionnaires were delivered to the participant along with a letter of explanation, either by email or by hand via the group host and were collected prior to the beginning of the focus group. Participants were asked to return the questionnaire direct to the researcher in one of three ways: via email to the researcher; by post using an enclosed postage paid envelope; or by bringing the completed questionnaire with them to the focus group. Instructions included an assurance of confidentiality of information. Time was allocated at the beginning of each focus group to ensure each participant had completed the questionnaire and allow any who had not yet filled it in to do so, thereby ensuring a $100 \%$ completion rate. Delivery direct to the researcher enhanced confidentiality while options to return the questionnaire via email or by hand helped to reduce postage costs. 
However, lack of control over when questionnaires were returned meant demographic data could not be collated prior to focus groups, so removing the opportunity to pre-arrange groups by participant characteristics, such as income or education. This was partially offset through planned selection of the location of the group and the social characteristics of the group host. Nevertheless a reduced ability to analyse by socio-economic characteristics was a disadvantage of the return method.

\section{Critical Discourse Analysis}

Critical discourse analysis is a method of analysis that has developed from critical theory's emphasis on language, and symbolic systems in general, as an expression of agency (Macey, 2000). Discourse most generally refers to an extended piece of text, or the verbal equivalent, that forms the unit of analysis. It also is used more widely to describe "any organised body or corpus of statements and utterances governed by rules and conventions of which the user is largely unconscious" (Macey, 2000, p100). Discourse analysis involves the critical examination of texts or narratives in order to identify underlying beliefs, assumptions and ideology. These may be revealed by identifying the use of slogans or figures of speech and by determining themes, concerns and concepts (Marshall, 1998).

Critical discourse analysis seeks to understand how discourse reproduces social and political inequality and reflects relations of power. There is a focus on the positioning of texts and on whose interests are being served by that placement, and on the context in which dominant ideas emerge, are communicated and maintain (or lose) their authority. It recognises that all social practice is historically and culturally located. 
In this study, critical discourse analysis is used to explore representations of boomers and older people within key literature and policy documents, and to analyse themes emerging from the boomer focus groups, in order to reveal prevailing ideas about the baby boomers and their ageing in an ageing society. The aim is to explore how discourses are used to control and regulate the experiences of boomers and older people and to legitimise narratives concerning their role (Jamieson, Harper and Victor, 1997).

The works of Foucault and Derrida have particular relevance to critical discourse analysis. For Foucault discourses (which he saw as not merely a chain of words, but also the practices that systematically form the objects of which they speak) and power strategies are enmeshed, as power/knowledge complexes that are connected to wider social and political practices (Scott, 2006). His 'archaeology of knowledge' centres on the conditions under which statements of knowledge are deemed acceptable or truthful.

Derrida (1972) emphasises the import of deconstructing texts through close reading, to critique the rhetoric that the text simultaneously asserts and denies. His textual analysis is associated with Nietzche's earlier philosophy that there are no facts, only interpretations (Macey, 2000). For Derrida there is no final reading of the text - each reading generates a supplementary reading as language and meaning are seen to have no point of origin and no end. Deconstructing a text means "working through its concepts and logics in such a way to discover and determine what it cannot describe, what its history has excluded in order to constitute it as what it is" (Macey, 2000, p87). Textual analysis is the starting point for discourse analysis, but it is analysis of the situational context and the intertextual context that is central to the process of interpretation (Fairclough, 1995). 
Exploring situational context includes consideration of time and place when was the text produced; could it have been produced in a different place or time in history; what contextual factors influenced the production and interpretation of the text? Exploring intertextual context includes consideration of which discourses, of the many available in society, have been drawn upon and how has the privileging of discourses served particular interests.

Critical discourse analysis was selected as a method for its potential to reveal how the "problems of old age and their solutions, are socially constructed, interpreted and internalized using mechanisms that frequently obscure the power relations that determine them" (Estes et al, 2003, p62). The method is useful for revealing how policy can be influenced by the assumptions and interpretations of the various policy actors involved, including authority figures, as well as by the political and institutional setting. Estes et al (2003) argue that policy discourses provide 'professional rationales and personal techniques' to regulate older people (and baby boomers) and to legitimise narratives about their role. Policy makers draw on the ideas promulgated by experts and politicians and other policy actors, to provide an evidential base for policies and make policy choices (Miskin, 2004). Critical discourse analysis illuminates how ideas legitimate and stimulate policy decisions and provide a framework through which policy makers discern problems and find solutions.

\section{Secondary Data Analysis}

Data from other sources was used to explore context and to supplement findings from the focus groups. This included census data, demographic data provided by other researchers, and data obtained through secondary analysis of the World Values Survey (WVS) data (available at www.worldvaluessurvey.org). 
This use of existing statistics and other secondary data has both advantages and disadvantages (Kellehear, 1993, Stewart and Kamins, 1993). Advantages include time and cost savings and being able to make use of reliable data that was not otherwise available. A disadvantage was that some data was old, only partially disaggregated, and potentially decontextualised.

World Values Survey (WVS) data was obtained from the online WVS database, supplemented by tables and analysis provided in published reports. Key reports using WVS (New Zealand) data are those by Perry and Webster (1999) and Webster (2001) which are based on 1998 data (the 1998 New Zealand Study of Values, or NZSV), and three reports by Rose et al (2005a, 2005b, 2005c) on data collected in 2004 and 2005 (the 2005 New Zealand Values Study or NZVS, produced for the Centre for Social and Health Outcomes Research and Evaluation (SHORE) and the Whariki Research group at Massey University in New Zealand).

There were some limits to these data sets. Firstly, accessible WVS data was partially disaggregated by age group or birth year, but categories did not exactly match the boomer cohort (as defined in Chapter One).

Additionally, cohort analysis was limited by differences in age categories between the two sets of data. Consequently, the 30-49 age group in the 1998 data set has been used as a proxy for boomers then aged 32 to 51 . In the 2005 data, the 35-54 year age group most closely matched boomers and was used as a proxy for boomers then aged 38 to 58 years. Findings from these studies should therefore be considered as broadly indicative of the boomer cohort and this limitation taken into account when drawing conclusions. Differences in question wording between waves were also apparent, limiting ability to compare. Finally, the broad age ranges of the oldest age groups (50+ years in 1998 data and 65+ in the 2005 data) meant variation within those age groups could not be identified and only general conclusions about differences between boomers and older age groups were able to be made. 


\section{Triangulation of Data}

Results from the focus group were triangulated with findings from other sources, in order to explore consistency between texts and coherency in discourse. A key New Zealand study drawn upon was an online survey of over a thousand New Zealand baby boomers undertaken by Buckland (2009) as part of a Masters of Business Administration. Her study replicated an attitudinal survey of boomers in the United States by Smith and Clurman (2007).

A key limitation of the Buckland's study was that the sample was a self selected sub population of boomers that was not fully representative of the New Zealand boomer population. Boomers without internet access (identified by Buckland as $11.4 \%$ of the baby boom cohort) were excluded by the method.

Of those participating, there was an overrepresentation of female boomers and boomers from northern New Zealand, and an under-representation of younger boomers and 'Maori boomers'. Nevertheless as the largest survey to date to specifically target the New Zealand boomer age cohort, findings provide a valuable source of indicative information.

\section{Research in Practice}

\section{The Focus Groups}

Eleven focus groups were completed between October 2007 and March 2008, with six groups held between October and December 2007 and five in March 2008. A two month gap between groups was planned to accommodate the Christmas and summer holiday season in New Zealand. 
The break also enabled initial analysis of participant characteristics and emergent themes to assist the planning of final groups.

A total of seventy participants took part in the study (including one who completed the pre-group questionnaire but was unable to attend the focus group on the night). Most groups had six to eight participants, with two groups of five and one of four (average six participants).

\section{Location of Groups}

Groups were held in seven regions around New Zealand (Wellington, Kapiti, Horowhenua, Manawatu, Taranaki, Waikato, and Canterbury). The goal of focus group planning was to increase the diversity of the sample by including boomers living in both metropolitan and provincial/rural areas, and high and low socio-economic regions (as indicated by the socioeconomic deprivation atlas of New Zealand ${ }^{9}$ - see Crampton et al, 2000). This was based on the assumption that where and how people live can influence their attitudes, beliefs, and expectations of lifestyle in older age.

Regions not represented were the more isolated north and east coast of the North Island, which have a much higher proportion of Maori, and a higher deprivation score, and the major metropolitan area of Auckland (population approximately 1.4 million) with its more culturally diverse population. Less densely populated and more isolated regions of the far south and west coast of the South Island were also not represented (although at least three participants had grown up in these areas).

\footnotetext{
${ }^{9}$ This index measures the level of deprivation experienced by groups of people living in private accommodation by small areas based on mesh blocks, and is based on nine deprivation variables: no access to a telephone; aged 18-59 receiving a means tested benefit, unemployed, or without any qualifications; aged under 60 living in a single parent family; low household income; no access to a car; not living in own home; living in a crowded home as measured by bedroom occupancy. (Crampton et al, 2000, p15.)
} 
Of the eleven groups, three were held in a large city (population more than 350,000 ) including the capital city, two in a medium sized city (population between 200,000 and 350,000$)$, three in provincial cities $(50,000$ to $100,000)$, two in a small town less than $50 \mathrm{~km}$ from a major city, and one in a rural community less than $100 \mathrm{~km}$ from a major city.

All but one of the groups were hosted in a participant's home. The remaining group was held in a small community house. All rooms were sufficient in size to accommodate the group, with minimal outside distractions, including noise. These locations allowed for a more natural setting that helped to put participants at ease. Relaxed environments, and a permissive and a non-judgemental moderation style, are important factors in generating sufficient trust within the group for free discussion and disclosure (Kreuger, 1994).

\section{Recruiting and Selecting the Sample}

Participants were recruited using a modified snowball technique.

Approaches were made to twelve community organisations and individuals representing the target age and gender group, inviting them to host or suggest a host for a group who would invite one or more participants with specific characteristics. Those people were in turn invited to recruit one or more participants. The aim was to form a group where each person knew at least one other from the group, to put participants at ease.

Up to twelve groups were planned and arranged according to age and gender. A recruitment matrix was used as a guide to the selection of contacts and characteristics of participants to be recruited. The goal was to form four groups of leading boomers, four of trailing boomers, and two or more groups of mixed ages. The total number of groups needed to be sufficient to allow comparisons between groups of leading and trailing and male and female boomers. The final number of groups was decided as the research progressed when no new themes were being generated. 
Separate groups for male and female boomers were planned to facilitate disclosure (Kreuger, 1994) and allow exploration of any gender based issues that might arise. The intended group size was between six and ten participants.

These first contacts represented a purposive sample, having been selected to allow a broad representation of the boomer cohort. Eight of these first contacts were known to the researcher but came from a variety of backgrounds. Three were representatives of community organisations. Other contacts included a public service manager, a company director, a community worker, a development consultant, a family carer, a pastor from a morally conservative church, a farmer, a builder, and a health professional. One contact declined to take part in the research, on the grounds that their members (unemployed workers) were too diverse and/or too vulnerable to be involved in research about their futures.

Contacts and potential participants were provided with a written summary of the research and a consent form. A small incentive was offered to participants in the form of a cinema voucher. Those agreeing to attend were then given a short anonymous questionnaire which was to be returned directly to the researcher, either before or on the day of the group. A stamped addressed envelope was included to reduce costs to participants. Ongoing communication with the host was maintained to provide support and assistance where needed (such as drafting email reminders sent out by some hosts), monitor progress and to show appreciation of their efforts in organising the group. A reminder was sent to participants prior to the day of the focus group.

The characteristics of participants in the first groups guided the recruitment of later participants. For example boomers from rural areas and from lower socioeconomic groups were initially under-represented and so approaches were made to agencies representing these groups, including a rural association, a tenants' advocacy group and an organisation for unemployed workers. 
The final groups included two groups of colleagues and neighbours, one group of ex-pupils from a college, one book club, three groups of work colleagues, one church group, one neighbourhood group, and two organisation related groups.

\section{Research Ethics and Consent}

Prior to commencing the research, approval was gained from the Victoria University Research Ethics Committee. Confidentiality and anonymity were key issues to be addressed. Due to the face to face nature of data collection, full anonymity was not possible. However participants were informed that their written comments on the questionnaire would be anonymous and any identifying information in questionnaires would remain confidential and accessible only to the research team. Verbal comments would be anonymised in any and all reports so individual participants' views would not be identifiable to anyone outside of the focus group. Only members of the research team would have access to transcripts and recordings of the discussion, which would be destroyed within two years of the thesis being completed. These matters were laid out in the Information Sheet provided to participants before consent was signed and were summarised again at the beginning of each focus group prior to discussion commencing.

It was not possible to guarantee confidentiality of information shared within the group, given the number of people involved in the discussion group, and the fact that some members knew each other. Participants were asked to remain mindful of, and show respect for, each others privacy should personal information be revealed as discussion progressed. Participants were advised that they would not be asked to reveal any sensitive information during the focus group discussion, and they could at all times choose the nature of their involvement in the discussion. 
Participants were informed of the intended use and security of information collected. An outline of the research was provided to all participants to inform them of the purpose of the research and to provide them with information on who to contact if they had any questions or concerns about the researcher, the study itself or the research process. It was important for all participants to receive the same background information and to keep the description of the research general to avoid leading participants to form early judgments that might influence the subsequent discussion. An opportunity for questions or concerns to be raised was provided by including the contact details of the researcher and research supervisor.

The consent process also advised participants of their right to withdraw from the research at any time before and up to one month after the focus group. This time limit on withdrawal was intended to avoid potential problems with extracting analysed data late in the research process.

Participants were offered a summary of the results of the research when it was completed. This posed a dilemma for the researcher, given the longer than expected research period. The communication of early results risked the spread of information that may be later deemed inaccurate, but by waiting for final results to become available, some participants contact details were no longer valid. The provision of preliminary findings would have been a better option.

\section{Techniques of Data Collection}

All participants were asked to complete a short written questionnaire prior to participating in the focus group. This enabled demographic data to be collected and allowed the participants' age to be confirmed. Completion of the questionnaire prior to the group meeting meant that time was not wasted gathering this information. The twenty-four questions were all short answer tick box category questions with one 'other comment' option. See Appendix One for a copy of the questionnaire. 
A semi structured interview schedule was used by the researcher to guide the discussion (see Appendix Two) and all sessions were digitally recorded. Open ended questions were developed in a multi stage process that included background reading on the topic to identify relevant components of questions, and familiarisation with other studies using the same method. As initial questions were formed these were tested through talking to boomers and to research supervisors. Questions aimed to gather information on participants' perceptions, feelings and manner of thinking about the topic (Kreuger, 1994).

Questions included probes that were used by the researcher to gather more detail on topics and to prompt ideas and thoughts. Probes were used after the topic had been discussed in a general way and acted as a guide to items of interest the researcher hoped to cover in each group. This approach helps the researcher to judge whether the non-mention of an issue is an oversight or an item deemed not important (Kreuger, 1994). The first focus group was used as a pilot for the interview schedule, providing an opportunity for changes.

Questions were ordered from the general to the specific to allow participants to develop their thinking about the topic. The last key question on the influence of baby boomers' attitudes and values built on the context of previous questions on participants' expectations of older age. To close the group a brief summary of the topics raised was given and participants were asked if there was anything else we hadn't covered that they would like to add.

Audio recordings of group discussion were made. Transcripts of recordings were written and were used in analysis, supplemented by hand written notes taken by the researcher during the focus groups. 


\section{Moderating the Discussion}

The focus groups ran for between one and a half to two hours. Refreshments (finger food and drinks) were provided before the discussion commenced, which helped the group to warm up. However this meant the researcher needed to take care to avoid leading the conversation into topics to be discussed as part of the focus group.

As researcher I moderated the discussion. Formal discussion commenced with an opening statement from me welcoming participants and briefly summarising the purpose of the group. Participants were reminded that they shared a common characteristic which was that they were baby boomers. This reminded participants of their alikeness and served to enhance disclosure (Kreuger, 1994). Participants were advised that there were no correct or incorrect answers and that consensus was not required. They were reminded that the session would be recorded and data collected would be held securely. This introduction was kept brief to avoid introducing any sense of formality.

As a warm up participants were asked to briefly introduce themselves to the group. To break the ice and get all participants involved, each was asked to complete the statement "to me older age is...". This worked well in most groups, allowing early thoughts about older age to be revealed and each to have their say. However in some groups, more dominant members immediately launched into a discussion of the statements, requiring greater moderation to redirect the discussion and invite quieter members to speak.

Participants were then asked about their expected lifestyle in future years; what forms of assistance they expected to give or receive within their family, and from the state; and what attitudes and values they felt baby boomers typically had that may influence their behaviour in older age. This last question was quite complex with two parts (identifying boomers' values and attitudes and considering how they may influence boomers' 
behaviour in older age) and was therefore asked in two parts. Sometimes boomers' attitudes and values had already been raised in earlier discussion, and the group were therefore reminded of earlier comments to assist their thinking about how these attitudes and values may influence behaviour in late life. Prompts were used for topics that had not yet been mentioned.

As all participants knew at least one other member of their group, this helped attendees to quickly feel at ease and the discussion to flow, with both humour and at times robust debate. Ending the focus group was sometimes a challenge and some groups continued their discussion even after recording had stopped. Body language was used (such as changing sitting position) to remind the group that the session had ended and in one case to assist the host to encourage guests to leave (by getting up to clear dishes). Where possible comments made after the recorder was turned off were added to hand written notes as soon as possible after the group had gone. Time after the group was also set aside to review handwritten notes and add any additional thoughts or observations.

\section{Analysing the Data}

Data from the questionnaires was entered into Excel spreadsheets to support analysis and tabulation. The transcripts were then analysed with content ordered according to topics of interest and themes emerging from the data. Inductive analysis was used to identify themes, through reading and re-reading of transcripts and hand written notes. Age and gender based groups were compared and the demographic characteristics of group participants were kept in mind to assist interpretation. 
Overarching themes across topics were also considered. What was said first, frequently mentioned concerns and topics that generated extensive discussion were noted as potential indicators of hot topics or matters that these boomers felt strongly about. Issues discussed only briefly were considered as possible indicators of easy and early consensus, rather than as areas of disinterest. Context and informed judgement needed to be used to clarify which was more likely.

Topics and themes were entered into tables to aid inter-group comparison. However care was needed to ensure that any relevant context (such as what preceded the comment, tone or use of humour) was not missed as quotes were extracted. This required repeated reading of transcripts and occasional re-listening to audio files to check initial conclusions. A range of identified beliefs and attitudes were grouped under each theme. Beliefs were identified as knowledge-based statements or constructs that could be deemed true, false, accurate or inaccurate, while attitudes were views expressed that could be deemed positive, negative or neutral. Aspects of textual and discourse analysis were drawn upon to identify underlying values. Values were identifiable in statements about broad preferences, orientations and judgements. Attention was paid to common or recurring values as well as outliers. Initial findings were compared with findings from other studies to assess commonalities and coherency.

In Chapters five and six a summary of findings from the focus groups is presented, organised by themes. This provides a first level of interpretation of the data, while preserving as much as possible the participants' own perspectives. Data has been reduced so that only issues most relevant to the research topic are presented. Quotes have been used to aid the description of findings and were selected to illustrate either the range or diversity of comments or common ways the participants responded (Kreuger, 1994). Quotes also demonstrate authenticity and privilege boomers' views. Additional interpretation of the data then follows in Chapter Seven incorporating findings from other studies. 


\section{Strengths and Limitations of the Focus Groups}

The snowball recruitment method proved successful with most contacts being able to attract the desired number and type of participants without difficulty. The most difficult to attract were groups recruited through organisations, with one declining to participate and another only being able to attract four participants on the day. One other small group of five had a further participant unable to attend on the day.

In most of groups in this study only some participants knew each other well. One group was friendship based, though not all were in regular contact. There were risks associated with such a group; friends can have their own language or comments may be based on prior knowledge rather than the group discussion, thereby making analysis of findings more difficult. Additional banter and detouring could also occur between friends. In this group moderation was indeed more challenging, with a lot of good natured talking on top of each other, teasing and rebuttal of others comments. Dominant members in two groups did throw the discussion into chaos on several occasions through humour. Time management and redirecting the discussion was a resulting moderating challenge.

In one group the topics were not able to be fully canvassed before the discussion reached a natural conclusion. Nevertheless the level of disclosure from each participant in this group was high. This experience illustrated the advantage of a series of focus groups to ensure there is opportunity to collect sufficient data with allowance made for variation between groups. 
A disadvantage of the recruitment process was a reduced control over who actually attended the groups. In each of three groups, an individual came who was outside the intended age range. In the first case the individual was more than a fifteen years older than the oldest boomer. This person was respectfully asked not to participate in the discussion and after staying to share refreshments and to listen to the first question as an observer, this person left the group. In the second case the person was born in 1966, but was allowed to participate in the group as their birth date was less than 6 months outside of the specified range. In the final example one participant was a leading boomer in a group meant to be of trailing boomers, and was twelve years older than the youngest boomer there. This proved advantageous overall, as the ensuing discussion on age based differences in experiences and attitudes contributed valuable intragroup data. However it meant that this group's data could not be used for analysis of inter-group differences between trailing and leading boomers.

The same approach to analysis was used for a gender-based group that included one participant of the opposite gender. This person was the spouse of the intended participant and proved to be the quieter partner of the two. Nevertheless their attendance may have affected the level or nature of disclosure from other participants.

An additional issue was the impact of perceived differences in power or authority between participants in a group. This was a potential influencing factor in two work based groups where one of the participants was in a position of authority. Differences in levels of education between participants could have been a further factor inhibiting discussion. Overall these did not appear to be inhibiting factors with free and frank discussion in each of the groups, but it remains possible that quieter participants may have contributed more in alternatively structured groups. 
Analysis of raw data from the focus groups proved time consuming and required a focus on factors of central interest to the study. I found the three dimensional visual and spatial cues of a paper-based process supported the more intuitive elements of inductive analysis that add value when combined with a methodical approach.

The use of an interview schedule with probes was effective, although flexibility was needed to allow for serendipitous questions and to accommodate the natural flow of the discussion. In one group the order of the interview was changed as discussion flowed to the last question early in the group process. Redirecting to the earlier questions was achieved but with the loss of full coverage of some items. However, with a sufficient number of groups in a series it is not necessary to ensure that every group discusses every item, and it can be disadvantageous to attempt to do so if it means interrupting a successfully flowing discussion.

Although audio recordings were made of the focus groups, supplementary hand written notes were also made to record discussion and act as a back up to audio files. These notes proved invaluable in one group where the recorder failed part way through the discussion. Being both moderator and note taker was at times challenging. If the budget had allowed for it, a second person to take notes would have been helpful and would have provided an opportunity for additional observation of the group. On the other hand, being note taker meant I was kept fully occupied, thereby reducing the risk of becoming engaged in the conversation and influencing the content of the discussion.

\section{Reflections on the Choice of Methods}

The use of focus groups as the key method of data collection enabled the rapid collection of primary data from a broad range of New Zealand boomers. The groups provided lively interchanges that resulted in an 
interesting wealth of data that was relevant to the focus of this study. A large number of topics were discussed by participants, providing additional indicative data that may be useful for a range of other studies.

When designing the research, methods of data collection other than focus groups were considered, including survey research via a self administered questionnaire, either postal or as an online survey. Generalisability would have been a key advantage of a survey that was well designed and large enough to ensure a representative sample, but the method was rejected due to insufficient resources for this to be achieved. Additionally, anticipated disadvantages of a mail survey were increased difficulty of recruitment compared to the method chosen; anticipated lower response rate; and, in the case of a mail survey, the higher cost of postage and printing. An online survey would have had the further disadvantage of excluding participants without access to or experience with an internet based research, thereby introducing the possibility of a social class bias.

A standardised questionnaire would have allowed greater control over data collected, however the necessary uniformity of questions would introduce a degree of artificiality and potential to miss what is most appropriate to respondents. In addition questionnaires offer limited ability to explore responses and there is no opportunity for the group interaction which is possible in focus groups.

The potential to piggy back on other surveys that were underway, such as the Enhancing Wellbeing in an Ageing Society (EWAS) study of mid life adults was explored, through for example including a question in the EWAS survey or by secondary analysis of a sub group of data. However the timing of the studies conflicted while differences in study goals meant EWAS data did not offer an adequate measure of key areas of interest. 
Individual interviews via telephone or face to face were also considered. Telephone interviews can be cheap and quick to administer, but do exclude those without a landline and those who choose to keep their number private. Individual interviews may have allowed greater control over data collection and additional probing of responses, but the richness of data that evolves through group interaction would not have been obtained.

\section{Chapter Conclusion}

This chapter has outlined the theoretical perspective and methods of the study. A pluralist approach is described, one that has been influenced by post-structuralism and postmodernism, world views and bodies of theory that emphasise the inevitable plurality and instability of meaning in contemporary society. This approach acknowledges that meanings, for example of ageing, will inevitably vary.

The research approach is positioned within a social constructionist epistemology, with a focus on the collective (rather than individual) generation of meaning. A critical realist approach allows for the acknowledgment of the biological reality of human ageing while recognising that the meanings are themselves socially constructed. The focus is on how these constructions influence expectations, behavioural norms and experiences in late life. The critical perspective taken and the underlying assumptions have been outlined. This critical perspective assumes that all thought is mediated by power relations that are social in nature and are historically constituted. The multi method approach has been described and strengths and limitations of the selected methods have been outlined.

In the next two chapters, key findings from the boomer focus groups are presented. 


\section{Chapter Five: Findings Part One: "Talking 'bout my generation!"}

\section{Introduction}

The attitudes, behaviour and underlying values of the New Zealand baby boom cohort will influence their behaviour as older workers, consumers, voters and family members. In turn this will have an impact on how New Zealand responds to population ageing. The next two chapters summarise findings from qualitative research on the baby boomer cohort, completed in 2008. A series of eleven focus groups were held in regions around New Zealand. The research aimed to explore boomers' attitudes to ageing and their expectations about their own old age.

Chapters Five and Six summarise key themes emerging from the focus group data. In the first half of Chapter Five boomers' sense of themselves as a distinct generation is explored. Boomers talk about influences and experiences as children within baby boom families, as young adults, and as adults in mid-life beginning to think ahead to their own ageing. Then in the second half of this Chapter, boomers' lifestyle expectations and attitudes to work and retirement are discussed and linked to their preparedness for life in older age.

Quotes from participants are provided, with individual comments that are indicative of themes across groups. Indications of agreement to an individual comment (such as murmurs from others in the group) are also included. Some extracts of group discussion are also presented, to illustrate diversity or commonality of participants' views ${ }^{10}$.

\footnotetext{
10 In quotes of a discussion where more than one participant's comment is included, each individual's comment begins on a new line.
} 
This chapter concludes with a summary of key themes emerging from the data, providing a snapshot view of boomers' thinking about their own generation and how prepared they feel for life ahead.

\section{The Participants}

The seventy participants in the focus groups were aged $42-63$ years of age. Of the seventy participants, 33 were men and 37 were women. Five of the groups were female boomers, four were male, and two were mixed gender groups. There were four groups of leading (older) boomers (born 1946 to 1955), four of trailing (younger) boomers (born 1956 to 1965) and three mixed age groups.

Analysis of the data revealed a range of boomers were represented, including low, mid and upper income groups and professional, semi professional, trades and service workers (see Appendix Three: Focus Group Characteristics). Employed and self employed workers were represented, as were boomers not in the paid workforce (including currently unemployed, carers of children or other adults, and currently out of the workforce due to injury / illness). None of the participants identified as retired, although two commented they had been, or were now in a form of semi-retirement, though they preferred not to use that term. Some participants noted on their questionnaire that they had reduced work hours as preparation for life in their older years.

Participants came from a variety of social backgrounds. The final groups included two groups of colleagues and neighbours, one group of ex-pupils from a college, one book club, three groups of work colleagues, one church group, one neighbourhood group, and two organisation related groups (a rural association and a tenants' advocacy group). At least three groups included participants with a background in social advocacy or who had been active in protests on social issues. All participants were living independently in the community. 
Of the seventy participants 38 identified as married, 16 had never married, 13 were divorced, two were separated and one was widowed. Seven participants indicated they had been married (or joined in a civil union) more than once. Most were homeowners (59 out of 70 ) with or without a mortgage. Their household composition varied. Three lived in single parent plus children household, nine participants lived alone, 21 lived in a couple only household, and 26 lived in a couple plus children household. Eleven said they lived with flatmates, friends, co-owners, boarders or other regular guests. One participant lived with their parents, three lived with their grandchildren and two indicated they lived with their stepchildren.

More than half of participants had lived all their lives in New Zealand (38 out of 70 participants). Twenty one of the fifty-nine New Zealand born participants had lived overseas for a year or more (range one to twelve years, with an average of five years lived overseas).

Eleven of the seventy participants were not born in New Zealand. Two of those had migrated with their family when less than two years old. Six of the 11 had lived in New Zealand for more than half their lives. The newest migrant had lived here for six years, but the remaining four migrants had lived here for more than a decade (range six to 19 years lived in New Zealand, average 14 years). Those not born in New Zealand came from England (three), Scotland (one), Ireland (one), America (one), Canada (one), Australia (two), (Hong Kong (one) and Fiji (one). Participants were not asked to identify their ethnicity, however during discussions three selfidentified as Maori, one as of Pacific ethnic origin and one as Fijian Indian.

Most participants were well educated, with 33 of the 70 participants with a degree or higher level qualification. Twenty two identified their qualification as 'other' and 15 had no formal qualification. 


\section{Views of Boomers in Mid Life}

Common and conflicting views emerging in the focus groups are presented below, with comment on areas of agreement or variance.

\section{Boomers' views on their generation}

Many participants felt that the baby boomers are a distinct generation with a developed sense of identity. This resulted from cohort size as well as the shared socio-historical context in which they had collectively matured.

I do sense that we're different... yes, we are somewhat unique (female, leading boomer).

There's so much in our generation that is different... it's a whole new consciousness (male boomer, mixed group ${ }^{11}$ ).

Commonly participants felt that boomers had been a lucky generation, growing up in a time of security and plenty.

We are the lucky generation. We grew up in a time when life was pretty simple and we had a first rate time (male, leading boomer).

We were privileged... (as we) grew up in a wealthy country, (and we) had it good - no war, no military, unions, full employment (male, trailing boomer).

All groups identified a supportive welfare state and strong economy as having been beneficial to their generation through childhood and young adulthood.

11 'Mixed group' refers to those groups consisting of both leading and trailing boomers. 
(It was) a time of plenty - free tertiary education and school milk ${ }^{12}$... my parents still talked about growing up through the war and the depression, and there was a very palpable sense of change... there was a sense of having come from the terrible depression and the war into this better time... there was also low unemployment when I left school - so we developed a sense that it had been and was better for us than our parents (male, leading boomer).

We didn't have to pay fees to go to university, so we could go and do history, religious study, and the government would give you a $\$ 100 \ldots$ and you could get jobs in the holidays (female, trailing boomer).

You could walk into a job, and you could walk out of a job, and you could get a flat and reasonably afford it. You could socialize and move around at will, and feel free and easy about doing so and safe... the values that I was brought up with have stayed with me all my life, through rough times, hard times, tragic times and simply marvellous times... that has centred me (female, leading boomer).

However many felt that as a consequence of these stable times, expectations were raised.

Boomers have a huge sense of entitlement... free education probably had an effect... the feeling that it was all there for you... state provision... (we) didn't think about it till it disappeared.

It was accepted as normal... compared to our parents.

Yes, 'cos we didn't grow up under pressure like our parents.

(Discussion, females, leading boomers).

\footnotetext{
${ }^{12}$ Free milk for all children in primary school from 1937 to 1967 , as part of Labour's child health policy. Glass half pints of full cream milk were delivered in crates to the school in the morning, School milk is memorable to more than a few boomers as a consequence of having to drink sour milk that had been left sitting out in the sun at the school gate for too long. The dairy conglomerate Fonterra recently announced plans to reintroduce school milk nationwide by 2013 - albeit low fat milk in cartons, not bottles, guaranteed to be refrigerated., and provided using private rather than state funding.
} 
Some felt that a simpler and more stable society when they were growing up had enabled a sense of confidence - at least for those who were members of the dominant cultural group.

The egalitarian 50 s is a myth... there was a mainstream culture...a dominant culture... now there are a lot of subcultures (male, leading boomer).

We had a sense of community, neighbours hanging out together (male, trailing boomer).

We didn't have a lot of things... (agreement) but I grew up with a lot more freedom (agreement) (female, trailing boomer).

Some challenged the rosy picture of lucky boomers benefiting from the golden years of welfare and the freedom of the $60 \mathrm{~s}$. There were downsides as well.

We had a sense that it ... was better for us than our parents... but this also I suspect blinded us to the inequalities that were around (male, leading boomer).

I have a sense that our generation were both privileged and lucky and fortunate in one respect, and somehow sad in another.... Because over those years our level of expectation grew so much, and that instantaneous fix became the all important, and the whole revolution of sexual identity and freedom, and all of that, magnificent and wonderful as it is....(there was) fallout in some respects... an overabundance of choices... (female boomer, mixed group).

One of the oldest boomers remembered times that weren't so carefree. 
What had a big effect on me in were the atom bomb tests... and it was the Cold War ...I was terrified about the atom bomb and threat of nuclear war...and another World War... (male, leading boomer).

Participants talked about other influences on their sense of identity, including location, religion, education and personal experiences.

In the sixties when I was about 12 years of age... there was much discussion of Catholic values... this brought a huge change in our Catholic way of life within the family...

And in the Protestants... (laughter, agreement)

(Discussion, males, leading boomers).

We were influenced by the people and experiences in our lives...my mother said there is no such word as can't... (but) at boarding school (I was called) a dumbo... and I spent my whole life proving them wrong (male, leading boomer).

One personal thing that influenced my life, made me think the most, was having children...suddenly being responsible for a new life. (female, trailing boomer).

Those who had grown up in rural areas felt this had an impact on their experiences and values. Living at a distance from the city, and the shops, required resourcefulness through making the most of what you had, including mutually dependent relationships with family and neighbours.

It depends on your upbringing - I grew up in rural area in small school of twenty or so kids, it was lovely, you had your family, we were out in the paddocks all the time... the rural influence was huge (female, trailing boomer). 
I grew up in the country environment and going to a restaurant meant going to your neighbour's down the road for a meal (male, trailing boomer).

We lived semi-rural... (there was) little money... (we were) a 'hand to mouth' family, but we made do... compared to my kids today - (they're) spending and consuming (male, leading boomer).

While individual experiences are influential on a person's sense of self and resultant behaviour, the socio-historical context had an impact, as these participants revealed.

I remember the Vietnam war and all the students, you didn't go to university in those days to get a degree, you went there to be a rebel and to flout the establishment, so for me the student uprisings and very radical thinking hippie and flower power (affected) me as a teenager in the sixties (female, leading boomer).

I was a son of a (World War II) soldier. Then growing up... all I wanted to do was to bloody kill anybody or anything. (My) father (was in) the desert for four and a half years. What was instilled in us as a family of boys was unbelievable. Nothing in our house was touched if it was made in Japan, nothing would be touched if it was made in Germany. He had a golf club and he said if any bugger comes near me they're going to wear it. And he is still like that... But l've learnt from that (and) l've got a huge appreciation now of what those men, our fathers and uncles did (male, leading boomer).

Not surprisingly, older boomers and younger boomers differed in some respects in the kinds of events they identified as having shaped a boomer identity. But there were overlaps as well. 
The politics of the late 70s and early 80s (with Muldoon ${ }^{13}$ ), the Springbok tour and all that stuff in NZ (at that time) (female, trailing boomer).

Man on the moon, Erebus ${ }^{14}$, decimal currency, 'Piggy' Muldoon (male, leading boomer).

The protests and what went on in the 1960's (female, leading boomer).

Vietnam War, JFK, Beatles, Fleetwood Mac, music from the 70s, 80s (male, trailing boomer).

Both Maori and Pacific participants identified race related political struggles as over-arching events affecting their people and that crossed generational boundaries. Christian values were also identified as influential.

The 60s hippie thing didn't have any effect on me, for me it was the dawn raids ${ }^{15}$, that was my period - it made me more resilient, my parents went through it... it had a huge effect... (Pacific female, trailing boomer).

In (our area) a lot of the Maori people are still (affected) by Parihaka ${ }^{16}$... They live it... (but) that feeling is slowly getting squashed out.... (Maori male, mixed group).

\footnotetext{
${ }^{13}$ Rob Muldoon served as a Prime Minster in New Zealand from 1975 to 1984 . He was a polarising figure, with a combative style which earned him the nickname 'Piggy Muldoon'.

${ }^{14}$ In 1979 a Air New Zealand plane with 257 on board crashed into Mt Erebus in Antarctica, while on a scenic flight, killing all on board. It was one of New Zealand's deadliest disasters. The resulting Commission of Inquiry found changes made to the coordinates for the flight path, and accused the airline of an 'orchestrated litany of lies', a phrase which entered popular culture.

${ }^{15}$ In 1974, raids by police of Pacific People's homes occurred at dawn, to arrest people who had overstayed their three month residency visas. In the context of an economic downturn, Pacific migrants were blamed for an 'overloading' of social welfare.

16 Parihaka was a settlement founded in 1867 by Maori prophet and chief Te Whiti o Rongomai, as a means of peaceful and spiritual resistance to the confiscation and sale of Maori land. The settlement was destroyed in a government raid in 1881. Parihaka is still invoked as a symbol of colonial aggression against Māori and more recently, as a celebration of non violent resistance. Source: http://en.wikipedia.org/wiki/Parihaka\#Parihaka_restored
} 
When I became a Christian my values changed. I had rebelled against my parent's values, and wanted to do my own thing, and (then) that changed again (male boomer, mixed group).

Participants talked about how the previous generation's values and attitudes had influenced their own.

My father... he worked really hard for his money, physically and mentally, and I think that was passed down to me and others of my age, the skills and commitment of their parents, their hard work and determination, has been passed down... (male, trailing boomer).

We were also taught that you work hard, you're a good person if you do rightly by others you will succeed... (male, leading boomer).

Like my parents wallpapered the house, they didn't get tradespeople in...it's a life skill... I want to teach my children about that, about looking after themselves and repairing things - when I was growing up I used to be envious of people who had new things, but now I'm grateful you know... that Dad had a vegie garden... (agreement)... and would do things like build us a play hut and we weren't given lots of things... I'm appreciating the values we were brought up with (female, trailing boomer).

But while they recognised there were values they shared with the previous generation, a rapidly changing society and a new range of experiences resulted in shifts in attitudes, beliefs and behaviours. Many boomers identified differences between the generations. They compared themselves to their parents and to their children.

We learnt from our parents, that whatever you want, you work towards it. Nowadays it's a Macdonald's society (male, leading boomer). 
I like to be a free individual and be able to choose what to do and not be told what to do by others and to give my children choices_like that as well- instead of being straight jacketed like (my parents generation) were... (male, trailing boomer).

Now( there's a sense that) you can do anything you want to - the world's your oyster. Whereas it was different for our parents... like you can't do that, because you're blue collar class (male boomer, mixed group).

My mother when she was 36, she was married for the second time, and had 3 children, eldest of $14 \ldots$...(By comparison) at 35 I was pregnant with my first child... the demographics have shifted so much. She'd had babies 10 years before I did...my generation has pushed everything back, this white middle class thing of doing it later and later (female, trailing boomer).

Rapid change had sometimes caused a sense of insecurity. But it had also resulted in a sense of opportunity and a view that 'anything was possible'. Access to information through technological change, such as television and satellite communications, and a longer education brought both greater awareness of social issues and a new opportunity to experiment with alternative lifestyles. The role of the media, that brought news of world events and politics into households, was recognised.

The technology, connecting (us) to the rest of world, (showing) what was possible, and taking lids off things, and Martin Luther King and those guys, and the world opened up for women and for people in general, there was a watershed (female, trailing boomer.)

Many boomers felt these changes had had a powerful influence on their generation. 
I think it certainly did affect my personal perception of what was possible, anything was possible... and that sense 'you can' be different from your friends and choose (your lifestyle) and to me that's a wonderful thing, you can choose! (Female, trailing boomer.)

(There was more) freedom of thought. This will carry through - it gave us... an easy going attitude (male, trailing boomer).

Change in gender based roles was commonly mentioned as having had a significant impact. These shifts were seen as continuing, resulting in comparisons between boomers and the following generational cohort.

There certainly has been a difference in gender roles. That's something where there has been a significant shift during our time. (But) you look at lot of younger women, and they seem to go along with what the status quo is, they've lost that willingness to change the system.

(Discussion, females, trailing boomers.)

While many felt their generation had been the first to experience and participate in major shifts in gender roles, some recognised the contribution of their parents. The influence of feminism had crossed generational boundaries.

I think that we are more stroppy. (But) I think that my mother must have been a real feminist. She brought up two children on her own in the 1930's. She was a strong stroppy woman well before feminism (female, leading boomer).

My mother and I went to all the feminist things, Helen Reddy, 'I am Woman', we did a course together, I watched my first pornography with my mother... with a group of women talking about the ethics of this stuff (female, trailing boomer). 


\section{Characteristics of Boomers}

Participants felt that theirs was a generation that had contributed to change. There was a common sense of boomers as an activist generation.

As a generation we organised change... and we set up childcare centres and kohanga reo ${ }^{17}$ (female, leading boomer).

Our experience of the 60s was of challenging things, organising and not letting things go... (male, leading boomer).

'Cos we said in the 60s, 'stuff you', we'll do what we like and we have gone ahead and done what we like (male, trailing boomer).

Participants commonly believed boomers were more demanding than previous generations. Some viewed this trait positively, while others felt high expectations had resulted in a 'me' generation; one that expected instant gratification. A privileged upbringing had fostered this.

We are more demanding...

We're more informed...

Boomers are able to take care of themselves...

Women are more liberated...

We're materialistic...

There is an expectation that we will be doing what we want to do (agreement).

(Discussion, mixed group of male and female, trailing and leading boomers.)

\footnotetext{
17 Kōhanga reo (Māori: literally "language nest") are Māori immersion kindergartens, founded in 1982, amidst fears that the Māori language was dying out. The success of the kōhanga reo programme is such that they have been followed by primary schools and secondary schools (Kura Kaupapa Māori) where Māori is the primary language of instruction.
} 
Some labelled the boomer generation as selfish, self-centred, and overindulged. Others disagreed.

Boomers are selfish. We will want our toys till the day we die. We are... into ourselves... into self improvement... the 'me' generation...

But we do that because we are able to...

We feel 'life's too short'... we don't compromise, it's like; 'I know what I like so don't waste time'...

We are individualistic...

We were sheltered - it affected us.

(Discussion, male trailing boomers.)

No (we aren't selfish). We expect good health care and good social support, but that doesn't mean we are selfish (male leading boomer).

There's this liberalism that we all grew up with, the relative affluence that the boomer thing stems from, that gets passed on to our own children and becomes a rod for our own back, so they are more... selfish is not the word... more individualistic.

If we are, its only cos we have not had to go through a war or depression and or had to help out our neighbours. If we are selfish it is because we can be!

(Discussion, male trailing boomers.)

A contrasting view expressed in more than one group, was that boomers have a strong work ethic. This was seen as due to the influence of their parents' generation and the values they had instilled.

I think baby boomers have been taught to work quite hard... and that's why we're very much sought after in the workforce because we're very dedicated (agreement)(male boomer, mixed group).

I think one of the major things we have been gifted... is our work ethic as baby boomers... work wasn't just a trade... it was how to be. 
I think it would be the same for most of us...you worked bloody hard... it made you respect what (your parents) did, where you came from. Yes, good values that we learnt from our parents.

(Discussion, males, leading boomers.)

Some recognised differences between older and younger boomers.

It's almost like two generations when you are talking about the baby boomers, because I was one of two children and there was a generation gap between my older sister and brother and my younger brother (male, leading boomer).

I don't know - I'm at the end of the baby boomers, but I see myself in comparison to Generation X, (that's) my younger sister and her friends... (for them) its very much (about) a level playing field (and) individual effort, and if you don't get there it's your own problem, and I just am so much against that and see myself as different to them. (We are) more community based... (agreement).

Yes, I see them as very individual, but I don't know if that is the same or different to the other end of the boomers.

(Discussion, females, trailing boomers.)

Individualism was commonly mentioned as a characteristic of the boomer generation, but also of younger generations, who were considered to be even more individualistic. Some boomers felt they had contributed to this.

I can differentiate younger down, my sister is 10 years younger and the whole climate had changed (to) conservatism, out for yourselves, no social conscience... Our sense of right was different, we had a collective view and less of an individualist view (female trailing boomer).

The consumerism and a fast pace of change of modern society was viewed with concern. Some boomers felt responsible for these changes. 
Our generation have encouraged the younger generation to be consumerist...Its not the young consuming (It's us) (male leading boomer).

We're materialistic... (female boomer, mixed group).

Nevertheless, for some there was a sense of generational pride and a belief that boomers had something important to contribute, and that they remained a vanguard generation.

One positive thing is that our generation has the opportunity to hold on to those values that we have been brought up with. This is the generation which will uphold those standards. The way society is going, they're going to need people who will uphold those values. We'll have something that they are looking for.

(Discussion, male boomers, mixed group.)

Yet there was also a sense that the good fortune of the 'lucky generation' was running out.

It was tough for our parents, with the Depression and the War they went through, but it's also tough now, it's faster, you've got to earn more dollars, work harder, its concentrated, full on ... (male, trailing boomer).

Everything is moving so fast, every week something new has changed (male, trailing boomer.)

The boomer generation is starting to pass out of influence now (male, trailing boomer). 
I think we will be constrained by what's going on in the infrastructure, global change, rising sea levels, rising cost of travel, higher risks, new global diseases (male, leading boomer).

\section{Views on the younger generation}

When talking about the next generation, some boomers felt that something had been lost as generational values changed.

The next generation with their 'hoodies' and their Ipods, and their pants hanging down over their boxes... Others of my age, the skills and commitment of our parents, their hard work and determination had been passed down...and I think its been lost now ...(male, trailing boomer).

Many participants expressed concerned about their children's future.

Life is a lot more complicated for kids now (male, leading boomer).

A number of boomers felt responsible for these changes and were quite critical of their own generation's parenting style.

I feel the attitudes of the hippie period have really affected our children's attitudes... that real liberal 'what will be will be' attitude, we were at the tail end of that... some friends who really embraced the flower power (they think) you don't smack (there's a) lack of discipline, a lack of respect... their attitudes are 'wishy washy'... (female, trailing boomer).

We didn't get our kids to go out and get work...we've made things so easy for them (male, leading boomer). 
The children of the boomers, for some reason we are not passing those skills, (that work) ethic down as we should be, that determination... I don't think I'm as hard on them as my parents were on me... They have a lot more choice, a lot more freedom, cell phones, technology (male, trailing boomer).

Not all agreed. Some felt that concerns about the younger generation were to be expected.

But isn't that what each generation says about the previous one? (male, trailing boomer).

I read something about how kids 'these days' are rude and disrespectful, but it was written hundreds of years B.C., so it hasn't changed! (Female leading boomer.)

Some valued the changes in parenting style.

We never talked to our parents, whereas now we share everything with our kids.

Yes, there's a lot more openness.

(Discussion, males, leading boomers.)

Home was pretty scary (for me) growing up... we aren't the dreaded ogres that maybe our parents were... (male, trailing boomer).

I have a really good friendship with my kids, my dad was lovely but we never had a friendship relationship with him (female, trailing boomer).

Some felt there was less of a generation gap now than there had been.

Boomers listen to the same music as their kids, they wear the same clothes and go on skateboards still... you've got son and dad playing 
same music and people who look same (across generations) and everyone is wearing jeans.

It is very different, we never went out to a restaurant or went out with our parents in the same way, we never travelled with them! (Discussion, females, trailing boomers.)

\section{Boomers looking after parents}

A number of participants were or had supported their parents as they grew older and in need of care. For some this had coincided with time caring for dependent children. For others, caring for dependent family members was sequential.

In our generation, there seems to be a new dependence - you just get your kids off your hands and then your parents become dependent (male, leading boomer).

Boomers are looking after their kids, who are still at home or have come back, and are looking after their parents, so they are actually quite busy (agreement) (male, leading boomer).

Caring for parents as well as other family members was not a wholly negative experience, but did require good management strategies.

I had my mother living with us for quite some time, and the children enjoyed it... On the downside you've got to be very careful... with your partner... make sure you spend time with them... (agreement) (female, leading boomer).

For some decisions about providing care or support were not easy. 
My mother fought against moving into a rest home...but she couldn't live at my place, she was depressed, very difficult to live with... (male, trailing boomer).

My mother-in-law became sick and we had to make a very quick decision (about residential care) which was very hard to make. We didn't want to make a decision because we hoped that she would come back home (from hospital) (female, leading boomer).

Caring from a distance was part of reality and something that many boomers felt was a greater issue than it had been in previous generations.

I'm very aware that father is in (a distant city), if he needs care, none of we three children will go there to look after him, whereas before we would have been in the same neighbourhood (female, leading boomer).

My mother had an operation and I couldn't be there physically, but I could make arrangements, and emotionally I was there for her because of phone and email and things (female, trailing boomer).

Changing family structures also complicated care arrangements, though for some boomers blended families resulted in an extended network of family carers.

My parents (living overseas) have split up long ago, but because they are both remarried they will have their partner's support - but my mother has made some sort of arrangement to be looked after, as has my father, so I have a sense that this kind of thing can be arranged (female, trailing boomer).

Some were apprehensive at the thought of needing to provide care for older family members in the future and felt conflicting desires. 
In thinking about it, looking after my partner's mum, she wont be so bad, but I think the dad, he's going to be diabolical trouble... and that scares the hell out of me... and her too... but we'd do it and we are (living) the closest to them too... (male trailing boomer).

There was an expectation that a greater range of care arrangements would be needed and would be available.

If they became in need of care you think of other options... Father had nurses sleeping over... (then) when he had to, he moved to a rest home (male, trailing boomer).

It may be that Mum might have to go into care, and Dad will just have to come and live with one of us. Those are the options, at the moment. We will cross that bridge when we get to it.

They are good plans, but then he may get dementia, or he may break his hip and be unable to work, and then what? He then would need twenty-four hour care.

It seems to me that there has to be stages of plans. (Discussion, mixed group, male and female boomers.)

Differences in intergenerational care arrangements across cultures were identified. A 'Pacific way' was discussed, with a high value placed on family caregiving and on living in close proximity to family members.

Mum lives with my sister and next door to that is my brother and next to that is my other brother and his family... and I drop over every day... and the neighbours say - we love seeing everyone dropping in and out, in and out... just checking up making sure she's ok... I wouldn't let a stranger look after her, and I wouldn't put her in a nursing home (Pacific female, trailing boomer). 
Participants who had emigrated from Europe also spoke of close networks back home with family living near by, different in style to that in New Zealand, where people shift location more often.

Traditionally in (my country) children did look after their parents, and when my parents got married my grandfather was still alive, and my mother looked after him till he died and he was living with us till I was about six years old - and there is still an expectation of that. My parents and siblings are all close (on neighbouring land)... coming from that tradition where children looked after their parents, it's kind of hard to shift from that and... be here alone. (European female, trailing boomer.)

\section{Being middle aged}

A common sentiment expressed was that they felt the same as they had in their twenties - it was only when they realised that those they grew up with were getting older or when looked in the mirror that they were reminded of their age.

I keep bumping into people I grew up with and think they look old (female, trailing boomer)

In your head it's hard to know what age (you are) but it's when you look into the mirror... (female, trailing boomer).

Some wished to be younger again. Others disagreed and felt they had matured in their attitude and approach to life and they enjoyed their stage of life.

(I like the) freedom of this age. It's like going back to what it was like before the children, because you're not tied down (female, leading boomer) 
I don't want to be younger and have all those crises, I liked the decade in my thirties, and I look forward to my sixties (female, trailing boomer).

But there was an awareness of persistent negative stereotyping and ageist attitudes in society. As adults in mid life, some participants had already felt dismissed by others on the basis of their age.

When you get older, people kind of look through you.

They used to turn their heads and look because you looked a bit sexy, but now...!

In shops, shopkeepers (see you as) just another old lady... they treat you as somebody's mother, rather than as a woman, though perhaps that's just me thinking that.

(Female trailing boomers.)

\section{Thinking ahead}

When asked to think ahead to their life in later life, some found this hard to do. Both older and younger boomers felt this way.

It still seems like its miles away and unrealistically what I do now doesn't seem to bear much relationship to that (female, leading boomer).

Some were just beginning to think ahead.

In the last few years l've been thinking more of the future, trying to become more financially secure...it's on my mind more than it was 15 years ago... (male, trailing boomer).

Others felt the need to plan for older age was not yet upon them. 
I feel I'm still at the stage where l'm still raking it in, still preparing myself for that (female, trailing boomer).

I'm relaxed about that, choosing not to because l'm looking long term... it would be different if I thought I only had 5 years to live (male, trailing boomer).

Male boomers recognised their reluctance to think ahead.

We sort of think we are indestructible, invincible and we don't sort of think of the future... (agreement) (male, leading boomer).

Sometimes inability to think ahead was due to a belief life would be short.

My family also hasn't lived very long and I don't expect to reach 70, so my talk for the last 20 years has been 'if I make it', 'if I last that long'... (male, trailing boomer).

I haven't managed to accumulate a lot 'cause I never thought l'd be around for that long...suddenly l've got to 53 and might be around for longer than I thought (male, leading boomer).

One participant expressed a sense that time was catching up with her.

I'm just beginning to get that feeling that, when I go somewhere, this might be the only time I get to do this in my life, which l've never felt before (female, leading boomer).

Another felt old age was close and this was something she needed to adapt to.

Older age...it's getting close to me now. ...it's frustrating because your physical strength is waning...it's about letting go of some things, those 
expectations...acceptance that you are getting older... (female boomer, mixed group).

\section{Expectations of future lifestyle}

When asked to think about their future, many looked forward to a time with more freedom from obligations, less responsibility. They imagined themselves living a more leisure orientated lifestyle as they got older, often in a coastal or semi-rural environment.

I've always thought of myself as living in an open plan cottage by the beach, nothing flash, with a deck, in a small seaside village, up north. If my children were off, I have a vision of myself in little two bed roomed stone cottage by a river... with a pretty garden.

(Females, trailing boomers.)

These boomers anticipated an active lifestyle in older age. Many expected to stay involved in paid work to a later age than their parents. But a number of participants remained unsure about their future level of work. They knew they wanted to remain active, but they had not yet decided what balance of work and leisure would be right for them.

My observation is that the people who keep active seem to live for a lot longer. The ones who become stagnant are the one's who have problems. So the idea is to keep active and have an interest all the way through your life (boomer, mixed group).

I hope to be still riding horses and skiing down the mountain! (Male, mixed group.)

Some planned a semi-nomadic lifestyle. 
We have a notion of caravanning... around New Zealand and overseas (male, leading boomer).

l'd like to have a mobile home to travel the country (female, trailing boomer).

I think a lot of people in our age group would like to split (their time) live six months in Australia, six months in New Zealand (male, leading boomer).

Travel was commonly mentioned as one of range of activities they wished to pursue.

We want to travel around the country. For us home is a base (female boomer, mixed group).

I want to be the older person who my kids say "haven't heard from mum for a while, last I heard she was driving somewhere in Iran"... (and) on some motorbike, or in the combi van driving from London to Singapore (female, trailing boomer).

Previous travel experiences influenced expectations.

In my sixties I would like to live overseas again and maybe do some kind of work...it would be nice to be able to afford a little travel too! (Female, leading boomer.)

I didn't do it earlier (so) that's something for me that I'm desperate to do. (female boomer, mixed group).

Those with family overseas also anticipated travel, or a shift to be closer to children. 
I see a lot of our children moving to Australia... I see our kids have a lot more opportunities and experience there and so that might draw us to Australia (male boomer, mixed group).

Some participants anticipated more local travel in years ahead, either because they had already explored overseas, or because they anticipated local travel to be an attractive and more realistic option due to economic and environmental constraints.

I feel like I'll have done my travelling before I retire, I want to just hang around in NZ... it's beautifu!! (Female, trailing boomer.)

Sustainability issues (might be a barrier), green issues, carbon miles... It might take three months to get across the world again in a sailing ship! (Female, trailing boomer.)

I think we will be constrained by what's going on in the infrastructure, global change, rising sea levels, rising cost of travel, higher risks, new global diseases.

(You) cant go travelling overseas on a pension!

(Males, leading boomers.)

Personal constraints on travel in mid and late life were also anticipated, such as health changes or family commitments.

I just want to have enough health to still be able to travel and do the things I want to do, still be mobile (male, leading boomer).

Family commitments (may be a barrier) because if you've got sick parents you are not going to do the overseas travel in retirement (female, trailing boomer).

I want to go travelling before our old age (male, leading boomer). 
Some boomers anticipated little change in their lifestyle. Life in older age would be much as it was now, with perhaps some adaptations to accommodate ageing bodies.

I think I would like to continue as long as I can, doing the same things as when younger. I'm going to continue being active... and training...there's a continual growth no matter how old you are. Age is no barrier to change! (Male boomer, mixed group.)

Still playing scrabble and going for an occasional swim, and of course engaging in a little bit of lovey dovey... and taking out the bike and going for a ride. Very much the same but a little slower it think! That's my vision (female, leading boomer).

More time spent with family members was anticipated.

Hanging out with family, with my grandchildren ...lovely! (Female, trailing boomer.)

Grandparenting was viewed positively by both men and women, and was a motivation to stay healthy and fit. These boomers wanted to be youthful and active grandparents.

We've just found out that we are going to be grandparents... it made us realize that we want to be younger and fitter as grandparents... so we can grow up with them, and still go down to the beach, go out fishing and swimming with the grandchildren (male, leading boomer).

I would like to be a grandmother. My 25 year old daughter is still a student, she's married... so that would be a big part of my life, to have grandchildren. I had wonderful grandparents, my children had wonderful grandparents (female, leading boomer). 
For some grandparenting could not come soon enough.

I look forward to time with grandchildren. But... if they wait as long as I did to have their babies, my time of active grandparenting will be short (female, trailing boomer).

I want to have input into my grandchildren's lives... I would like to stay home and look after them (and) have time to do that...We're going to have some serious talks soon! (Female, trailing boomer.)

However other boomers were happy to wait. For some grandparenting represented being old. Others resisted future care responsibilities.

Someone asked me if I was a grandmother yet - oh my god no! (Female, trailing boomer.)

I want to be a grandparent but l'm quite fearful that my (teenage) kids will have kids before they are ready, and my visions of me in my fifties travelling the world (will go) - (instead l'll be) parenting grandchildren! (Female trailing boomer.)

Other forms of activity anticipated were creative pursuits, hobbies and retraining.

Whenever I've sold a business or changed jobs, and I've had a gap between jobs l've always done something, (trained for a qualification and) whatever l've trained for l've used later on in life. So that's what I want to do - keep on training (male boomer, mixed group).

l'd like to do something arty (female, trailing boomer). 


\section{Expectations of work and retirement in older age}

Commonly these boomers expected to continue in paid work to a later age than their parents. Partly this was because they recognised their cohort's better health would enable them to work later in life.

Seventy-five year olds these days are a lot healthier. We haven't had our bodies thrashed, not like my old man; he was in the war, went through the depression... (male, trailing boomer).

The removal of compulsory retirement was identified as a major influence. Several boomers talked about the effect forced retirement had had on their parents.

I remember when my father retired at 65, he'd been a hard working man all his life, then all of a sudden compulsory retirement, you are on the scrapheap... and it blew him away for the better part of two years, he didn't know what to do with himself, he lost his self esteem, no meaning to get out of bed every day, it took him a long time to adjust and he hadn't prepared himself for that. He had financially, but he hadn't mentally. So for me, I agree (I expect to retire, and) I like to think I'll still be active, (but) I want to have more choices and fewer obligations... I'll be able to choose more what I do and how I do it (male, trailing boomer).

Some knew they wanted to remain active and they saw work as a way to achieve this. Work was also seen as a way to be productive and to make a contribution.

(I want to) still be able to make a contribution, whether paid for it or not (male, leading boomer).

Others had a different attitude to work which influenced their approach. 
I actually took my retirement in my twenties... I've never taken work very seriously...work is the curse of the drinking class... I enjoy what I do... I have a theory; trust that everything is going to turn out fine and it does... work comes in when you need it... I've always worked hard, and (overworked) at one stage, but I realised I had to stop... relax... (male, trailing boomer).

This participant was confident the choice to work would remain his to make.

I see that continuing... yes if you can do something, someone will want you to do something for them and if you do a good job, you're reliable and people like your company, then you're perfectly ok (male, trailing boomer).

For many there was an expectation that employment opportunities would be there for them. Some participants recognised that older workers may be in greater demand.

They'll be wanting everyone (to work) you'll be lucky if you're allowed to stop! (Male, trailing boomer.)

Others recognised potential constraints on working.

There are less job opportunities after 50 - that seems to be a cut-off for most jobs.

Yes, but not so much these days.

(Females, trailing boomers.)

Some worried that boomers' expectations were characteristically unrealistic.

We have much higher expectations of what we want to do, (which) may not be realistic. 
Our generation have bigger horizons.

(Males, leading boomers.)

Some feared a loss of income and limited ability to do anything about it.

The thing that worries me and what l've heard from other people is the incapacity to be able to go out and earn some money... if things are tight and if you've some financial problem, you can't just go out into the workforce and earn money. That is something that I find very scary.

I don't want to be in ill health and have no money... because in our society at the moment you don't get any opportunity to increase your income.

Sometimes there are also physical restrictions without the financial problems.

(Male and female boomers, mixed group.)

Commonly participants were optimistic about work opportunities. Some found it hard to imagine no longer working.

I can't imagine ever stopping work - its one of the joys of life, doing stuff, achieving things (male, trailing boomer).

I don't have any plans to do less employment, 'cos I get bored too quickly (male, trailing boomer).

Some younger participants had greater difficulty thinking ahead.

I'm not sure - 20 years time I'll be $62 \ldots$ I'll be still working I think... it's hard to think that far ahead... I think about what l'd like in the next five years... but there's still a lot to do in the meantime... I really find that quite hard (female, trailing boomer). 
I'm not looking that far ahead, I'm making the most of what I'm doing now (male, trailing boomer).

Some older participants remained unsure about their future level of work and had not yet decided what balance of work and leisure would be right for them.

I find the notion of retirement problematic. My parents retired at 65 and played golf and got in the garden... for me I cant see myself stopping, I will do work of some sort... I feel ambitious... but l'm wrestling with the idea, as I turn 60 soon (male, leading boomer).

Some participants did look forward to a time when they could reduce the amount of work they were involved in. For some this reflected their view of older age as a time of fewer responsibilities, an opportunity to reflect on a full life and to reap the rewards of a life well lived.

Old age is to be able to relax and do the things you've always wanted to do, without having responsibilities of needing to keep the bank manager off your back... 'cos you've done all the hard yards and its 'time for me' time (male, trailing boomer).

Others viewed retirement as a negative marker of old age. For them stopping work was equated with decline, physically and psychologically.

Older age is retirement... not being able to lift above your shoulders, not being able to do a good solid days work... injuries that take 3 or 4 times longer... so I don't think I'm old yet (male trailing boomer).

If you go out fishing thinking you're old, that's fatal, isn't it? (Male, leading boomer.)

Most participants could anticipate reduced paid work at some point, but they expected the transition out of work would be a gradual one. 
It needs to be gradual - I love the notion of more time, but to go cold turkey - particularly when your chums are working... (female, leading boomer).

There were some who were already altering their pattern of work or were actively anticipating the need to alter their work to accommodate bodily ageing. Those in physically demanding jobs were especially aware of changing capacity as they aged.

At 50 that's when you start looking at other options (female, trailing boomer).

For many, 'retirement' included some work, both paid and unpaid.

I will not completely stop work...my father retired at 65 but he kept doing odd things for people, keeping himself busy. I think that's important as you get older (male, trailing boomer).

A smattering of sometimes working sometimes not, the mix changing as I get older (male, trailing boomer).

Some felt it was important to not assume by the time they retired they would still have the economic or physical capacity to put their plans in place. They therefore looked for opportunities to live a life of 'retirement' even before they retired.

I have my own super...but I fear the economy will change and that may wipe it out... all the efforts of the last 15 years may go... so its pretty dicey, health is dicey, financial situation is dicey, economy is dicey, so you should just do what you want to do now, and not think you'll have all this time in 10 years (male, leading boomer). 
Yes, l've watched friends with health scares - my partner is wondering should we do it now... but I wonder if this (do it now approach) is distinct to baby boomers, compared to our parents who went through the war, knew about the value of thrift and it was a much more structured approach and in leaner times (male, leading boomer).

Participants identified push and pull factors when they talked about their expectations for ongoing work. For some what they wanted to 'retire' from, was not work as a whole, but some of the conditions of work.

It's something to do with wanting to get rid of obligations and stuff but at the same time pick up commitments that are more meaningful.

For me also, it's a matter of living a variety of life... (getting away from) the suburban work commute thing... I need to do that (work) right now... but l'd like something new.

(Males, trailing boomers.)

Many boomers stressed that what was important to them was having the choice to work longer and the freedom to make the decision as to when and how to stop working.

I don't see myself stopping work until l'm ready... it will be under my terms (male, mixed group).

This valuing of choice was apparent in many boomers' perceptions of retirement. Some were apprehensive that choices may be reduced, as became apparent when discussing current policy emphasis on working longer as a way to cope with an ageing population.

Retirement is - not having to do work you don't want to do (male, trailing boomer). 
I contribute to my country by paying taxes... and I can see myself maybe working a couple of days a week...but I don't want to feel that I should have to work longer than I want to (agreement)... I know our productivity per head is not as high as other countries, and so that's why the Government's message... but bugger that (agreement)! (Male, mixed group).

But there were also those with a more optimistic view and a feeling that policy would meet boomers needs and wants.

It's going to be great, 'cos demographically, if government wants us to work, they are going to have to make work that suits people like us. Unless they are going to compel people, (but) imagine the quality of work you'd get (laughter)... they are going to have to make it attractive and that means all the things l've been saying about the kinds of things that would suit me at that point in my life. I don't want to work a 40 hour week at that stage but I might be interested in working 10 or 15 , or whatever, working from home, all of that (male, trailing boomer).

\section{Attitudes to Planning for Late life}

Some anxiety about the future and inadequate preparation was apparent.

I'm concerned that I'm not going to have any money... I would be much more concerned if I was less well off (male, leading boomer).

You look at the paper that say what you need for your care - I'm earning a reasonable amount and think I can only get half of that, so for others it must be totally impossible (male, leading boomer).

Every so often I pinch myself and say to myself - you're 56, you've got to get real - there is this concept in my brain that old means 80 and 
how am I going to live, but l'm not doing much about it now (female, leading boomer).

Some participants felt they were not good at planning ahead for their older age.

I'm not good at planning, I live for the moment and don't think too much about the financial reality... there's far too many steps to think about where I'll live... and the world is changing... what's it going to be like? (Male leading boomer.)

Many believed that boomers were characteristically unprepared.

I have this mentality that I think is different from other generations where it's a little of 'right now' (female, leading boomer.)

I think it's a characteristic of our generation as well, because there are a lot of people in our generation who have not thought forward to the future at all... (agreement) (female, leading boomer).

Participants felt they should be planning more.

We have much higher expectations of what we want to do, which may not be realistic... but the reality is... you do have to think about how you can cut your costs (male, leading boomer).

You need a balance between living now and the future, you have to put money aside for the future. Not that I think the state pension wont be there, but I would hate to have to live off it alone, its not enough, you have to live a frugal life, pretty impossible (male leading boomer).

Yes you've got to (think ahead), I only have a few more income years... I must admit I've done nothing about financial planning for the 
future, l've tried but not followed it through, (but) I don't want to discover at 60 that its only 5 years away, what am I gong to do now (male, trailing boomer).

Others felt that too much planning could be a waste of time.

You have goals and dreams from day one...but circumstances change and you have to change track (male, leading boomer).

The thing is you don't know what's going to happen. That's why planning too far ahead is a bit silly (female, leading boomer).

Some felt unable to plan due to current responsibilities.

Well l've still got a child at home. We won't be making any changes till she leaves, and I don't know when she's going to leave, she may be staying till she's 40 ! (Female, mixed group.)

When we were first told we have to save for our retirement, we said...we have to put our children through university, we're supposed to look after them, and look after our parents, and save for our old age at the same time. So there's been a squeeze put on us (female, leading boomer).

They say to live comfortably at 60 you are going to have to save $\$ 60,000$ and I'm thinking how on earth am I going to achieve that on top of everything else? (Male, trailing boomer.)

Planning may have been delayed due to other commitments and changes within the family affected thinking.

I have to go to Australia (for better work)... 'cos I've been a single parent for 20 years... But I'm behind in terms of plans... (male, trailing boomer). 
Our daughter is back home with her child, so we are supporting them at the moment... that wasn't planned at all... that taught me your best plans can get out of kilter, so we have stopped planning (male, leading boomer).

Some boomers felt frustrated that careful preparing for their older age through saving could yield little benefit.

What I find irksome I suppose, is that we saved hard when we were farming, we had little to come and go on. A lot of our friends have had trips, and so on, and spent their money.... and at the end of the day they're going to have to be supported in their old age because they haven't saved. I don't have a problem with those who have never managed to save money for their old age because they've never had any. What I do have a problem with are those who have had a lot of money and who have just frittered it away (female, leading boomer).

Some recognised that boomers were being encouraged to save for life in older age to reduce costs to the state and found this a bitter pill to swallow.

We are the generation who missed out on the benefits of KiwiSaver (male, leading boomer).

It's only for the last 10 or 15 years since they've been saying we have to save for our own retirement (female, leading boomer).

Several participants identified socio-political and environmental changes at a global level as adding an additional layer of uncertainty to planning.

Changing global politics may affect us, the economy may go... (male, leading boomer). 
It was apparent that some participants were future-orientated planners who thought well ahead, while others were focused on the present.

The only asset I have is my house and l've just remortgaged that 'cos of some financial difficulties..._ live for the moment and don't think too much about the financial reality (male, leading boomer).

At 45 this is my last twenty odd years to earn a good income before retirement. I see a lot who are struggling. My partner wanted another child, but I said we'd be into retirement... (it would have affected our) chance to set ourselves up (male, trailing boomer).

For some there was also a feeling that adequate financial preparation was just too difficult to achieve.

I met someone who, many years ago, had a million dollars, this was back in (the 1970s), and he lived until he was 82 (and) they struggled for money towards the end, because it doesn't take long to use it up. So what we think is enough to retire on to lead a reasonably good life... financial advisers now say that we are going to be struggling (boomer, mixed group).

I still have a seven year old and can't see me (as 'retired') - I heard on the radio some financial advice "now that you are 40 and your mortgage is paid off" - what world are they living in?! (Female, trailing boomer.)

Others expressed a sense that even if they tried to plan it may not make a difference.

Providing you have the plan in place early on... it's a bit hard for me to start planning for retirement now... and keep working on it. 
You have goals and dreams from day one...but circumstances change and you have to change track.

I think a lot of where we go from here in the next 10 or 15 years is already set in what we've done... so I don't see how it's going to change dramatically.

(Male leading boomers.)

Some participants had experienced unanticipated events that had affected their approach to planning, such as a marriage breakdown or a health scare.

I don't care a ${ }^{* *} t$ about retirement any more, because l've lost my way (since my marriage broke up), because in fact l'm worn out! (Male, leading boomer.)

You don't know what's going to happen... you'll have things happen, unplanned illnesses in your life, its not all bad, its just the way life is... so I suppose it does make it hard to plan... life is uncertain... so I think, just have fun (male, trailing boomer).

Preparing was recognised as involving more than just financial preparation. It included looking after health. Lifestyle changes were also apparent. Preparing the home was also identified as part of planning.

I no longer smoke (male, trailing boomer).

I'm not living as flamboyant lifestyle as I could be now cos I'm thinking of the future (male, trailing boomer).

Trying to get your home low maintenance and so on... (although) I'm not sure if it's right, because if I did that, then l'd have nothing to do (male, mixed group). 


\section{Discussion}

These participants viewed boomers as a distinct generational group, different to older and younger generations as a result of events and circumstances they had commonly experienced while growing up. Many articulated and appeared to have internalised common discourses about the boomer generation.

Some participants externalised the boomer generation, referring to 'they' rather than 'we', even though participants' involvement in the focus group was on the basis of their membership of the boomer cohort. There was some uncertainty amongst participants as to the boundaries of the boomer generation, with a few saying they had been surprised to find they were themselves a boomer. Nevertheless, a belief that boomers had a common identity was apparent.

While there was acceptance of a boomer identity, participants did not always agree on the key characteristics of the boomer generation. They recognised there were multiple influences shaping boomers. Perceived differences between members of the boomer generation were therefore seen as a result of individual circumstances, including religion, ethnicity and place. Shared experiences they identified as influential included the political and economic climate, the social policies of the welfare state, fashions and social trends promulgated through the media, and new technologies including computers, aircraft and health technologies.

Commonly, boomers were described as a pioneering generation, desiring of change and prepared to create it, in a way the previous generation had not and the next generation didn't think about. Participants commonly felt that boomers had fought for and created new opportunities, especially for women and for minority groups. Both older and younger boomers felt they had benefited from, and contributed to an increasingly liberal society and there was pride in their achievements. 
Continuities across the generations were mentioned. Participants felt they had similar cultural interests to their children, which helped them to enjoy time together. Participants also recognised they had learnt from their parents who had instilled a range of positive values, including a strong work ethic, and there was a common discourse of the previous generations' sacrifices, at war and during the economic depression of the 1930s.

However participants felt they had rebelled against the values they saw as outdated and negative, including racism, sexism, conservatism, and a more passive attitude to authority within the previous generation. Some recognised that rebellion was a behaviour each generation exhibited when they were young, but there was a common view that boomers were especially rebellious, more liberal and more assertive than their parent's generation had been.

Participants recognised they were part of a much more diverse population, ethnically and culturally, with many more choices than had been the case when their parents were their age. Greater choice was seen as both negative and positive, allowing greater opportunities but creating more stress. The boomer generation was viewed as being responsible for many of the changes that brought more freedom of choice.

Participants also recognised diversity within the boomer cohort which was viewed as a consequence of rapid societal change and individual circumstances. Rural boomers felt they had a distinctive perspective. Maori and Pacific participants and Christian participants had broader views of influences and it seemed their attachment to a boomer identity was not as strong.

Many of the boomers in the focus groups were actively thinking ahead to their old age and some were planning with the future in mind. Their dreams for their personal lifestyles were generally optimistic, though they recognised and sometimes worried about potential constraints. 
Participants commonly felt that boomers had high expectations and some wondered just how realistic their generation was. There was a strong sense that life was less predictable now in comparison to their parents' experience. This meant opportunities as well as some uncertainty.

A number of cross cutting themes emerged and these are summarised below.

\section{View of selves as a lucky generation}

This was a strong theme, expressed by all groups. Many felt they had been brought up in times of prosperity and security and they believed they had benefited from a supportive welfare state and a stable economy and a peaceful and optimistic post World War society during their childhood. Technological developments were also seen as having provided boomers with new opportunities and improved health. New opportunities for women and minority groups also meant they felt luckier than previous generations. Some however recognised that not all had benefited equally from the 'good times' of their early years. There was also a sense that boomers' luck may be running out, as they age within the context of population ageing, global economic recession and reduced welfare.

\section{Nostalgia for the past and concern for the future}

There was a sense of nostalgia for the 'simpler and less stressful' society of their younger years and criticism of individualism, consumerism and materialism, and the fast pace of change. Participants expressed concern for the economic and environmental conditions facing the next generation. Older boomers who had been active politically expressed pride in their achievements and concern that the next generation did not appear to have a similar commitment to social justice and human rights issues. 


\section{Sense of responsibility for society's problems}

Some felt the social 'revolution' they had been involved in had some negative consequences. A number felt that boomers' hedonistic tendencies and indulgent parenting styles had contributed to a more individualistic society and a more self-centred younger generation. These participants were critical of boomers. Some viewed boomers as selfish and self indulgent, failing in their marriages and failing as parents to pass on values of thrift and the importance of hard work.

\section{Desire for Work / Life balance}

Many older and younger boomers saw themselves as having a strong work ethic but there was also a strong desire for work/life balance. There was a desire for choice and autonomy in decision-making regarding participation in the workforce and a valuing of leisure activities and time with family.

\section{Recognition of Change in Family Roles and Responsibilities}

Participants noted change in family structure, roles and responsibilities compared to the experience of their parents and grandparents. They recognised greater diversity of family forms at present and less formal relationships between parents and their children. They noted that geographic distance between family members required new methods of communication and support. They also noted that periods of dependency had changed, with boomers' children likely to require support for longer, while their parents were likely to be older before needing additional support. Some boomers had or now lived in multi-generation households and these were commonly viewed positively, but most boomers expected older family members to live apart from their family. 


\section{$A$ redefining of retirement}

Some participants struggled with terminology, questioning the meaning of retirement. Many participants expected to continue working in old age but to gradually reduce their level of participation. 'Retirement' from work was viewed as a choice they wished to retain. Retirement was talked about as a lifestyle which could include paid work. Some were already working part time as a lifestyle choice. A range of 'push and pull' factors were identified as influencing decisions about workforce participation.

\section{Scepticism about retirement planning}

Some scepticism about planning was evident and a range of influences on and barriers to planning were described. Some felt that boomers were characteristically poor planners. Those who said they were less inclined to plan identified that things can happen that you can't control for, including events within the family, but also events at a national and global level.

\section{A globalised view of society}

The impact of globalisation was a theme emerging in most groups, with a focus on environmental, economic and workforce issues. Global warming was mentioned as an issue that added a layer of uncertainty to planning. Migrant workers and flows of workers between countries were mentioned, with concern about workforce shortages within New Zealand, but also an awareness of work opportunities for boomers and boomers' children. Dispersed family networks and the impact of family living in different countries were significant areas of discussion. 


\section{Intergenerational concerns}

These boomers expressed respect for the previous generation and concern for the next, with a strong sense of responsibility that runs counter to a common stereotype of boomers as selfish and self centred. Now in mid life, these boomers were acutely aware of the needs of both younger and older generations. Many expressed concern about their ability, as individuals, to meet both their own and their family's needs in the future. They were also aware that as a large cohort, boomers required a significant slice of state resources and they were aware of concerns about intergenerational equity (see next chapters for discussion of this issue).

\section{Chapter Conclusion}

This chapter presented Part One of findings from focus group research with boomers. In the first half of this chapter boomers' sense of themselves as a distinct generation was described. Boomers talked about influences and experiences as children within baby boom families, as young adults, and as adults in mid-life beginning to think ahead to their own ageing. In the second half of this chapter, boomers' attitudes to work and retirement and their sense of preparedness for late life were outlined.

Chapter Five has focused primarily on boomers' mid- life experiences. In the next chapter, our attention turns to late life. Chapter Six presents Part Two of research findings and reveals boomers' attitudes to old age and their expectations of late life. 


\section{Chapter Six: Findings Part Two: "When I grow old..."}

\section{Introduction}

Boomers in the focus groups saw themselves as a distinctive cohort in terms of their attitudes and experiences and believed they had been a lucky generation. While optimistic, they had some concerns about the future and their preparedness for late life.

In this Chapter, participants' attitudes to growing older and their expectations of life in old age are explored further. Their feelings about growing old and their hopes and concerns around health, housing, living arrangement, care and support are identified. Boomers' views on their ability to influence policy and their expectations of support from the state are also outlined.

\section{Views on Boomers in Late Life}

\section{Thoughts about old age}

Boomers in the focus group were asked what old age meant to them. A common response was that the period of old age had shifted - that 70 was the new 60 . Becoming old was represented by a change in attitude and lifestyle. This meant you could choose when to appear to be an 'old person'.

Times have changed, just because you are getting into your 60s and 70s, life doesn't stop there anymore... now we are aware that you don't need to be 'old', if you want to, you can still 'do it'... pick up your fitness and do those things you want to (female, trailing boomer). 
You see people (aged) between 60 and 75 doing all these brisk walks, doing the Milford Sound Walking track... (male, leading boomer).

I think (for) the (previous) generation... (old age) was.... mental thing more than anything... when they got to 60 they retired (male, leading boomer).

These boomers felt there were fewer social constraints compared to previous generations. Reasons mentioned included a broadening of gender based roles, increased levels of education, more diverse family structures and more liberal attitudes.

There (used to be) so many rules....society is more tolerant now (female, trailing boomer).

Our relationships will be different, there won't be such stereotyped gender roles... fewer older people were separated in those days... they were more likely to be married (female, leading boomer).

Participants felt that it was not just their own generation that was changing what it meant to be old. Some felt that current generations of older people were paving the way.

When we look at our parents' generation, we can see different models - people who have done things differently - our parents haven't all done the same things (female, leading boomer).

There's an old person out there who's done anything now - a role model for everything - (I recall) a guy who died at 104, surfing! You can do anything you want (female trailing boomer).

Some participants noted that representations of old age in the media were more positive (and more common) than they had been. Others felt a greater range of positive role models was still needed. 
The media have a role to play in our society. When they highlight young celebrities as our role models there's something wrong! (Male boomer, mixed group).

Most participants felt that being old had little to do with number of years lived. You could be therefore be old 'before your time' or be 'younger than your years'. Old age was more about behaviour and attitude.

I know very active 70 year olds who do enormous amounts of unpaid work - I think they do think they're old, but behaviourally they are not old (female, trailing boomer).

I was doing work for an 86 year old, but she acts like a 30 year old ...she'll talk and talk...I couldn't call her old. She drives her car, she's financially independent, she's responsible, she runs her life on her own...it's incredible to see it (male, trailing boomer).

When 'number of years lived' was mentioned as a marker of being old, the age at which you might be considered old varied.

70 is a significant age (female, trailing boomer).

80 is getting old (male, trailing boomer).

(People are)...old at probably 80 or 90 (female, trailing boomer).

Old age was seen as a relative category - that is an individual was considered to be old in relation to others. As a result the onset of older age shifted according to the perspective of the viewer, moving upwards as the viewer themselves aged. Hence, participants who are now aged in their forties no longer viewed fifty or sixty to be old. 
To me when I was younger, I thought being 60 was really old, but now I have reached it, the goal posts have shifted again (female, leading boomer).

Some markers of old age varied by gender. Women were more likely to identify changes in appearance as a marker of old age. The men more often talked more about loss of fitness and onset of health conditions as making them feel they were getting older.

Old age is... when you are not able to lift above your shoulders... when injuries take 3 or 4 times longer to heal (male, trailing boomer).

Old means wrinkles, hair on your chin, your face getting old... you look in the mirror and then you feel old (female trailing boomer).

Old age was also linked to family context, work context, and culture. Old age was a therefore a social category and a life stage.

You are an older worker at fifty... and that's when you start looking at other options (female, trailing boomer).

For me its not age that does that to you, its more my 18 and 19 year olds leaving home... that gets to me, makes me more aware of my age (female, trailing boomer).

I noticed that you're really getting old when your kids start to treat you like their kids! (male, leading boomer).

\section{Attitude to self growing older}

Participants did not welcome the physical changes they associated with growing older. 
I now recognise that there's a period when your knees start giving out, it's a gradual process, a gradual decline....and the more I think about it the less I want to (male, leading boomer).

A growing sense of one's own mortality was also expressed.

I'm more worried about health, cos l've had some issues lately - it feels like it could hit me anytime - its statistically getting more likely - and also your chance of being dead is higher as you get older and I'm not happy about that! (Female, trailing boomer.)

I was thinking of time... wanting more time... (female, leading boomer).

Many participants expressed concern about losses in old age - loss of physical strength and wellness, loss of their mental faculties, loss due to separation or death of friends and family members, and loss of respect and security. Fear of a decline in health was a recurring theme.

I'm a bit scared of it, I don't want to think about being 80, I don't want to get Alzheimer's...it's the unknown... my mother had Alzheimer's and her whole world closed in around her, which must have been claustrophobic (male, leading boomer).

Participants feared losing their independence as a result of poor mental or physical health, or through loss of work and income. Male participants spoke strongly of their fear of becoming dependent on family or having to rely on carers.

I think our independence is very important to us (male, leading boomer)

I would like to be independent, not be in care, have mobility and all my senses (male, leading boomer). 
I wouldn't want or expect my kids to put up with me. l'd like to be independent (male, trailing boomer).

Its (your kids) who get to choose the retirement home...the lack of control over your destiny... that's the bit that sounds scary to me... (male, trailing boomer).

However, many participants were optimistic about their own older age. They anticipated having more time to spend doing the things they enjoy.

I'm looking forward to having space - an internal space - I look forward to that (and to) freedom when my kids are older (female, trailing boomer).

I want to have more choices and less obligations. I'll be able to choose more what I do and how I do it (male, trailing boomer).

Some looked forward to older age as a period when they could give to others, through support of grandchildren and other family members who might require it, and by offering their accumulated experience and skills to others in the community. Older age was a 'chance to give back to others'.

l'd like to take on a bit of part time work or volunteer work (male, trailing boomer).

I'm looking forward to connection... to connect in a contributing way... (female, trailing boomer).

I can imagine myself giving support, like in a crisis, supporting (my) child or grandchild (female, trailing boomer).

Remember (your) parent has given all your life, it's a time for the tables to turn (female, leading boomer). 
Older age also meant being released from pressure to conform.

I will be a different person when older... and not having to conform to peer pressure like you did when you were a teenager... I can be out of fashion... (female, trailing boomer).

A common view was older people should be respected and acknowledged. Maori and Pacific participants most clearly expressed their view of older people as honoured elders, within the family and community. For Maori participants, being an honoured elder also meant increased responsibilities.

It's your time to step up and take the place of your father/mother for your grandchildren. There are older people who are revered, respected who pass on all their knowledge they have and experience to others (Maori male, trailing boomer).

A Pacific view was also expressed. Elder's lifetime contributions were to be rewarded and support of elders was a family and community priority.

Its important for my kids to understand how to value older people - I don't mind if they go overseas and disappear for a while (like I did for 10-15 years) but there's a time you come back, you need to come back... you don't forget that... there's things they need to understand... older people are just as important... (it's about) acknowledging... (my mother) she's still head of the family, not financially, but she has that status (Pacific female, trailing boomer).

I've been influenced by the 'Pacific way' - I'm trying to inculcate this onto my children - where when your parent is old they come to live with you... I don't view my children as having any obligation to look after me, but that is so foreign to parts of the Pacific that I travel and work in ...you'd have them with you, they'd come down... and I can see the value of that (female, trailing boomer). 
But many participants felt that older people were not treated as well as they should be and were disrespected by younger generations. Some felt this had been getting worse in recent times, while others were not so sure.

Once upon a time old people were respected, because that's how you were brought up, but now there's no respect (Maori female, leading boomer).

When I think of my parents in (a Pacific country) we showed huge respect to them... the culture for my kids has hugely changed since then...for my kids things are very different because they were born here (male, leading boomer).

Participants felt older people should be valued, but were instead subjected to ageist attitudes. Some expected this would happen to them.

The worst part is being patronised - such as by the media who publish stories saying 'isn't it amazing' that they have done such and such l'm not looking forward to that - cos your body looks old (female, trailing boomer).

(To me old age is) not fitting in to the rest of society (male, trailing boomer).

But there was also confidence that their own experience of older age would be better than it had been for earlier generations. Participants agreed there were many ways to 'be old' and most expressed optimism about their own future choices.

I don't think society looks after old people (but) I think society will by the time we get there! (male, trailing boomer).

(To me old age) is whatever you make it (female, leading boomer). 


\section{Concerns about health and well being}

Participants were concerned about how they might cope with physical change as they grew older.

Watching people grow old is very rarely a positive experience... My partner's mother - her body is packing up - I don't want to go there (male, leading boomer).

Some recognised that poor health could be a barrier to the active life they hoped for.

What I see as scary is (that) the things I want to do when I retire, I don't know whether I'll be able to do them any more. I don't know whether my health will be good enough to do all those things l'd like to do, and that troubles me (female boomer, mixed group).

It just feels scary.... I don't expect to live a long time! I don't want to be in ill health and have no money (female, leading boomer).

Some boomers mentioned the importance of maintaining good health as long as possible.

My partner and I have talked about this and we actually push each other to stay reasonably healthy because we want to be able to share retirement together, we want to do the walks, we want to be able to go sailing, we want to do these things together, and it would be terrible for one to be healthy and one to be not (male boomer, mixed group).

I was on a fast decline, but I got better, lost weight, got fit, I enjoy feeling energised - you can do it... the body responds...though it might not at $70 \ldots$ use it or lose it (male, trailing boomer.) 
Being healthier... means that I don't want to go and be a burden to our children (male, leading boomer).

Some were positive about their prospects for good health, while others were not.

You turn into your parents - my dads healthy so l'll be all right.

My Dad had a bypass at young age, so l'm a bit concerned.

(Discussion, males, trailing boomers).

Loneliness and isolation were also mentioned as concerns.

I see too many old people who on the surface are living ok, but their lives are so lonely and they are so isolated. They lead desperately lonely lives, in fear of violence and attack (female, leading boomer).

It can be scary to be (living) alone (male, leading boomer).

Having good support networks made some feel more confident.

I'm part of big family anyway, and they're quite close, so l'd never feel alone (female, trailing boomer).

I don't fear old age. I feel that l've lived a life that will result in there being someone there for me. I have children that l've brought up, that I've loved well, who are wonderful young people, and I feel that even if my present situation changed and I was back on my own, that I wouldn't be alone, that I may live alone, but l'd never be left alone (female boomer, mixed group).

The availability of health care and residential care was an area of concern. 
We may be the generation that just misses out on advances in medicine, our children will benefit (male, leading boomer).

The demands of health care will be so high, far more (so), and its already high... I don't think anyone knows what will happen when the vast number of us hit our 80 s... the baby boomer at 80 , or 90 , we will need double the number of hospitals and rest homes (male, leading boomer).

The availability of home support services was also identified as a current concern.

(Home support) is a huge problem... it is very hard to get in rural areas... there are anomalies... we do lack a cohesive health support service... it's so fragmented... it's a major problem (rural female, leading boomer).

We've got an incredible system these days where people are supported living in their own homes for as long as possible. There are so many systems out there now.

I'm not so convinced about that.

(Discussion, male and female boomers, mixed group.)

(People are saying) that rest homes would become a thing of the past (agreement) cos you can stay in own homes with support.

Yes but the quality of the care, it's not reliable.

(Discussion, females, leading boomers.)

Policy supports ageing in place, but there are problems and tensions... resourcing is fragile... I think the state will cut back ... its easier to cut back on the ramp or the home support (male, leading boomer).

Some remained optimistic that their needs would be met. 
It's your network of people our age, friends, that we will create our own environment of support.

It's going to be articulate people like us who will get on the phone and ask for support.

Collective groups like Grey Power or Age Concern will play a role.

We will create alternatives!

(Discussion, males, leading boomers.)

\section{Making decisions about housing and location}

As discussion progressed, some boomers commented that housing needs could change and adaptations may be needed as they grew older. A positive attitude prevailed.

Managing at home is about attitude - embracing your health ... I meet people who say, well I'm going to be old and my health is going to disappear - there is that stereotype where you're going to enjoy bad health because you're older, but that is not necessarily the case... going up and down the stairs is good for you, so you stay in a house with stairs (female, leading boomer).

Some recognised they may need to move from their current home.

I know the reality is no matter what house you choose, when it comes to the day, it may not be right (female, leading boomer).

Downsizing was an option some considered.

I'm concentrating on getting the house freehold, then I'll downsize, take half the equity - that's the form of retirement I'm looking forward to... if 
the house is too big, I'll go to a two bed unit somewhere (male, trailing boomer).

This place (house) is my superannuation... we'll just downsize... that's why we put so much into this place (male, trailing boomer).

But others wished for more space that included enough room for family to stay.

l'd like to be in a bigger place, because l'd like everybody to come, the grandkids, friends... my mum has a big house, with six bedrooms and at Christmas we can all come and all fit and I like that... I'd be the wise old granny that everyone wants to come to if they are having trouble (female, trailing boomer).

We're now looking for a home where the kids can bring their friends home... you know, a child friendly house, and dog friendly (as) my kids have got dogs (male, leading boomer).

Rural boomers were divided on whether a move off the farm would be needed.

We'll (stay rural)... absolutely! And that is why we bought a house that was on the flat on one level... we don't want to be shifting out of here in any great rush.

Moving depends if you want to release some of your money really (agreement).

That's one of the things for a lot of farmers, their savings or retirement scheme is tied up in the farm, so to realize your retirement scheme you may have to lease the farm, or sell.

We bought the farm cottage....the kids had the run of the property. 
Friends decided when he was 65, that they needed to get off the farm and they went straight into a retirement home... and he absolutely hated it.

If it came to the stage where I couldn't drive and I had to leave the farm, I wouldn't hesitate to go into a retirement home.

(Discussion, female rural boomers, mixed group.)

For some an emotional attachment to the family home also influenced thinking.

I don't intend to leave my house ... I have everybody's height measure on the side of the door...I would have one of those stair chairs put in.

I don't have attachment to a house at all, I have moved round quite a bit. I'm in a house that suits me for now.

(Discussion, females, leading boomers.)

Choices were influenced by country of birth. Participants from Europe remarked on New Zealanders' high propensity to relocate.

My family have lived in same house for generations and never thought of moving - its different here (female, trailing boomer).

Some migrants planned to spend time in two locations - both the country of their birth and their adopted country.

You think about what are you going to do when you retire... that's why I've built this house in (Pacific home country), we are not using it now, but the plan is we will have summer here, summer there... you have more money to do things like that... that's 'the plan'... but it might change next year (Pacific female, leading boomer). 
A desire to live close to family was mentioned, but this could be difficult for some boomers to achieve.

My partner is a Kiwi, but I'm from (another country) where my parents are and I have a step child born in NZ but living in (a third country) - so there's no way we can ever get it right, no way through it (female, trailing boomer).

I am now happy to be here in this country but ... I know my children will want to live (in European country) and at least one may choose to stay there and we will be stuck here on our own, and that thought is unpleasant, so I can imagine going back there to be where we can grow old with our family... have the stability of that... where as here in $N Z$ friendships are not stable in the same way (female, trailing boomer).

If my son married overseas, l'd move there to be close to them (agree, disagree), like my sister did, her kids all ended up in Perth... and odds are my son will settle in Asia somewhere... but then my other child will settle here (female, trailing boomer).

\section{Desired living arrangements}

Some participants did not want to live alone. Instead they visualised other arrangements.

I can see myself going flatting again, sharing accommodation (male, leading boomer).

I want to flat with all of you ... l'd like to know I wouldn't be relegated to a house by myself, with or not with husband...l'd like to be able to live with a group, live with a group of women, and do stuff together (female, leading boomer). 
The one thing that I think would be a good idea (is) people of a certain age living together, (as they) could combine their facilities so they can help each other with their minor weaknesses.... I'm thinking of privately arranged enterprises, actually living together, helping each other (agreement).

I think that also happens in retirement villages too... (they are) close knit communities.

(Discussion, male and female boomers, mixed group.)

Others wanted to have their own space but in close proximity to others. There was a common desire to re-create a sense of community and to share resources with like-minded friends and neighbours.

I like the idea of being in some type of communal village in some way... but I don't know what kind... it would be nice to have people close... friends around me in some way... like out at the beach or something.

Yes, but not in same house, in the same area. (Discussion, male, trailing boomers.)

Some wished for a living arrangement that would provide good social support. Innovative living arrangements were proposed that reflected prior experiences of communal living and a desire to move away from current models of independent housing for older people.

I don't have kids (so) I'm thinking, will I have someone there for me... or if my partner dies or we are not together... so a cluster housing situation with friends has some attraction (male, leading boomer).

I would like to live somewhere tranquil... but (close to others) (male, trailing boomer). 
We need to have a way of doing it... where you have an institution that keeps at least $50 \%$ equity... like Abbeyfields ${ }^{18}$, but then again maybe not... but you must be compatible (female, trailing boomer).

'Intentional communities' were mentioned in several groups, as a potential living arrangement built around shared values, such as sustainability.

(With) global warming, some of us may look for self sufficiency, purchase more land and get back into where our parents were and get into growing our own food, supplying our own needs... staying in some kind of community whether it be your own family, or a self sufficient one or a retirement village.

A commune? ${ }^{19}$

Yeah. (Agreement).

(Discussion, males, trailing boomers.)

I like the idea of being in some type of communal village in some way... but I don't know what kind.

In separate dwellings. (Agreement).

Eco villages!

\footnotetext{
${ }^{18}$ There are currently 10 Abbeyfield Houses in New Zealand which provide affordable shared rental housing for older people in 10 areas of New Zealand, with another 4 at various stages of development in other areas. Houses have a live in housekeeper who prepares meals. Dining and living areas are communal. The houses are managed by a charitable trust but with residents involved in management.

${ }^{19}$ Early communes or intentional communities in New Zealand were religious or tribal based. In the 1960s and 70s the commune movement grew as part of 'counter culture' activity, with groups of younger people purchasing cheap rural land in scenic areas such as the Coromandel. In the 70s a government scheme leased land to groups who wished to set up cooperative communities known as ohu, usually in more isolated areas. In the 2000s, Eco-villages are the fastest growing intentional community. Source: http://www.teara.govt.nz/en/communes-and-communities
} 
When I'm that age I want to hang out with my peers... I've been imagining myself as I am now and surrounded by whole bunch of old people, but in actual fact if all my mates will be the same age and interested in doing the same stuff it will be just fine.

(Discussion, males, trailing boomers.)

A desire for a sense of community was a recurring theme in groups.

I love it here (in this) community... Here, you know your neighbours, you put out for each other, you pick up each others kids when you are sick (male, trailing boomer).

We are living where we are because of family, and it is close to work and so on, (but) as those things fall away... but then again, you've got kids, you want to be close to grandkids (but)... it would be nice (to be) close to mountains, not way in wilderness, but more nature.

Yes, me too... but expectations change... as I get older I find I am starting to reshape my expectations, my "needs"... I find material stuff is getting lower and lower down the list and people are becoming more important, and especially family, and that sense of community is (strong) here... its having a big impact on how I see the future, cos community had never been a part of what I envisaged, it had always been living on an island, not caring if there was anyone around, but actually I'm staring to revise all that.

(Discussion, males, leading boomers.)

Several boomers talked about the benefits of intergenerational living, yet it wasn't usually seen as a realistic option for themselves.

Though in theory I can see the value of extended families living together... it would be horrible if my father came to live with me. 
I would love it if my parents (from Europe) came to live near me... but not in my front room

(Discussion, females, trailing boomers.)

I think our culture misses out though, its only really the last half a century that we've gone into this... cos my great grandparents, they all lived generations in the same house and that was so kids grew up around old people and different generations, whereas that doesn't happen now (male, trailing boomer).

l'd like to think that if my kids were going to look after me l'd be in a financial position so that it wasn't a bad situation for them, so they could do it without it ruining their lives.

Like a granny flat at the back. (Agreement).

(With) financial support for them if they are not working 'cos of a child help them out that way.

(Discussion, males, leading boomers.)

I don't want my children to have that responsibility.

I've seen my parents live with their children and it could have worked out quite well... my wife's parents lived next door to us for a while and it's been a great thing for the children growing up with their grandparents (agreement).

(But) before it gets to the 24 hours a day care stage. (Discussion, male and female boomers, mixed group.) 


\section{Retirement villages and Residential care facilities}

Some boomers thought that additional support needs might lead to their move into residential care at some stage.

I probably will be lucky to be alive when I'm 80, probably have some constraints that might force me into that (male, trailing boomer).

(Deciding to move into care...) you do it for the family's sake... boomers wont be pushed, but...The only difference we'll make is we'll say we want to be able to do it in a different kind of way (female, leading boomer).

I know that statistically most of us will not end up in residential care, so what are we worried about... at our age we are all relating to our own or our partner's or friend's experience of growing old... (but) if you see good models you think yes, Id like that (male, leading boomer).

Opinions on the retirement village model were divided. Some felt they provided a good model for those who could afford them, offering company and security, and reducing concerns about home maintenance.

l'd be happy to move into a unit... it's yours, (you) can come and go (and) there's back up (female, trailing boomer).

When my father died my mother sold the family home and went into one of those retirement villages and you can choose to be part of the village or not, be involved $100 \%$ or nothing at all, gym, sauna, swimming pool... for her it's a great place to live and she's really enjoying it and I think good on her... you need to have less responsibility as you get older, need to have less stuff to take care of, the gardens, the maintenance... (it's) taken care of in those homes. (male, trailing boomer). 
Others disliked the structured nature of residential care facilities and retirement villages, or were concerned at the level of financial resources they used up.

I have this fear that I would end up in the middle of a retirement complex, still organising everybody... being the secretary or the president... maybe I need to position myself somewhere on a hippy type commune! (Female, trailing boomer.)

Retirement villages eat money, so there's nothing left for your kids (male, trailing boomer).

Big providers of residential care are unimaginative (female, leading boomer).

Some just couldn't see themselves in residential care.

No l'd rather be gone (male, leading boomer).

I couldn't imagine it (male, trailing boomer).

Comments about hospital level care and rest homes were more negative.

I don't want to go there... I've spent time in rest homes and watched people semi-conscious (male, leading boomer).

l'd take up heroin at that stage (laughter).

I find it quite horrifying.

Yes scary. 
But I have had opportunity to work in old folks home and there is quite a sense of community, as long as you're not infirm... whereas in my parents' time, most people were in hospital.

(Discussion, males, trailing boomers.)

Care of older people in rest homes and hospitals was criticised.

The standards are slipping recently and old people are becoming just a thing to keep an eye on (female boomer, mixed group).

(We need) a better health system, because it must be so stressful for old people... to be sitting all day waiting for assistance...it's unacceptable at the moment (agreement) (female, leading boomer).

In old age hospitals or homes it's horrible... I think that's going to have to change as baby boomers start going into them, because we will not shut up or put up with all the bullshit that's dished out now! (Female, mixed group.)

There was also concern about whether there would be enough carers available to look after boomers. Some participants had concerns about health workforce shortages and the implications of that.

But with the number of baby boomers getting old - where will the workers come from? They will be migrants from countries who didn't have a boom, who are attracted to rich New Zealand... There will be more migrant carers with strong accents... there could be communication difficulties perhaps (male, leading boomer).

We may have migrants (as our carers) (female, leading boomer). 


\section{Expectations of family support}

There was an awareness amongst participants that family support arrangements and expectations had shifted during their and their parents' lifetime, from intergenerational care in the family home, to rest home care and now a move to 'in own home' care. Participants recognised their generation had been in the middle of this shift. Some older participants had experienced their parents caring for grandparents in their home, while more of the younger participants had seen their grandparents in rest home care.

My grandfather went from house to house, month to month.

I would never do that!

(Discussion, males, trailing boomers.)

My experience of older people's homes is limited to my partner's two grandmothers... and they seemed to be having a good time (male, trailing boomer).

Our parents took care of their elderly parents - our grandmother lived with my parents for fifty years (female, leading boomer).

There's been a shift - in our parents generation the debate was would you go and live in their house, or would they come and live in yours (female leading boomer).

Both older and younger participants expressed some regret that family care arrangements had become distanced, but they accepted that for most this was a necessity.

I think it's a worry that not being in touch with old people and frail people these days on a daily basis makes you not know what being frail is all about (female, trailing boomer). 
I wonder whether our kids will feel like looking after us... in the previous generation, if there was an older parent, you felt guilty if you didn't have them with you... in our generation, when your parents are in trouble, you do organise your life so you can look after them, but its getting a bit more distant - and our kids may be on the other side of the world, will they feel like coming home when we need help? (Female, leading boomer.)

Those who had migrated to New Zealand had some difficulty reconciling to current realities, with family members distanced from each other. Those born in New Zealand also had families who were dispersed.

I have lived in different countries, my child was born in another country and my husband is from a different country again - I had thought I would grow old in (my country of birth) but... now I may just visit there... whereas my family have lived in the same house for generations and never thought of moving - I found that claustrophobic, but I also yearn for that stability and security (female, trailing boomer).

It gets harder as family disperses - my brother is in (Europe), we were living in (the Pacific). My mother had grandchildren spread out over the world in different countries... you need money to visit each other (female, trailing boomer).

Some participants had considered the possibility of moving to be closer to their children, for mutual support and company.

If my son married overseas, l'd move there to be close to them (agree, disagree), like my sister did, her kids (and she) all ended up in Perth.

Odds are my son will settle in China... but my other child will settle here!

(Discussion, females, leading boomers.) 
Commonly participants wished to avoid burdening their children with their care. Physical care was considered too demanding and too difficult for family carers, and perhaps too personal.

Whether or a not a person can give good care an issue.

In some ways, it would be better that the burden of physical care is born by people who are paid to do it, and that the family are there for emotional support, rather than being worn out by doing washing, cleaning.

l'd prefer to have it done by well paid health care assistants, home care workers, highly qualified... and paid for by the state.

(Discussion, females, leading boomers.)

I don't want to open the door to them looking after me physically if I'm not well, because that seems quite strange (female, trailing boomer).

But participants did look to their children for emotional support. They hoped their kids would stay in contact and talk by phone or email if at a distance, or visit if living close by. Physical or financial support was not expected.

I can see different parts - the emotional support that you can give across the sea... I spend my time on the phone with (my mum) listening to things I don't really find very interesting, but that is kind of my support to her, and I hope that my kids will humour me when I rabbit on and I kind of expect that (female, trailing boomer).

Some also looked to friends as a support network. With family likely to be living at a distance, they felt that friends would become more important.

I don't imagine following my kids around or them following me around, they have their own lives, so it's your network of people your own age, 
friends, that we will create our own environment of support (male, leading boomer).

My daughters may be in a different part of the world... (so) my main inclination is towards friends, groups of friends that have common interests... (as) a mutually supportive arrangement... part of a social network (male, leading boomer).

\section{Expectations of support from the State}

Commonly, participants had low expectations of support from the state. Some remembered policy changes in the past that left them with less confidence in the state.

There will be bugger all!

I'd like to think that public health services will still be there... but there are problems with that now.

Resourcing is fragile... the state will have support for (ageing-in-place) there but whether the access is what it should be.

(Discussion, males, leading boomers.)

I don't expect anything!

A number of elderly folk have found that all their superannuation has dwindled away. All the promises that governments have been made in the past that have not been fulfilled, so if that's happened to the people in the 70's and 80's already, you can't tell me that these governments are going to change all of a sudden to look after me!

I think free hospital care is basic. Fifteen years ago that was under threat. I think that's hugely important, and that threat could come 
back....long waiting lists and old people on (waiting lists) needing things like cataract operations and a great many of them may never have them done, and their quality of life is severely affected by that. (Discussion, female boomers, mixed group.)

(My expectations of state support) are very low. (Agreement.)

I think you will get help from the state.

I think it will be both. The public system will be so overrun... I think there will be (a system for) the rich and (one for) the poor. (Discussion, male and female boomers, mixed group.)

Commonly, participants did expect that a state pension would remain. However, some changes were anticipated.

I expect there will be state provided superannuation (agreement)...as long as they don't put the 'retirement age' up before we get there! I think we will see state entitlements change with more targeting, with thresholds and tests...simply because there are so many of us.

I think we are about to enter a period of increasing power of the 'New Right'... we will see some shocks that will affect the pension, and I don't think we can be complacent... but I do believe that its part of our culture that something will be there.

(Discussion, males, leading boomers)

Commonly, participants supported a sharing of responsibilities, but strongly advocated for state support for those who needed it. There was concern for those who would struggle if support was too low.

I would expect something, that's what the welfare state is for, it has a responsibility for old people...but I think its got to be a mix of what you can do for yourself and what the state does and what the family does 
and what the community does, you give and something comes back... (male, trailing boomer).

The state owes it to citizens not to leave them destitute... they should always provide a base something, but it's up to us to do something else about our lifestyle above that, but I do think the state has an obligation to provide the basics (agreement).

Yeh, because some people don't have the option of putting away a nest egg, because they are looking after others.

But for the state to provide we have to pay taxes for that and I wonder is that the most efficient way to look after people? I would like a system where I wouldn't get support (if I didn't need it) because I wouldn't like the tax to go into paying for people who are comfortable.

But then there's that question of whether all your assets belong to you or your children... when you only get a subsidy for aged care after assets are worked down... and those who are experienced, shaft those who aren't, and people can get around (asset testing) through (family) trusts... its an interesting question.

(Discussion, females, trailing boomers.)

Some participants had a rights based perspective of welfare, while others perceived they had a contract with the state - that is taxes were paid on the understanding support would be provided.

They (health care and social support) are all basic human rights which we signed up for as a country (agreement)... (we signed) the universal declaration of human rights... (male, leading boomer).

We pay taxes all our lives so we should not be screwed anymore as we have been screwed enough. 
I'm more than happy for my taxes to go to supporting a pension. (Discussion, males, trailing boomers.)

If they bring in means testing for our superannuation, I would be a very crooked businessman, because we've been paying our taxes all these years, why shouldn't we get the same as everyone else? (Male, leading boomer.)

Commonly there was recognition that costs of support were rising with population ageing and most participants expected reductions in support as a result. Reductions were expected but not necessarily accepted, and opinions varied as to the priorities.

New Zealand is not big enough to provide for (social) housing and other things for the aged. ...the government will not be able to afford it.

The ageing population situation we've got in this country... there will be three times as many people retired within twenty years, more retired than workers, so there is no way that the government can provide help.

No (we don't expect government to provide for us) (agreement). (Discussion, male and female boomers, mixed group.)

(But) building complexes and housing for the elderly and their families is a must! (Female boomer, mixed group.)

I think the state will cut back... there is a high percentage of heath funding going on health care for older people and it is expensive... I am worried about future health care and support services, it is less of a visible issue than the pension and much more difficult to make it a political issue and to understand how it works... it is (too) easy to cut back on mobility aids and in-home support (male leading boomer). 
In terms of quality of care it's the responsibility of government to ensure that our elderly and our young are properly cared for (female boomer, mixed group).

I don't expect any support, never had any, no benefits or welfare, never... I'm on my own. Superannuation? I don't expect it, if its there it's a bonus.

I'll be bloody annoyed if its not there, l've been paying taxes all my life...but l'd be an absolute fool if I depended on it being around. I'm being cautious and assuming it wont be there.

I think we are a humane society and I think there will always be something there.

I hope there will be something, however small, but you obviously have to look after yourself...

I'd be very surprised if it isn't targeted... and I really hope that I'm in the targeted group (laughter).

(Discussion, males, leading boomers.)

\section{Ability to influence policy}

Some who had been politically active in the past were confident boomers could have some influence on policy for older people.

We've got every reason to think that we will be able to change it, when you think of the gender inequality we experienced when were younger, we and lots of other people, we changed it, and lots of other issues, we did change them (female, leading boomer). 
When you look at the protests and what went on in the 1960's compared to what happens now, we were very vocal and very focused on what we thought was right and what was wrong and prepared to go out and lobby for it....we have the ability to lobby hard for the things that we want, and from that point of view we are probably luckier than generations that have gone before (female, leading boomer).

While some expected cohort size would enable boomers to influence policy, others were less optimistic about the impact.

I've always thought we'd be able to muster the numbers.

But I'm wondering how we are going to stay connected to make that difference... there are young people who don't think we can change anything, and who think you've just got to accept it... how do we actually sustain good change, collectively but also politically... because there isn't a huge movement about alternative housing... are we all going to decide in ten years that we want it to change.

We are too busy living our lives as they are now to think ahead (to future needs).

(Discussion, females, leading boomers.)

We will be active politically.

Yes, but Generation X will also push, plus there are those in our age group who say why should the state provide when you haven't provided for yourself.

The decision makers will be younger too. (Discussion, males, leading boomers.)

All I can say is we have to be quite organised when we are old, and it seems like we can be (female, leading boomer). 
Our ability to influence will drop off (the older we get).

But our experience of the 60s, of challenging things, organising and not letting things go.

I am pessimistic, how are we going to...there's going to be so much working against that.

I don't want to spend my retirement organising... been there, done that.

(Discussion, males, leading boomers.)

Access to care and support was spoken of with concern in all groups and was identified as one area where lobbying might be successful.

The state should provide care and there should be a lot of choices what's available now is not adequate and is scary (female, leading boomer).

(Issues) like the support the state gives... expecting the state to keep some commitment to health - we might have some strength in that area (female, leading boomer). 


\section{Discussion}

Boomers in the focus groups believe they will age differently to current generations of older people and they are interested in more flexible lifestyles and more supportive living arrangements. They expect to have a more active old age and believe they have more choices, with fewer societal constraints. They feel the boundaries of old age have shifted and there were many ways to 'be old'.

Some anxieties about ageing were evident. Fear of a decline in health was a recurring theme and there was a strong desire to resist any loss of independence. Despite these fears these boomers were optimistic about their future experience of older age, which could be enhanced with the right attitude, attention to health and fitness and strong social networks.

There was support for a sharing of responsibility for wellbeing between individuals, families and the state. These boomers believed they should prepare for their own future and provide for their families, but they also believe that the state has a responsibility to support those in need. Like their parents they value self-reliance and independence, but there was a strong sub-theme around family responsibilities.

Some boomers expressed a 'rights based' sense of entitlement that motivated them to challenge and question. Those who had direct experience of political activism felt more confident that boomers could act collectively to create alternative solutions to social problems.

There was a desire for more innovative care and support services and living arrangements. These boomers were critical of current models of residential care and the level and quality of support and health care available for older people. They desired more communal housing and were wary of further cuts to home support services and health care. 
In addition to the cross cutting themes identified in the previous chapter, several new themes have emerged from the study.

\section{A redefining of old age}

The category of old age was viewed as relative, malleable and responsive to individual action. Old age could be resisted and reinvented and the ageing experience could be transformed through individual and collective effort. There was a desire to improve the ageing experience by drawing from a range of perspectives, such as from other cultures, but also by drawing on the experience of previous generations.

\section{View of selves as innovative and creative}

Boomers looked to themselves for creative solutions to identified problems. Alternative living arrangements were being considered with a do-it-yourself approach that would enhance their autonomy. There was a desire to collectively create innovative arrangements that would be true to their values.

\section{A collective orientation}

There was a valuing of a sense of 'community' and an interest in more options for communal living, albeit with sufficient space and flexibility to maintain privacy and autonomy. Bonds with friends were valued as a social support network. Collective action was admired as a route to improving society. 


\section{Concern for distanced families}

Boomers' viewed family networks as increasingly complex and commonly stretched across large physical distances. It was apparent these boomers were exploring new ways to maintain networks. Some had relinquished old models of family support but were still in the process of negotiating new ones. Stretched networks required additional resources.

\section{Low expectations of the welfare state}

Boomers articulated common discourses about the demands on the state resulting from population ageing and the high numbers of boomers about to become entitled to New Zealand Superannuation. They anticipated a reduction in support from the state but it was not clear how acceptable reduced entitlements might be or what might be 'bottom line' positions.

\section{A negotiated relationship with the State}

These boomers support a sharing of responsibility for wellbeing in older age between individuals, families and the state. They consider they should prepare for their own future and provide for their families, but they also feel that the state has a responsibility to support those in need. Boomers' sense of collective power was apparent, though views varied amongst boomers as to the likelihood of age based collective action. Boomers' prior experience of political protest and awareness of significant social change contributed to a general optimism about the transformation of old age. It also provided a basis for a generational identity. 


\section{Chapter Conclusion}

In this chapter, boomers views on late life have been presented, based on findings from the boomer focus groups. These boomers anticipate a new old age, one different to their parents and within their power to transform further. Their views on ageing are influenced by their experiences, hopes and concerns about changes in society. While optimistic about increased role flexibility in late life, some concern about themselves growing old was apparent, including a fear of reduced autonomy and income, and of overburdened services. Some, but not all, were optimistic about boomers' collective ability to influence policy to improve quality of life for older people. They recognised that previous experience of collective action offered skills, but could be both a barrier and motivator for future action. These boomers expressed a sense of responsibility for challenges resulting from the demands of a large cohort of boomers and a desire to develop innovative solutions. But there was also a strong view that government has responsibility to ensure the welfare of older citizens in need, and common concern about the adequacy of current and future services for older people.

In the next chapter boomers' views are contextualised and triangulated with findings from other studies and underlying beliefs and values are identified. 


\section{Chapter Seven: Boomer Beliefs and Values}

\section{Introduction}

In Chapters Five and Six, boomers attitudes and expectations of future lifestyles were revealed. In this chapter the underlying beliefs and values of boomers are identified and links to behaviour are considered. The discussion compares and contrasts findings with other studies. This chapter explores how being a member of a (relatively) large cohort has impacted on boomers view of themselves and explores the following questions: have labels attached to their generation influenced their collective identity; do they share common beliefs and values that make them a distinct group; and how might beliefs about the boomer generation influence future behaviour?

Exploration of beliefs and values is important for a variety of reasons. Beliefs act as signposts and boundaries as to how we respond to our world, while more deeply held values are "the bases for the specific norms that tell people what is appropriate in various situations" (Schwartz, 1999, p25). Beliefs about self or others can be limiting or empowering, while values affect our world view and our personal interests. Value gaps can divide opinion and act as a barrier to understanding and empathising with another's position, while groups whose values differ from the majority can experience discrimination or bullying. Beliefs and values therefore affect our choices, our preferences, our tastes, and can affect our quality of life. Commonly held values within a culture can also influence politics consider for example how religious values can impact on foreign policy.

Knowledge of common values within a cohort can aid understanding of group norms and predicted behaviour, which in turn may assist policy development. Without knowledge of boomers' priorities, preferences and values, it is impossible to know what policy change might be needed. 
Huber and Skidmore (2003) argue there is a risk of policy being premised on a stereotype of boomers as "an entire generation of rebellious, antiestablishment '68ers'”, (2003, p34) that not only experienced common social transformations, but actively instigated them. Identifying boomers beliefs and underlying values is "...crucial to understanding how their transition to later life will play out" (Huber and Skidmore, 2003, p34).

\section{The relationship between attitudes, beliefs, values and behaviour}

Predictions need to take account of factors that influence the relationship between beliefs, attitudes and values and behavioural intent, and the translation of intent into action.

Values are considered to be more central than attitudes as predictors of behaviour (Rokeach, 1973) and are more stable and fewer in number than attitudes. Attitudes do predict behaviour but not strongly (Terry, Hogg and White, 1999). There are factors that influence the relationship. For example, situational factors influence the likelihood that behaviour will express privately held attitudes - people who hate their jobs may still go to work. But if the work is voluntary, attitudes will influence the likelihood of going to work. Motivation is also a factor. Attitudes are more predictive of behaviour when people have a vested interest in the issue; when people are under time pressure; and when situational clues make the person's attitude a focus of attention.

Knowledge of boomers' perceived generational identity and group norms is useful for an understanding of behavioural intent and motivation. Both personal and social identity influence a person's actions (Tajfel and Turner, 1986). An individual's role identity (such as being a grandmother) and social identity (such as being a baby boomer) help to define the self and influence attitudes and behavioural decisions. Group norms influence behavioural intention and the behaviour itself, at least for people who identify strongly with the group. 
If a group behaviour is an important part of a person's self-concept and perceived role, they are more likely to want to perform the behaviour. Social identity theory has highlighted how an important part of self-concept comes from membership of social groups (Terry, Hogg and White, 1999). People define and evaluate themselves, looking at differences between ingroups and out-groups, and similarities between self and the in-group members (including beliefs, attitudes, feelings and behaviours), based on stereotypical dimensions, and favouring the in-group over the out-group.

"Thus, social identities should influence behaviour through the mediating role of group norms - people will be more likely to engage in a particular behaviour if it is in accord with the norms of a behaviourally relevant group membership, particularly if the identity is a salient basis for self-definition" (ibid, p228).

In the following sections boomers' beliefs about their generation and how they see themselves as a social group is outlined and the nature of that identity is explored. Boomers' beliefs about what being old will be like for them are described, including the level of involvement in paid and unpaid work and the nature of care and support in late life. This exposes some fears and stereotypes about old age which may impact on whether boomers will, as many predict, transform the ageing experience, and some insight into behavioural motivations and potential constraints on their ability to age well. Values underlying their beliefs and how they expect to behave are identified and results are triangulated with findings from other relevant studies. 


\section{Exploring Boomers' Beliefs}

\section{Participants' Beliefs about the Baby Boom Generation}

Focus group discussions revealed common beliefs amongst participants about the boomer generation. They believe that baby boomers share characteristics that give them a distinct identity although there was some questioning of the extent of shared characteristics and some uncertainty as to who qualifies as baby boomer. Participants believed boomers are different to other generations and they agreed that the large boomer cohort is a dominant group in society, influencing trends and demand on services.

Participants commonly believe their generation is less deferential and more assertive than their parents' generation. Younger boomers viewed older boomers as more radical and pioneering. Older boomers agreed with this view and expressed a strong sense of themselves as change agents. Both younger and older participants perceive boomers as innovative, flexible, adaptable and able to challenge, with the determination, experience and capacity to overcome barriers. Younger participants were more likely to identify boomers as impatient, materialistic, a 'me generation' with a sense of entitlement and a pleasure seeking tendency that can extend to self indulgence.

Both positive and negative discourses about the boomer cohort were apparent in discussions amongst participants. Two competing social identities were revealed (see Table 1), that of boomers as 'social reformers' or a 'problem generation'. Those with a more positive view of boomers as reformers appeared more optimistic about their generation's ability to redefine old age and make the most of opportunities in late life. 
Table 2: Boomer Identity: Self-Identified Characteristics and Beliefs

\begin{tabular}{|c|c|c|}
\hline Boomer Social Identity & $\begin{array}{l}\text { Characteristics of } \\
\text { Boomers }\end{array}$ & Beliefs about Boomers \\
\hline $\begin{array}{l}\text { 'Positive social } \\
\text { reformers' }\end{array}$ & $\begin{array}{l}\text { liberal } \\
\text { confident } \\
\text { informed and aware } \\
\text { optimistic } \\
\text { expansive } \\
\text { challenging } \\
\text { adaptable } \\
\text { flexible } \\
\text { assertive } \\
\text { active } \\
\text { creative } \\
\text { open to change } \\
\text { hard working } \\
\text { dedicated } \\
\text { assertive } \\
\text { influential }\end{array}$ & $\begin{array}{l}\text { Will redefine older age } \\
\text { Will contribute } \\
\text { Will participate } \\
\text { Will challenge and advocate } \\
\text { for selves and others } \\
\text { Will take responsibility for } \\
\text { selves and other generations } \\
\text { Will find creative solutions to } \\
\text { problems in older age }\end{array}$ \\
\hline 'A problem generation' & $\begin{array}{l}\text { materialistic } \\
\text { individualistic } \\
\text { selfish } \\
\text { self centred } \\
\text { sense of entitlement } \\
\text { high expectations } \\
\text { poor planners } \\
\text { demanding } \\
\text { impatient }\end{array}$ & $\begin{array}{l}\text { Will redefine old age } \\
\text { Will fail to prepare adequately } \\
\text { and adapt poorly to old age } \\
\text { Will demand support from the } \\
\text { state } \\
\text { Will challenge and advocate } \\
\text { for selves not others } \\
\text { Will be more dependent on the } \\
\text { state } \\
\text { Will cause intergenerational } \\
\text { conflict }\end{array}$ \\
\hline
\end{tabular}

Participants expressed a range of beliefs as to how a generational identity had evolved. A central belief was that the 'golden age of welfare' had influenced their generation, enabling greater security and confidence in their early years. They felt they had been a lucky generation, with policies supporting family life and prosperous economic conditions, low unemployment, and low rates of crime. These had contributed to a generational optimism that had raised their expectations and influenced their values. 
Participants' views are consistent with Smith and Clurman's (2007) argument that sustained economic prosperity has united baby boomers. According to Smith and Clurman, a 'psychology of affluence' has influenced boomers' understanding of 'place, opportunities, and potential' as well as their attitudes, choices, life skills and view of the future.

However, boomers view of themselves as a 'lucky generation' is not supported by Thompson's analysis of the benefits of the welfare state (1991). Thomson looked at the effects of accumulated experiences of the welfare state in New Zealand, linked to birth year. His was a study of 'relativities', comparisons of tallies of gain and loss. He argues that the generation born about 1920 to 1945 (boomer's parents and grandparents) benefited more from the welfare state than their successors (the baby boomers). Those born in the 1920s and 30s benefited from the youth oriented welfare state of the 40s, 50 s and 60 s, and the elder orientated welfare state of the $70 \mathrm{~s}, 80 \mathrm{~s}$ and $90 \mathrm{~s}$. Thompson predicted that boomers' parents will collect benefits across their lifetimes several times greater than the taxes they paid, whereas boomers will contribute more through direct taxes from increased workforce participation and indirect tax, for example GST and user charges in health and education. He maintained that boomers will have 'much reduced' benefits from the welfare state as a result of reduced per capita spending on services and reduced state assistance for families (such as housing assistance) in boomers' establishment years. His analysis presupposed that boomers' parents benefited from the free education of their children, which is open to challenge, and there were necessary assumptions made about the future. His intergenerational comparisons were being made at a time of cut backs in public services and amidst concerns about equitable access to services.

Callister (2006) and Pool and Hillcoat-Nalletamby (1999) also revealed constraints on New Zealand boomers in their adult establishment years, including reduced entitlements to welfare in the 1980s, periods of high unemployment through 1980 s and early 90 s, a decline in the value of real personal incomes and an increase in income inequalities. 
The above analyses emphasise the danger of broad generalisations and the need for careful scrutiny of sub groups within the boomer cohort. The diversity of boomer circumstances were evident in boomers comments about their own financial circumstances and preparedness for late life (explored below).

\section{Beliefs about (Post)Modern Society}

Some focus group participants felt boomers were responsible for the development of an overly individualistic society. But this was balanced by a view of themselves as a generation with a social conscience and the skills to collectively create a more positive future, not only for themselves but for generations to follow. Such skills included those developed through past experience in lobbying, advocacy and networking. They viewed themselves as a 'vanguard generation' (Huber and Skidmore, 2003), albeit one with both positive and negative influences on society.

There was a common, but not unanimous view amongst focus group participants that younger generations were more materialistic, more individualistic, more impatient and more affected by consumerism.

Boomers view of themselves lends support to Inglehart's findings. on values across the generations (Inglehart (2008) in the World Values Survey (WVS). Younger generations score more highly on indices of postmaterialism, emphasising freedom and prioritising self esteem, and aesthetic and intellectual stimulation (WVS, 2004 data).

\section{Beliefs about Boomers as Parents}

Focus group boomers commented on their role as parents. Some participants felt boomers over-indulged their children, with less focus on teaching them about the importance of working hard in order to achieve goals. 
They linked these views to greater affluence in society, resulting in boomers being more liberal with their children, wanting them to experience greater freedom from responsibility and fewer obligations in childhood. Some felt their children lacked resilience as a consequence.

Participants felt they had contributed to cultural change in the goals parents have for their children. According to Inglehart (2008), people's views as to the important values to teach a child have shifted from emphasising hard work towards an emphasis on tolerance and imagination. Intra cohort diversity is noted by Webster (2001) however, whose studies of New Zealand data concludes that views on the qualities that children should learn vary by ethnic group, level of education and socioeconomic class.

Modern parenting practices have been linked to a general increase in the societal level of narcissism (that is an excessive belief in self-worth, with self promotion, self enhancement and reduced empathy) (Twenge and Campbell, 2009). They argue narcissism has been bolstered by the 'self esteem' movement. Concern centres on children being constantly affirmed for their uniqueness and praised out of proportion to the effort put in. One consequence of the resulting overconfidence is said to be that people take too many risks, leading to, for example, high levels of borrowing and the recent mortgage crises in the United States. New Zealand research on narcissm by cohort is limited. Wilson and Sibley (2011) have demonstrated that younger New Zealanders are more narcissistic than older New Zealanders, but longitudinal data is needed to identify if this is an age effect.

\section{Beliefs about Activism}

Harkin and Huber (2014) argue that the boomer generation has come to symbolise activism, social freedom and innovation. "For many of them, challenging received wisdom is deeply embedded in their own self-image" 
(Harkin and Huber, 2004, p11). They expect therefore to continue to do so. This was a common view amongst boomers in the New Zealand focus groups. However some older focus group participants expressed weariness resulting from past activism and were not keen to spend time on this in late life.

There has been speculation that boomers' higher education, expectations, wealth and status will result in more effective governance through greater political participation (Dychtwald, 1999; Huber and Skidmore, 2003). New Zealand Values Survey (NZVS) data (Rose et al, 2005) indicates that boomers do participate more in political action than older and younger age groups, being more likely to have signed a petition, joined a boycott and attended a lawful demonstration. However, the nature of political action varies within the boomer age group, with younger boomers more likely to have joined in boycotts and older boomers more likely to have joined unofficial strikes (Rose et al, 2005).

Older participants in focus groups expressed more confidence than younger participants that they will act collectively to create alternative solutions to social problems. NZVS data also indicates that older boomers are slightly more optimistic than younger boomers about the influence the public has on government, though they are more optimistic about talking to public officials than they are about the level of control the public has over politicians in office (Rose et al, 2005).

Some boomers in the focus groups expressed confidence in the ability of organisations such as trade unions, women's organisations and the ecology movement, to take action on social issues. However the level of confidence varied. Findings from NZVS data indicates confidence in institutions varies between older and younger boomers. Older boomers have more confidence in the women's movement. They also have more confidence in the public service than younger boomers, as well as in the police, the legal system, government, parliament, political parties and the Press (Rose et al, 2005). 
Younger boomers on the other hand have more confidence in the Green or ecology movement, and in community organisations, trade unions, the United Nations, and television compared to older boomers. (By comparison, those aged $65+$ had more confidence in community organisations and political parties, but less confidence in Parliament, the green movement, the United Nations, major companies and television.) Rose et al (2005) conclude that level of confidence in organisations follows political orientation and indeed NZVS data indicates younger boomers are more left leaning in political preference than older boomers (and are more likely to vote for the minor parties, including the Greens) (ibid).

\section{Boomers' beliefs about what it means to be old}

Focus group participants' beliefs about ageing were revealed in their comments about old age (see Table 3 ), with a range of positive and negative comments. Key discourses on ageing were that old age was a life stage with opportunities (for example to do new things), privileges (such as not having to conform) rewards (self knowledge) and changing responsibilities (less work, but time to step up as an elder). Some features of ageing could be resisted or controlled by the individual (a state of mind) but others may require change in others (not being respected). Time in old age would be spent differently, with a change of pace. For some that meant slowing down however others did not anticipate reducing activity. Life in old age was also difficult to predict and scary. Old age therefore may be resisted, but participants identified inevitable change (getting closer to death). 
Table 3 Boomers' beliefs about old age:

\begin{tabular}{|c|c|c|}
\hline \multirow{2}{*}{\multicolumn{3}{|c|}{$\begin{array}{l}\text { "To me old age is..." } \\
\text { Positive }\end{array}$}} \\
\hline & & \\
\hline $\begin{array}{l}\text { A privilege } \\
\text { A time of honour } \\
\text { A new life stage / } \\
\text { Chance to do things } \\
\text { haven't had time for } \\
\text { before / A time to have } \\
\text { fun } \\
\text { Being wiser / Having } \\
\text { more confidence and } \\
\text { self knowledge } \\
\text { A time to enjoy life's } \\
\text { pleasures, at a slower } \\
\text { pace/ more leisure time } \\
\text { / A time to relax / sleep } \\
\text { in / listen to the radio } \\
\text { Not having to conform } \\
\text { A time when you are } \\
\text { financially secure and } \\
\text { work because you want } \\
\text { to not 'cos you have to } \\
\text { A time to spend with } \\
\text { grandchildren } \\
\text { A time of less } \\
\text { responsibility / less } \\
\text { worry } \\
\text { A time of more } \\
\text { responsibility and } \\
\text { status/ your time to step } \\
\text { up as an elder / A time } \\
\text { to pass on knowledge/to } \\
\text { teach/ be role models / } \\
\text { A chance to give back, } \\
\text { to family and community } \\
\text { To be celebrated / } \\
\text { Beautiful! / To be } \\
\text { appreciated - you're } \\
\text { lucky to make it }\end{array}$ & $\begin{array}{l}\text { Scary /frightening } \\
\text { Closing in } \\
\text { To be railed against / } \\
\text { resisted / put off / } \\
\text { avoided } \\
\text { Becoming decrepit } \\
\text { Getting closer to death/ } \\
\text { a slow death } \\
\text { Time of loneliness } \\
\text { Something I don't want } \\
\text { to think about } \\
\text { Not something to } \\
\text { celebrate } \\
\text { Not fitting in } \\
\text { Not being respected } \\
\text { A time of struggling } \\
\text { financially } \\
\text { A time of frustrations } \\
\text { and worries (whether } \\
\text { can get work or have } \\
\text { enough money) }\end{array}$ & $\begin{array}{l}\text { A state of mind } \\
\text { In the future / something } \\
\text { that happens later } \\
\text { Not happening to me / } \\
\text { something I cant imagine } \\
\text { Getting close } \\
\text { How seen by/treated by } \\
\text { others } \\
\text { Dependent on your } \\
\text { perspective / relative } \\
\text { Changing/different than } \\
\text { before } \\
\text { Inevitable } \\
\text { A time for slowing down, } \\
\text { reflection and appreciation } \\
\text { A time to work less } \\
\text { A combination of head } \\
\text { space and changes to body } \\
\text { Part of life } \\
\text { Dependant on your health } \\
\text { An adventure - 'cos you } \\
\text { don't know what it's going } \\
\text { to hold } \\
\text { Whatever you can make it. }\end{array}$ \\
\hline
\end{tabular}


Changing self identity was apparent in markers of old age described by participants (see Table 4). 'Old age' meant adapting to a new body image and both letting go and taking on of roles. There were losses anticipated, including loss of independence, loss of capacity, ability and strength as well as loss of respect. Positive gains were also apparent, in roles as grandparent, elder, and worker in a new role, as well as gains in status, credibility, and respect. Glasses and wrinkles and new facial hair might also be considered gains, and were spoken of with some humour, however none spoke of these as welcome additions.

Table 4 When is Old - Boomers' Beliefs about Markers of Old Age

\begin{tabular}{|c|c|c|c|}
\hline $\begin{array}{l}\text { Physical } \\
\text { markers }\end{array}$ & $\begin{array}{l}\text { Attitudinal } \\
\text { markers }\end{array}$ & $\begin{array}{l}\text { Behavioural } \\
\text { markers }\end{array}$ & $\begin{array}{l}\text { Social } \\
\text { markers }\end{array}$ \\
\hline $\begin{array}{l}\text { Old means } \\
\text { being late } 70 \text { s } \\
\text { and older. } \\
\text { When your } \\
\text { husband turns } \\
60 \\
\text { Wrinkles, grey } \\
\text { hair, hair on } \\
\text { your chin, } \\
\text { flabby bits, } \\
\text { bags under } \\
\text { your eyes. } \\
\text { Limping. } \\
\text { Waning } \\
\text { physical } \\
\text { strength. } \\
\text { Injured joints. } \\
\text { Arthritis. } \\
\text { Needing } \\
\text { glasses. } \\
\text { Lack of a } \\
\text { second wind. }\end{array}$ & $\begin{array}{l}\text { Becoming } \\
\text { sexually } \\
\text { unattractive } \\
\text { Avoiding trying } \\
\text { new things. } \\
\text { Withdrawing } \\
\text { from activities. } \\
\text { Being excluded } \\
\text { from job } \\
\text { opportunities. } \\
\text { Letting go. } \\
\text { Being less } \\
\text { reckless. } \\
\text { Giving up. } \\
\text { Being expected } \\
\text { to come up with } \\
\text { the answer / } \\
\text { have wisdom. } \\
\text { Gaining } \\
\text { credibility and } \\
\text { status and } \\
\text { having wisdom } \\
\text { and } \\
\text { experience. }\end{array}$ & $\begin{array}{l}\text { Having adult } \\
\text { children / kids } \\
\text { leaving home. } \\
\text { Becoming a } \\
\text { grandparent. } \\
\text { When look for } \\
\text { other work } \\
\text { options / less } \\
\text { work / retire } \\
\text { Moving to a } \\
\text { retirement village } \\
\text { Not being active / } \\
\text { time of less } \\
\text { activity. } \\
\text { Entering } \\
\text { residential care } \\
\text { Passing on } \\
\text { knowledge to } \\
\text { younger } \\
\text { generations } \\
\text { Being a member } \\
\text { of 'Grey power' } \\
\text { and becoming } \\
\text { political }\end{array}$ & $\begin{array}{l}\text { Being a } \\
\text { member of } \\
\text { eldest } \\
\text { generation. } \\
\text { Being older } \\
\text { than those in } \\
\text { positions of } \\
\text { responsibility } \\
\text { (police, } \\
\text { doctors, } \\
\text { pilots). } \\
\\
\text { Being treated } \\
\text { as an older } \\
\text { worker at age } \\
\text { 50. } \\
\text { Being } \\
\text { afforded } \\
\text { respected } \\
\text { status as a } \\
\text { leader, } \\
\text { mentor, } \\
\text { teacher }\end{array}$ \\
\hline
\end{tabular}


As boomers consider their own old age they are negotiating an ageing identity. Age interacts with social circumstances to influence how people see themselves and others and upon which they build their own life narratives (Holstein and Gubrium, 2000). Awareness of the finite nature of life can provoke a rethinking of identity in late life. Older age can offer an opportunity for prior identities to be carried forward into late life, or to be transformed. But ageist attitudes and negative stereotypes of older people can limit identity choices and reinforce fears of personal ageing.

Some common stereotypes about old age were apparent in participants' views, including that of old age as decline, disengagement and separation from society, but also the more positive image of old age as a time of reward for past participation and respect for ongoing contributions as a wise and experienced elder.

Comments revealed that participants commonly felt being old had little to do with number of years lived. There was no particular age at which you became 'old' but it was related to being the eldest. Focus group participants were not asked to specify an age but some thought around 70 or 80 years of age was old. Boomers in Buckland's (2009) study also agreed that age is not only about years lived and almost all (98\%) agreed that age is a state of mind. When asked to specify an actual age for 'how old is old', the average age given in Buckland's study was 81 years, much older than the age at which New Zealanders qualify for retirement income (65 years of age).

Boomers in the focus groups agreed that the boundaries of old age had shifted, that is an individual was considered old at a later age than before. They were aware however that employers tend to treat applicants as old from about age 50, and they commented on advertising in the media aimed at 'seniors' aged fifty and over. 
Other researchers have commented on a downward trend in the age at which an individual is treated as a senior. Martin (2005) notes a trend to lower the age at which seniors organisations accept members, such as to age 50 for National Seniors in Australia, AARP in the United States, and Grey Power in New Zealand. New Zealand's SeniorNet organisation, which teaches older adults computer skills, has a joining age of 55 , while the Cyber Seniors Organisation and Web Wise Seniors in the United States both have a joining ages of 50 . Biggs et al (2006) suggest a lowering of age has occurred because it allows advocates to appeal to a wider group.

These age categories conflict with boomers' view of themselves. Boomers are indicating a desire to view old age as starting much later than others may think. Participants in the focus groups agree with theorists such as Arber and Ginn (1991) who note a 'fluidity' of life stages and a trend to extend middle age into late life. Featherstone (1991) argues that social divisions based on age are becoming irrelevant. Gilleard and Higgs (2005) suggest older adulthood can no longer be understood as a single experience common to all, while Blaikie (1999) suggests there are no rules, only choices.

A key area of agreement between participants was a belief that life in older age will be different for them compared to previous generations. Focus group boomers believed there were more roles for older people now than had been the case for their parents. Differences resulted from changing lifestyles and changes in values, as well as changing circumstances. Some acknowledged that current generations of older people were already transforming lifestyles in late life. A common view was that there were already many ways to live life in older age.

In Buckland's 2009 study almost all of the respondents (94\%) agreed that 'in the future older people will be much more active and engaged than older people in the past', while $89 \%$ agreed 'there is no reason that you have to feel less vital and energetic as you get older'. However when 
considering their own situation there was more doubt with just 70\% agreeing 'I do not see myself as facing any limits whatsoever because of my age'. Focus group boomers in the current study also believed older people were more active now than previous generations and they anticipated and active lifestyle themselves, though some older boomers were already experiencing some physical constraints.

Beliefs about and attitudes to ageing are a key factor in people's ability to age well (Day, 1991) and to live independently in old age (Dwyer et al, 2000; Dyson, 2001). Negative beliefs can limit opportunities, reduce life satisfaction and affect resilience or ability to adapt to challenges in late life. For example people tend to modify their speech when communicating with older people, often without realising it. People tend to speak slower with:

"exaggerated intonation, high pitch, increased loudness, greater repetition, simpler vocabulary and reduced grammatical complexity. Also identified in the literature are occurrence of: baby talk, patronising talk, controlling parental talk, feigned deference, avoidance of talk due to anticipated verbosity or generation gap, less listening to concerns, restricted range of topics, age-biased interpretation of elder's comments, and discussion of the older person's problems with a third party as if the elder were not present" (Bouchard et al., 1995, p. 92).

Participants were aware of consequences of being treated this way, including feeling disrespected and lowered self esteem. A number of participants believed boomers would be more resistant to such attitudes, being less deferential and more skilled in challenging and speaking out, a finding supported in Buckland's study (Buckland 2009). 


\section{Beliefs about Older Bodies}

Focus group participants did expect that physical changes as they aged would affect their lives and most did not welcome changes associated with old age. They recognised that physical changes can impact on communication, through, for example, impaired hearing and vision, and slower processing of information. There was a belief also that technology could enable physical and sensory deficits to be overcome, reducing perceptions of difference between older and younger people. However social influences interact with physical.

Participants' believed they could manage changes to their bodies as they aged. Fear of reducing health or loss of fitness and strength appeared to be a motivation for health related behaviours. This was also apparent in Buckland's study. For two-thirds of respondents, health was the biggest issue that worried them, including worry about getting sick and frail, losing their mental sharpness, losing their ability to live independently and being short of energy and vitality. In response, $91 \%$ agreed they are likely to make health their priority over the next $5-10$ years and $80 \%$ were concerned about trying to keep in shape (Buckland, 2009, p59).

Turner (1992) notes that in post-modern society the body has become a project, with the condition of the body core to personal identity. The body is monitored, transformed and controlled through, for example, diet and exercise. This view was apparent amongst focus group boomers. They noted that in old age the body demands additional attention, in a manner that can threaten a positive sense of self. Estes et al (2003) note a "... reluctance in contemporary society to come to terms with the ageing body" (p37). For some there is a sense of a younger self being trapped in an ageing body (Featherstone and Hepworth, 1991). For others the state of one's body has a moral overtone (Cole, 1992). 
The challenge, according to Estes et al (2003) is to find strategies to build an identity that takes into account the ageing body rather than ignoring it. They imply that this will also enable the development of the common identity that is needed for social action on the basis of age.

Participants in the focus group seemed reluctant to focus on ageing bodies in the discussion, keeping comments brief and indicating a determination to remain upbeat. They focused instead on their belief that boomers will be healthier and fitter than previous generations. Many participants in the focus groups indicated a desire to maintain the same activities of their younger years and implied the ability to do so meant 'ageing well'.

In Buckland's study, few boomers saw ageing as a time to slow down only $46 \%$ agreed that 'ageing is inevitable so we just have to get used to slowing down and doing less'. Buckland concludes from responses to statements that boomers are 'youthful' in profile, which she defines as flexible, idealistic, individualistic, challenging and searching for answers, and optimistic about the future. They have a more 'vigorous' profile than boomers in the comparative American study, being more likely to agree they have no intention of having a quiet retirement (73\% compared to $58 \%$ of American boomers) and to say they have no intention of acting their age (80\% compared to 68\%) (Buckland, 2009).

It is unclear whether the rhetoric of a 'new old age' apparent in focus group discussion is a sign of the development of a more positive attitude to ageing, or an attempt to resist an old age still perceived negatively. While some participants did talk about the benefits of being old, and many talked about the importance of valuing older people, few explicitly welcomed old age as a positive stage of life. It seemed that old age was not so much being transformed as being shifted to later years. 


\section{Beliefs about work, leisure and retirement}

Commonly focus group participants expected to work later in life, but believed that at some point they will reduce work. They believed in their right to choose whether and when to retire from work. Participants want to work longer but on their own terms.

They identified a range of 'push and pull' factors influencing their decisions about workforce participation that have been similarly described in other New Zealand studies (Davey, 2008; Keeling, Davey and Glasgow, 2009). Focus group participants commonly believed health will be a key factor influencing their ability to work, but many also believed that age discrimination could limit their work options. However, there was a shared optimism that employment opportunities would be there for them.

Focus group participants believed that boomers have a strong work ethic. Increased labour force participation rates seem to support this view (Callister, 2006) with higher rates in mid life compared to previous generations. However, there is greater diversity too, with more men in part time work, more women in full time work and more self employed than in previous years (Davey, 2003).

Boomers are right to be optimistic about work opportunities. The ageing of the workforce in New Zealand is expected to lead to significant labour and skills shortages (Stephenson and Scobie 2002). As smaller cohorts follow the baby boom bulge through the population, the average age of the workforce will continue to rise and growth in the labour force will become negative within twenty years (MSD, 2012). Employers will be dependent to a greater degree on older workers and policies are consequently emphasising the prolongation of participation in paid work. However ageism is predicted to continue to influence job opportunities for older workers and it is unclear whether job opportunities will match the kind of work and the conditions of work which boomers wish to do. (This issue is explored further in Chapter Seven.) 
A few boomers in the focus groups believed they had a responsibility to leave jobs to create spaces for younger people, but others disagreed. World Values Study data indicates this is a minority view and one that boomers are less likely to hold compared to older generations. Analysis of New Zealand data revealed $19 \%$ of all respondents agreed that when jobs are scarce older people should be forced to retire, with $17 \%$ of boomer age groups and $25 \%$ of older people agreeing with this statement (WVS 1998 data set).

Commonly, focus group participants believed that the meaning of 'retirement' had changed. Findings from other New Zealand studies support their view (Davey, 2007; McGregor and Gray, 2003; Gee et al, 2000). Retirement is no longer seen as a discrete event (Keeling, Davey and Glasgow, 2009) and part time work is increasingly being used as a transition to retirement (Callister 2006). Many older workers intend to undertake some form of paid work after retirement (Gee et al 2000) and strongly support free choice in their decision to leave work (McGregor and Gray 2003). Focus group participants' views matched these patterns.

\section{Beliefs about care and personal support}

Many boomers in the focus groups believed that it was likely that, in later life, they would live at a distance from family members. This might be as a result of their own move to a desired location, such as a semi-rural, coastal or lifestyle based community. It may also be as a result of family members' mobility, including movement to overseas destinations. There was an expectation that additional resources would therefore be needed, including money to travel to spend time with family members, additional space at home to accommodate visiting family, and financial reserves to purchase support services. 
It was common for these participants to anticipate support from friends and like minded neighbours, which they believed could be reciprocated in a variety of ways. There was evidence of a desire for intra-cohort reciprocal care and support arrangements.

Most participants believed that as their personal support needs increase as they age they will require support from outside the family. Some believed purchasing personal care was more acceptable and also more appropriate than asking family to provide it. There was a strong desire to ensure family were not burdened. There was also a belief that paid care workers should have the necessary skills and providers of services should ensure this was the case. But participants were concerned that support services will be in short supply, due to the increased demand from the large boomer cohort and shortages of trained care workers. Many also believed their access to publicly funded health and disability support services would be restricted through limited funding. Buckland's (2009) boomers had similar views - nearly $70 \%$ did not feel confident that the health and social support system will be able to support them as they age.

Focus group boomers believed that while the state would provide some care they would need to be prepared to look after themselves as much as possible, and they would need to be creative to find ways to get the support they would need. However, they strongly believed the state has a responsibility to support those in need and should ensure both well being and avoidance of poverty.

Boomers' concerns about access to health care and support are well founded. Health workforce shortages in New Zealand have been widely predicted (for example see HWAC, 2002; NZIER, 2004; Cornwall and Davey, 2004; Cox and Hope, 2006). 
While data indicates that younger cohorts in New Zealand are ageing in better health overall, increasing incidence of some chronic diseases and increased numbers of older people with conditions such as dementia, will increase pressure on health and disability services (Cornwall and Davey, 2004) and a large increase in demand resulting from population ageing is expected (Cox and Hope in Boston and Davey, 2006). Those on low incomes experience the most health problems (National Advisory Committee on Health and Disability, 2007) and are at greater risk of unmet need.

Predictions are that boomers will be more demanding of health services due to higher expectations of treatment to maintain active lifestyles and independence, and a less deferential attitude (Wanless, 2000; $\mathrm{MOH}$, 2002; Huber and Skidmore 2003). Focus group participants also expressed a belief that they would be more assertive and more demanding than their parents had been.

Some commentators predict an increased level of interdependence between family members and generations (Huber and Skidmore, 2003) and more generations coexisting and sharing care and household arrangements (Dench and Ogg, 2002). This was the situation for at least one participant, whose adult child and grandchild had moved back home. He was caring for his grandchild but also had responsibilities for an older family member. He managed by not being in fulltime employment. Reducing paid work was a strategy also used by a participant who decided to work fewer hours so she could spend more time with her parent. But not all boomers will be able to reduce work, and therefore income, to manage care responsibilities.

Younger boomers in particular may be sandwiched between the needs of their parents and their children, having had children at later ages. Huber and Skidmore speculate that boomers are likely to have extended responsibility for younger generations through "extended adolescence and the new costs of higher education" (2003, p86). 
In New Zealand there is evidence of extended responsibility for younger generations with household composition studies indicating an increase in children aged 25+ years co-residing in their parents' households (Pool et al, 2005). However Hillcoat-Nalletamby et al (1999) analysis of interviews with 750 New Zealanders aged 40-54 years in 1997, as part of the Mid Life Transactions Project, did not find clear evidence that a longer period of adult child dependency caused an increase in a sandwiching of middle life age groups. Further analysis of those interviews found that mid-lifers were engaged in complementary rather than competing forms of support in mid life (Hillcoat-Nalletamby and Dharmalingham, 2004).

The age difference between mothers and their children differs across cohorts and this has an impact of the sandwich generation effect. McPherson (1993) found much variation in incidences of doubledependency across cohorts. Her exploration of mother-daughter dependencies indicates that the youthful child bearing of older boomers means their daughters will likely be freer to manage their elder care responsibilities compared to cohorts preceding them (McPherson, 1993).

Petrie (2006) notes that the factors affecting intergenerational transfers of support within families are complex. Expectations and attitudes to family support, policy support for elder care, and socio-economic influences on workforce participation need also to be considered, for example, when attempting predictions of future trends. His analysis of New Zealand data leads him to conclude that "it does seem likely that more mid-life and young-elderly adults will be faced with elder-care responsibilities at the same time as they are in part-time or full-time work. The young elderly may also increasingly face work-life balance concerns in terms of competing demands from paid work and caring for grandchildren" (Petrie in Boston and Davey, 2006, p329). 
An increasing percentage of boomers living alone in late life are forecast with changing rates of divorce and more childless adults (Evandrou and Falkingham, 2006). However, an increase in remarriage and reconstituted families means support networks will be affected in a range of ways, with extended family networks and overlapping responsibilities for children and stepchildren.

One of the boomers in the focus groups spoke with reluctance about the level of responsibility for grandchildren she may need to take on. Another was caring fulltime for a grandchild to allow the child's mother to work. Overlapping responsibilities and needs prompted Huber and Skidmore to ponder whose needs can be met and when. "Many baby boomers are likely to value their independence highly; though they are likely to want some involvement in family life (where they have children and grandchildren), the prospect of maintaining regular and demanding caring communities may not be especially attractive" (Huber and Skidmore, 2003, p93).

\section{Beliefs about future financial circumstances}

Most focus group participants believed they would require additional income on top of the old age pension (NZS) to meet all their future needs and wants. Some believed it was not possible to save enough to meet anticipated needs in late life, either because of circumstances limiting their ability to save, or because they believed total costs would inevitably exceed what they could save over their lifetime. Costs they anticipated might be difficult to meet included those associated with maintaining their health and purchasing care beyond that provided by the public health system. Some anticipated difficulty meeting costs associated with visiting distanced family members. Travel was desired by many but was an area of spending that could be cut. Some believed they would cope financially because they would need less as they got older, becoming content with less or able to spend less as costs associated with work reduced. 
Some participants planned to 'simplify' as part of a desire to live a better life that was less materialistic. Others resisted suggestions they might reduce their standard of living, believing late life was a time they should be able to afford a few luxuries in late life, perhaps more than before.

Focus group participants commonly believed they would not receive financial support from family members, except perhaps via an inheritance. Practical support from family was more acceptable than financial support and there was a general belief that assistance ought to be reciprocated in some way. Participants expressed a strong desire to avoid burdening their own children. Although attitudes were against receiving financial support from family, participants commonly believed it was acceptable to provide this to family members, in certain circumstances. Some believed ongoing support to younger generations was not desirable, either because significant support to help them on their way had already been provided, or because it was better for children to learn to stand on their own two feet. But others expected to continue providing financial support to assist younger family members in need due to study costs or relationship breakdown. It was also acceptable to provide financial support to assist adult children to become financially secure (such as assisting with the purchase of a home).

Some parents in the boomer focus groups believed they should keep children's needs in mind when making decisions about their own spending, including what to do with the farm or family home. Some were keen to protect their assets, believing it was their responsibility to save resources for their children to inherit.

Beliefs about inheritance varied. Some participants indicated that expectations of inheritance were neither appropriate (as self reliance was highly valued) nor realistic (as longer lives and asset or income testing policies would mean resources would be used up before death). Huber and Skidmore (2003) found a similar assumption amongst boomers that they would need to use up their assets to support them in late life. 
Huber and Skidmore (op cit) concluded that the traditional view of property as a nest egg to pass onto children is changing, though evidence of attitudes is conflicting. They note adults in Britain are happy for their parents to use up the equity in their house to support themselves rather than pass it on as an inheritance, yet most of these same adults plan to pass on an inheritance to their own children.

Many focus group participants felt ill-prepared for their older age. There was a common belief that boomers were not good at planning for old age, with unrealistic expectations and a focus on today rather than the future. Some hadn't saved in earlier years because they had not expected to live a long life. Others hadn't saved because they believed the future was too hard to predict and it was therefore better to live for today. Others believed that careful saving could yield little benefit in the context of income or asset testing.

Despite their views on planning, most focus group participants were actively preparing, via KiwiSaver and other means, although some believed KiwiSaver had come too late for their generation. These boomers ability to prepare financially varied, with some participants still supporting young children, some 'empty nesters', and others supporting 'boomerang' children, back living with them after a period living independently. Those with private or work based superannuation plans in place felt fortunate, though some commented on constraints of schemes, including a lack of portability.

Keeling, Davey and Glasgow (2009) found a similar range of attitudes to planning amongst 55 to 70 year olds in their research on health, work and retirement in New Zealand. They found some mid-lifers were future orientated and others preferred to let the future take care of itself. The authors identified four groups of planners; lifetime planners, late onset planners, thrown off course planners and non planners (who couldn't, didn't, or felt no need to plan (see also Hill et al, 2007). 


\section{Exploring Values}

\section{Common Values identified in the Focus Groups}

Some values were explicitly identified by focus groups participants while others were implied within comments. Characteristics they explicitly valued were hard work, determination, alongside a 'can do' and 'do it yourself' attitude, which they observed in previous generations. These were values they believed boomers shared with their parents and held more strongly than younger generations. They also admired their parents' thrift, viewing it as a desirable value but not one common to their generation.

Focus group participants indicated they valued work for a variety of reasons, including as a source of income, but also as a way to contribute, retrain and learn new skills, maintain social relationships and feel acknowledged. Work is therefore expected by boomers to be interesting and meaningful, and there is a desire for work to fit in around individual needs, rather than the employee having to fit in to institutional arrangements. These views indicate that boomers value autonomy (Schwartz, 1999).

Often repeated phrases indicated participants valued freedom, choice, independence, and self responsibility. They also valued respect for elders, mutuality of family support, self sufficiency, community spirit, space and time, and speaking up about civil rights. More implicit in comments were values of fairness, reciprocity, equality and social justice.

There was ambivalence concerning some values, such as responsibility, duty and obligation. Participants spoke of welcoming reduced obligation and responsibility in older age. But they admired the more traditional model of family care of elders that was seen to characterise Maori and Pacific families, where responsibility was expected and shared, and familial piety, duty, obligation and respect for elders were highly valued. 
Somewhat contradictorily, many participants did not want their children to have the 'responsibility' of looking after them, viewing it as too burdensome. Some were also conflicted as to the level of responsibility for parents they would be comfortable with. It seemed that, for many participants, responsibility, duty and obligation were desirable but not necessarily desired. Some ambivalence concerning responsibility was reduced where reciprocity and mutuality were emphasised.

Other values were revealed in participants' judgements as to what was good or bad about boomer behaviour. For example, fairness was a desirable value within participants' belief that boomer assertiveness could enable ageism to be challenged, and also in their view that boomers' selfindulgent habits could have negative consequences on intergenerational equity.

Desirable values were also apparent in identified constraints and motivations for future behaviour. For example, while many boomers wished to travel to experience new challenges (desired value of adventurousness), they might need to focus instead on supporting the needs of family (desirable value of responsibility).

To explore the conflicts and contradictions between desired and desirable values, and the links between values and predicted behaviour, further analysis was undertaken to categorise values revealed in the focus groups as personally desired and socially desirable. Identified personal and desirable (social) values were then linked to commonly expressed goals, constraints and motivations (see Appendix Four). The categorisation of values draws on and extends Rokeach's list (1973) of terminal and instrumental values (personal values) and the value orientations identified by Schwartz (1999) and Inglehart (2008) (social and cultural values). No attempt is made to rank these and conflicting values are included. 
Personal values are assumed to be desired, but they may also be desirable. Desirable values, with their moral component, are by definition social, as morals imply a judgement on the rightness or wrongness of a behaviour in relation to others.

Assessments of 'desirable values' are useful for an understanding of the influence of group norms on behaviour. Vauclair (2009) argues that desirable values provide a better link to predictions of behaviour as they contain a level of 'oughts' and 'shoulds', thereby increasing motivation to adhere to the value. When behaviour is the norm within a social group an individual may behave the same way even if it is not congruent with their own personal values. Further, participants that rate a value as strongly endorsed by the group are more likely to themselves identify with the value (Wan et al, 2007, cited by Vauclair, 2009).

Desirable values will be influenced not only by group membership but also the context of the group, as well as other cultural influences on individuals within the group. Participants believed their values had been shaped by the circumstances they had grown up in and the experiences they had had.

Participants also identified continuity in values across generations. They believed they had absorbed the previous generations' work ethic and egalitarian social values, and noted the influence of their parents and grandparents experiences during the Depression years and in World War II, They also believed they had inherited values of self sufficiency and a 'number 8 wire' do-it-yourself mentality ${ }^{20}$, features deemed to be significant 'Kiwi' cultural characteristics.

While absorbing some of the previous generation's values and attitudes they believed they had rejected others, under the influence of broader changes in society. They agreed that the greater choices available to them

20 'Number 8 wire mentality'means innovation and creating solutions out of what resources are at hand. 
in a global and consumer orientated society had been influential.

Technological developments, including television and air travel, had raised their expectations and desire for more individualised lifestyles, while higher levels of education had created opportunities. They believed this had led to more comfort with risk taking and a rejection of their parents' emphasis on planning for the future.

Boomers are often portrayed as individualistic and there was evidence within focus groups of a valuing of individuality, innovation and creative lifestyles. Huber and Skidmore (2003) argue that boomers' individualism is based on their orientation away from formal authority and distrust of established institutions. They found that British boomers were more antiestablishment, more non-conformist, less deferential and less trusting of those in authority compared to older age groups and more hostile to organised religion (Huber and Skidmore, 2003, p34-35). Boomers in this study focus groups displayed similar attitudes. Having grown up in a more individualistic and consumerist culture boomers have been encouraged to define themselves by their personal choices. Huber and Skidmore suggest boomers define 'the good life' in more consumerist terms then older generations ( $p 36$ ), hailed by advertisers keen to trade on their nostalgia and interest in staying young.

The second key value commonly associated with boomers is liberalism. Findings from Rose et al (2005) and the WVS indicate the boomer age group is more liberal than older cohorts, for example in their social attitudes to marriage, abortion, sexuality and tolerance of as neighbours UK boomers also have more liberal views than older age groups on sex before marriage, having children outside of marriage, cohabitation and homosexuality (Huber and Skidmore, 2003). These attitudes and values have been influenced by the advent of the contraceptive pill and reform of divorce and abortion law and have contributed to change in family structures in ways which Huber and Skidmore argue will impact on support needs in late life. 
Their liberalism affects their view of public institutions, being more likely than older age groups to trust public services that treat people equally irrespective of race, religion or colour. The primacy of personal choice may also influence boomers stance on issues such as euthanasia and death.

Evidence of liberalism as a common value was mixed in this research, though there was agreement that the boomer cohort was more liberal than previous generations. Boomers considered themselves more liberal in their politics than older cohorts, a finding supported by Rose et al's research (2004), which shows boomer age groups are more supportive of gender equality, and issues relating to the environment, and more liberal on attitudes to drugs.

But they are not a homogeneous group, having different experiences in formative years which have influenced their attitudes and circumstances. Some leading boomers in focus groups strongly expressed social tolerance and valued diversity, while some younger boomers expressed more conservative views on issues such as immigration. In contrast, Rose et al (2004) found that compared to leading boomers, trailing boomers are typically more liberal,5more supportive of multiculturalism and more internationalist in their focus.

Not all boomers are left leaning in their politics, nor are they the same in terms of level of education, wealth, health and life expectancy, with class, ethnicity and gender differentiating the boomer cohort as well as age. Focus groups provided data on the range of views but because of the mixed nature of groups, it was not possible to draw clear conclusions about the extent of sub-group differences due for example to education, ethnicity and income.

Other studies provide greater detail. For example, in the focus groups it was clear that participants commonly valued work, but also work-life balance, and there were indications of differences between older and younger boomers. The 2005 New Zealand Values Survey data indicates 
that those aged 35-44 were more likely to agree that less importance on work in our lives in the future would be a good thing, compared to those aged 45-54 (48\% compared to 38\%) (Rose et al, 2005). Webster (2001) found other factors influenced views on work-life balance in his analysis of New Zealand data, finding that class, level of education and ethnicity influence the degree to which leisure was valued. While $89 \%$ of all respondents valued leisure highly, the more educated valued leisure more (92\% did). Upper middle class respondents also rated leisure more highly than lower class (93\% and $72 \%$ respectively) and those identifying as 'New Zealander' and as 'above all Maori' valued leisure more highly than Pacific respondents (92\%, 79\% and $65 \%$ ).

Webster's (2001) analysis also reveals that those with a high level of education were less likely to see job security and good hours as important. They were more likely to place importance on a job that is interesting and which allows them to take initiative. Working class respondents valued a job with not too much pressure more than other classes. Pacific peoples were more likely to value good job security, generous holidays and good hours than other groups and they rated responsibility in the job more highly as a source of job satisfaction than other ethnic groups.

Webster identified other values that varied by ethnicity. For example while $60 \%$ of all New Zealanders surveyed agreed that central government should provide a decent standard of living for older people, support was stronger amongst Maori ( $72 \%$ of those identifying as 'above all Maori' agreed with the statement). Those identifying as 'above all Maori' were also more likely to agree they had much to say about the running of government (50\% agreed compared to $38 \%$ over all) but were less likely to support competitive achievement, with fewer agreeing that competition is good or that hard work brings a good life. There were also ethnic differences in values revealed in statements about the qualities children should learn at home, with Pacific respondents placing less emphasis on determination and independence. (Webster, 2001.) 
These findings are a reminder to pay attention to the range of factors influencing attitudes and values, and indicate opportunities for further research.

\section{Situating Boomers Values - World Values Surveys}

Inglehart (2008) identifies a range of values that are typical of advanced industrial societies. His theory of generational change suggests that boomers are influenced by, and part of, a global shift in values. He concludes there are two significant cultural value shifts occurring globally: first between traditional and secular-rational values, and second, between survival and self-expression values. 'Traditional' values, which tend be held in agrarian societies, emphasise religion, respect for authority, high national pride and low tolerance for abortion and divorce. 'Secular-rational' values, stronger in industrialising societies, emphasise the opposite. (Inglehart, 2008) 'Survival' values emphasise deference to external authority while 'self-expression' values give priority to individual freedom, tolerance of diversity, and norms associated with the pursuit of individual well-being.

New Zealand data indicates a shift in values between generations with a movement towards secular-rational and self expression values. Inglehart's thesis on generational change rests on a hypothesis that "one's basic values reflect the conditions that prevailed during one's pre-adult years" so that change in cultural values is slow, occurring "mainly through intergenerational population replacement" (p131). Value changes will be apparent over time, and will have most impact "fifteen to 20 years after an era of prosperity began (when) the birth cohorts that had spent their years in prosperity would begin to enter the electorate' (Inglehart, 2008, p132).

Inglehart argues that self-expression values give higher priority to quality of life issues including environmental protection and anti-discrimination, and rising demands for participation in decision making in political and 
economic life. There is an increased emphasis on freedom of expression. Changing priorities result, from those linked with survival, to goals such as belonging, esteem and aesthetic and intellectual satisfaction (Inglehart, 2008, p131). Greater security brings more permissive attitudes amongst younger generations towards abortion, divorce, extra-marital affairs, prostitution and euthanasia, more tolerance of out groups and a rejection of hierarchical institutions, corporate power and elites.

Boomers' values appear to align with Inglehart's thesis. Respondents in or close to boomer age groups are more permissive and more tolerant of diversity than previous generations. In the focus groups boomers commonly emphasised freedom, quality of life and choice. They lacked confidence in institutions and they valued opportunities to participate politically. Some desired lifestyles based on notions of sustainability and looked for creative and intellectual pursuits as part of a balanced lifestyle, all indications they valued self expression.

Webster (2001) identifies greater traditionalism overall amongst those who identify as Maori and Pacific in New Zealand and those who are less educated and within a lower class. He also concludes that values associated with individualistic enterprise and a caring society tend to be held by those in higher or mixed classes and educational levels, while the poorer sectors of society show strongest demand for a stronger political voice. Webster argues there is no one identity within New Zealand, but there is overall movement away from traditional / survival values which is especially strong within the 'dominant' culture (the core of which is the upper middle class and the higher educated). His results confirm that age and cohort historical location are intersected by other factors and more research would be useful. 


\section{Discussion}

A range of anxieties have been expressed about the future behaviour of the baby boomer cohort (see Phillipson, Leach et al, 2008) including concern about the impact of boomers' high lifestyle expectations and patterns of consumption, and the economic effects of their exit from productive activities. However boomers commonly do not expect to stop contributing. Rather they expect to remain productive in a variety of ways for as long as possible. They look forward to ongoing part time or voluntary work in areas of their own choosing, and they expect to provide financial, emotional and cultural support to family members and younger generations. They view late life as an opportunity to balance selected work activities with creative, spiritual and recreational pursuits, and an opportunity to spend time with family and to give back to their communities. However they do expect to individualise the nature, timing and level of their participation.

Some participants were also questioning their patterns of consumption. Many believe they have contributed to an overly materialistic society and some now strive for a return to more simplified and sustainable lifestyles. However it remains unclear to what extent such ideals may alter boomer behaviour and priorities. Many participants also expressed a consumer based desire for increased travel, active recreation, and a comfortable and pleasurable home and holiday environment, which conflicts with the goal of sustainability.

A key concern has been whether boomers will act collectively to bring about or block change, or to challenge organisational power in order to secure a common goal. Many participants had been involved in past protests where they have been in conflict with organisations whose objectives and outlook they oppose. But some felt they would lose their influence as younger generations came of age and moved into positions of authority. 
These boomers felt their ability to influence decision makers would need to be actively fought for. A few participants felt their time of political activity had past, perhaps reflecting a desire for a comfortable life ahead. Some felt it was likely that future alliances would cross generational boundaries due to common interests and as a result of diversity of circumstances within the cohort.

Participants in the focus groups commonly agreed that the state ought to support older people and this is a view shared by most New Zealanders. Webster's 2001 analysis shows $60 \%$ of New Zealanders agree that central government should provide a decent standard of living for the old.

Buckland (2009) also concluded that boomers' view a social safety net as their right and responsibility.

But there was also general agreement in focus groups that responsibility for older people should be shared between the state, the individual and families. There were varied views as to what a fair share looked like and what level of support the state should provide. These boomers do feel a responsibility to prepare for their own future, but they also expect the state to provide a 'fair' pension to prevent hardship. They also want access to sufficient support services to allow them to remain active and to ensure they do not become a burden on their families. It appears likely that those who have the financial resources to do so will actively seek out treatment and services to alleviate common health problems associated with old age.

Overall participants had a low expectation of support from the state. This may reflect broader changes in society. Various scholars have commented on changing expectations of welfare, arguing that a 'sea change' in opinion on social policy has occurred. Poverty and unemployment have become more accepted, viewed as inevitable to a degree, and not as painful as in the past (Wilding, 1992). 
Van Kersbergen (2000) argues that changes have resulted in a generation which "although raised in the welfare state, has been taught not to expect too much from it... (they) will be much less attached politically to the welfare state than the preceding generations that built it and profited from it” (2000, p29). This appears to be so for many boomers. Rudd (2001) argues that previously Keynesian notions of collective responsibility to assist disadvantaged individuals through state intervention have been transformed into an acceptance of neoliberal policies based on the notion of individual self-responsibility. Whereas once the welfare state was seen as desirable, it now was considered in terms of 'affordable'. Rudd further argues that neoliberalism has permeated the attitudes of New Zealanders, influencing their expectations of the welfare state.

Some are concerned that intergenerational conflict will result if boomers act collectively in their own interests. This rests on several assumptions. The first is that boomers view themselves as a group with distinct interests. Boomers see themselves as different to their parents' generation, with distinctive values, but they also tend to align themselves with the generation immediately below them. Boomers see themselves as not so different from their children, sharing an adventurousness and appreciation of cultural icons. The degree to which the younger generation agrees with this view is an area for future research. But it does raise the possibility that boomers' desire to stay young will drive them to continue to find ways to align themselves with younger age groups thereby reducing conflict between these generations. When different groups share compelling goals, they may cooperate if one group can not attain the goal independently through its own efforts. Over time hostility and social distance between the groups will reduce and group membership will be redefined (Reich and Adcock, 1976). 
A second assumption driving concerns about intergenerational conflict is that boomers will act in their own self interest. The findings from this study don't support this view. Boomers' sensitivity to social issues, guilt about the demands of their cohort, and their concerns about their own family members means they are concerned about the impact of their behaviour on future generations. It is plausible that boomers views will coalesce on issues that are most relevant for the next generation, including access to education, housing and affordable child care, and the sustainability of resources. Links across generations appear more likely in these areas. Access to healthcare might also be an issue that cuts across generations, given boomers' strong desire to avoid burdening their children.

Overall these boomers expressed a sense of common identity resulting from cohort size, perceived difference from older and younger generations, and knowledge of a shared socio-historical context. Many articulated and appeared to have internalised common discourses about the boomer generation, although differences between older and younger, urban and provincial, socio-economic and ethnic groups were suggested. Older boomers expressed a clearer sense of themselves as pioneers and change agents and younger boomers viewed older boomers as more radical and politically active. Younger boomers also felt they had a more secure and relaxed upbringing that resulted in a self-centred sense of entitlement. However, both younger and older boomers expressed appreciation for the struggles and sacrifices of those who had gone before.

Commonly, both older and younger boomers felt they had benefited from an increasingly liberal society. Many felt they were brought up in times of prosperity, security and supportive policy (including free education) and expressed concern for the economic and environmental conditions facing the next generation. 
There was a sense of nostalgia for the 'simpler and less stressful' society of their younger years and criticism of today's consumerist and materialistic values. Some felt that boomer hedonistic tendencies and indulgent parenting styles had contributed to a more individualistic society, and to increasing self-centeredness amongst the younger generation.

Most believed they would age differently to current generations of older people. These boomers are interested in new forms of work and more flexible, creative, individualised ways of living and more supportive living arrangements.

In contrast to portrayals of boomers as a powerful voting bloc, these boomers do not appear to have a common set of demands. Younger boomers feel they grew up with more affluence and security, so do not aspire to change the world. Older boomers who have been politically active do not necessarily want to be absorbed by these activities in their older age. In addition, some boomers feel they are just as likely to forge links across age groups. Some ingredients for collective political action were evident, including a sense of cohort identity, a pool of experienced activists, and common concerns, such as the level and quality of late life support.

There has been a tendency to base planning for New Zealand boomers on international research. However, Buckland (2009) argues that New Zealand boomers, while similar, are not the same as boomers overseas. She argues New Zealand boomers have a distinct character that causes them to react in different ways to their environment. Compared to American boomers, New Zealand boomers are less conservative, younger in their attitudes and less entrenched in traditional models of retirement. Buckland found that New Zealand boomers are more 'vibrant' more adventurous and searching. 
Accoring to Buckland (2009) both American and New Zealand boomers search for meaning and self-actualisation. Their intentions are also the same - both American and New Zealand boomers "want to enjoy every moment of their lives to the fullest, on their own terms (and) both want to leave the world a better place when they die... They want to stay involved, continue to indulge themselves and pursue their passions. However, New Zealand boomers display a desire to "do all these things more proactively and with greater ingenuity" (p74).

Buckland's comments reinforce a finding of this study that suggests boomers in New Zealand are influenced by their place in the Pacific. Boomers in this study recognised and were drawn to Pacific models of family care. They also were proud of the respected place that Maori elders have in their community. While European boomers believed these models were not so relevant to their own experience, a Pacific based identity in older age may gain currency as demographic shifts continue. New Zealand boomers are experiencing a rapidly increasing diversity of cultures in their communities, including from south east and central Asia. The effect on a valuing of 'being in a Pacific place' is an area worthy of additional research. 


\section{Chapter Conclusion}

New Zealand baby boomers are accepting of their status as a different generation and enjoy their defined role as change agents. They believe they have been at the forefront of social change and may draw on previous experience to collectively influence policy in the future. While it remains unclear on which issues they may converge, findings suggest that the boomer cohort has the potential and, at least for some, the inclination to advocate for social change.

Boomers in the study had high expectations for their own active and healthy ageing, but were concerned about the level and quality of support currently available. They were critical of current access to health care and are likely to become more demanding about care and support if their needs, or their parents' needs, are not met. This issue will be explored further in the next chapter.

They have a strong work ethic but also value work/life balance, choice, freedom and autonomy in decision making. They want to remain active and to contribute and participate, but on their own terms. These boomers support a sharing of responsibility for wellbeing in older age between individuals, families and the state. They believe they should prepare for their own future and provide for their families, and they value self reliance and independence. But they also believe that the state has a responsibility to reduce inequities and to support those in need. Like their parents they value self-reliance and independence, but some boomers also value inter-dependence and inter-generational care responsibilities. There was also evidence of a desire for more innovative intra-cohort reciprocal care and support arrangements. 
Many expressed a 'rights based' sense of entitlement that has motivated them to challenge and question. Commonly these boomers value a 'just and fair' society. Those who had direct experience of political activism felt more confident that boomers could act collectively to create alternative solutions to social problems.

Processes of policy development will need to adapt to effectively work with the values of the large boomer cohort. Specific policy implications are explored in the next chapter. 


\section{Chapter 8: Policy Implications}

\section{Introduction}

How boomers' attitudes, beliefs and values relate to policy on ageing is explored in this chapter. The focus is on the degree of mismatch or congruency between boomers' views and current policy for older people. Boomers' views, as illustrated in the focus group discussions and additional available data, provide a context for assessing current policy goals. Key questions addressed in this chapter are:

- how congruent are boomers' values and attitudes with current policy paradigms;

- how may policy influence boomers' attitudes or behaviour as they age;

- how may boomers' values and attitudes inform and shape the future policy agenda in an ageing society.

Chapter Eight draws on the outline of policy described in Chapter Three. Here additional focus is placed on the policy goals set out in the New Zealand Positive Ageing Strategy (Dalziel, 2001) and related policy documents, and the underlying policy values.

\section{Policy Values}

Policy values relevant to boomers are identifiable in the Positive Ageing Strategy (PAS) and the Business of Ageing (BOA). Within PAS, boomers as 'future generations of older people' are encouraged to make choices to enable them to continue in work, maintain a healthy lifestyle, and remain active, involved and independent. 
PAS's message for boomers is to take responsibility for preparing for their own ageing, through maintenance of good health, ensuring adequacy of income and ongoing involvement in productive work. Key values promoted in PAS are self reliance, mutual obligation, and social responsibility. Also valued are productivity, contribution, participation, duty and intergenerational equity.

These values reflect shifts in political ideology through the 1990s, with increasing emphasis on the social responsibilities of citizens, epitomised in National's 'From Welfare to Wellbeing' slogan (Davey, 2000) and Labour's 'social development' approach to welfare (Glasgow, 2005). PAS represents "the emergence of a new social contract between the generations, based on... 'active' citizenship" (Boston and Davey 2006, p371).

In the more recent Business of Ageing (BOA) a policy discourse of 'consumer citizenship' (Jones et al, 2008) has been promoted. BOA seeks to promote opportunities to 'tap into the growing mature consumer market' as well as to increase the number of older people who choose to remain active in the workforce (MSD website, 2012). As active consumers, boomers are encouraged to maintain their contributions. The report's authors acknowledge that not all baby boomers will want to remain in paid work, but recommend "flexibility and changing attitudes (as) key to harnessing the potential of those who do" (MSD, 2011, p2). Additional contributions are recognised with a broadened definition of productivity, perhaps in acknowledgment of earlier critiques (see Chapter Three). There remains an economic focus on the contribution that future older New Zealander's will make through employment earnings, taxes and spending. Both the state and the market are seen as necessary participants for enhancing future well being. The rhetoric in BOA arguably has a less authoritarian tone than was apparent in earlier policy documents, but the emphasis on citizen's responsibility to their family and community remains. 
In BOA there is a stronger emphasis, compared to the Positive Ageing Strategy, on 'choice and voice' alongside a promotion of 'partnership', reflecting the more developed social democracy of Third Way social policy being adopted by this time. The Third Way approach supports "a different style of politics and governance that recognises the need for political decision-making to have legitimacy through greater citizen participation, the need to overcome citizen distrust of and cynicism about politicians, and an emphasis on the role of civil society" (Cheyne et al, 2008, p77).

At the time of writing, both the Positive Ageing Strategy and the Business of Ageing remain as key policies for future generations of older people. In the following sections, boomers values and attitudes are compared with those within these policies, with a focus on key areas identified by boomers as issues of concern.

\section{Boomers and policy - mismatch or congruence}

\section{Retirement Income Policy}

Focus group boomers accept they have a responsibility to prepare for their older age and they value self reliance. But they strongly believe that the state has a responsibility to support older people in need. Universality of New Zealand Superannuation (NZS) was supported by most boomers in the groups. Some felt it was unfair that those who had sufficient resources still received NZS, but others argued that a basic universal pension was fair as it treated everyone equally.

The Retirement Commission agrees, arguing that despite changes over time, the system upholds longstanding principles of adequacy, simplicity, flexibility, certainty, equity and fairness (Retirement Commission, 2012). Retirement income policy supports a universal pension supplemented by voluntary provision from savings or earnings. 
The first goal of PAS seeks "secure and adequate income for older people". NZS is paid to people aged 65 and over, who meet residence criteria, at a flat rate regardless of prior earnings or contributions. It provides a basic income that aims to keep older people out of poverty (Ministry of Social Development, 2007) and allow them to participate in the community (Retirement Commission, 2012).

Boomers in the focus groups agree that the level of NZS should be sufficient to ensure avoidance of poverty and hardship in old age. They are less confident that NZS will be adequate to support participation in society in the ways of their choosing and they expect to need to top up NZS with savings or other income. These boomers express social justice concerns for those without additional income. They recognise that public policy has an influence on socio-economic conditions and on life chances. They therefore support shared responsibility for adequacy of income in late life.

Although there is concern amongst these boomers about the costs of population ageing, there is a strong desire for security and stability of retirement income policy. Some boomers in the groups were angry at the prospect of goal posts shifting and there was evidence of a collective memory of past policy changes, with bitterness remaining over historical reversals in superannuation policy and the welfare reforms of the 1990s. Some feel strongly that they have a right to expect support as they have contributed through taxes throughout their lives on the understanding support will be available when they retire.

Focus group boomers lack confidence in the stability of policy. While they believe that a state pension for older people will continue, they have high expectations that the parameters will be changed. They commonly anticipate a raising of the age of entitlement to NZS. Some feel that raising the age of entitlement would be unfair to older boomers with little time to adjust their planning. 
The fairness of policy was a strong theme in focus group discussions about possible changes to NZS policy, indicating boomers who perceive policy changes as unfair are likely to protest.

There is ongoing policy debate on the issue of raising the age of entitlement. The Retirement Commission (2012) supports a gradual rise in the age of entitlement, but the current Prime Minister John Key has promised no change under his leadership, arguing that at its height, NZS would comprise an affordable $8 \%$ of GDP (www.national.org.nz). In opposition Labour has indicated support for a graduated rise in the age of entitlement, while the Green and Maori parties are seeking further debate on the topic to explore the impact on more vulnerable population groups.

While these boomers were commonly reluctant to support a rise in age, some voiced concerns about the fiscal demands of NZS. However New Zealand is considered better able to adjust to demographic change than many other countries (Todd Taskforce, 1997; Else and St John, 1998; Periodic Report Group, 2003) given the flexibility and simplicity of NZS. More recently, Paul, Rashbrooke and Rae (in Boston and Davey, 2006) looked at the ability for revenue to meet the costs of NZS as the population ages. Under a range of scenarios, they predict a modest revenue shortfall, able to be substantially offset by an increase in labourforce participation rates of those over 55 years of age. Importantly, this modelling was done prior to the Global Financial Crisis and the suspension of contributions to the New Zealand Superannuation Fund (NZSF). The focus groups also took place before the significant effects of the recent Global Financial Crisis were felt in New Zealand. It is possible boomers' fears about the impact of population ageing have since increased but it is unclear whether this will reduce resistance to change to NZS. Currently political and policy debate on possible changes to NZS is ongoing. 
Overall few of these boomers support substantial change in NZS policy and there is evidence of some resistance to the shifting of responsibility from the state onto individuals and their families. Some boomers see their generation as under pressure, expected to support both themselves in old age and younger family members in need due to reduced entitlements. Some boomers feel that any reduction in the level of NZS would be unfair as they are already being expected to pay more for services that had previously been provided by the state.

Boomers in focus groups valued choice and this suggests little support for a compulsory savings scheme. Most of the boomers in this study were enrolled in KiwiSaver, a voluntary savings scheme introduced in 2007. This was significant given the scheme was only a year old when focus groups were held (and may reflect the popularity of the lump sum top up new members receive when they join). The Retirement Commission ${ }^{21}$ agrees that a voluntary scheme is preferable, arguing the model encourages New Zealanders to take responsibility for managing their own finances. The Commission identifies flexible savings schemes as important, as a 'one size fits all' approach fails to allow for the diversity of New Zealanders' needs and reduces choice. Compulsion would contribute to greater inequality. It may also create pressure to means test NZS (Retirement Commission 2012). Focus group boomers expressed views that are well aligned to those of the Commission.

Uncertainty about policy added to a degree of anxiety about the future amongst boomers in the groups. Callister's (2006) research indicates that it is likely there will be a significant group of boomers who have experienced difficulty accumulating assets and savings. Income support will need to be sufficiently flexible to address the diverse needs within the cohort. Current additional means tested benefits such as the Accommodation Benefit and Disability Allowance, will remain important. ${ }^{21}$ Recently renamed the Commission for Financial Literacy and Retirement Income
(CFLRI) 
Discount card schemes and free off peak public transport for older people are another important mechanism to enhance well being in late life.

Additional policy options to access funds tied up in housing are likely to be demanded by boomers. Older homeowners currently have some choices to release funds through home equity conversion schemes and calls for improved consumer protection have led to a new Code. There has been a low uptake of such schemes to date amongst older people, with attitudes to bequests and to loans in late life identified as contributing factors (Davey, 2005). However boomers' attitudes to finance and loans appear less conservative than older generations (ibid). There is also evidence of a shift in attitudes on using assets to fund current lifestyle with diverse views on inheritances. Some boomers viewed contributions to family during their lifetime, such as to assist with home deposits, as more realistic and more helpful than holding on to assets till after their death. These boomers value flexibility of options and they will likely resent any policy barriers to transfer of assets within families.

A significant proportion of boomers in the study had spent time overseas and policies on pension portability are expected to become increasingly important as more boomers reach pension age. Options for dealing with overseas pensions are currently being explored and Littlewood and Dale (2012) argue for regulations to be principle rather than rules based, to ensure policy flexibility. One option is for each country to pay the pension accrued by a resident during the time they lived there, with residents here receiving NZS based on their years of contribution here, regardless of what they get from overseas. This would avoid some of the current difficulties of trying to blend pensions with different rules of entitlement, but it would result in greater diversity of support, and there might be a group who would not be entitled to any support as a result of insufficient residency in any country. It might also result in a shifting of responsibility onto individuals to collect a pension from their former country. Boomers may accept additional responsibility if they believe it would result in a more flexible and equitable system. 
These boomers are aware that the size of their cohort demands higher resources compared to smaller generations and this contributed to their reduced expectations of support. They also share concerns about intergenerational equity, but they recognise that exchanges between generations are varied and complex. They feel it is government's responsibility to ensure equity and the stability and sustainability of retirement income.

\section{Work and retirement}

Most of the boomers in the focus groups anticipate working to a later age than the previous generation. They strongly value having the choice to continue working and they desire flexibility of work, to meet changing needs and personal goals. Increasingly boomers are seeking flexible conditions and part time work. They anticipate ongoing family responsibilities including support for parents, adult children and grandchildren, and they wish to have time for leisure.

It seems that boomers' desires and policy goals are well aligned. Boomers value the choice to work in late life and this fits in with government needs to manage costs. PAS encourages ongoing participation in the workplace. A stated priority for the Minister of Senior Citizens (MSD, 2012) is to encourage flexible work options and opportunities for older workers to remain in work.

Boomers in this study commonly desired a phased transition out of the workforce with options for future return to work, a finding supported by other research on older workers (Alpass and Mortimer, 2007; Keeling et al, 2009). Reasons why boomers wanted to work varied, including to 'top up' income, to maintain skills and contacts, to feel valued and to gain a sense of satisfaction (see Chapter Six). 
However, barriers to work at older ages are apparent and include attitudes and skill mismatches (Davey and Cornwall, 2003). 'Maximising the potential of older workers' requires strategies to retain older workers, maintain their skills; and ensure their workplace health and safety. Options include variable hours, improvements to the design of the job or reassignment of the worker, leave arrangements, or job sharing (Davey, 2006b). Boomers in the study were keen for flexible work arrangements that would enable them to balance work and leisure, or to move in and out of the workforce.

Recommendations provided in a 2007 Department of Labour Discussion Paper on age discrimination include a call for more research to examine attitudes about the productivity of older workers and mature job seekers; the factors that influence decisions about workforce participation and retirement; and successful compensatory strategies used by older workers in response to declines in health and functioning (Alpass and Mortimer, 2007).

The qualitative stream of the Health Work and Retirement (HWR) Study looked at factors that affect individuals' ability to work at their desired level. Mismatch resulted from health and care responsibilities, financial needs, lack of funding for more hours, and attitudinal barriers of the worker or the employer (Keeling et al, 2009). Interviewees said they desire flexible work practices to enable them to balance work with family-care responsibilities and their desire to do other things. Boomers in the focus groups expressed similar views (see Chapter Five).

There is evidence that some businesses and organisations are becoming aware that the ageing of the workforce means they will increasingly need to rely on older workers in future (DOL, 2012). However Human Rights Commission research showed that young people were six to 12 times more likely to be short-listed for a range of jobs than 55-year-olds (HRC, 2011). 
Patterns in hiring of older workers vary, with some sectors showing lower recrutiment, including many of the manufacturing industries, forestry and logging, food and beverage services, library and other information services, broadcasting, sport and recreation activities, air transport, and telecommunication services (Dixon, 2009). Given ongoing barriers some boomers may find their expectations of work are overly optimistic.

Boomers had high expectations of flexibility in employment, and further work is needed if these expectations are to be met. More flexible attitudes and policies are needed from employers to assist older workers to manage care-giving responsibilities and to enable options for a gradual and later transition out of the workforce. In 2001 less than a third of employers offered flexitime and less than $20 \%$ offered gradual retirement options (Ministry of Social Development, 2001). By 2006 some government agencies had initiated policies to meet the needs of their older workers, with retirement seminars, flexible work conditions and mentoring (OSC, 2006). However employers in smaller businesses are less likely to be offering these programmes and need additional encouragement to do so.

There are measures to assist boomers to meet their aspirations for longer workforce participation and there are lessons which New Zealand can learn from overseas. A number of programmes offer models for New Zealand, including the Finnish National Programme for Ageing Workers that offers age management training, promotes work-ability, and combats age discrimination (Davey, 2006b). Education of business owners on the value of older workers, especially in a society where the consumer is also ageing, needs greater attention. Support for older workers who are job seeking is also needed, and has been inconsistent to date, such as the short lived Jobs Jolt programme by Work and Income intended to provide active case management. Skills matching will also demand increasing attention. While there is evidence of changing attitudes to work and retirement and growing awareness of the value of older workers, myths about older workers persist (OSC, 2006). Ageism in the workplace is explored in the following section. 


\section{Attitudes and ageism}

Boomers in the focus groups recognised evidence of ageism in the workplace and in New Zealand society generally. But they felt negative stereotypes of older people were reducing as older people became more visible and less marginalised in society and they viewed the media as influential, with older people now portrayed in less stereotypical ways. They also believed older people were traditionally afforded more respect within Maori, Pacific and Asian cultures and they were attracted to a discourse of older people as honoured and respected elders.

These boomers are nevertheless concerned that they may be patronised and marginalised as they age. Though they believe they will stand up for their rights, and attitudes are improving, they support more action to improve attitudes towards current and future generations of older people. These boomers feel older people have the right to be treated with dignity and respect and they believe government has a responsibility to ensure older people are protected from harm.

Improving attitudes to older people is a key objective of PAS. Actions to progress this include Goal 8 (People of all ages have positive attitudes to agineg and older people, and Goal 9 (The elimination of ageism and and the pormotion of flexible work options). Boomers and policy goals appear to be in alignment here. Boomers want respectful attitudes and they share the goal of positive (active) ageing. However boomers seek attitudes that will maximise their freedom and choice of activity and value their contributions over the lifetime. The more narrow focus in PAS is on attitudes that promote contribution and ongoing involvement in productive activity in late life. In BOA, attitude change is focused on making contributions visible and BOA encourages ongoing engagement in consumerist society. BOA's consumerist message may not be as attractive to some boomer who hold negative views about an overly consumerist society. For some boomers the choice they sought was to seek an alternative, less materialist lifestyle. 
Actions under PAS to improve attitudes (OSC, 2012b) have included encouraging the support of older workers in the state services, promoting mentor programmes, promoting positive images of older people in government campaigns, fostering intergenerational programmes (such as LinkAge $^{22}$ ) and promoting collaborative relationships between government and other sectors that promote positive ageing. Intended actions to eliminate ageism in the workplace are leading by example by supporting older workers in the government sector, ensuring those providing services are aware of older peoples' issues, and promoting mentor programmes.

Assumptions made by employers about the ability and performance of older workers are based on persistent negative stereotyping of older workers (McGregor and Gray 2002; DOL, 2012) despite evidence that older workers are productive, reliable, flexible, amenable to change and interested in further training (Davey, 2006). This opens up the opportunity for employers to learn and change their beliefs about older workers.

A 2008 survey of New Zealand recruitment consultants found that attitudes towards older job seekers are becoming increasingly positive (McPherson 2008) perhaps reflecting work being done in this area. The Equal Employment Opportunities (EEO) Trust has taken a leading role on work and family issues by initiating work and life awards, promoting the issue through conferences and media releases, newsletters and projects, and by tracking performance of employers, and operating a fund for work and family initiatives, but funding of the EEO Trust has been insecure. The Department of Labour (DOL) has also promoted research and information resources as part of its Future of Work Project. This has now been absorbed into the broader work of the Ministry.

22 A resource to promote intergenerational programmes and older volunteers in schools. 
Some boomers from the focus groups believe that older people will become more valued as labour shortages increase. This is a view promoted in a report on age discrimination (DOL, 2012). The authors argue that as more perceptive employers, and older people themselves, recognise the productivity value of older workers, entrepreneurial activity will increase and discrimination will reduce. The authors argue there is no requirement for detailed co-ordination to break down stereotypes, as a single alert entrepreneur can break through and employ the older workers that were undervalued by rivals. The solution, they argue, is to alert coworkers and customers to the costs of their prejudices and show them the many gains from greater interaction with previously disfavoured groups. This approach emphasises the influence of economic and technological factors, while de-emphasising the impact of ideological and social factors. Nevertheless, as the authors argue, there is likely to be a strong market force for change, as when a minority becomes a majority the costs of employment discrimination increase (DOL 2012). Employers that do not hire older workers on merit will limit their access to the talents of older workers and will put their business survival at risk as they compete for a diminishing pool of younger workers.

An approach that emphasises businesses' role in supporting attitude change fits well with government's desire to increase responsibility within the private sector. BOA promotes the economic effectiveness of marketing to older consumers. The role of employers, government and business are outlined, with Government to be a 'catalyst' by prioritising workplace best practice in the public sector (MSD, 2011, p30). Government 'cannot work in isolation' (p3) with action also needed by business groups, NGOs and individuals to make the most of the potential of older people's contribution. Boomers support shared responsibility and their desire for flexibility means partnership approaches are likely be acceptable. 
Indicators of positive attitudes towards ageing and older people developed by MSD (2007) include measures of life satisfaction amongst older people, a measure older persons' physical activity (as a measure of their attitude to living a healthy active lifestyle), and a general survey of perceptions of age discrimination. The indicator used to measure age discrimination is the proportion of the population aged 15 years and over who, in the past 12 months, perceive they have been treated unfairly or discriminated against because of the group they belonged to or seemed to belong to (MSD, 2007). However the number of older respondents was too small to identify the proportion who felt discriminated against because of their age. Additional measures of ageism would appear useful. MSD states "we lack data on attitudes to ageing and older people, which makes it difficult to assess the extent and impact of ageism" (MSD, 2012 website). Additional measures of ageism and discrimination would be valuable. For example while employment rates and earnings are used as proxies for measures of ageism in the workplace, training for older workers is not assessed.

Boomers and policy makers agree that ageism affects well-being and selfperception and has a detrimental effect on quality of life in older age. Ageism in New Zealand has been recognised by the inclusion of age as a category of discrimination in the Human Rights Act 1993 and the Human Rights Amendment Act 2001, which ended the Government's exemption from full compliance with the Act, and made provision for the appointment of a full time Equal Opportunities Commissioner (HRC, 2012 website). However, legislation may not be effective on its own. A lack of recognition of life experience, background and culture, and a failure to value lifetime contributions can contribute to poor treatment of older people. There are calls for training to improve attitudes amongst those providing services to older people (Human Rights Commission, 2012).

Health services and the long term care of older people are areas where these boomers feel negative attitudes are more firmly entrenched. Boomers in focus groups expressed concerns about quality of care and the treatment of older people in residential care and they believe ageism is 
a factor. In a recent study on aged care, the Human Rights Commission (2012) also noted that ageist stereotypes influence the low status and pay of workers caring for older people and contribute to difficulty in recruiting health professionals and care workers. The reports authors note that the value we place on older people in New Zealand society is linked to the value we place on those who care for them.

There has been less attention paid to ageism within health and social services in New Zealand compared to ageism in the workplace, and research on ageism in the New Zealand health sector is limited (HRC, 2012). The Health of Older People Strategy (HOPS) (Dyson, 2002) does include action to enhance attitudes within the health sector (Action 1. 4: "Positive attitudes to ageing and older people are modelled"). However, research on the implementation of HOPS identified organisational culture in the health sector as a barrier to achieving policy objectives (Hood, 2008). Interviewees in Hood's research identified resistance to change and a reluctance to take on additional responsibility. For example those in the secondary sector identified a need for the primary sector to do more to ensure older people were informed of entitlements. There were concerns also about the attitudes of staff, who were identified as needing more awareness, patience and respect for older people (ibid).

Age Concern NZ argues that ageist attitudes lead to disrespect and are a contributing factor to elder abuse and neglect (ACNZ website, 2012). ACNZ have called for a campaign similar to the 'It's Not Okay' campaign against family violence but aimed at combating ageism and promoting respect for older people. Age Concern coordinators also call for improved consultation with older people in the health sector. While there was agreement that consultation by DHBs on planning of health services had improved, they indicated the level of feedback sought by DHBs on satisfaction with services was inadequate (Hood, 2008). 
Internationally there are a range of programmes to improve attitudes to older people, including increased training for health practitioners, workers in the social sector and others providing services for and on care of older people. Examples include a practice guide for the health sector published $a$ in the UK by the Department of Health (Achieving Age Equality in the $\mathrm{NHS}, \mathrm{DOH}, 2010)$. The NHS identifies that professional attitudes can be a barrier to older people receiving a full range of treatment options. A Help the Aged survey of 200 geriatricians in 2009 suggested that almost half believed that the NHS was 'institutionally ageist' and were worried about how it would treat them in old age, whilst more than $70 \%$ said older people were less likely to be considered and referred on for essential treatments. Both active and passive discrimination can be a factor, with older people not being given as much information about treatment options or being told they don't have a high chance of recovery, but without proper assessment on their health being done. There is some evidence this also occurs in New Zealand (HRC, 2012, Hood, 2008).

Balanced media portrayals of older people can counteract myths and stereotypes and can destigmatise the ageing process. With the growing number of 'young old' increasingly seen as an important consumer market, some advertising campaigns have attempted to portray more positive images of ageing. Even so, marketing discourses and print and television media still tend to perpetuate and reinforce ageist stereotypes (Sawchuk, 1995; ACNZ, 1999, 2012). PAS is silent on the role of the media beyond an action to promote positive portrayals of older people in government resources and government. Age Concern New Zealand has developed an annual Award for media portrayals of older people that challenge ageist stereotypes (see www.ageconcern.org.nz). Public education programmes can also be effective in changing attitudes. ACNZ has since 1999 offered a community education programme to foster positive attitudes as a mental health promotion initiative. ACNZ also promotes positive attitudes as part of their elder abuse and neglect prevention work, training workers and producing and distributing public health education material (see www.ageconcern.org.nz). 
There is concern that the model of positive ageing promoted in PAS and similar strategies is overly focused on productive activity, thereby allowing for negative attitudes towards older people deemed inactive (Davey and Glasgow, 2006). Boomers also expressed fears about losing their 'voice' in society once perceived as old or frail. Those with chronic conditions can experience stigma and blame and a more balanced view of contribution may be needed. To improve understanding the 2010 campaign to improve attitudes to people with disabilities, Think About It (Office for Disability Issues, 2010) could be extended to include older people with chronic conditions.

Martin (2005) criticises PAS for not including a goal to improve the political involvement of older people. He argues that PAS was as much to do with keeping older people quiescent as it was a deep concern for positive ageing. Government does have a range of mechanisms to consult with older people, and maintains a relationship with a group of Volunteer Community Coordinators who work with government to gather feedback. This model could be developed. However boomers, who value autonomy, may seek alternative means of political activity and ways to be involved where they feel able to retain a high degree of control.

\section{Meeting future care and support needs}

Boomers value quality of life for older people and expect government to ensure adequate support for older people. They are concerned about carers and standards of care at present and boomers expect government to do more to ensure a good standard of services. While Hood's research (2010) suggests that District Health Boards (DHBs) are making some progress with implementation of the Health of Older People Strategy (HOPS), variability in services across the DHBs appears to be an issue. There has been little evidence of DHBs aligning planning with HOPS objectives and data collection is an area requiring improvement. 
Suggestions include research on patient satisfaction and longitudinal studies that follow the patient's journey through the health care system. Poor access to training and inadequate supervision of home based support staff is also identified as a barrier to improving the quality of care for older people. (Hood, 2010.)

Focus group boomers' preferences on care provision reflect expectations concerning family support. These boomers value their independence and wish to avoid burdening their family. Some feel it is better to have a trained carer with appropriate knowledge and skills rather than a family member. It is possible boomers would feel more self reliant when they have a contractual relationship with their carer. Boomers also expect their family members to live at a distance so they do anticipate the use formal services. Both factors point to a likely increased demand for such services.

Women's increased workforce participation may reduce the supply of informal carers at the same time as the number of people needing care will grow. Many informal carers must balance work and care responsibilities. Family friendly workplaces that include provisions for elder care will be increasingly important.

Family caregivers, particular spouses who will be of similar age, require support in looking after others, for the sake of both their own health and the health of those receiving their care. Formal help can play a valuable role in supporting informal care networks (MSD, 2009). The benefits to society of this work have recently been recognised by the state, with agreement reached that family carers may be paid but criteria are still in development at the time of writing. A Carers Strategy (MSD, 2010) has also been produced. 
At present targeted assistance is available for older adults in New Zealand who find it difficult to manage independently at home. They are assessed for level of disability and receive differing levels of paid home care assistance according to their situational requirements. Needs assessment services prioritise using a holistic assessment process but level of support allocated is dependant on available funding. Funding of support has come under pressure in the present fiscal climate..

There has been a number of initiatives to improve the recruitment and retention of home based care workers with a focus on co-ordination, quality assurance and training and career pathways. However significant shortfalls in the number of workers are expected, though research in lacking (Cox and Hope, 2006). Further policy work is also needed to support the integration of migrant workers in the sector. Demand for carer relief and support services is also likely to grow. There may be lessons for improved coordination and support for carers in the way this is organised in Britain (Harvey 1995). There are three main organisations. The Carers National Association works at a political level to raise awareness and recognition. Local 'Crossroads' schemes, involving carers and the cared for, representatives from health agencies and voluntary organisations, organise help in the home and a respite service for carers. The Princess Royal Trust has established a network of centres that focus on the carer, rather than those cared for.

Boomers value choice about where to grow old and desire flexible responsive services to meet their individual needs. A policy of 'Ageing in Place' allows greater autonomy for those receiving care and boomers desires are in alignment with this policy approach. However there are some policy risks that need to be taken into account, including the cost of transport for carers, the degree of dependence of client on carer, isolation for those living alone, and lack of supervision of the carer. 
Older people ageing in place can be at risk of hidden elder abuse or neglect from family members, carers, and others with whom they have a relationship of trust (ACNZ, 2012). Elder abuse and neglect prevention services are provided by NGOs such as ACNZ, with funding from government, but current service provision may struggle to keep pace as demographics influence demand. New Zealand research is needed to increase knowledge about elder abuse and improve ability to both prevent abuse and respond appropriately when it occurs. Age Concern notes that "attitudinal change, public awareness and understanding, and community responsibility, are all fundamental to preventing elder abuse and neglect" (ACNZ, 2012 website).

\section{Meeting expectations for housing and living arrangements}

Boomers in the focus groups value choice, autonomy and self reliance and these are reflected in their aspirations concerning living arrangements. They desire a broader range of options and are interested in innovative forms of shared collective living. Many were looking for ways to ensure they did not live alone, which suggests predictions as to the increasing number of one person households as boomers age may be too high. There was an interest in multi-family dwellings and multi unrelated person houses with 'flatting' style arrangements. A strong motivation to co-reside was for social contact. Interest in collective ownership of a dwelling was also motivated by a desire to avoid institutionalisation and retain a greater degree of control. Cost was another factor, with co-residence enabling pooling of resources, shared maintenance tasks and costs of support.

A range of housing options will be needed to meet boomers aspirations. Schofield et al note (2006):

"In housing, new mechanisms for tenure are required to encourage collective home ownership for people with limited wealth or increasing support needs. Innovative accommodation options also need exploring..." (p. 299). 
One of the goals in PAS is affordable and appropriate housing options for older people. However a shortfall in accommodation for older people is anticipated (Boston and Davey, 2009). The government is putting some resources into building affordable housing (Housing New Zealand Corp, 2005). But the state reduced its role as a provider of social housing as part of reforms in the 1990s, selling state houses and introducing market rents to state tenants (Gee et al, 2000). The Housing Innovation Fund (HIF) used to provide grants to 'third sector' social housing providers, but loans were suspended in 2010 as part of housing sector reforms. An evaluation of the fund found it laid the foundation for community group organisations to develop in the social housing sector. HIF is an example of a policy approach where the state acts as a facilitator of community provided housing and would fit with the partnership model that boomers look likely to find acceptable.

Boomers indicated they value environmental sustainability, social capital and community based living. They are likely to be attracted to approaches that allow for individuality. There was interest in new types of community housing that offered options for mutual exchanges of support. Design that allows flexibility for individual needs and flexibility in financial contracts would be attractive to boomers, as would contracts and financing arrangements for joint ownership or tenancy.

Boomers are suspicious of institutions and current trends in New Zealand for large retirement village complexes may not appeal. Future planning will need to take these views into account and current complexes may need to be adapted to attract new residents. The retirement village sector in New Zealand has grown rapidly over the last few years, under policy that supports private sector involvement. The Retirement Villages Act and related Code of Practice have increased protection and security for village residents. However there was criticism from some boomers of the institutionalised nature of retirement village living and the lack of individuality in design and management structure. Large providers were seen as unimaginative and profit orientated. 
Boomers in the focus groups also indicated a distaste for the rules associated with some village living. They were interested in cluster housing where residents were loosely linked by common values, such as an eco-village style, cooperative community or, for some, a commune or intentional community. Additional consultation with boomers on their preferences may be useful.

There were also boomers who were emotionally attached to their current home. 'Home' represents a place to express identity and individuality (Keeling, 1999), and family history. For those wishing to remain in their family home there was a recognition that adaptations and modifications may be needed and some were already looking for ways to make their homes lower maintenance. There was an expectation amongst boomers that services may need to be purchased in the future to help maintain the garden and property. Though cost was acknowledged as a factor, purchase of services was seen as an acceptable way to reduce burden on family, and a means of coping if family lived at a distance. The trend in PAS is towards supporting older people's choice to remain living independently in their own homes as long as possible. Remaining in the home of choice can depend on the ability to have houses modified, adapted or maintained. There are a range of services that aim to meet this need but more will be required to meet growing demand (Davey, 2006a; Schofield et al, 2009).

Some boomers anticipated setting up networks of support with friends and neighbours, or establishing 'green dollar' systems of skills exchange. These indicate boomers valuing of self-reliance, their entrepreneurial character and belief in their organising abilities. Support from the state to increase these forms of social capital could have multiple benefits. 
Participants in the study who rented expressed the most negative visions of their future. Currently most older people own their own homes but the rate of home ownership is declining (Davey, 2006c). Older renters have less security of tenure and less autonomy and may be in a renting situation due to past adverse circumstances. Their ability to modify their home to manage changing needs as they age is limited. Landlords may need incentives to fund changes. Home insulation subsidies available to private landlords are an example of a policy that has been beneficial.

In New Zealand old age, renting, poverty and ill-health go together (Else and St John 1998; Davey, 2006c). Tenants on low incomes can suffer financial hardship if rentals are fixed at an unreasonable level.

Government provides funding for Tenant Advisory Services, as well as state housing property managers, to assist people to access support. The Healthy Housing programme assists state tenants living in conditions that are bad for their health and involves health and housing services. Similar support in the private sector may assist other tenants.

A number of boomers anticipated downsizing as a way to release some equity from their homes. Age Concern New Zealand president Liz Baxedine says downsizing, while frequently cited as a way of resolving the income and housing needs of older owner-occupiers is by no means straight forward and is no easy option (Press release, Feb 13 2012). There have also been concerns that housing values may crash if large numbers of boomers attempt to sell to release equity and offload investment properties. However, Stephenson (in Boston and Davey, 2006) finds no evidence for such an argument, though he cautions his analysis is limited. With $90 \%$ of the wealth of New Zealanders tied up in their homes, additional analysis of the determinants of house prices in the context of population ageing would be useful. 
A lack of housing options can lead to premature entry into residential care. Predictions by Cox and Hope (2006) are that the demand for residential care will outstrip service availability with a doubling of demand between 2001 and 2021 as the number of older people aged 85 and over increases. But New Zealand has very limited supported accommodation, or "housing designed specifically for older people with some 'warden' services and communal facilities' (Davey, 2006, p265). The 'Abbeyfield' model is an option that is available in a few communities and is in line with some boomers aspirations for independence and desire to avoid institutionalisation.

Boomers dislike of residential care may motivate them to explore alternative in-home care to a greater degree than current assumptions. Both cost and the degree of health and disability will be determining factors. Care at home is cheaper to the state than residential care only to a point, becoming less economical as disability increases (Tinker et al, 1993). Workforce issues and availability of family carers will be significant factors influencing choices.

A license to drive is very important in maintaining mobility and independence in the community. In some areas, public transport services are limited, which can contribute to older people being isolated in their homes. Where suitable public transport is not available, alternative transport services for older people are needed. Community operated transport services have developed in some areas to meet the needs of older people, for example in Golden Bay (Vandeskog et al, 2012). Lack of transport can also be a problem for older people travelling to health care appointments, particularly in rural areas. For those experiencing disability, frailty or sickness, travelling distances to services can be arduous, uncomfortable and expensive. Taxi discount schemes are one means of support. There have also been private sector commercial responses which government is likely to favour, such as ‘Driving Miss Daisy'. 


\section{Meeting Health needs}

Boomers in the focus group value an active lifestyle and studies indicate the boomer age group is aware of the health protective effects of exercise and diet (SPARC, 2003 in MOH, 2003). They appear to have internalised the health behaviour messages that have been promoted in the last decade on the importance of staying active and the need to 'use it or lose it'. A match of values may have contributed to success in this policy area.

Boomers are nevertheless concerned about their future health needs. They were cynical about the future adequacy of health services and critical of hospital level care of older people. They were also concerned about the impact of health on their work and leisure activities. Concerns about health appear to be little changed in the last two decades. In 1990, more than half of older adults reported that they feel that their health prevents them from living their lives as they would like (Age Concern, 1990)

Despite concerns about health needs, studies show that older people generally have a positive outlook on their health (Dyson, 2002). It is unclear whether boomers will continue to rate their health so positively. Some boomers in focus groups expressed frustration at limiting health conditions they were already experiencing in mid-life. Predictions are that boomers will be more demanding of health services, being more educated about possible treatments and more assertive in seeking care (Boston and Davey, 2009). Boomers in the focus groups also expected they would demand good services from the health system.

Boomers have experienced better health overall than their parents did at the same ages, with advances in medical technology being a major contributing factor. But it remains unclear how their last years of life will be experienced. A 'compression of morbidity' in older age has been predicted (Fries 1988), as changes in lifestyle reduce risk factors and delay the onset of chronic disease and disability until very late in life. 
There is ongoing debate as to whether ill health and disability will be compressed into fewer years, or whether extended years of life will be lived with disability. International studies indicate that rates of severe disability in older age are falling, more so for those less than 80 years and more for men than women (OECD, 1996, and Jacobzone et al, 1998). But it is not clear whether rates will continue to fall. Increasing rates of adult obesity are a concern, with related increases in diabetes particularly amongst Maori and Pacific peoples $(\mathrm{MOH}, 2004)$

As more people survive to older ages, diseases that are more prevalent in very old age, such as Alzheimer's disease, are predicted to increase. Government initiatives have seen increases in government funding in some areas. For example Budget 2011 allocated $\$ 10$ million per year to DHBs to provide dementia beds in residential care facilities on a more sustainable basis, and a further $\$ 1$ million per year to DHBs to provide additional dementia respite services (www.national.org.nz). Further funding will be required to meet growing needs as boomers reach older ages.

There was a high level of agreement amongst boomers that the quality of care for older people was variable and that rest home and hospital level care could be a distressing environment to be in. Some had had positive experiences of older people in care, but many, including those working in the sector, were critical of standards and funding.

Future labour shortages in the health and disability sector have been identified as a significant issue (Cox and Hope, 2006; NZIER, 2004) as demand exceeds service capacity. Some boomers in the focus groups were aware of this issue and some with experience of migrant carers were concerned about cultural mismatch and language barriers. Others recognised a need for more Maori and Pacific health workers as these population groups increased. 


\section{Intergenerational Equity}

These boomers valued equity and fairness and were aware that each generation will require resources to meet their needs. Boomers valuing of intergenerational equity appears well aligned with policy. These boomers recognised links between generations within families and felt a responsibility for those older and younger than themselves.

The children of the baby boomers may be subject to triple demands of having to save for their own older age, supporting their parents when they need it, and investing in their own children. In the context of policy instability there is greater uncertainty about "who will need what and when during the family cycle" (Huber and Skidmore, 2003, p93). Changes to the funding of pensions (for example from 'Pay as You Go' to 'Save as You Go') may create political instability as boomers look to the state to provide effective policy to support themselves and to improve the situation for their children and grandchildren.

Policies that pay attention to the impact on all age groups will be well received by boomers. Housing policy and student loan policy are two examples of policies that impact on multiple generations in a family.

\section{Discussion}

Boomers' values are aligned in a number of ways with those in key policy on ageing. However there are some differences of emphasis that warrant further attention and there are gaps in services that will become only more challenging if they are allowed to widen.

There is congruency on values concerning mutual obligation and shared responsibility. Boomers and policy are also aligned in their emphasis on active ageing and ongoing participation. 
Boomers value fairness and strongly support the ongoing universality of pensions on these grounds. This is also an area of policy congruency. It will be important to support a continued common discourse on what 'fair' policy means. For boomers, this has an intra-generational as well as intergenerational focus.

Boomers valuing of autonomy and freedom are not fully congruent with the policy emphases on productivity. Boomers also value choice and flexibility, values warranting further policy attention.

Social justice and older adults' right to dignity, respect, freedom of choice and support are valued by boomers. Current policy seeks a balance of these rights with responsibilities, with an emphasis on citizen responsibilities. Boomers' distrust of authority and desire for individualised lifestyles suggest they may resist policy approaches that emphasise obligation while reducing entitlements.

For example, boomers' optimisitic views on work/life balance and flexible work conditions are held in a context of universal entitlement to NZS, which ensures there is no disincentive to work, while providing a minimum income. Potential change to NZS would impact on boomers' options. These boomers value choice and may resist any policy shift that looks like compelling people to continue in work.

A less rigid approach to welfare would match the values of the boomers in this study. St John (2011) argues the recent Welfare Working Group report (2011) did not consider the values appropriate to our evolving and complex society. She argues for a social inclusion agenda that does not see 'any job' as desirable and that recognises the value of care. "For too long people have been told only of their 'work obligations with welfare... while unpaid care has been invisible and largely supplied at huge opportunity cost by women" (p3). 
St John (op cit) advocates for 'carefare' rather than the concept of 'workfare', with policy that reflects care obligations. This would include less emphasis on attachment to the fulltime workforce with less rigid work requirements and family tax credits that are not conditional on work effort.

Boomers value community and collective responsibility. Cheyne et al (2008) noted a resurgence of conservative liberal pragmatism within the centre-Right National government of 2008. They argue that "the idea that welfare should only be a residual safety net, available to the very poor, has shifted to the right-wing margins of social policy debate" and they see the multi-party support for the superannuation fund as an example of the "rejection of the notion that individuals alone should have the responsibility" to prepare for their own retirement (2008, p233). They note however that the debate over the appropriate balance of responsibility between the individual and government is far from over and remains a pervasive theme in policy debates in New Zealand.

Jordan (2006) notes the emphasis on individual self-responsibility in citizenship that was central to Third Way models, has resulted in an underestimation of the importance of collective elements of well-being, including the intra-personal and relational factors. He proposes a 'cosmopolitan citizenship' of the kind advocated by Delanty (2000), and a democratisation of services (Dean, 2005) as a way forward, within a political culture that recognises common interests between members of diverse groups. Similarly Cheyne et al (2008) identify a contemporary interest in social capital in New Zealand arising from a concern that an excessive emphasis on market relations poses a threat to social cohesion. They argue there has been increasing acknowledgment by both neoliberalists and their critics of "...a failure to recognise the interdependence of human beings, interdependence between human beings and their environment, and interdependence of generations" (p241). This is a view also expressed by boomers in the study. 
Cheyne et al (op cit) note that the building of social capital through stronger communities is identified as an effective strategy for the enhancement of well-being. They also identify the availability of new forms of communication technology as having potential to enhance capacity for geographically dispersed groups and those with disabilities, to participate in in policy development. These positions resonate with boomers values and indicate increased potential for boomer perspectives to influence policy.

\section{Chapter conclusion}

There is both congruency and mismatch between boomer and policy values. There is some evidence of a shift in the social policy agenda towards a greater recognition of interdependence and collective notions of well being, which would improve congruency with boomers values.

These boomers desire flexible policy with an emphasis on choice, autonomy and fairness, with a balancing of rights and responsibilities. Boomers may resist policies they view as unfair to their own as well as to other generations. Potential areas of contention may be work and support services in late life. Flexible policy responses will be the key to successful policy for boomers. These and other policy issues are explored further in the final chapter. 


\section{Chapter 9: Conclusion}

\section{Key Findings}

This study has explored boomers views about their own ageing and their expectations, attitudes and beliefs about the future. Underlying values have been identified. Key findings and implications are summarised below.

\section{Evidence of a generational identity}

Boomers do have a sense of a common identity. They believe they are a distinctive generation, different from those that have come before them and also different (but less so) to younger generations. Common identities expressed by boomers in the study group were of boomers as a 'lucky generation,' boomers as 'pioneers and social reformers' and boomers as a 'problem generation'. These findings are similar to those from other studies and common discourses in the social media. Boomers appear to have internalised common discourses about their generation.

\section{Diversity within the cohort}

Despite an acceptance of a common generational identity, boomers don't necessarily agree on the characteristics of their cohort. Indeed a defining characteristic may be their resistance to being categorised and their desire for diversity. Older and younger boomers had different experiences which they believed influenced their attitudes and values. Older boomers expressed a clearer sense of themselves as pioneers and change agents. Younger boomers perceived boomers as more self-centred. Ethnicity is a key variable, influencing attitudes to ageing and beliefs about roles and responsibility. Supporting data indicates that level of education is also a key factor in diversity of values and beliefs, both within the cohort and between boomers and the previous generation. 


\section{Belief in their collective power}

Boomers view of themselves as a large distinct cohort has produced a sense of security and a confidence in collective action. Many, but not all boomers in this study felt confident that the state could be forced to listen to their concerns due to the power of numbers. They are a well educated cohort compared to their parents and they have experience of social activism. However they don't yet have a common set of demands.

There was some evidence that confidence in their collective authority is reducing. Some boomers were cynical about their ability to change things. Some appeared burnt out. It is unclear if this is a consequence of a 'high productivity' life. Certainly there were boomers feeling the strain of competing demands of work and family and in many cases care of children or ageing parents.

\section{Shared values}

Though distributed unevenly, a range of common values were evident across their age group, which were different to older generations. Boomers display more post modernist and self expression values than older age groups.

Boomers are often portrayed as individualistic but older boomers believed they were more collectivist in outlook than younger generations. Often repeated phrases indicated boomers value freedom, choice, independence, and self responsibility. They also value respect for elders, mutuality of family support, self sufficiency, community, and civil rights. More implicit in comments were values of fairness, reciprocity, equality and social justice.

Boomers have been accused of hedonistic materialism, narcissism and selfishness. This research does not support that view. Boomers' individualism is balanced by their responsibility and their consumerism by notions of sustainability. They have a rights and social justice based approach and they are concerned about other generations needs. 
They do take pride in their generation's achievements and they want to remain active participants in their family and communities.

\section{Common expectations}

There were some common views about what life will be like in the future which set them apart from previous generations, although boundaries between the generations are permeable.

- Boomers believe they will age differently from current generations of older people. They expect to have greater choice of lifestyle, activity and living arrangement and they have an optimistic view of selves as active and independent in older age.

- They commonly intend to work past age 65 years and plan a phased exit from the workforce. They see work as a way to contribute, remain self reliant and to meet own needs. They want to work for a variety of reasons, but they also desire work life balance and they feel poorly prepared for late life

- They have low expectations of state support and anticipate some change in NZS policies. They expect to have to supplement their income with paid earnings and accept a shared responsibility to prepare for late life. Many are concerned about their ability to manage financially.

- Many expect to age at a distance from family and they look to friends and neighbours for support they can reciprocate. Some anticipate difficulty accessing help to age-in-place.

- Attitudes to inheritance varied but some expect to use assets to support their own lifestyle or to help their adult children.

- They are aware of cultural differences and see merit in more traditional models of family care and in attitudes to older people in Maori, Pacific and Asian cultures.

- Some are seeking new forms of collective housing to enhance support. Views on retirement villages varied with some seeing them as too structured and too costly. Some would consider multi-generational or multi-family living if design of housing enabled it. 
- They expect to be more assertive than previous generations and they feel confidant in their ability to speak up about issues. They expect good communication and information from with service providers.

\section{Continuities between the generations}

There was evidence of beliefs and expectations that crossed generational boundaries. Like older people before them, boomers identify poor health, social isolation, poverty and ageist attitudes as potential barriers to their wellbeing. They see government as responsible for ensuring there is support for older people at risk.

Boomers believed they shared interests and attitudes with their children and they felt closer to younger generations than older generations. There was diversity of views however, with some younger boomers feeling they had shared the cultural revolution with their parents.

\section{Influence and Relevance of Values}

Participants believed their values had been shaped by not only the experiences they had had, but also by their parents and grandparents' experiences. They had absorbed some of the previous generations' egalitarian ethics, but they felt they were a very different generation. Boomers feel they are closer to and more like their children's' generation than their parents. Findings support Inglehart's theory of generational change, which suggests a slowing of change between generations in advanced capitalist societies. If values and interests are more aligned it may be that there will be less potential for intergenerational conflict. 
Findings also support Jones et al's (2008) and others argument that mass consumer society and globalised capitalism underpin the cultural field of boomers and the 'third age'. Boomers value having lifestyle choices and are active consumers. But it also appears that some are resisting the excesses of materialism and mass consumption. Some boomers are choosing to consume less. Others who have had less success in consumer society are forced to. Many boomers felt poorly prepared to cope with reduced income in late old age and there is a significant group of boomers who are entering late life with limited resources.

Inglehart $(2000,2008)$ argues that a cultural shift from materialist to postmaterialist values has occurred with increased levels of security associated with economic growth and the rise of the welfare state in postindustrial societies. World Values Study data indicates that post materialist values are stronger amongst younger age groups as generational change has occurred. Boomers have been in the centre of this shift. Associated values of autonomy, self expression and quality of life are evident amongst the boomer cohort. Evident also is a generational emphasis on freedom of expression and political participation, and a prioritising of goals of belonging, esteem and aesthetic and intellectual stimulation.

Boomers are also in the midst of a transition from productive to nonproductive forms of lifestyle. They value active leisure and there is evidence of resistance to an over-emphasis on productivity. Nonproductive forms of identity (such as those centred on music, fashion, travel) have become increasingly available as affluence has increased. The cultural revolution of the 1960s was part of this trend. 


\section{On 'Being Old'}

It is unclear whether the rhetoric of a 'new old age' apparent within the boomer generation is a sign of the development of a more positive attitude to age identity, or an attempt to resist an old age still perceived negatively. While some participants did talk about the benefits of being old, and many talked about the importance of valuing older people, few explicitly welcomed old age as a positive stage of life. It seemed that old age was not so much being transformed as being shifted to later years.

Vincent (2005) notes that generations change as they age and their experience of transitions in later life will be informed by multiple factors and experiences. Individuals need to transform their identity as they move through life stages. Available models of ageing influence identity choices. Models are important because they influence constructions of ageing that are drawn upon by individuals as they create their own life narratives, and they are used by politicians and policy makers to influence the behaviour and attitudes (Estes, Biggs and Phillipson, 2003).

Boomers view old age as a period of work-life balance, with more leisure and a lifestyle based on non-production-based sources of identity such as travel, music and art. But many also anticipate being active members of their families and community and view late life as a time when this can occur. Retirement has become a less of a social category marked by age. For most boomers, work-life balance has replaced retirement as the desired core of identity in late life. The concept of retirement has been transformed from a state sanctioned unemployment to a leisure lifestyle based category with permeable boundaries. The current cohort of 'young old', many of whom are the parents of baby boomers, have paved the way, creating a 'third age' identity (Laslett, 1989) based on active leisure and practices of consuming (Gilleard and Higgs, 2005). 
I have argued that old age cannot be understood separately from the social context. The social construction of old age based on withdrawal from the labour market suited the early demands of advanced capitalism but resulted in a portrayal of older people as 'other', a dependant separate and problematic category. Older people reclaimed a role and purpose in society with the development of 'active retirement'. Policy supported active retirement to ensure a healthy older population. Now concerns about population ageing have made productive activity the key focus, the older population is being called back to work as a 'reserve army of labour'. PAS promotes this as being in everyone's interest. Yet not all will have equal opportunity to participate in the new order.

Policy is having an impact on factors influencing participation in the workplace, and there is increasing flexibility of working conditions at least in some sectors. There is a tug of war for some boomers between work and leisure. Work-life balance has become the route to balance competing desires. The acquisition of a leisure based lifestyle is being transformed into one based on activity and contribution.

As is the nature of social construction, models of ageing are subject to change in relation to economic and social circumstances. Some boomers will seek a new identity that fits with their needs, values and beliefs. There is potential for a Pacific or Maori model of ageing to become an identity available to more boomers and to the next generation.

Boomers are only now approaching older age and their mid life attitudes may shift as they grow older. Indeed a denial of ageing apparent within the boomer cohort means it is difficult to predict future behaviour from currently expressed attitudes and beliefs. Blaikie (1999) notes that where old age differs from adulthood in general, is in the system of constraints, not only social, but physical and mental, that gradually enforce conformity. Resistance is more difficult for those who by definition are deemed 'communicatively incompetent' by dementia, or whose 'bodies betray them'. Resistances that do occur tend to happen in the private sphere of 
the home or institution and are thus less recognised by those not experiencing them. Few boomers have faced these constraints but some are observing their parents experience. It remains to be seen whether boomers will continue to successfully resist any 'conformity' of ageing along the lines that Blaikie describes. They will certainly want to try.

Current policy paradigms and values (neoliberalism, individualism) place some constraints on the choices available to boomers. There are some gaps in current policy including meaning and purpose for the frail old in a society based on productivity, and ethical issues such as euthanasia. While the Positive Ageing Strategy has successfully contributed to a reduction in the 'dependency discourse' of older age, the moral tone that underpins the positive ageing discourse has yet to be successfully challenged.

The policy approach of BOA aims to challenge the discourse of competing generations. But the focus on economic contributions is a double edged sword. On the one hand boomers will benefit from a policy emphasising their earnings and spending power. On the other it risks reinforcing a stereotype that boomers are well off.

A key challenge for policy is to resolve the contradictory forces of growing demand and limited resources. There remains potential for intergenerational conflict in an environment of economic recession. Once seen as competing for resources compassion turns to conflict and support becomes burden. If boomers are seen as well off, calls for reduced welfare will only increase. This is a concern for boomers who have been unfairly stereotyped as richer than previous generations of older people. Diversity within the cohort needs ongoing consideration. 


\section{Boomers and Old Age Politics}

Boston and Davey (2006) ask how changing demography will influence "public opinion, electoral behaviour, the nature and relative importance of age-related interest (or pressure) groups and the character and policies of political parties" (p363). They note we are moving into uncharted territory, with such a large proportion of older voters. In the middle decades of the twenty first century older people will comprise nearly a third of the population eligible to vote.

Concerns about a 'greying electorate' often focus on whether boomers will vote as a bloc in their own interests. Boston and Davey argue this seems unlikely for a number of reasons. While older people are more likely to vote, there is little evidence of significant 'block voting'. Instead people tend to vote according to party loyalties and issue orientations that are the product of their previous socialisation (Metz, 2002). Voting also tends not to be age or generation based.

Political parties do court the older vote, and with some success, for example the New Zealand First Party in New Zealand, the Retired Persons Party in Israel and the General Elderly People's League in the Netherlands) (see Boston and Davey, 2006). A party focused on 'grey issues' is more likely to emerge where the proportional representation system has a low thresholds for electoral success, as in New Zealand. Parties who pursue policies that undermine their older supporters do so at their own peril. In New Zealand this has been the case for both Labour and National who lost support over policies on superannuation in the 1980s and 1990s. The notice to impose the surcharge caused outrage and widespread bitterness, and led to the formation of the New Zealand Superannuitants Federation, later known as Grey Power. They garnered increasing support through affiliation with associations throughout the country, and ensured that newspaper articles, radio and television programmes kept the issue in the public eye. The minor political Party 
New Zealand First took up the issue in a successful strategy that secured them a position in a coalition Government in 1996. The surcharge was removed, albeit eventually, and the power of the 'grey vote' was demonstrated.

Boston and Davey (2006) suggest that major cutbacks in the welfare state are less likely in the future than has been the case given that older voters do tend to support higher state spending and pension increases, though they do foresee the potential for 'modest amendments', such as a small rise in the age of entitlement to NZS. This seems particularly likely in the context of economic recession, when concerns over distributional equity increase.

Governments are aware of the need to tread carefully. A fight for the 'grey vote' may already be developing. At the time of writing the main parties have taken opposing positions on the issue of raising the age at which people qualify for NZS. Despite the cuurent Global Financial Crisis, National has promised that "on our watch, the age of eligibility will remain at 65" (Media Release, Foss, 2011). This position came under much srcutiny given the election was centered on the need for austerity and tight fiscal planning. Under pressure from media and opposition to debate the age of eligibility, Key said he would 'rather resign as Prime Minsiter than break this election promise' (TV3 Media Statement). There are other measures taken that will have a negative impact on support for older people in the future. These include extending the suspension of contributions to the NZSF announced in National's first term. Other actions are a capping of employer contributions to Kiwisaver and a reduction of the minimum employee compulsory contributions. An end to the staggered reduction of the asset threshold for the residential care subsidy was also announced. Changes affecting older students have also occurred, with the introduction of a lifetime limit on student loans and an end to access to Student Allowances for those receiving NZS. These actions result in reducing support for older boomers. 
On balance it seems likely that competition for the 'grey' vote will intensify and interest groups representing older people will become more numerous. Hudson (2004 in Martin, 2005) argues that workplace discrimination will be one of the most critical issues of the future. There has been considerable policy attention on this issue, but more change in behaviour is needed to support the mature worker.

\section{Issues for further research}

Each generation has different needs and expectations of economic and social well being than those of earlier generations, expectations which will have been shaped by the experiences of generations before them. Longitudinal research is needed to assist our understanding of cultural and generational value change. Additional analysis is needed on how class, race, gender and place influence attitudes and values within cohorts.

Inglehart (2008) World Values Study analysis suggests that as younger cohorts grow up under high levels of existential security generational change in materialist to post materialist values will slow down. He notes that post war cohorts are now displaying similar values. This suggests generations may be more aligned on issues than before and decrease the possibility of significant intergenerational conflict. Additional cohort analysis would be useful to assess if value differences are stable over time and to measure the impact of life cycle and period effects. This will require survey data over a long period, carried out at numerous time points, with large numbers of respondents to allow break down into sub cohorts without causing too high a margin of error.

In New Zealand we need research on the large number of boomers living overseas with information on their intentions to return and their plans for work, retirement and lifestyle in late life. Information on migrants desire to return to the land of their birth may yield valuable data. Little is currently 
known about the support networks of migrants and desire and ability to sponsor family members to come to New Zealand.

Buckland (2009) suggests research on the reactions of other sectors of the population to the stated intentions of boomers. Useful would be greater understanding of whether boomers will be perceived as holding on to the best positions or projects, and additional critical analysis of the discourse of intergenerational conflict.

\section{Concluding comments}

To understand the meaning of cultural shifts they need to be contextualised. In this research I have attempted to do just that. I have argued that there is a relationship between social conditions and policy values and changing notions of what it means to be an older citizen in contemporary society. Prevailing theories and ideas about the role of the state and about ageing, including those held by boomers themselves, influence and are influenced by policy.

I have argued that public policy remains entrenched in a neoliberalism that emphasises economic market driven values and the competitive struggle to maximise growth. In the process issues of social justice and equality have been marginalised. But rampant individualism is being questioned and there is a movement to search for alternatives that encompass an ethical approach (Jordan, 2005). A policy paradigm transition may be on the horizon. Public policy still emphasises material growth, but there are calls for this to be balanced by considerations of ethics and sustainability (Jordan, 2005, Treasury 2012). 
Within the boomer cohort there is a simultaneous acceptance and questioning of the neoliberalism dominating policy of recent decades. Boomers have absorbed dominant messages, but there is evidence of resistance. Boomers are aware that inequalities have increased and they talked about modern society with concern. They believe the pace of life has increased stress and society is too materialistic. They also recognise positive change over their lifetime which they feel they contributed to, such as more lifestyles choices and diverse roles and more liberal attitudes to ethnic and minority groups. Jordan argues a generational loss of trust in traditional institutions may be contributing to a new drive for individuals to be in control over their lives through group membership and involvement in social causes. Some see this as the rebirth of civil society (Jordan, 2005).

Jones et al (2008) predict there may be new ways of resisting the excesses of consumption and the 'new old' may have a role to play in creating a new social movement, as many did in the late 1960s, though changing patterns of daily life. Boomers see themselves as active citizens, with concerns they believe they share with younger people. While they may not take collective action on issues that are based on age, their shared values may bring them together on issues in the future. In families and homes the intergenerational contract remains strong. It may be that the power of boomers may not be as a united front with each other, but as large issues based groups with alliances across the generations.

The dominant paradigm on ageing remains a discourse of active, productive and positive ageing that is rooted in the neoliberalism that pervades global policy. Boomers have also been influenced by that dominant ideology. But there are signs of resistance. Political action by groups can limit the power of prevailing policy discourses as the history of superannuation shows. There is conjecture as to the influence of the rapidly growing 'grey electorate'. What is clear is that boomers are likely to resist suggestions of compulsion in policy. Their identity is rooted in notions of flexibility and choice. 
New Zealand boomers believe they are an influential cohort and this study provides some indication of issues that may lead to political activity. They are accepting of their status as a different generation and enjoy their defined role as change agents. They believe they have been at the forefront of social change and may draw on previous experience to collectively influence policy in the future. Findings suggest that the boomer cohort has the potential and inclination to advocate for social change. Processes of policy development will need to adapt to effectively work with and not against this cohort. It remains to be seen whether boomers will act according to generational interests, or whether other sources of identity will determine their behaviour. There nevertheless is a need to ensure boomers' interests are fully considered in public policy development. 


\section{Thesis Bibliography}

AARP (2004) Baby Boomers Envision Retirement II: Survey of Boomers' Expectations for Retirement. Prepared for AARP by RoperASW. Washington DC: AARP.

Achenbaum, W. A. (1997) 'Critical Gerontology'. In Jamieson, A., Harper, S. and Victor, C. (Eds.) (1997) Critical Approaches to Later Life. Buckingham and Philadelphia: Open University Press.

Achenbaum, W. A. (2005) Older Americans, Vital Communities. Baltimore: The Johns Hopkins University Press.

Adler, R. P. (2006) Aging Baby Boomers: A Guide for the Perplexed. Institute for the Future. Washington D C: AARP.

Age Concern New Zealand and the Older Persons Health Forum (1997) Core Issues in Health Care Services for Older People. Wellington: Age Concern New Zealand.

Age Concern New Zealand (1998) Report of the Successful Ageing Focus Seminars Wellington: Age Concern New Zealand. Available at www.ageconcern.org.nz.

Age Concern New Zealand and Glasgow, K. (1999 \& 2005) Ageing is Living: an education and training resource to prepare for positive ageing. Wellington: Age Concern New Zealand.

Age Concern New Zealand (1999) Older People in the Media (unpublished research report). Wellington: Age Concern New Zealand.

Age Concern New Zealand (2000) Report of the Positive Ageing Strategy Forum. Wellington: Age Concern New Zealand.

Age Concern New Zealand (2009) It's All About Respect: Preventing Elder Abuse and Neglect. A Handbook for people working with the older population. Wellington: Age Concern New Zealand.

Age Concern New Zealand (2012) 'What we are saying.' Webpages 2012. Available at http://www.ageconcern.org.nz/what-we-are-saying. Last accessed 28/11/12.

Alcohol and Public Health Research Unit (1999) Advice for Purchasing Strategy on Public Health Issues: Health of Older Adults. Auckland: Auckland District Health Board.

Allpass, F. and Mortimer, R. (2007) Ageing Workforces and Ageing Occupations: A Discussion Paper. Wellington: Department of Labour.

Andrews, K. (2002) National Strategy for an Ageing Australia: An Older Australia, Challenges and Opportunities for all. Canberra: Commonwealth of Australia.

Arber, S. \& Ginn, J. (1991). Gender and Later life. A sociological analysis of resources and constraints. London: Sage Publications.

Baltes, P. B. and Baltes, M. (Eds.) (1990) Successful Ageing:Perspectives from the Behavioural Sciences. New York: Cambridge University Press.

Bass, S. A., Caro, F. G. \& Chen, Y. (1993) Achieving a Productive Society. Westport, USA: Auburn House.

Baumann, Z. (1998) Work, Consumerism and the New Poor. Buckingham: Open University Press. 
Belich, J. (2001) Paradise Reforged: A History of New Zealanders from the 1880s to the year 2000. Auckland: Penguin Press.

Bevan, C. and Jeeawody, B. (1998) Successful Ageing: Perspectives on health and social construction. Victoria, Australia: Mosby.

Bengtson, V. L. Gans, D., Putney N., Silverstein, M. (Eds) (2008) Handbook of Theories of Aging, Second Edition New York: Springer.

Biggs, S, Leach, R., Money, A. M. and Phillipson, C (2007) 'The Mature Imagination and Consumption Strategies: Age and Generation in the development of a UK Baby Boomer identity.' International Journal of Ageing and Later Life, Vol 2, No.2 pp31-59.

Biggs, S., Phillipson, C., Money, A. M. and Leach, R. (2006) 'The Age-Shift: Observations on Social Policy, Ageism and the Dynamics of the Adult Life Course'. Journal of Social Work Practice, Vol 20, No.3, pp239-250.

Biggs, S., Phillipson, C., Leach, R. and Money, A. M. (2006) Baby Boomers and Adult Ageing in Public Policy: The Changing Relationship Between Production and Consumption. Cultures of Consumption Working Paper Series. Working Paper No: 27

Biggs, S. and Powell, J. (2001) 'A Foucauldian analysis of old age and the power of social welfare', Journal of Ageing and Social Policy, 12(2):93-112.

Blaikie, A. (1999) Ageing and Popular Culture. Cambridge: OUP.

Bolger, J. (1990) 'Statement by the Prime Minister'. In Economic and Social Initiative December 1990. Wellington: New Zealand Government.

Bond, J. \& Coleman, P. (1990) Ageing in Society: An Introduction to Social Gerontology. London: Sage Publications.

Borowski, A., Encel, S., Ozanne, E. (1997) Ageing and Social Policy in Australia. Australia: Cambridge University Press.

Boston, J. and Davey, J. A. (eds) (2006) Implications of Population Ageing: Opportunities and Risk. Wellington: Institute of Policy Studies, Victoria University of Wellington.

Boston, J., Dalziel, P. and St John, S. (1999) Redesigning the Welfare State in New Zealand: Problems, Policies, Prospects. Auckland, New Zealand: Oxford University Press.

Bourdieu, P. (1972) Outline of a Theory of Practice. Cambridge: Cambridge University Press.

Buckland S. (2009) Not the Retiring Sort: New research into the intentions and aspirations of the New Zealand Baby Boomers. Auckland: Auckland University.

Butrica, B. and Uccello, C. (2004) How Will Boomers Fare at Retirement? The Urban Institute. Available at: http://www.aarp.org/ppi. Last accessed 28/11/12.

Callister, P. (2006) "Are New Zealanders heading for older age richer, better educated and more likely to be employed?" In Boston, J. and Davey, J. (2006) Implications of Population Ageing: Opportunities and Risks. Wellington: Institute of Policy Studies, Victoria University.

Carolan, M. S. (2005) 'Realism Without Reductionism: Toward an ecologically embedded sociology'. Research in Human Ecology Review. Vol. 12, No.1. 
Chattergee, S. (1999) The New Politics: A Third Way for New Zealand. Dunmore Press: Palmerston North.

Cole, T. (1992) The Journey of Life: A Cultural History of Aging in America. Cambridge: Cambridge University Press.

Cornwall, J. and Davey, J. A. (2004) Impact of Population Ageing in New Zealand on the Demand for Health and Disability Support Service and Workforce Implications:

Background Paper. Wellington: Ministry of Health, available from www.moh.govt.nz.

Cox, M. and Hope, S. (2006) 'Health Service Needs and Labour Force Projections'. In Boston, J. and Davey, J. A. (eds) (2006) Implications of Population Ageing: Opportunities and Risk. Wellington: Institute of Policy Studies, Victoria University of Wellington.

Crampton, P., Salmond, C., Kirkpatrick, R.,Scarborough, R., \& Skelly, C. (2000) Degrees of Deprivation in New Zealand. Auckland: David Bateman.

Crotty, M. (1998) The Foundations of Social Research: Meaning and Perspective in the Research Process. NSW, Australia: Allen \& Unwin.

Cumming, E., and Henry, W. E. (1961) Growing Old: the Process of Disengagement. New York: Basic Books.

Dalziel, L. (2001) The New Zealand Positive Ageing Strategy: Towards a society for all ages - He anga oranga kau mo nga whakatipuranga katoa. Wellington: Ministry of Social Policy.

Davey, J. A. (1998) Tracking Social Change in New Zealand: From Birth to Death IV. Wellington: Institute of Policy Studies, Victoria University of Wellington.

Davey, J. A. (2000) Another New Zealand Experiment. A Code of Social and Family Responsibility. Wellington: Institute of Policy Studies.

Davey, J. A. (2002) Active ageing and education in mid and later life. Ageing and Society, 22, pp95-113.

Davey, J. A. (2003) Two Decades of Change in New Zealand: From Birth to Death V. Wellington: Institute of Policy Studies.

Davey, J. A. (2005) Prospects and Potential for Home Equity Release in New Zealand. Wellington: Office of the Retirement Commissioner.

Davey, J. A. (2006a) 'Ageing in Place: The views of Older Homeowners on Maintenance, Renovation and Adaptation'. Social Policy Journal of New Zealand 27 pp128-141.

Davey, J. A. (2006b) 'The Labour Market'. Boston, J. and Davey, A. (eds) (2006) Implications of Population Ageing: Opportunities and Risk. Wellington: Institute of Policy Studies, Victoria University of Wellington.

Davey, J. A. (2006c) 'Housing'. Boston, J. and Davey, A. (eds) (2006) Implications of Population Ageing: Opportunities and Risk. Wellington: Institute of Policy Studies, Victoria University of Wellington.

Davey, J. A. (2008) Health, Work and Retirement (HWR) Project-Qualitative Interviews 2006 - Summary of Findings. Palmerston North: Massey University

Davey, J. A., \& Cornwall, J. (2003). Maximising the Potential of Older Workers. Wellington: New Zealand Institute for Research on Ageing. 
Davey, J. A. \& Glasgow, K. (2006) 'Positive Ageing - A Critical Analysis.' Policy Quarterly, Vol 2, Number 4.

Day, Alice T. (1991) Remarkable Survivors: Insights into Successful Ageing Among Women. Washington, USA: Urban Institute Press.

Deacon, B. (2000) Globalisation and Social Policy. United Nations Research Institute for Social Development (UNRISD) Occasional Paper 5. Geneva: UNRISD.

Dean, H. (2005) A Short Introduction to Social Policy. Cambridge: Polity.

Delanty, G (2000) Citizenship in a Global Age: Society, Culture, Politics. Buckingham: Open University Press.

Department of Labour (2012) A Literature Review of the Forms of Age Discrimination: An economic perspective. (Online document.) Available at

http://www.dol.govt.nz/services/lmi/workforce2020/ageing/discrimination/age-

discrimination_02.asp.

Department of Social Welfare (1996) From Welfare to Well-being - Bringing the threads together. $3^{\text {rd }}$ Edition. Wellington: Department of Social Welfare.

Dench, G. and Ogg, J. (2002) Grandparenting in Britain: a baseline study. London: Institute of Community Studies.

Denscombe, M. (2002) Ground Rules for Good Research: a 10 Point Guide for Social Researchers. Buckingham, UK: Open University Press.

Dharmalingam, A., Pool, I., Sceats, J., \& Mackay, R. (2004) Patterns of Family Formation and Change in New Zealand. Wellington: Centre for Social Research and Evaluation, Ministry of Social Development.

Dixon, S. (2009) Who Hires Older Workers? A first look at industry variations in the recruitment of mature workers. Wellington: Statistics NZ and Department of Labour.

Dunn, W. (1986) (Ed) Policy Analysis: Perspectives, Concepts and Methods. Connecticut: Jai Press Inc.

Dunstan, K. and Thomson, N. (2006) Demographic Aspects of New Zealand's Ageing Population. Wellington: Statistics New Zealand.

Durie, M. (1995) 'Te Hoe Nuku Roa Framework: A Maori Identity measure'. Journal of Polynesian Society, 104, 461-470.

Dwyer, M., Gray, A., and Renwick, M. (2000) Factors Affecting the Ability of Older People to Live Independently: A Report for the International Year of Older Persons. Wellington: Ministry of Social Policy.

Dychtwald, K. (1999) Age Power: How the $21^{\text {st }}$ Century Will Be Ruled By The New Old. New York: Jeremy P Tarcher/Putman.

Dyson, R. (2002) Health of Older People Strategy. Health Sector Action to 2010 to Support Positive Ageing. Wellington: Ministry of Health.

Eckersley, R. and Dear, K. (2002) 'Cultural correlates of youth suicide.' Soc Sci Med; 55:1891-904 p8.

Economic and Social Commission for Asia and the Pacific (ESCAP) (2000) Guidelines on the Implementation of the Macao Plan of Action on Ageing for Asia and the Pacific. New York: United Nations. 
Edmunds, J. and Turner, B. (2002) Generations, Culture and Society. Buckingham: Open University Press.

Edmunds, J. and Turner, B. (2005) Global Generations: Social Change in the Twentieth Century. The British Journal of Sociology, 56, 559-577.

Ekerdt, D. J. (1986) 'The Busy Ethic: Moral Continuity Between Work and Retirement'. The Gerontologist, 26, 239-244.

Elder, G. H. (1974) Children of the Great Depression. Chicago, IL: University of Chicago Press.

Else, A. and St John, S. (1998) A Super Future: The price of growing older in New Zealand. Auckland: Tandem.

English, J. (2011) 'Speech to the Institute of Public Administration New Zealand', 29 March. http://www.beehive.govt.nz/speech/speech-institute-public-administration-newzealand

Estes, C. L., Biggs, S., \& Phillipson, C. (2003) Social Theory, Social Policy and Ageing: a critical introduction. Berkshire, England: Open University Press.

Evandrou, M. (ed) (1987) Baby Boomers in the $21^{\text {st }}$ Century. London: Age Concern, England.

Evandrou, M. and Falkingham, J. (2006) 'Will the Baby boomers be better off than their Parents in Retirement?' In Vincent, C. and Downs, M. (Eds) Futures of Old Age. London: Sage Publications with The British Society of Gerontology.

Fairclough, N. (1989) Language and Power. London: Longman.

Falkingham, J. (1987) 'Who are the baby boomers? A demographic profile', in M Evandrou (ed) Baby Boomers in the 21 ${ }^{\text {st }}$ Century. (pp15-40). London: Age Concern, England.

Families Commission Research Report No. 3/08 (2008) The Kiwi Nest: 60 Years of Change in New Zealand Families. Wellington: Families Commission.

Featherstone M. and Hepworth, M. (1991) 'The mask of ageing and the postmodern lifecourse', in Featherstone M., Hepworth, M., and Turner, B. (eds) The Body. Social Process and Cultural Theory. London: Sage.

Fergusson, D., Hong, B., Horwood, J., Jensen, J., \& Travers, P. (2001) Living Standards of Older New Zealanders: A summary. Wellington: Ministry of Social Policy

Ferraro, K. F. and Pylypiv Shippee, T. 'Aging and Cumulative Inequality: How Does Inequality Get Under the Skin?' The Gerontologist Volume 49, Issue 3 Pp. 333-343.

Fischer, F. and Forester, J. (Eds.) (1993) The Argumentative Turn in Policy Analysis and Planning. Durham and London: Duke University Press.

Freedman, M. (2002) Primetime: How Baby Boomers Will Revolutionise Retirement and Transform America. New York: Public Affairs.

Fries, J. F. (1988). 'Aging, Illness and Health Policy: Implications of the compression of morbidity'. Perspectives in Biology and Medicine, 31, 407-427.

Gee, S., Glasgow; K., Ng, S. H., Weatherall, A. Higgins, T. R. and Loong, C. S. F. (2000) Creating Communities for all Ages. Wellington: Victoria University of Wellington. 
Grabinski, C. J. (1998). 'Cohorts of the future.' In J. C. Fisher \& M. A. Wolf (Eds.) Using learning to meet the challenges of older adulthood (pp. 73-84). San Francisco: JosseyBass.

Giddens, A. (1984) The Constitution of Society. Cambridge: Cambridge University Press.

Giddens, A. (1991) Modernity and Self-identity: Self and Society in the Late Modern Age. Cambridge: Polity Press.

Giddens, A. (2009) Sociology. $6^{\text {th }}$ Edition. Cambridge: Polity Press.

Gilbert, N. (1993) (Ed) Researching Social Life. London: Sage Publications.

Gilleard, C. and Higgs, P.(1996) 'Cultures of Ageing: Self, Citizen and the Body'. In Minichiello, V et al. (Eds.) (1996), Sociology of Ageing: International Perspectives. Australia: International Sociological Association.

Gilleard, C. and Higgs, P. (2005) Contexts of Ageing: Class, Cohort and Community. Cambridge UK: Polity Press.

Glasgow, K. (1999) Ageing is Living: an Education and Training Resource to Prepare for Positive Ageing. Wellington: Age Concern New Zealand.

Glasgow, K. (2005) Developing Policy to Reflect the Positive Ageing Needs of Baby Boomers in New Zealand - how well will the new old age? Unpublished thesis submitted in partial fulfilment of the requirements for the Degree of MA (Appl) Social Science Research. Wellington: Victoria University of Wellington.

Gleisner, B. Llewellyn-Fowler, M and McAlister, F (2011) Working Towards Higher Living Standards for New Zealanders Treasury Paper. Wellington: The Treasury.

Glenn, N. D. (1977) Cohort Analysis. London and California: Sage Publications.

Goldsmith, J. (2008) The Long Baby Boom: An Optimistic Vision for a Graying Generation. USA: The Johns Hopkins University Press.

Gramsci, A. (1971) Selections From Prison Notebooks. London: Lawrence and Wishart.

Habermas, J. (1973) Legitimation Crisis. Cambridge: Polity Press.

Hamilton, M. and Hamilton, C. (2006) Baby Boomers and Retirement. Discussion Paper No.89. Sydney: The Australia Institute.

Harkin, J. and Huber, J. (2004) Eternal Youths. How the baby boomers are having their time again. London: Demos.

Harper, S. (2006) Plenary Address to the $39^{\text {th }}$ National Conference Australian Association of Gerontology, November 2006, Sydney, Australia.

Hawke, R. (2005) Retirement Income Provision in New Zealand: a Way Forward. Wellington: Institute of Policy Studies, Victoria University of Wellington.

Health Workforce Advisory Committee (HWAC) (2003) The New Zealand Health Workforce Future Directions - Recommendations to the Minister of Health 2003. Wellington: Health Workforce Advisory Committee.

Higgins, J. (1999) 'From welfare to workfare'. In Boston, J., Dalziel, P. and St John, S. (1999) Redesigning the Welfare State in New Zealand: Problems, Policies, Prospects. Auckland, New Zealand: Oxford University Press. 
Higgs, P. (1997) 'Citizenship theory and old age: from social rights to surveillance'. In Jamieson, A., Harper, S. and Victor, C. (Eds.) (1997) Critical Approaches to Later Life. Buckingham and Philadelphia: Open University Press.

Higgs, P. (2007) From Passive to Active Consumption: Ageing and Consumption in Britain 1963-1998. Full Research Report. ESRC End of Award Report. RES-154-25-007. Swindon: ESRC.

Hillcoat-Nalltamby, S. \& Dharmalingam, A. (2002) 'Constraints of Multi-Generational Support for Those in Mid-Life - An emerging policy issue?' Social Policy Journal of New Zealand. Issue 19, December 2002:128-140.

Hills, M. D. (2002) Kluckhohn and Strodtbeck's Values Orientation Theory. International Association for CrossCultural Psychology. Online Readings in Psychology and Culture, 4(4). http://dx.doi.org/10.9707/2307-0919.10404.

HM Government (2005) Opportunity Age - Meeting the challenges of ageing in the $21^{\text {st }}$ century. London, United Kingdom: HM Government.

Hofstede, G. (2001) Cultures Consequences: Comparing Values, Behaviours, Institutions and Organisations Across Cultures $\left(2^{\text {nd }} E d\right)$ Thousand Oaks, CA: Sage Publications.

Hogwood, B. W. and Gunn, L. A. (1984) Policy Analysis for the Real World. New York: Oxford University Press.

Holstein, J. and Gubrium, J. (2000) The Self We Live By. New York, N Y: Oxford University Press.

Hood S. J. (2010) An Evaluation of District Health Boards Implementation of the Health of Older People Strategy. Report for the HOPE Foundation for Research on Ageing. Available at:

http://www.hopefoundation.org.nz/pdf/Sarah\%20Hood\%20Research\%20final\%20.pdf. (Last accessed 21/11/12.)

Howe, N. and Strauss, W. (1997). The Fourth Turning: What the Cycles of History Tell Us About America's Next Rendezvous with Destiny. New York: Broadway Books.

Howe, N., \& Strauss, W. (2000). Millennials Rising: The next great generation. New York: Vintage Books.

HSBC (2005) The Future of Retirement: in a world of rising life expectancies. HSBC Insurance. Available at www.hsbc.com/futureofretirement.

HSBC (2006) The Future of Retirement: What people want. HSBC Insurance.

HSBC (2007a) The Future of Retirement: The new old age. HSBC Insurance.

HSBC (2007b) The Future of Retirement: Gender Analysis. HSBC Insurance.

HSBC (2008) The Future of Retirement: Investing in later life. HSBC Insurance.

Huber, J. and Skidmore, P. (2003) The New Old Age. United Kingdom: Demos and Age Concern England.

Hudson, R. B. (Ed.) (2008) Boomer Bust? Economic and Political Issues of the Graying Society (Vols 1 \& 2). Westport, Connecticut: Praeger Publishers.

Hughes, G. and Fergusson, R. (2000) Ordering Lives: Family, work and welfare. London: Routledge. 
Hughes, M. and Rand, A. (2004) The Lives and Times of the Baby Boomers. New York: Russell Sage Foundation and the Population Reference Bureau.

Human Rights Commission (2011) Tracking Equality at Work. Wellington: HRC.

Human Rights Commission (2012) Caring Counts. Report of the Inquiry into the Aged Care Workforce. Wellington: HRC.

Human Rights Commission (2012) Website pages available at www.hrc.co.nz .

Humpage, L. (2011) 'What do New Zealanders think about welfare?' Policy Quarterly, Vol 7, Issue 2 May pp8-13.

Hyman, P. (1997) 'Gender inequality in paid employment.' In Rudd, C. and Roper, B. (Eds.), The Political Economy of New Zealand. Auckland: Oxford University Press.

Inglehart, R. (1990) Cultural Change in Advanced Industrial Societies, Princeton, NJ: Princeton University Press.

Inglehart, R. (2000) 'Globalisation and Postmodern Values'. The Washington Quarterly, Winter 2000.

Inglehart, R. F. (2008) 'Changing Values among Western Publics from 1970 to 2006. West European Politics, Vol. 31, Nos. 1-2, 130 - 146, January-March.

Jackson, F (2011) 'Values, Welfare and Work: Aspects of the Labour Market and Welfare Dependency'. Policy Quarterly, Vol 7, Issue 2 May pp29-37.

Jackson, N. (2011a) 'The Demographic forces shaping New Zealand's future. What population ageing (really) means'. NIDEA Working Papers No. 1, University of Waikato, National Institute of Demographic and Economic Analysis.

Jackson, N. (2011b) 'Maori and the (Potential) Demographic Dividend'. NIDEA Working Papers No. 2, University of Waikato, National Institute of Demographic and Economic Analysis.

Jacobsen, J. K. (1995) 'Much ado about ideas: the cognitive factor in economic policy'. World Politics, 47: 283-310.

James, C. (1997) 'The policy revolution 1984-1993.' In Miller, R (Ed) (1997) New Zealand Politics in Transition (pp13-22). Auckland: Oxford University Press.

Jamieson, A., Harper, S. and Victor, C. (Eds.) (1997) Critical Approaches to Later Life. Buckingham and Philadelphia: Open University Press.

Jones I. R., Hyde, M., Victor, C., Wiggins, R., Gilleard, C. and Higgs, P. (2008) Ageing in a Consumer Society: From Passive to Active Consumption in Britain. The Policy Press: Bristol, UK.

Jordon, B. (2006) Social Policy for the Twenty-First Century: New Perspective, Big Issues. Cambridge, UK: Polity Press.

Karisto, A. (2007) Finnish Baby Boomers and the Emergence of the Third Age. International Journal of Ageing and Later Life. 2(2): 91-108.

Katz, S. (1999) Old Age as Lifestyle in an Active Society. Occasional Papers 19.

California: The Doreen B. Townsend Center for the Humanities, University of California. 
Keegan, C. and Gross, S. (2004) Boomers at Midlife: The AARP Life Stage Study, United States: AARP.

Keeling, S. (2001). 'Relative Distance: ageing in rural New Zealand', Ageing and Society, Vol 21, 5, September: 605-619.

Keeling, S., Davey, J. \& Glasgow, K. (2009). Qualitative Interviews. Summary Report for the 2008 Data Wave, Health, Work and Retirement Survey, School of Psychology, Massey University. http://hwr.massey.ac.nz/resources/HWR NZIRA August 09 4 1.pdf.

Kellehear, A. (1993) The Unobtrusive Researcher - a Guide to Methods. NSW, Australia: Allen \& Unwin.

Key, J. (2011) 'Prime Minister's Statement to Parliament', 8 February, http://www.beehive.govt.nz/gallery/statement-parliament-2011.

Kincheloe, J. L. and McLaren, P. L. (1994) 'Rethinking critical theory and qualitative research'. In Denzin, N. K. and Lincoln, Y. S. (eds) (1994) Handbook of Qualitative Research. Thousand Oaks: Sage Publications.

King, M. (2003) The Penguin History of New Zealand. Auckland: Penguin Press.

Koopman-Boyden, P. (1993) New Zealand's Ageing Society: The Implications. Wellington: Daphne Brasell Associates Press.

Krishnan, V., Jensen, J, and Ballantyne, S. (2002) New Zealand Living Standards 2000. Wellington: Ministry of Social Development.

Krueger, R. A. (1994) Focus Groups: A Practical Guide for Applied Research. (2 ${ }^{\text {nd }}$ Edition) California, USA: Sage Publications.

Labrum, B. (2004) 'Negotiating an Increased Range of Functions: Families and the Welfare State' in Dalley, B and Tennant, M. (eds) Past Judgement: Social Policy in New Zealand History. Dunedin: University of Otago Press.

Laczko, F. and Phillipson, C. (1991) 'Changing Work and Retirement'. Philadelphia, PA, Open University Press. In Minichiello, V et al. (Eds.) (1996), Sociology of Ageing: International perspectives. Australia: International Sociological Association.

Laslett, P (1989) The Fresh Map of Life: The emergence of the Third Age. London: Wiedenfeld and Nicholson.

Leach, R., Biggs, S., Phillipson, C, Money, A. (nd) Boomers and Beyond: Intergenerational consumption and the mature imagination. Findings: Cultures of Consumption Research Programme 2005-2007. UK: ESRC. Available at www.consume.bbk.ac.uk.

Lemke, J. I. (1995) Textual Politics: Discourse and Social Politics. London: Taylor \& Francis Ltd.

Lindlof, T. R., and Taylor, B. C. (2002). Qualitative Communication Research Methods, 2nd Edition. Thousand Oaks, CA: Sage.

Littlewood, M. and M. Dale, C. (2012) New Zealand Superannuation and Overseas Pensions: Reform Option 2. Auckland: Retirement Policy and Research Centre.

Macey, D. (2005) The Penguin Dictionary of Critical Theory. London: Penguin Books. 
Macrae, D. (1993) 'Guidelines for Policy Discourse: Consensual versus Adversarial' in F. Fischer and J. Forester (Eds.) The Argumentative Turn in Policy Analysis and Planning. Durham and London: Duke University Press.

Mannheim, K. (1952/1997) The Problem of Generations. Reproduced in M. A. Hardy (Ed), Studying Ageing and Social Change, Sage Publications, London, 22-65.

Mannheim, K. (1960) Ideology and Utopia. London: Routledge. (First Published 1936.)

Marshall, G. (1998) Oxford Dictionary of Sociology. Oxford and New York: Oxford University Press.

Martin, A. (2005) Older Adulthood, Education and Social Change. PhD Thesis. Auckland: University of Auckland.

McDonald, A. (1988) 'Developing Long Term Policy: The Approach Used by the Recent Prime Ministerial Task Force on Positive Ageing'. Social Policy Journal of New Zealand. Issue 10. June 1998: 39-57.

McFee, G. and Rowley, N. (1996) 'Developing a Positive Ageing Agenda'. In Minichiello, $\checkmark$ et al. (Eds.) (1996) Sociology of Ageing: International Perspectives. Australia: International Sociological Association.

McGregor, J. \& Gray, L. (2003) Older Worker Employment Transition. Research report. Palmerston North: Massey University.

McLennon, G., McManus, R. and Spoonley, P. (2010) Exploring Society: Sociology for New Zealand Students ( $3^{\text {rd }}$ Edition) Auckland, New Zealand: Pearson.

Metz, D. and Underwood, M. (2005) Older Richer Fitter. London: Age Concern England.

McPherson, M. (2004) 'Cohort Vulnerability to Lack of Extended Family Support: The Implications for Social Policy'. Social Policy Journal of New Zealand, Issue 21, March 2004: 60-177.

McPherson, M. (2008) Boomers and Beyond: Recruiters Tell their Stories. Wellington: Equal Employment Opportunities Trust. Available at http://www.eeotrust.org.nz/research/index.cfm.

McPherson, M., Smith-Lovin, L. \& Brashears, M. E. (2006) 'Social Isolation in America: changes in core discussion networks over two decades'. American Sociological Review, 71, 353-375.

Miller, R. (Ed) (1997) New Zealand Politics in Transition. Auckland: Oxford University Press.

Minichiello, V., Chappell, N., Kendig, H., and Walker, A. (Eds.) (1996), Sociology of Ageing: International Perspectives. Australia: International Sociological Association.

Ministry of Culture and Heritage web pages 2012. Available at www.mch.govt.nz.

Ministry of Health (2002) Health of Older People in New Zealand: A Statistical Reference. Wellington: Ministry of Health.

Ministry of Health (2003) Implementing the New Zealand Health Strategy. Wellington: Ministry of Health.

Ministry of Health (2004) A Portrait of Health: Key Results From2002/03 New Zealand Health Survey. PHI Occasional Bulletin No.21. Wellington: Ministry of Health. 
Ministry of Social Development (2001a) Positive Ageing in New Zealand: Diversity, participation and change. Status Report 2001. Wellington: Ministry of Social Development.

Ministry of Social Development (2001b) The Social Development Approach. Wellington: Ministry of Social Development.

Ministry of Social Development (2007) Positive Ageing Indicators 2007. Wellington: Ministry of Social Development.

Ministry of Social Development (2009) 'In A Place I Call My Own: Support Networks of Older People Ageing in the Community'. Ministry of Social Development, Wellington: New Zealand.

Ministry of Social Development (2011) The Business of Ageing. Realising the Economic Potential of Older People in New Zealand 2011 - 2051. Wellington: Ministry of Social Development.

Ministry of Social Development (2012) website pages: www.msd.govt.nz.

Miskin, S. J. M. (2004) The OECD: Ideas, Institutions, and Social Justice. A Thesis Submitted for the Degree of Doctor of Philosophy of the Australian National University.

Mitchell, S. (1998) American Generations: Who They Are, How They Live, What They Think. Ithaca, N.Y.: New Strategist.

Moody, H. R. (1992) 'Gerontology and Critical Theory.' The Gerontologist, 32 (3): 294-5.

Morgan, D. L. (1988) Focus Groups as Qualitative Research. (Qualitative Research Methods, Vol. 16.) California, USA: Sage Publications Inc.

Morgan, D. L. (Ed) (1993) Successful Focus Groups. Thousand Oaks CA: Sage Publications.

Morrow-Howell, N., Hinterlong, J. and Sherraden, M. (Eds) (2001) Productive Aging: Concepts and Challenges. Baltimore: Johns Hopkins University Press.

Mutchler, J. E. and Burr, J. (2008) 'Boomer Diversity and Well-being: Race, Ethnicity and Gender' in Hudson, R. B. (2008) Economic and Political Issues of the Graying Society (Vol 1 \& 2). Westport, Connecticut: Praeger Perspectives.

Myers, D. G. (2000) The American Paradox: Spiritual Hunger in an Age of Plenty. New Haven, CT: Yale University Press.

National Advisory Committee on Health and Disability (2007) Meeting the Needs of People With Chronic Conditions. Wellington: Ministry of Health.

Neugarten, B. L. and Hagestad, G. O. (1976) 'Age and the Life Course', in R. H. Binstock and E. Shanas (eds) Handbook of Aging and the Social Sciences, New York, NY: Van Nostrand Reinhold.

Ng, S. H. and McCreanor, T. (1999) 'Patterns in discourse about elderly people in New Zealand.' Journal of Ageing Studies. 1999 Win; Vol. 13(4): 473-489.

Nitta, H. (2206) Capitalising of Retirement of Japan's First Baby-Boomers. JETRO Japan Economic Report, April-May 2006.

http://www.jetro.go.jp/en/reports/market/pdf/2006_18_u.pdf.

NZIER (2004) Ageing New Zealand Health and Disability Services: Demand Projections and Workforce Implications 2001-2021. Wellington: NZIER. 
O'Brien, M. and Wilkes, C. (1993) The Tragedy of the Market: A social experiment in New Zealand. Palmerston North: Dunmore Press.

OECD (1996) Ageing in OECD Countries: a Critical Policy Challenge. Paris: OECD.

OECD (1998) Maintaining Prosperity in an Ageing Society. Paris: OECD.

OECD (1998) Ageing Populations: the Social Policy Implications. Paris: OECD.

OECD (2000) Reforms for an Ageing Society. Paris: OECD.

Office for People with Disabilities (2010) 'Think About It: Changing attitudes and behaviour to people with disabilities'. Online web pages available at http://www.odi.govt.nz/what-we-do/improving-attitudes-and-behaviours/index.html Wellington: Ministry of Social Development.

Office for Senior Citizens (2003) Briefing to the Incoming Minister - Towards Lifelong Participation and Independence. Wellington: Ministry of Social Development.

Office for Senior Citizens (2006) The New Zealand Positive Ageing Strategy Progress Report, 2006. Wellington: Ministry of Social Development.

Office for Senior Citizens (2008) Highlights From the Positive Ageing Report and Plan 2007 -2010. Wellington: Ministry of Social Development.

Office for Senior Citizens (2012a) New Zealanders: Getting Older, Doing More. Briefing to the Incoming Minister. Wellington: Ministry of Social Development.

Office for Senior Citizens (2012b) Positive Ageing Strategy Action Plans and Annual Reports 2001-2010. Wellington: Ministry of Social Development. Online documents available at http://www.msd.govt.nz/what-we-can-do/seniorcitizens/positiveageing/strategy/index.html (last accessed 21/11/12).

Office of Seniors Interests (1997) A Guide to Marketing to Maturity. Perth, Western Australia: Office of Seniors Interests.

Ogg, J. and Renault, S. (2006) 'The Support of Parents in old age by those born during 1945 - 1954: A European Perspective'. Ageing in Society, Vol 26, pp.1-21

Opie, A. (1999) 'The New Zealand Prime Ministerial "Taskforce on Positive Ageing": Discourses of Aging and Research Practice'. In Conference Proceedings: Promoting Inclusion - Redressing Exclusion - the Social Work Challenge. Conference of the AASW, IFSSWE and AASWWE, September 1999, Brisbane, Australia.

Paul, S., Rashbrooke, G. and Rea, D. (2006) 'Retirement Incomes'. In Boston, J. and Davey, A. (eds) (2006) Implications of Population Ageing: Opportunities and Risk. Wellington: Institute of Policy Studies, Victoria University of Wellington.

Periodic Report Group (2003) Retirement Income Report 2003. Wellington: Retirement Commission.

Perry, P. \& Webster, A. 1999. New Zealand Politics at the Turn of the Millennium: Attitudes and Values about Politics and Government. Alpha Publications: Auckland.

Petrie, M. (2006) 'Implications of Population Ageing for Families'. In Boston, J. and Davey, J. A. (eds) (2006) Implications of Population Ageing: Opportunities and Risk. Wellington: Institute of Policy Studies, Victoria University of Wellington. 
Pew Research Centre (2005) Baby Boomers Approach Age 60: From the Age of Aquarius to the Age of Responsibility. Available at www.pewresearch.org. Last accessed 23/9/13.

Phillipson, C. (1982) Capitalism and the Construction of Old Age. London: Macmillan.

Phillipson, C. (1997) 'Employment and Training: Planning for 2020 and Beyond'. In Evandrou, M. (ed.), Baby Boomers: Ageing in the $21^{\text {st }}$ Century. London: Age Concern England.

Phillipson, C (1998) Reconstructing Old Age: New Agendas in Social Theory and Practice. London; Thousand Oaks.

Phillipson, C (2006) Globalisation, Ageing and Inequality: Conference presentation, $39^{\text {th }}$ National Conference Australian Association of Gerontology, November 2006, Sydney, Australia.

Phillipson, C., Leach, R., Money, A. and Biggs, S. (2008) 'Social and Cultural Constructions of Ageing: the Case of the Baby Boomers'. Sociological Research Online, Vol 13, Issue 3. http://www.socresonline.org.uk/13/3/5.html.

Phillipson, C. and Smith, A. (2005) Extending Working Life: A Review of the Research Literature. Research Report No 299, London: Department for Work and Pensions.

Pool, I. (2007) 'The Baby Boom in New Zealand and Other Western Developed Countries.' Journal of Population Research, Vol 24, No 2, 141-161.

Pool, I., Baxendine, S., Cochrane, W., and Lindop, J. (2005) New Zealand Regions, 1986-2001: Household and families and their dwellings, Population Studies Centre Discussion Paper No 55. Hamilton: Population Studies Centre, University of Waikato.

Pool, I., Dharmalingam, A., Bedford, R., Pole, N., and Sceats, J. (eds) (2003) Population and Social Policy. Special Issue of New Zealand Population Review, Volume 29, No. 1. Wellington: Population Association of New Zealand.

Pool, I., Dharmalingam, A. and Sceats, J. (2007) The New Zealand Family From 1840: A Demographic History. Auckland: Auckland University Press.

Pool, I. and Hillcoat-Nalletamby, S. (1999) 'Fathers, Families, Futures: A Population Perspective.' In Birks, S and Callister, P. (eds) Perspectives on Fathering: Issue Paper No. 4, Centre for Policy Evaluation. Palmerston North: Massey University.

Powell, J. L. and Wahidin, A. (eds) (2006) Foucault and Aging. New York: Nova Science Publishers Inc.

Prime Ministerial Taskforce on Positive Ageing (1996) Facing the Future. Wellington: Department of the Prime Minister and Cabinet.

Prime Ministerial Taskforce on Positive Ageing (1997a) Facing the Future: A Possible Way Forward. Wellington: Department of the Prime Minister and Cabinet.

Prime Ministerial Taskforce on Positive Ageing (1997b) Facing the Future: A Strategic Plan. The Final Report. Wellington: Department of the Prime Minister and Cabinet.

Putman, R. D. (2000) Bowling Alone: The Collapse and Revival of American Community. New York: Simon and Shuster.

Quine, S. and Bernard, D. (2006) 'Intergenerational comparisons: Australian baby boomers discuss their perceptions.' Generations Review, Vol 16, No 2, 4-7. 
Quine, S., Bernard, D., and Kendig, H. (2006) 'Understanding baby boomers' expectations and plans for their retirement: findings from a qualitative study.' $A J A$, Vol 25, Issue 3, September, 2006.

Quine, S. \& Carter, S. (2006) 'Australian baby boomers' expectations and plans for their old age'. AJA. Vol. 25, No 1, March 2006.

Reich, B. and Adcock, C. (1976) Essential Psychology: Values, Attitudes and Behaviour Change. Herriot, P. (ed) Suffolk, UK: The Chaucer Press.

Retirement Commission (2002) Preparing for Retirement - Extract from a Report prepared for the Retirement Commission. Wellington: Office of the Retirement Commissioner.

Retirement Commission (2012) Policy Position Papers 2012. Available Online at http://www.cflri.org.nz/research-and-reports/retirement-income\#s3.

Richardson, V. (1996). 'The role of attitudes and beliefs in learning to teach'. In J. Sikula (Ed.), The Handbook of Research in Teacher Education ( $2^{\text {nd }}$ ed., pp.102-119). New York: Macmillan.

Riley M. W., Foner, A. and Riley, J. W. Jr. (1999) 'The aging and society paradigm', in V.L. Bengston and K.W. Schaie (eds) Handbook of Theories of Ageing. New York, NY: Springer.

Riley M. W. and Riley, J. W. (1994) 'Structural Lag: past present and future', in M. W. Riley, R. L. Kahn and A. Foner (eds) Age and Structural Lag: Society's Failure to Provide Meaningful Opportunities in Work, Family and Leisure. New York, NY: Wiley.

Robertson, R. (1994) 'Glocalisation: Space, Time and Social Theory.' Journal of International Communication. Vol 1/1.

Rokeach, M. (1972). Beliefs, attitudes, and values: $A$ theory of organization and change. San Francisco: Jossey-Bass.

Rokeach, M. (1973) The Nature of Human Values. New York: Free Press.

Roper, A. S. W. (2004) Baby Boomers Envision Retirement II: Survey of Baby Boomers' Expectations for Retirement. AARP, October 2004.

Rose, E., Huakau, J., Casswell, S. (2005) Economic Values: A Report from the New Zealand Values Study. Auckland: Centre for Social and Health Outcomes Research and Evaluation \& Te Ropu Whariki, Massey University.

Rose, E., Huakau, J., Huckle, T., Casswell, S., Perry, P., Howden-Chapman, P., Duignan, P. (2005) Public Life Values: A Report from the New Zealand Values Study. Auckland: Centre for Social and Health Outcomes Research and Evaluation \& Te Ropu Whariki, Massey University.

Rose, E., Huakau, J., Sweetsur, P, Casswell, S. (2005) Social Values: A Report from the New Zealand Values Study. Auckland: Centre for Social and Health Outcomes Research and Evaluation \& Te Ropu Whariki, Massey University.

Rowe, J. W., \& Kahn, R. L. (1987) 'Human Aging: Usual and Successful.' Science, 237, $143-49$

Royal Commission on Social Security (1972) Report on Social Security in New Zealand. Wellington: Government Printer. 
Rudd, C. (1997) 'The Welfare State' in Rudd, C. and Roper, B. (Eds), The Political Economy of New Zealand. Auckland: Oxford University Press.

Rudd, C. (2001) 'The welfare state'. In Miller, R (Ed) New Zealand Politics in Transition. Auckland: Oxford University Press.

Schwartz, S. H. (1999) 'A Theory of Cultural Values and Some Implications for Work'. Applied Psychology: An International Review, 48 (I), pp23 - 47.

Schofield, V., Davey, J., Keeling, S. and Parsons. M. (2006) 'Ageing in Place'. In Boston, J. and Davey, J. (2006) Implications of Population Ageing: Opportunities and Risks.

Wellington: Institute of Policy Studies, Victoria University.

Scobie, G., Gibson. J., and Le, T. (2004) Saving for Retirement: New Evidence for New Zealand. Working Paper 04/12. Wellington: The Treasury.

Scott, J. (2006) Sociology: The Key Concepts. Oxon: Routledge.

Scott, J. (2007) Fifty Key Sociologists: The Contemporary Theorists. Oxon: Routledge.

Senior Citizens Unit. (1996) Issues Papers for the Minister for Senior Citizens. Wellington: Ministry of Social Policy.

Senior Citizens Unit. (1999) Post-Election Briefing Papers. Wellington: Ministry of Social Policy.

Sidorenko, A. and Walker, (2004) A. 'The Madrid International Plan of Action on Ageing'. Ageing and Society, 24, 2, 147-165.

Siemienska, R. (2002) Intergenerational Differences in Political Values and Attitudes in Stable and New Democracies. (World Values Survey Downloadable Document.) Available at

http://www.worldvaluessurvey.org/new_index_publications?start:int=40\&publication_search_fiel $\underline{\mathrm{d}}=$ (last accessed 21/11/2012).

Skidmore, P and Huber, J. (2003) 'Ageing, Values and the Baby Boomers'. Generations Review. Vol. 13, No 4:16-19.

Smith J.W. and Clurman, A. (2007) Generation Ageless. New York: HarperCollins Publishers.

St John, S. (1992) 'Superannuation Policy: Or How Not to Make Policy'. In Boston, J and Dalziel, P. (Eds) The Decent Society? Essays in Response to National's Economic and Social Policies. Auckland: Oxford University Press

St John, S. (1999) 'Superannuation in the 1990s: Where Angels Fear to Tread'. In Boston, J., Dalziel, P. and St John, S. (1999) Redesigning the Welfare State in New Zealand: Problems, Policies, Prospects. Auckland, New Zealand: Oxford University Press.

Statistics New Zealand (1995). New Zealand Now: Baby Boomers. Wellington: Statistics New Zealand.

Statistics New Zealand. (1997). Ageing and Retirement in New Zealand. Wellington: Statistics New Zealand.

Statistics New Zealand (1998). New Zealand Now: 65 Plus. Wellington: Statistics New Zealand. 
Statistics New Zealand (2002) Demographic Trends 2001. Wellington: Statistics New Zealand.

Statistics New Zealand (2006a) Demographic Aspects of New Zealand's Ageing Population. Wellington: Statistics New Zealand.

Statistics New Zealand (2006b) Quick Stats, 2006 Census data. Available at: http://www.stats.govt.nz/Census/2006CensusHomePage/QuickStats.aspx.

Steinhorn, L. (2006) The Greater Generation: In Defense of the Baby Boom Legacy. New York: Reed Elsevier.

Stephens, R. (1999) 'Poverty, Family Finances and Social Security', in P. Dalziel, S. St. John and J. Boston (eds), The Redesign of the Welfare State in New Zealand, Auckland: Oxford University Press, pp. 238-259.

Stephenson, J. \& Scobie, G. (2002) The Economics of Population Ageing. Wellington: NZ Treasury.

Stewart, D. W. and Kamins, M. A. (1993) Secondary Research: Information Sources and Methods. (2nd edition). California: Sage Publications.

Strauss, W., and Howe, N. (1991) Generations: The History of America's Future, 1584 to 2069. New York: William Morrow.

Tajfel, H and Turner, J. C. (1986) 'The Social Identity Theory of Intergroup Behaviours.' In Worchel, S. \& Austin, W. G. Psychology of Intergroup Relations. (pp 7-24), Chicago:

Nelson-Hall.

Te Ara: The Encyclopedia of New Zealand (Online): Available at www.teara.govt.nz.

Terry, D. J. \& Hogg, M. A. (1996). 'Group norms and the attitude-behaviour relationship : A role for group identification.' Personality and Social Psychology Bulletin, 22, 776-793.

Terry, D. J., Hogg, M. A. and White, K. M. (1999) 'The theory of planned behaviour : Self identity, social identity and group norms.' British Journal of Social Psychology (1999), 38, 225-244.

Thomson, D. (1991) Selfish Generations?: The Ageing of New Zealand's Welfare State. Wellington, New Zealand: Bridget Williams Books Ltd.

Thornhill, M. (2005) Marketing to the Middle Age of Aquarius: Five 'New' Priorities for Boomers Over 50 (The Boomer Project White Paper). April. www.Boomerproject.com/Middle)Age_if_Aquarius.pdf.

Thorns, D. (1996) 'Generational capture? The Debate about Intergenerational Equity in New Zealand'. In Minichiello, V. et al. (Eds.) (1996), Sociology of Ageing: International Perspectives. Australia: International Sociological Association.

Tinker, A., Wright, F., McCeadie, C., Askham, J. and Hancock, R. (1993) Alternative Models of Care for Older People: Report for the Royal Commission on Long Term Care. Research Volume Two London: Stationery Office.

Tong, R. (1986) Ethics in Policy Analysis. New Jersey: Prentice-Hall Inc.

Townsend, P. (1986) 'Ageism and Social Policy'. In Walker, A. and Phillipson, C. (Eds.), (1986) Ageing and Social Policy, Hants, England, Gower Publishing Company Ltd.

Trotter, C (2007) No Left Turn: The Distortion of New Zealand's History by Greed, Bigotry, and Right-Wing Politics. Auckland: Random House. 
Turner, B. S. (1989) 'Ageing, Status Politics and Social Theory.' British Journal of Sociology, 40, 588-606.

Turner, B. S. (1992) Regulating Bodies. Essays in Medical Sociology. London and New York: Routledge.

Turner, B. S. (1998) 'Ageing and generational conflict: a reply to Sarah Irwin.' British Journal of Sociology, 49, 299-304.

Twenge, J. M. (2006) Generation Me. New York, N. Y. Free Press.

Twenge, J. M. and Campbell, W, K. (2009) The Narcissism Epidemic: Living in the Age of Entitlement. USA: Free Press, Simon \& Schuster Inc.

Twenge, J. M., Campbell, S. M., Hoffman, B. J., \& Lance, C. E. (2010) 'Generational Differences in Work Values: Leisure and Extrinsic Values Increasing, Social and Intrinsic Values Decreasing.' Journal of Management Vol. 36 No. 5, September 2010 1117-1142.

Twenge, J. M., Konrath, S., Foster, J. D., Campbell, W. K., \& Bushman, B. J. (2008). Egos inflating over time: A cross-temporal meta-analysis of the Narcissistic Personality Inventory. Journal of Personality, 76, 875-901.

Uhlenberg, P. and Miner, S. (1996) 'Life Course and Aging: A Cohort Perspective'. In Handbook of Aging and the Social Sciences, Fourth edition. USA: Academic Press Inc.

United Nations, Department of Economic and Social Affairs, Population Division. (2002) Policy Responses to Population Decline and Ageing. Population Bulletin of the United Nations, Special Issue Nos. 44/45. New York: United Nations Publishing Section.

Van Dijk, T. A. (1993) 'Principles of Critical Discourse Analysis'. Discourse and Society, Vol 4(2): 249-283.

Vandeskog, B., Vandeskog, A. and Liddicoat. ( 2012) Ageing in Place in Golden Bay: An investigation of the ageing population in Golden Bay and what they need to be able to 'age in place'. Golden Bay: Golden Bay Workplace Trust.

Vauclair, C (2009) Measuring Cultural Values at the Individual-Level: considering morality in cross cultural value research. School of Psychology Online doc. Available at: http://www.researchgate.net/profile/Melanie_Vauclair/publications.

Vincent, J. (2003) Old Age. London: Routledge.

Vincent, J. (2005) 'Understanding Generations: political economy and culture in an ageing society'. British Journal of Sociology, Vol 56, No.4, pp579-99.

Vincent, C. and Downs, M. (Eds) (2006) Futures of Old Age. London: Sage Publications with The British Society of Gerontology.

Waldegrave, C. and Cameron, M. (2008) 'The Impact of Poverty on Wellbeing During Midlife'. New Zealand Journal of Psychology Vol. 39, No. 2. Hamilton:

University of Waikato and Family Centre Social Policy Research Unit,

Waldegrave, C. and Koopman-Boyden, P. (2010) Midlife New Zealanders Aged 40-64 in 2009: Enhancing Wellbeing in an Ageing Society. Lower Hutt, Wellington: Family Centre Social Policy Research Unit, and Hamilton: the Population Studies Centre, University of Waikato.

Walker, A. (1996a) 'Towards an international political economy of ageing'. $25^{\text {th }}$ Volume Celebration paper. Ageing \& Society 25, 2005, 815-839. 
Walker, A. (Ed) (1996b) The New Generational Contract: Intergenerational relations, Old Age and Welfare. United Kingdom: UCL Press.

Walker, A. (Ed) (2002) 'A Strategy for Active Ageing.' International Social Security Review, Vol 55 1/2002.

Walker, A. (2005) 'Towards an international political economy of ageing.' Ageing and Society, 25, 2005, $815-839$.

Walker, A. and Minichiello, V. (1996) 'Emerging Issues in Sociological Thinking, Research and Teaching'. In Minichiello, V. et al. (Eds.) (1996), Sociology of Ageing: International Perspectives. Australia: International Sociological Association.

Webster, A (2001) Spiral of Values: The flow from survival values to global consciousness. An Interpretation of the New Zealand Study of Values. Hawera, New Zealand: Alpha Publications.

Welfare Working Group (2011) Reducing Long Term Benefit Dependency: Recommendations. Wellington: Institute of Policy Studies.

Welzel, C., Inglegart, R., \& Klingemann, H. (2003) The Theory of Human Development. European Consortium for Political Research.

Wilson, M. S. \& Sibley, C. G. (2011) 'Narcissism Creep? Evidence for age related differences for Narcissm in New Zealand general population.' New Zealand Journal of Psychology, 40, 89-95.

World Bank (1994) Averting the Old Age Crisis: Policies to Protect the Old and Promote Growth. Oxford: Oxford University Press.

World Health Organisation (WHO) (1999) Global Movement for Active Ageing. Geneva: WHO.

World Health Organisation (WHO) (2001) Health and Ageing: A Discussion Paper. Geneva: WHO.

World Health Organisation (WHO) (2002) Active Ageing: A Policy Framework. Geneva: WHO. Available online at http://www.who.int/ageing/publications/active_ageing/en/ [Last accessed 7/10/2013].

World Values Survey website. Available at http://www.worldvaluessurvey.org/ . [Last accessed 7/10/2013].

Yska, R. (1993) All Shook Up: The Flash Bodgie and the Rise of the New Zealand Teenager in the Fifties. Auckland: Penguin Books.

Zeitz, J. (2005) ‘Boomer Century’. American Heritage, Vol 56, Issue 5 Oct 2005. 


\section{Appendix One:}

\section{Questionnaire for Focus Group Participants}

\section{Introduction}

Thank you for helping with this important study about baby boomers and ageing. I will use this study as part of my $\mathrm{PhD}$ research on attitudes to ageing and implications for policy.

This questionnaire will take around 10-15 minutes to complete. Your answers will be completely confidential. No one other than myself as the researcher will be able to tell who answered this questionnaire. Your answers will be put together with those of others and no names will be included in any report.

Please bring your completed questionnaire with you to the focus group on at

If you have any questions, please contact me at

l'd like to thank you in advance for your time and effort.

\section{How to answer}

Put an $\mathrm{X}$ inside the box provided.

For example: [ ] [x] [ ] [ ] [ ]

If you change your mind or make a mistake, fill in the whole box and mark the correct one as shown:

\section{[ ] $\square[$ ] [ $\mathrm{x}]$ [ ]}

\section{About You}

l'd like to know a little about the people taking part in our focus groups. The following questions are similar to those asked in the New Zealand population Census or are questions based on other surveys about ageing. This will allow comparisons to be made with findings from other research and will show how similar or dissimilar those taking part in focus groups are from others living in New Zealand. Please note that all personal information you provide in this questionnaire is confidential and will only be used for this research.

1. In general, would you say your health is... (mark one box)

[ ] excellent
[ ] very good
[ ] good
[ ] fair
[ ] ] poor 
2. This question asks about your level of physical activity. "Physical activity" includes things you do that increase your breathing and/or heart-rate (this includes but is not limited to exercise). Examples of these physical activities include brisk walking, biking, swimming, dancing, aerobics, gardening, sports and other activities that "get you moving".

Overall, how physically active do you consider yourself to be? (Rate yourself on a scale of 1-7, with 1 indicating not at all physically active and 7 indicating very physically active.)

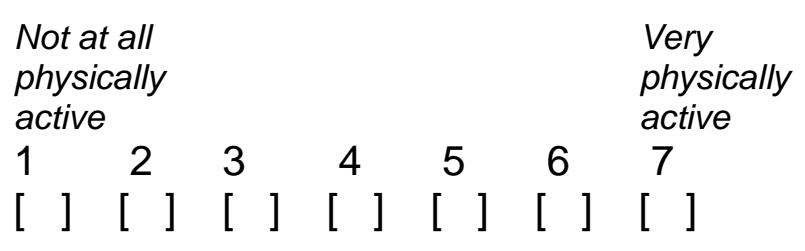

3. This question asks about your level of regular physical activity. "Regular physical activity" means at least 15 minutes of vigorous activity (makes you "huff and puff') or a total of 30 minutes or more of moderate activity (causes a slight but noticeable increase in breathing and heart rate) each day for

5 or more days each week. Include brisk walking.

Are you "regularly physically active" according to the definition above? (Mark one box)

[ ] No, and I do not intend to be in the next 6 months

[ ] No, but I am thinking about starting to be in the next 6 months

[ ] No, but I intend to begin in the next 30 days

[ ] Yes, I am but only began in the last 6 months

[ ] Yes, I am and have been for more than 6 months

4. Which one of the following best describes you? (Mark one box only - if more than one category applies, mark the one you spend most time doing over a week.)

[ ] Working for pay or profit (go to question 5)

[ ] Currently unemployed and seeking work (go to question 9)

[ ] Unpaid carer / childminder / housekeeper / volunteer (go to question 9)

[ ] Retired (go to question 9)

[ ] Out of workforce due to Sickness/ Disability or Invalid (go to question 9)

[ ] Student (full-time) (go to question 9)

[ ] Other - please specify:

5. If you described yourself as 'working for pay or profit' in question 4 above, which of these are you? (If you have more than one job, answer for the job that you work the most hours in.)

[ ] A paid employee

[ ] Self-employed and not employing others

[ ] An employer of other person(s) in my own business

[ ] Working in a family business or family farm 
6. What is your occupation in your main job?

Occupation:

7. For your main job, do you mostly:

[ ] Work at home

[ ] Work away from home

8. How many hours, to the nearest hour, do you usually work per week?

a) In the job you have answered questions 5 to 7 about: hours

b) In all other jobs (for pay or profit or on a family business or farm): hours

9. Mark as many boxes as you need to answer this question. In the last four weeks which of these have you done without pay?

[ ] Household work, cooking, repairs, gardening etc for my own household

[ ] Looked after a member of my household who is ill, frail or has a disability

[ ] Looked after a child (who does NOT live in my household)

[ ] Helped someone who is ill, frail or has a disability (who does NOT live in my household)

[ ] Other help or voluntary work for or through an organisation, group or marae

[ ] None of these

10. Since leaving school, what, if any, formal qualifications have you gained?

Don't count incomplete qualifications or qualifications that take less than 3 months of full-time study (or the equivalent) to get.

(Mark all that apply)

[ ] No formal qualifications since leaving secondary school

[ ] Bachelor Degree, higher degree or postgraduate certificate/diploma

[ ] Other complete qualification taking three or more months of full-time study, or the equivalent (e.g. diploma, trade certificate)

11. Are you currently enrolled in any course or programme of study?

[ ] Not studying

[ ] Studying Fulltime (20 hours or more a week)

[ ] Studying Part time (less than 20 hours a week)

12. Which one of these statements is true about your current legal marital /civil union status? If you have had more than one legal marriage or civil union answer for the most recent. (Civil unions are an alternative to marriage and have an equivalent legal status. To be joined in a civil union you and your partner must have gone through a formal ceremony and registration process.)

[ ] I have never been legally married and I have never been legally joined in a civil union (go to question 14)

[ ] I am divorced or my marriage has been dissolved

[ ] I am a widow / widower / bereaved civil union partner

[ ] I am permanently separated from my legal husband/ wife / civil union

partner

[ ] I am legally married

[ ] I am legally joined in a civil union 
13. How many times have you been married or joined in a civil union?

[ ] Once

[ ] Twice

[ ] Three or more times

14. Who do you live with?

Please mark as many spaces as you need to show all the people who live in the same household as you.

[ ] My legal husband or wife

[ ] My civil union partner

[ ] My de facto partner, boyfriend or girlfriend

[ ] My mother and/or father

[ ] My son(s) and/or daughter(s)

[ ] My husband / wife / partner / de facto's son(s) or daughter(s)

[ ] My grandchildren

[ ] My brother(s) and/or sisters(s)

[ ] My flatmates

[ ] Other - please state: (for example MY

GRANDMOTHER, NIECE, NEPHEW, MOTHER-IN LAW, MY PARTNER'S FATHER or BOARDER ETC.)

[ ] None of the above - I live alone.

15. Counting yourself (and any boarders), how many people in total usually live with you? Only count people usually living with you at least 2 days a week.

Number of people:

16. Of these, how many are:

[ ] aged 18 years or more

[ ] aged $16-17$ years

[ ] aged $5-15$ years

[ ] aged $0-4$ years

Total: (check: total should equal previous answer)

17. Do you yourself own, or partly own, the dwelling that you usually live in (with or without a mortgage)?

[ ] Yes

18. Do you yourself own, or partly own, another residential property (with or without a mortgage)?

[ ] Yes

[ ] No 
19. Which of these best describes your personal income before tax in the last 12 months? Include income from all sources including wages, profit from business income, benefits and retirement income. If you and your spouse / partner earn income jointly, only include your part of that income.

[ ] 15,000 or less

[ ] 15,001 to 20,000

[ ] 20,001 to 25,000

[ ] 25,001 to 35,000

[ ] 35,001 to 50,000

[ ] 50,001 to 70,000

[ ] ] 70,001 to 100,000

[ ] 100,001 or more

[ ] don't know

\section{On ageing}

20. What are you currently doing or have recently completed as preparation for your older years? (Mark all those that apply.)

[ ] signed up for / contributing to KiwiSaver

[ ] made contributions to other superannuation scheme or retirement fund

[ ] have paid off or are paying off your home mortgage

[ ] have invested in property or shares

[ ] made a formal arrangement for your care and support (e.g. an Enduring

Power of Authority)

[ ] legal planning (e.g. wills, trusts)

[ ] attending a course or programme of study

[ ] training or skills development to change jobs or work conditions

[ ] sought expert advice or attended a course on retirement planning

[ ] made plans for increased leisure time (e.g. new hobbies, interests or travel plans)

[ ] preparing to or have moved to a more suitable property/location/climate

[ ] adapting your house or garden to make it easier to live in when older

[ ] other (please describe:

[ ] none of the above

Any other comment:

\section{Final questions}

21. Are you:

[ ] male

[ ] female

22. In what year were you born? Year:

Thank you for taking the time to complete this survey. 


\section{Appendix Two:}

\section{Boomer Focus Groups: Discussion Guide}

1. Complete this sentence: To me old age is ... (Discuss)

\section{Prompts}

young old and old old; good and bad things about growing older; role of older people in society; feelings about self growing old

2. What kind of lifestyle do you expect you will have when you are in your 60 s, 70 s, 80 s and older?

\section{Prompts}

work, retirement, housing, living arrangements, leisure, travel, volunteering

3. What may change this / get in the way of your plans?

\section{Prompts}

barriers and opportunities; work issues, financial issues, family issues, relationship issues, health issues, policy issues, service issues

4. What forms of family support or assistance do you expect to give and receive in the next $10 / 20 / 30$ years?

\section{Prompts}

emotional, financial, or practical; ability of family members to provide support; comfort with receiving support; preferred source of personal care; willingness to pay for support or services from private providers

5. What kind of assistance or support do you expect to receive from the state in older age?

\section{Prompts}

financial, housing, transport, health, care \& support, workforce participation, education, leisure; state versus individual's responsibility

6. Baby boomers grew up in the 1950 s, 60 s and 70 s and their values and attitudes are likely to have been influenced by those times. Do you think that boomers values and attitudes will mean they will behave differently to today's older people?

\section{Prompts}

lifestyle, expectations, as consumers, as active citizens, sense of duty to others (family / younger generations), desire for freedom, choice, autonomy; sense of patriotism, globalism, individualism 


\section{Appendix Three:}

Table A: Focus Group Participants - Socio-economic Characteristics

\begin{tabular}{|c|c|c|c|c|c|}
\hline $\begin{array}{l}\text { Focus } \\
\text { Group }\end{array}$ & $\begin{array}{l}\text { Boomer } \\
\text { age } \\
\text { group }\end{array}$ & Gender & $\begin{array}{l}\text { Income } \\
\text { (personal) } \\
\text { Annual \$ }\end{array}$ & $\begin{array}{l}\text { Home Owner } \\
\text { (sole or } \\
\text { jointly) }\end{array}$ & $\begin{array}{l}\text { Highest } \\
\text { Educational } \\
\text { Qualification }\end{array}$ \\
\hline Group 1 & leading & women & $\begin{array}{l}70 k+x 5 \\
50-70 k \times 3\end{array}$ & $\begin{array}{l}8 \text { Yes (2 no } \\
\text { mortgage) } \\
0 \text { No }\end{array}$ & $\begin{array}{l}8 \text { Degree or } \\
\text { above }\end{array}$ \\
\hline Group 6 & leading & men & $\begin{array}{l}70 \mathrm{k}+\mathrm{x} 2 \\
50-70 \mathrm{k} \times 4 \\
35-50 \mathrm{k} \times 2\end{array}$ & $\begin{array}{l}8 \text { Yes (4 no } \\
\text { mortgage) } \\
0 \text { No }\end{array}$ & $\begin{array}{l}4 \text { Degree or } \\
\text { above } \\
2 \text { Other qual. } \\
2 \text { None }\end{array}$ \\
\hline Group 8 & leading & men $^{*}$ & $\begin{array}{l}70 \mathrm{k}+\mathrm{x} 4 \\
50-70 \mathrm{k} \times 1 \\
35-50 \mathrm{k} \times 2\end{array}$ & $\begin{array}{l}6 \text { Yes (3 no } \\
\text { mortgage) } \\
1 \text { No (1 rents) }\end{array}$ & $\begin{array}{l}1 \text { Degree or } \\
\text { above } \\
3 \text { Other qual. } \\
3 \text { None }\end{array}$ \\
\hline Group 9 & leading & women & $\begin{array}{l}25-35 \mathrm{k} \times 1 \\
20-25 \mathrm{k} \times 1 \\
<15 \mathrm{k} \times 1 \\
\mathrm{dk} / \mathrm{na} \times 2\end{array}$ & $\begin{array}{l}3 \text { Yes (3 no } \\
\text { mortgage) } \\
2 \text { Other ( } 1 \\
\text { trust) }\end{array}$ & $\begin{array}{l}0 \text { Degree or } \\
\text { above } \\
3 \text { Other qual. } \\
2 \text { None }\end{array}$ \\
\hline Group 2 & trailing & women & $\begin{array}{l}70 \mathrm{k}+\mathrm{x1} \\
50-70 \mathrm{k} \times 1 \\
35-50 \mathrm{k} \times 3\end{array}$ & $\begin{array}{l}6 \text { Yes (1 no } \\
\text { mortgage) } \\
0 \text { No }\end{array}$ & $\begin{array}{l}6 \text { Degree or } \\
\text { above }\end{array}$ \\
\hline Group 3 & trailing ${ }^{\star}$ & women & $\begin{array}{l}70 \mathrm{k}+\mathrm{x1} \\
50-70 \mathrm{k} \times 3 \\
35-50 \mathrm{k} \times 1\end{array}$ & $\begin{array}{l}5 \text { Yes (1 no } \\
\text { mortgage) } \\
0 \text { No }\end{array}$ & $\begin{array}{l}4 \text { Degree or } \\
\text { above } \\
1 \text { Other qual. }\end{array}$ \\
\hline Group 4 & trailing & men & $\begin{array}{l}50-70 \mathrm{k} \times 1 \\
35-50 \mathrm{k} \times 2 \\
25-35 \mathrm{k} \times 1 \\
<15 \mathrm{k} \times 1 \\
\mathrm{dk} / \mathrm{na} \times 1\end{array}$ & $\begin{array}{l}6 \text { Yes (3 no } \\
\text { mortgage) } \\
0 \text { No }\end{array}$ & $\begin{array}{l}0 \text { Degree or } \\
\text { above } \\
5 \text { Other qual. } \\
1 \text { None }\end{array}$ \\
\hline Group 5 & trailing & men & $\begin{array}{l}70 \mathrm{k}+\mathrm{x} 2 \\
50-70 \mathrm{k} \times 1 \\
35-50 \mathrm{k} \times 1 \\
25-35 \mathrm{k} \times 3\end{array}$ & $\begin{array}{l}7 \text { Yes (2 no } \\
\text { mortgage) } \\
0 \text { No }\end{array}$ & $\begin{array}{l}4 \text { Degree or } \\
\text { above } \\
1 \text { Other qual. } \\
2 \text { None }\end{array}$ \\
\hline Group 7 & mixed & mixed & $\begin{array}{l}70 \mathrm{k}+\mathrm{x} 2 \\
50-70 \mathrm{k} \times 3 \\
35-50 \mathrm{k} \times 1\end{array}$ & $\begin{array}{l}6 \text { Yes (0 no } \\
\text { mortgage) } \\
0 \text { No }\end{array}$ & $\begin{array}{l}2 \text { Degree or } \\
\text { above } \\
2 \text { Other qual. } \\
2 \text { None }\end{array}$ \\
\hline Group 10 & mixed & mixed & $\begin{array}{l}50-70 \mathrm{k} \times 1 \\
35-50 \mathrm{k} \times 3 \\
25-35 \mathrm{k} \times 1 \\
20-25 \mathrm{k} \times 3\end{array}$ & $\begin{array}{l}2 \text { Yes ( } 0 \text { no } \\
\text { mortgage) } \\
5 \text { No (5 rent) } \\
1 \text { Other }\end{array}$ & $\begin{array}{l}2 \text { Degree or } \\
\text { above } \\
3 \text { Other qual. } \\
3 \text { None }\end{array}$ \\
\hline Group 11 & mixed & women & $\begin{array}{l}70 \mathrm{k}+\mathrm{x1} \\
35-50 \mathrm{k} \times 1 \\
25-35 \times 1 \\
<15 \mathrm{k} \times 1\end{array}$ & $\begin{array}{l}2 \text { Yes (0 no } \\
\text { mortgage) } \\
2 \text { No (2 rent) }\end{array}$ & $\begin{array}{l}2 \text { Degree or } \\
\text { above } \\
2 \text { Other qual. }\end{array}$ \\
\hline
\end{tabular}

* In these groups there was one participant who did not meet the age or gender based selection criteria. That is, one leading boomer attended the trailing boomer group and one female attended the male boomer group. 


\section{Appendix Four:}

Table B: Boomers Common Goals and Related Values

\begin{tabular}{|c|c|c|c|c|}
\hline Desired goals & $\frac{\text { Constraints and }}{\text { influences }}$ & Motivation & $\underline{\text { Personal values }}$ & $\frac{\text { Desirable }}{\text { values }}$ \\
\hline $\begin{array}{l}\text { Work: } \\
\text { Balance of work } \\
\text { and leisure } \\
\text { Individual } \\
\text { choice to work } \\
\text { or retire } \\
\text { Flexible work } \\
\text { options }\end{array}$ & $\begin{array}{l}\text { Health } \\
\text { Economic } \\
\text { conditions } \\
\text { Job opportunities } \\
\text { Ageist attitudes } \\
\text { Family } \\
\text { circumstances } \\
\text { Employer } \\
\text { inflexibility }\end{array}$ & $\begin{array}{l}\text { Contribute skills } \\
\text { Social contact } \\
\text { Ongoing } \\
\text { learning } \\
\text { Active lifestyle } \\
\text { Secure income } \\
\text { Feel valued } \\
\text { Avoid decline } \\
\text { Choice } \\
\text { Saving }\end{array}$ & $\begin{array}{l}\text { Hard work } \\
\text { Pleasure } \\
\text { Freedom } \\
\text { Self-respect } \\
\text { A sense of } \\
\text { accomplishment } \\
\text { Time } \\
\text { Autonomy } \\
\text { Self reliance } \\
\text { Vigour } \\
\text { Helpfulness } \\
\text { Responsibility }\end{array}$ & $\begin{array}{l}\text { Determination } \\
\text { Responsibility } \\
\text { Participation } \\
\text { Contribution } \\
\text { Independence } \\
\text { Self reliance } \\
\text { Quality of life } \\
\text { Self esteem }\end{array}$ \\
\hline $\begin{array}{l}\text { Leisure: } \\
\text { Active leisure } \\
\text { Travel } \\
\text { Time with } \\
\text { friends }\end{array}$ & $\begin{array}{l}\text { Health } \\
\text { Costs } \\
\text { Work \& family } \\
\text { Networks } \\
\text { Transport }\end{array}$ & $\begin{array}{l}\text { New } \\
\text { experiences } \\
\text { Maintain health } \\
\text { and wellbeing } \\
\text { Travel and } \\
\text { adventure } \\
\text { An active } \\
\text { lifestyle } \\
\text { Social contact }\end{array}$ & $\begin{array}{l}\text { Freedom } \\
\text { An exciting life } \\
\text { Pleasure } \\
\text { Innovation } \\
\text { Imagination } \\
\text { Vitality }\end{array}$ & $\begin{array}{l}\text { Activity } \\
\text { Obligation } \\
\text { Creativity }\end{array}$ \\
\hline $\begin{array}{l}\text { Family } \\
\text { Provide care } \\
\text { and support } \\
\text { More time with } \\
\text { family } \\
\text { Balance of } \\
\text { contact/privacy } \\
\text { Mentor younger } \\
\text { generation } \\
\text { Avoid burdening } \\
\text { family }\end{array}$ & $\begin{array}{l}\text { Distance } \\
\text { Cost } \\
\text { Need for privacy } \\
\text { and } \\
\text { independence } \\
\text { Need for time for } \\
\text { self } \\
\text { Family size } \\
\text { Family culture } \\
\text { Size of home } \\
\text { Attitude to care } \\
\text { Work and other } \\
\text { commitments } \\
\text { Health }\end{array}$ & $\begin{array}{l}\text { Contact with } \\
\text { loved ones } \\
\text { Mutuality of } \\
\text { support } \\
\text { Share skills \& } \\
\text { knowledge } \\
\text { Support security } \\
\text { of next } \\
\text { generation } \\
\text { Support } \\
\text { wellbeing of } \\
\text { older generation } \\
\text { Provide } \\
\text { meaning and } \\
\text { purpose }\end{array}$ & $\begin{array}{l}\text { Inner harmony } \\
\text { Pleasure } \\
\text { Mature Love } \\
\text { Wisdom } \\
\text { Responsibility } \\
\text { Respect } \\
\text { Helpfulness } \\
\text { Reciprocity } \\
\text { Independence } \\
\text { Interdepen- } \\
\text { dence }\end{array}$ & $\begin{array}{l}\text { Responsibility } \\
\text { Respect } \\
\text { Duty } \\
\text { Obligation } \\
\text { Mutuality } \\
\text { Reciprocity } \\
\text { Interdepend- } \\
\text { ence } \\
\text { Independence } \\
\text { Generativity }\end{array}$ \\
\hline $\begin{array}{l}\text { Home \& Living } \\
\text { Arrangement } \\
\text { Control over } \\
\text { decision making } \\
\text { Pleasurable } \\
\text { setting / }\end{array}$ & $\begin{array}{l}\text { Health } \\
\text { Family culture } \\
\text { Proximity to } \\
\text { family and/or } \\
\text { friends } \\
\text { Location of } \\
\text { services }\end{array}$ & $\begin{array}{l}\text { Access to } \\
\text { support } \\
\text { Companionship } \\
\text { Manage home } \\
\text { and garden } \\
\text { A harmonious } \\
\text { environment }\end{array}$ & $\begin{array}{l}\text { Freedomy } \\
\text { Reciprocity } \\
\text { Sustainability } \\
\text { A world of } \\
\text { beauty } \\
\text { Self sufficiency } \\
\text { Adaptability }\end{array}$ & $\begin{array}{l}\text { Collectivism } \\
\text { Autonomy }\end{array}$ \\
\hline
\end{tabular}




\begin{tabular}{|c|c|c|c|c|}
\hline $\begin{array}{l}\text { Adaptable /Life } \\
\text { design / Space } \\
\text { to have family \& } \\
\text { visitors stay } \\
\text { Affordable } \\
\text { Meets individual } \\
\text { needs }\end{array}$ & $\begin{array}{l}\text { Cost } \\
\text { Transport } \\
\text { Maintenance } \\
\text { Housing options } \\
\text { Availability of } \\
\text { support services }\end{array}$ & $\begin{array}{l}\text { Security } \\
\text { Dignity } \\
\text { Flexibility } \\
\text { Choice }\end{array}$ & $\begin{array}{l}\text { Capability } \\
\text { Independence } \\
\text { Inter- } \\
\text { dependence }\end{array}$ & \\
\hline $\begin{array}{l}\text { Community } \\
\text { Contribute to } \\
\text { community in } \\
\text { ways of own } \\
\text { choosing } \\
\text { Be politically } \\
\text { active } \\
\text { Mentor /support } \\
\text { / teach others }\end{array}$ & $\begin{array}{l}\text { Work } \\
\text { Family needs } \\
\text { Health } \\
\text { Costs } \\
\text { Nature of task } \\
\text { Opportunities } \\
\text { Flexibility of role } \\
\text { Attitudes to older } \\
\text { people }\end{array}$ & $\begin{array}{l}\text { Give something } \\
\text { back } \\
\text { Share skills \& } \\
\text { knowledge } \\
\text { Enhance } \\
\text { community } \\
\text { Support valued } \\
\text { causes } \\
\text { Feel valued } \\
\text { Maintain social } \\
\text { contact } \\
\text { Learn new skills } \\
\text { Self-fulfilment }\end{array}$ & $\begin{array}{l}\text { Responsibility } \\
\text { A sense of } \\
\text { accomplishment } \\
\text { Connectedness } \\
\text { Civic } \\
\text { engagement } \\
\text { Generativity } \\
\text { Contribution } \\
\text { Reciprocity } \\
\text { Community } \\
\text { spirit }\end{array}$ & $\begin{array}{l}\text { Active } \\
\text { citizenship } \\
\text { Duty } \\
\text { Contribution } \\
\text { Individualism } \\
\text { Collectivism }\end{array}$ \\
\hline Health and & & & & \\
\hline $\begin{array}{l}\text { Physical, } \\
\text { intellectual, } \\
\text { spiritual and } \\
\text { creative activity } \\
\text { Make the most } \\
\text { of technology } \\
\text { Emotional and } \\
\text { practical } \\
\text { support from } \\
\text { family \& friends } \\
\text { Access to } \\
\text { health care and } \\
\text { support from } \\
\text { the state }\end{array}$ & $\begin{array}{l}\text { Cost } \\
\text { Limited care } \\
\text { options } \\
\text { Policy on care } \\
\text { Poor quality of } \\
\text { care } \\
\text { Shortage of } \\
\text { caregivers } \\
\text { Waiting lists } \\
\text { Level of disability } \\
\text { Death } \\
\text { Laws (on } \\
\text { euthanasia) }\end{array}$ & $\begin{array}{l}\text { Be fit and strong } \\
\text { Stay youthful } \\
\text { Avoid poor } \\
\text { health } \\
\text { Avoid isolation } \\
\text { Manage } \\
\text { disability } \\
\text { Remain } \\
\text { independent } \\
\text { An active life } \\
\text { Continue to } \\
\text { participate } \\
\text { Avoid being a } \\
\text { burden to family } \\
\text { Meet spiritual } \\
\text { needs }\end{array}$ & $\begin{array}{l}\text { Quality of life } \\
\text { Vigour \& Vitality } \\
\text { Autonomy } \\
\text { Choices } \\
\text { Dignity } \\
\text { Self reliance } \\
\text { A comfortable } \\
\text { life } \\
\text { Equality } \\
\text { Independence } \\
\text { Security } \\
\text { Assertiveness }\end{array}$ & $\begin{array}{l}\text { Good health } \\
\text { Independence } \\
\text { Activity } \\
\text { Self reliance } \\
\text { Dignity } \\
\text { Autonomy } \\
\text { Choice } \\
\text { Participation } \\
\text { Innovation } \\
\text { Fairness } \\
\text { Justice } \\
\text { Quality of life } \\
\text { Intellectual } \\
\text { stimulation } \\
\text { Affective } \\
\text { autonomy }\end{array}$ \\
\hline $\begin{array}{l}\text { Access to extra } \\
\text { care and } \\
\text { support }\end{array}$ & & & & \\
\hline $\begin{array}{l}\text { Control over } \\
\text { decision making }\end{array}$ & & & & \\
\hline
\end{tabular}

